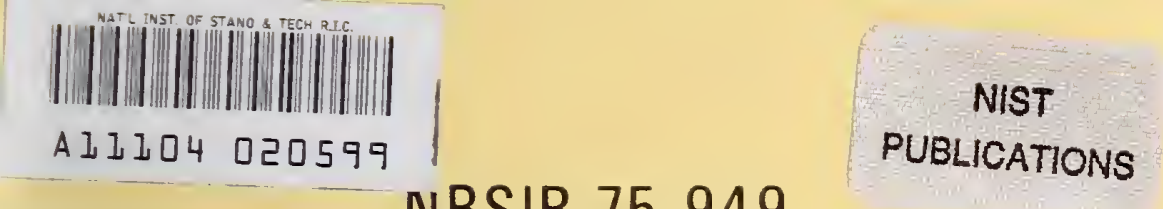

NBSIR 75-949

\title{
STRUCTURE AND FUNCTIONS \\ OF THE \\ NATIONAL MEASUREMENT SYSTEM
}

Raymond C. Sangster

Technical Report in connection with the IBS Study of the National Measurement System 1972.1975

Office of the Deputy Directer Institute for Basic Standards National Bureau of Standards

Boulder, Colorado 80302

July 1977

QC

100

.056

\#75-94C

1977 


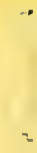

$=$

, 


\section{NBSIR 75-949}

\section{STRUCTURE AND FUNCTIONS}

OF THE

NATIONAL MEASUREMENT SYSTEM

Raymond C. Sangster

Technical Report in connection with the IBS Study of the National Measurement System 1972-1975

Office of the Deputy Directer Institute for Basic Standards National Bureau of Standards Boulder, Colorado 80302

July 1977

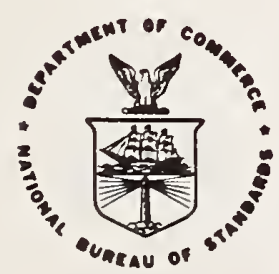

U.S. DEPARTMENT OF COMMERCE, Juanita M. Kreps, Secretary Sidney Harman, Under Secretary Jordan J. Baruch, Assistant Secretary for Science and Technology 


\section{FOREWORD}

The concept of a National Measurement System has, for many years, provided a useful focus for the considerations important to physical measurements in our technology intensive economy. Dr. R. D. Huntoon, in his October 6, 1967, article in Science, emphasized the basis for a systems viewpoint in interrelated measurements activities and the idea has continued to evolve. Today, we think of the U.S. National Measurement System in terms of all the intellectual, functional and institutional activities which enter into measurements throughout our society. Moreover, we seek to understand more completely the structural nature of this system and its architectural needs.

There have been a number of approaches to the study of our national system for physical measurements. The present series of studies was initiated in 1972 by Dr. Ernest Ambler, then Director of the Institute for Basic Standards. It was Dr. Ambler's purpose to organize the essential information necessary for the effective management of NBS resources and to promote the direct interaction between IBS staff members and the communities of users they serve.

This document reflects the results of the intensive studies carried out during the period from 1972 - 1975. It is one of a series of 27 reports describing various aspects of these studies; most of these are now in print and available from NBS or the National Technical Information Service. It is important to recognize that the National Measurement System is extremely complex having widely distributed elements and impacts. The detailed analysis of this system is well beyond the state-of-the-art of econometric modeling, and therefore, any study, no matter how intensive, is necessarily incomplete. Nevertheless, the information which is now in hand provides an important addition to our capability for planning and implementing the programs of IBS. It also represents a growing foundation upon which we can continue our efforts to build a more effective structure.

A. 0. McCoubrey

Director, Institute for Basic Standards National Bureau of Standards

June 1977 
The 1972-75 Study of the National Measurement System by the NBS Institute for Basic Standards has been a massive effort involving many people in all divisions of the Institute. The Study was organized around a central coordinator and a group of "National Measurement System Study representatives". The initial central coordinator was Dr. James R. Seed, a Presidential Interchange Executive from Dow Chemical Company, on temporary assignment to the National Bureau of Standards. Dr. Seed carried the project through to the generation of a complete set of comprehensive reports on the structure and operation of the various portions of the System, in December 1973. In August 1974, I took over the central coordinator position, and worked with the Study representatives from the divisions of the Institute, to round out the pattern of the Study and to develop the final reports for the different areas of measurement interest.

During this 1972-75 Study, a substantial amount of insight was developed into the structure and functions of that system. This insight is the subject matter of this report. The report proper describes the technical and institutional infrastructures of the System, the international context in which it operates, and the basic impacts and trends of the system. The balance of this document contains appendices and an extended bibliography, which provide detail regarding specific aspects of the System.

No report of this sort could be generated without many hours spent at the typewriter. This one would not exist without the competent and unstinting efforts of my secretaries and everyone else whom they could obtain to support them, and I wish to thank them, one and a 1l: Carol Ciufolo, Marty Tyner, Pamela Killian, Angela DiGiallonardo, Sheila Aaker, Sue Randolph, Nancy Mills, Kay Stephenson, Shirley Deeg, and Dorries Schaffner.

We trust that the availability of this document will be useful to many readers who need only an overview of the results of our Study of the National Measurement System. For those who want more detailed information about any part of this study, we have provided a "Report Request Card" at the back of this document, which can be used to request the specific reports wanted.

Raymond C. Sangster July 1977 


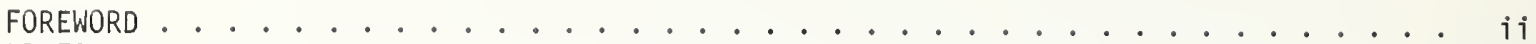

PREFACE . . . . . . . . . . . . . . . . . . . . . . 1 . . . . . . .

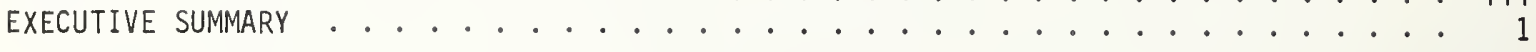

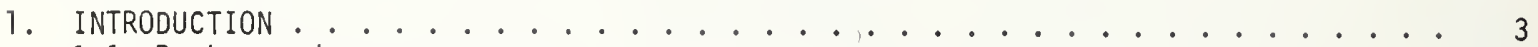

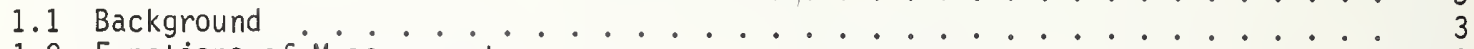

1.2 Functions of Measurement . . . . . . . . . . . . . . . 3

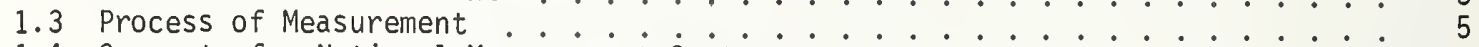

1.4 Concept of a National Measurement System . . . . . . . . . . . . . . . . . . . . 6

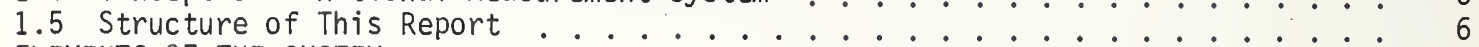

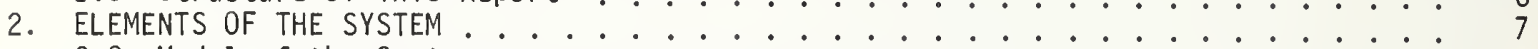

2.0 Model of the System ......................... 7

2.1 Measurement Quantities, Units and Standards . . . . . . . . . . 7

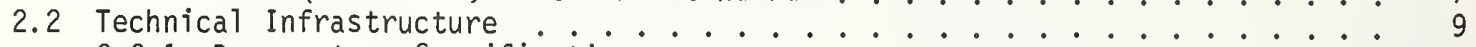

2.2.1 Documentary Specifications . . . . . . . . . . . . 11

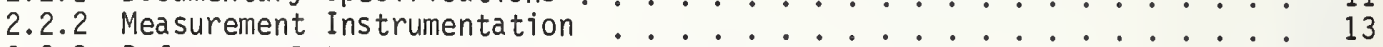

2.2 .3 Reference Data . . . . . . . . . . . . 17

2.2 .4 Reference Materiais $. . .20 . .20$

2.2 .5 Predictive Methods . . . . . . . . . . . . . 22

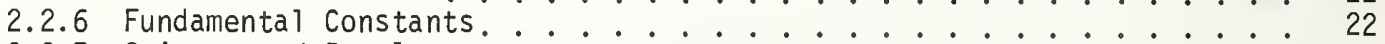

2.2 .7 Science and People

2.3 Realized Measurement Capabilities . . . . . . . . . . . . 25

2.4 Institutional Infrastructure .................. . . . . 25

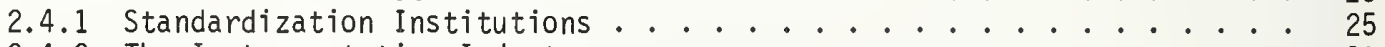

2.4 .2 The Instrumentation Industry ............... 29

2.4.3 State and Local Offices of Weights and Measures. . . . . . . . . 29

2.4.4 Standards and Testing Laboratories and Services. . . . . . . . . 33

2.4 .5 Regulatory Agencies. . . . . . . . . . . . . . . 35

2.4.6 The National Bureau of Standards . . . . . . . . . . . . 37

2.4.6.1 The Present--Scope of NBS Services . . . . . . . . 37

2.4.6.2 Alternate Sources for Services Provided by NBS . . . . . 39

2.4.6.3 NBS Funding and Staffing .............. 41

2.4.6.4 Evaluation Panels and Visiting Committee ........ 43

2.5 The Measurements Market Place: The Direct Measurements Transactions Matrices 43

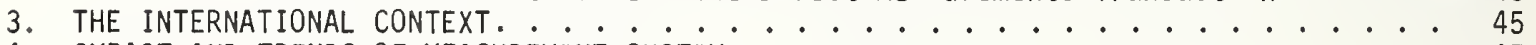

4. IMPACT AND TRENDS OF MEASUREMENT SYSTEM . . . . . . . . . . . . . . . . 47

4.1 Impact of Measurements. . . . . . . . . . . . . . . . . . . . . 47

4.1.1 Functional, Technological, and Scientific Applications . . . . . . 47

4.1.2 Economic Considerations...................... 48

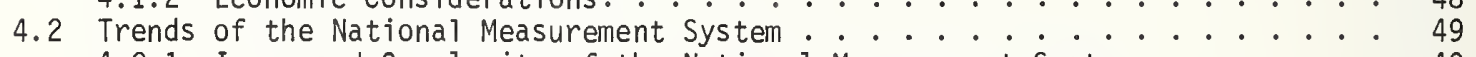

4.2.1 Increased Complexity of the National Measurement System. . . . . . 49

4.2.2 Increased Integration of the National Measurement System . . . . . . 52

4.2.3 Improved Qual ity Control in the National Measurement System. . . . . 52

4.2.4 Improved Information Resources for the National Measurement System . . 53

4.2 .5 Automation of Measurements .............. 54

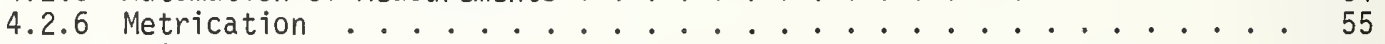

4.2 .7 science. . . . . . . . . . . . . . . . . 56

5. SUMMARY. . . . . . . . . . . . . 57

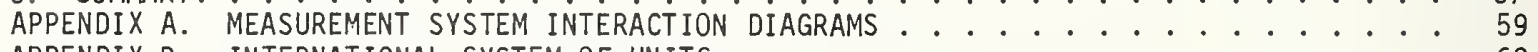

APPENDIX B. INTERNATIONAL SYSTEM OF UNITS

APPENDIX C. NBS NATIONAL MEASUREMENT REFERENCE STANDARD ARTIFACTS, INSTRUMENTS AND FACILITIES . . . . . . . . . . . . . . . . 70

APPENDIX D. NATIONAL STANDARD REFERENCE DATA SYSTEM PUBLICATIONS. $\cdots$

APPENDIX E. U.S. PRIVATE ORGANIZATIONS REPRESENTED IN NBS REFERENCE COLLECTION OF STANDARDS

APPENDIX F. STATE AND LOCAL WEIGHTS AND MEASURES ACTIVITY SUMMARY (EXCERPTS) $197 \dot{9}-\dot{7}^{\circ}$. APPENDIX G. DIRECTORY OF STANDARDS LABORATORIES AND CAPABILITIES. APPENDIX H. NBS CALIBRATION ACTIVITY SUMMARY FOR FISCAL YEAR 1975 . . . . . . . . . . 95 APPENDIX J. USERS OF NBS OUTPUTS, $1970-75 \ldots \ldots$. . . . . . . . . . . . . . 100

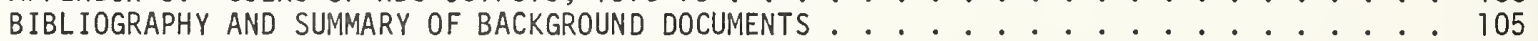

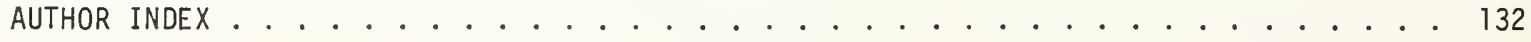


Figure 1. Figure 2. Figure 3. Figure 4. Figure 5. Figure 6. Figure 7. Figure 8. Figure 9. Figure 10. Figure 12. Figure 13. Figure 14. Figure 15. Figure 16. Figure 17.

Figure 18. Figure 19. Figure 20. Figure 21. Figure 22. Figure 23. Figure 24.

Figure 25. Figure 26. Figure 27. Figure 28. Figure 29. Figure $B-1$. Figure 11.
Chart of measurement quantities

Egyptian Royal Cubit

Flow diagram of the National Measurement System

The modernized metric system - SI base and supplementary units

Standards of physical measurement

Krypton-86 lamp in its cryostat

Cesium-beam atomic clock

Schematic of an atomic beam clock

Experimental realization of the candela

Josephson Junction standard voltage source

Photoelectric interferometric comparator

Automated $Y$-factor mm-wave noise measurement system

Deadweight machine

Proving rings

Temperature measurement sensors.

Location of measurement and control instrumentation companies

Measuring, analysis \& control instrumentation industries expenditures

\& sales

Instruments show variable trends

Location of weights \& measures governmental jurisdictions \& personnel

Location of members of National Conference of Standards Laboratories

Air Force measurements standards system

Army calibration system traceability chart

United States Navy temperature calibration chain

Energy Research and Development Administration National Measurement

Sys tem Subsystem

Other agency funding sources

Composition of staff

Model of the international measurement system.

International coordination of measurement standards

Composition of U.S. labor force, 1860-1980

Metric conversion card

\section{LIST OF TABLES}

Table 1.

Table 2.

Table 3.

Table 4.

Table 5 .

Table 6 .

Table 7.

Table 8.

Table 9.

Table 10.

Table 11.

Table 12.

Table 13.

Functions of measurements

Traverse of the National Measurement System Model

Measurement instrumentation categories and suppliers . . . . . . . . . 14

Calibration chain example: tire inflation pressure . . . . . . . . . . 15

Primary fixed points on International Practical Temperature Scale IPTS-68 . 20

Table of Contents from catalog of NBS standard reference materials . . . . 21

Realized measurement capabilities . . . . . . . . . . . . . 26

1974 Profile, instruments for measurement, analysis and control . . . . . 30

Instruments for measurement, analys is and control: projections 1974-80 . 30

Medical and dental instruments and supplies: projections 1974-80 . . . 30

1974 Profile--X-ray apparatus and tubes . . . . . . . . . . . . . 30

Outline of Contents of NBS Handbook 44, U.S. Specifications, Tolerances, and other Technical Requirements for Commercial Weighing and Measuring Devices

National Conference on Weights and Measures--Titles of non-routine sessions, 1970-75

Federal regulatory agencies

NBS funding by program

Table 15.

Direct measurements transactions matrix for IBS Study of the Nationa 1

Measurement System ..................... . 42

Direct measurements transactions matrix for outputs of NBS . . . . . . 44

SI base units........................ . . . . 68

SI supplementary units . . . . . . . . . . . . . . . 68 68

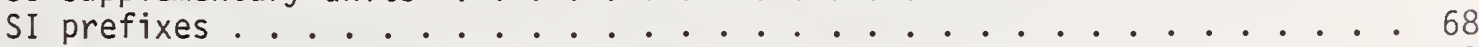

Table B-2.

Table B-3.

Table B-4. ${ }_{30}^{10}$

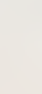


Table B-5. Examples of SI derived units formed by using supplementary units . . . . 68 Table B-6. SI derived units with special names . . . . . . . . . . . . 68 Table B-7. Units used with International System . . . . . . . . 69 Table B-8. Units used with International system whose values in SI units are

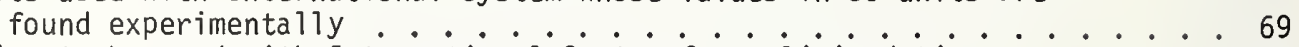

Table B-9. Units to be used with International system for a i imited time. $\ldots . . .69$

Table H-1. Calibration data for NBS by state. . . . . . . . . . . . 95

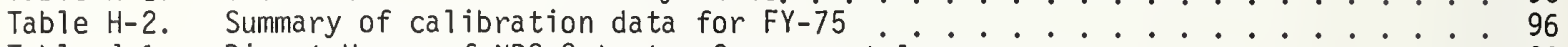

Table J-1. Direct Users of NBS Outputs--Governmental. . . . . . . . . . 100

Table J-2. Direct Users of NBS Outputs--SIC Major Groups 1-32................... 101

Table J-3. Direct Users of NBS Outputs--SIC Major Groups 33-49...$\ldots 102$

Table J-4. Direct Users of NBS Outputs--SIC Major Groups 50-89..................... 103 
STRUCTURE AND FUNCTIONS OF THE

NATIONAL MEASUREMENT SYSTEM

\section{Raymond C. Sangster}

Institute for Basic Standards

National Bureau of Standards

$$
\text { July } 1977
$$

\section{EXECUTIVE SUMMARY}

The National Measurement System consists of all of the activities and mechanisms-intellectual and operational, technical and institutional--used to provide physical measurement data to allow the creation of the objective, quantitative knowledge required by our society. This report describes the structural and functional aspects of the System.

Measurement is necessary in conduct of the life of the individual, pursuit of science, operations of society, and employment of technology. Measurements allow human beings to describe, predict, communicate, decide, control, and react in dealing with the physical universe. The process of measurement requires intellectual comprehension of the phenomenon, quantity, or property to be measured; definition of a reference unit in terms of which the measurement will be made; existence of a means of comparing the unknown to be measured with the reference unit; establishment of a physical reference standard which embodies the measurement unit; agreement within the human community on all aspects of the measurement process; and mechanisms to enforce honesty and clarity in measurements.

Uur model of the National Measurement System involves five structural levels.

1. Conceptual System of measurement phenomena, quantities, units, and definitions.

II. Basic Technical Infrastructure to provide tools, techniques, and agreements that allow the conceptual system to be reduced to practice.

III. Realized Measurement Capabilities, abilities to measure specific quantities to known accuracies under defined conditions.

IV. Dissemination and Enforcement Hetwork, institutions that disseminate realized measurement capabilities to users and enforce their use.

V. End-use Measurements.

The base phenomena or quantities to be measured include length, mass, time, electric current, temperature, amount of substance, and luminous intensity. Many subsidiary units are derived from the basic units. The United States uses both the customary "English" system of units and the modernized metric system, SI.

The technical means required to make measurements include both physical hardware and intellectual software. Software aspects include documentary specifications and standards, descriptions of measurement techniques, educational materials, reference data, predictive methods, and the basic recorded knowledge of science. Hardware aspects include basic artifact standards, transfer and working standards, reference materials, and measurement instruments.

Documentary standards and specifications in the broad sense include international treaties and conventions; Federal and state constitutions; Feceral, state and local law's and ordinances; engineering standards; and procurement specifications.

Suitable instrumentation is ar indispensable element in any measurement process. Both physical apparatus and the techniques by which it can produce the desired results must be available.

When a given aspect of matter, material, or fabricated product is sufficiently stable, well defined, and of wide enough interest, measurement data that characterize it can become useful as reference data. Existence of reference data takes a substantial load off the operational measurement system, since it eliminates much repetitive measurement. Measurements of unknown systems are often performed by comparison with known systems, using reference data. Such data may also be used to calibrate measurement equipment. Further, properties of materials may be used to define the measurement process itself, as in use of properties of water to define the temperature scale.

Reference materials complement and supplement reference data in the Measurement system. Their function is very similar to that of reference standards, and for some 
phenomena, such as density, the reference standards are reference materials.

In some measurement circumstances, the volume of data needed may be so large, or the experimental circumstances so inaccessible, that it is not physically or economically feasible to measure all of the desired data. Predictive methods--models of the phenomena being measured--then become an essential element of the Measurement System.

The central core of the Measurement System consists of knowledge or science and of the people who employ it. In some newer measurement fields, there is no further institutional infrastructure.

The institutional elements of the system include the documentary specifications and standardization organizations, the instrumentation industry, central measurement standards authorities, state and local offices of weights and measures, standards and testing laboratories and services, and technical regulatory agencies.

Institutions that produce documentary standards operate at levels from the international to the individual company or local governmental unit. Major relevant bodies are the International Organization for Standardization, International Electrotechnical Commission, American National Standards Institute, American Society for Testing and Materials, Department of Defense, and General Services Administration.

Over 5000 U.S. companies are known to produce measurement instrumentation. The instrumentation industry was at an \$8 billion level in 1974 and has been predicted to grow to $\$ 15$ billion in 1980 .

Legal responsibilities for enforcement of justice in the use of weights and measures in our domestic commercial marketplaces lie with the state and local offices of weights and measures; the National Conference of Weights and Measures is the central coordinating unit. Its paid staff and executive secretariat are employees of the NBS Office of Weights and Measures.

Standards and testing laboratories and services provide physical standardization services to specific portions of the National Measurement System. The most highly develcped institutional structures are in the military services. The National Conference of Standards Laboratories provides a central forum for this portion of the measurement system. NBS provides its central secretariat.
Promulgation, enforcement, compliance, and adjudication with respect to the regulatory actions of technical regulatory agencies require a substantial measurement base and comprise a significant portion of the System, making the regulatory agencies the newest recognizable institutional structural element of the System.

The National Bureau of Standards is the principal authoritative central measurement standards institution in the United States. Its calibration and related measurement services provide access to the national standards of physical measurement; it operates the National Standard Reference Data System and provides Standard Reference Materials; it provides coordination services to the System through the Offices of Weights and Measures and Measurement Services, and through the Standards and Applications Division, the Office of International Standards, and the Office of International Relations; and it provides a variety of information services.

The U.S. National Measurement System is embedded in and is part of an international measurement system, for which the International Bureau of Weights and Measures (BIPM) is the central institution.

The major trends of our National Measurement System are toward increased complexity, increased integration, improved quality control, improved information resources, automation, metrication, and an expanded scientific base. The increasing complexity of our society is reflected in the Heasurement System. Increased integration of the system is required to improve its ability to provide most economically and effectively the needed measurement data. Improved quality control of the measurement process, through such mechanisms as the NBS Measurement Assurance Programs, is needed to control complexity and effect integration. Automation is vastly expanding the technical power of the System. Passage of the Metric Conversion Act of 1975 recognizes a major trend in the System, which will have a permanent impact on this country. The scientific developments of the past quarter century have nearly put us in a position to realize the goals of the founders of the metric system, namely a universal system for physical measurements founded on natural law and a single constant of nature. 


\section{INTRODUCTION}

\subsection{Background}

The ability to measure is part of the basic fabric of human society [2] t. Regulation by law of weights and measures used in commercial transactions dates back far into antiquity $[136,3,10,16,17,29,61,73,79,236]$. With the maturing of the science-based phases of the later industrial revolution around the end of the nineteenth century, governmental participation in the field of measurement expanded in the major industrial countries to cover many areas of science and technology relevant to the mass production of goods and services [46]. During the past decade or so, still another major governmental involvement in the field of measurements has grown out of the rapid expansion of governmental regulation of our economy in areas such as health and safety and consumer and environmental protection.

The National Bureau of Standards was established in 1901. An oft-quoted statement by the House Committee on Coinage, Weights and Measures gives the flavor of the context in which the Bureau was created:

"It is therefore the unanimous opinion of your committee that no more essential aid could be given to manufacturing, commerce, the makers of scientific apparatus, the scientific work of Government, of schools, colleges, and universities than by the estabiishment of the institution proposed in this bi11." [46]

The Bureau was established as the source of national standards for physical measurements and their custodian. In carrying out this role, it seems fair to say that NBS over the years has developed a more comprehensive view of the role of measurements in our society than any other organization in this country.

About fifteen years ago, Dr. R. D. Huntoon and others in the National Bureau of Standards began to formalize their understanding of the measurement activities in this country around the concept of a "national measurement system" $[56,82,15,24,34,38,40,43-45,47,48,52$, $54,55,58,59,65,111,227,222]$. In 1972 , Dr. Ernest Ambler, then Director of the NBS Institute for Basic Standards, initiated an extensive Institute-wide study of the national measurement system, to accomplish an across-

+ Numbers in brackets refer to the references listed in the Bibliography at the end of this report. the-board analysis of the entire scope of Institute measurement and dissemination concerns. The approach to the study involved analysis of the totality of the physical measurements performed in this country to answer the question of the quality of the measurements being made by the system and whether NBS dissemination procedures are adequate for 1 ts needs $[133,134,144]$. This is one of the reports of the results of that study.

The overall study was subdivided into a series of "microstudies" of specific measurement fields (see fig. 1). In addition, a macroeconomic study was performed of measurements in our economy $[327,173,200,218]$. The overall design and specific findings of the study have been presented in a Final Summary Report [307]. Individual reports are being issued for the microstudies and other aspects of the total study $[254,263,269,282,294,295$, 298-305,312,313,317-28]. Readers interested in a total overview or any of the specific areas studies, are invited to use the request card bound in the back of this document to obtain the reports desired. There will be no systematic attempt made here to summarize the contents of these other reports.

The purpose of this report is to describe the structural and functional aspects of the national measurement system as a whole. Its content has been derived inductively from analysis of the reports from the different specialized study areas and from reading of the literature in this field. The intent is to assemble in one document in a unified fashion material that is otherwise found only in a multitude of sources. The author's contribution has been that of compllation, analysis, integration, and organization. He is indebted to the many sources cited in the Bibliography for establishment of the facts and observations upon which this report is founded.

\subsection{Functions of Measurements}

The functions of measurements include all 211 of the uses made by human beings of knowledge of the physical universe. Measurement is necessary in the conduct of life of the individual, in the pursuit of science, in the operations of society, and in the employment of technology.

Measurements allow human beings

to describe,

to predict,

to communicate,

to decide,

to controi, to react,

in dealing with the physical universe. Of 


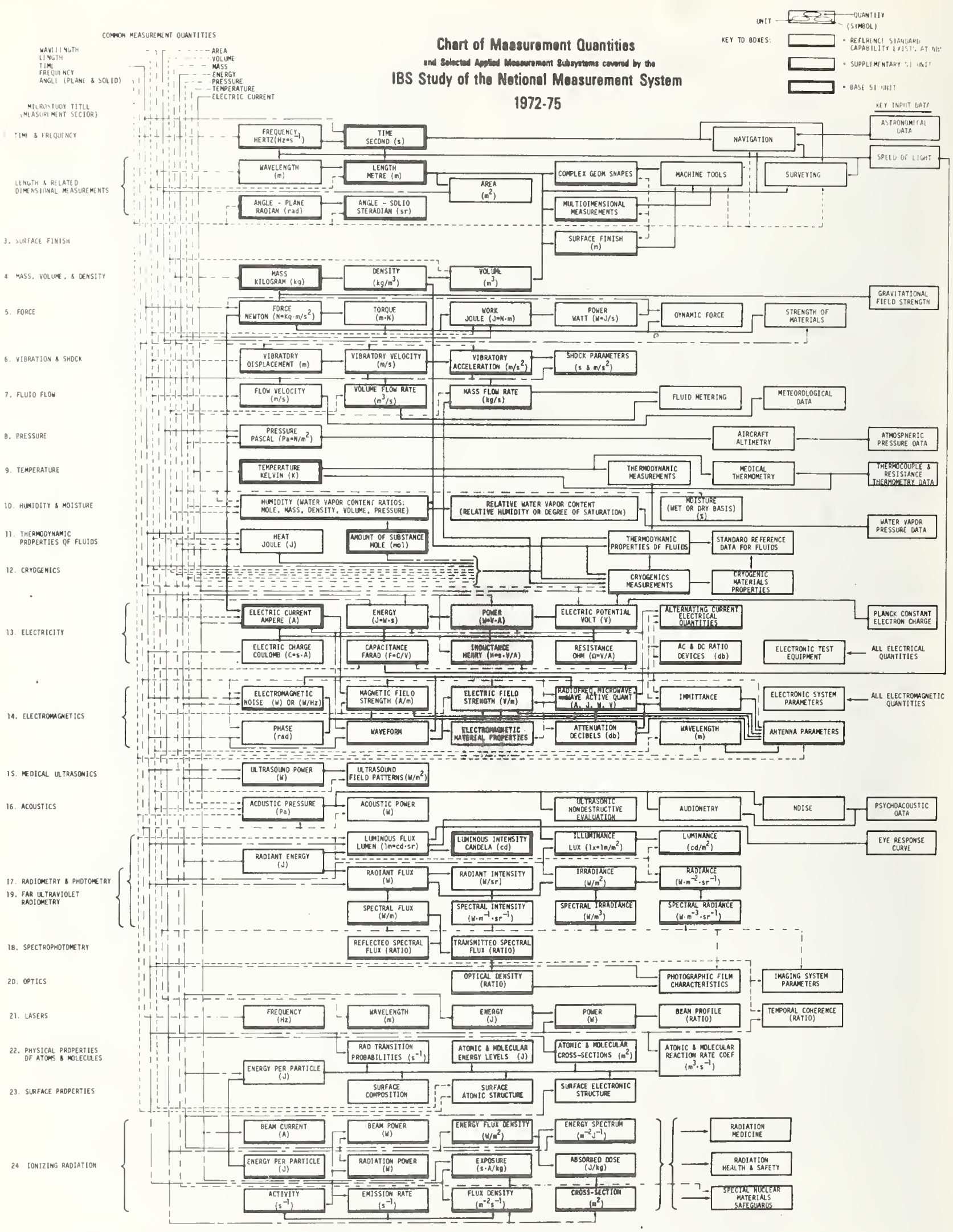

Figure 1. Chart of measurement quantities. 
Table 1. Functions of measurements

SCIENCE

To Describe

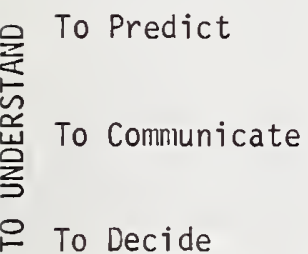

To Control

To React
PERSONAL

Knowledge

Prediction of

Future

Human

Communication

Decision Making

(Action Selection)

Action Initiation
SOCIAL

EFFICIENCY

Data Bases,

Maps \& Charts

Pubiic Planning

\& Forecasting

Property Ownership

\& Political Boundaries

Adjudication, Equity in Trade

\& Taxation, Payment of Wages

Regulation \& Policing
TECHNOLOGY IMPLEMENTATION

Resource Location

Engineering Design

Interchangeability

Quality Assurance

Process Control

Fault Diagnosis fundamental: To communicate and to decide. In the broadest sense of the words, to communicate can encompass communication to both the self and others, regarding past, present or future. Similarly, to decide can encompass both selection among alternate courses of action and maintaining a selected course of action or reacting in a predetermined fashion when faced with alternatives.

The functions of measurements are summarized in table 1 , the development of which will be described in section 4 .

\subsection{Process of Measurement}

The process of measurement involves a number of different activities. First and most fundamental, is the intellectual comprehension and definition of the phenomenon, quantity, or property to be measured. The travail involved here is often soon forgotten once the issues have been resolved, and the measurement process has become habitual. But in new fields of science, resolving the issue of just what to measure is often more difficult than learning how to make the mea surement.

Second, it is necessary to define a reference unit in terms of which the measurement will be made. Expressing the results of a measurement in terms of a number requires answering the question, "Number of what?" The reference units may be naturally occurring, such as a day, or man-made, such as an hour.

Third, there must be a means of comparing the phenomenon, quantity, or property to be measured with the reference unit. For some purposes, such as determining the number of days on the trail or the number of people in the tribe, this can be achieved by simple counting of natural units. For other purposes, such as determining the number of hours until dawn, more elaborate methods are needed.

The third activity often leads naturaliy to the fourth, the establishment of a physical reference standard which embodies the measurement unit. The cubit may have been defined in terms of the dimensions of the Pharaoh's body, but there was no way that the Pharaoh himself could be used directly to make the measurements needed for building a pyramid. Hence, a physical reference standard was derived from the basic definition and used to control the ancient Egyptian construction industry (fig. 2).

Individual resolution of the issues surrounding these four preceding aspects of measurement will allow an individual to obtain for himself the quantitative knowledge that he needs as an isolated human being, whether it be for the conduct of his personal life or the pursuit of the interests of science. However, when he proceeds to relate his measurements to those of other human beings he finds that something more is needed, namely agreement with in the hunan community on the definitions of what is to be measured and the units of measurement, and the measurement process in general. This fifth aspect of the measurement process requires social mechanisms to create and record agreement on the previous four aspects of measurement, so that communication among individuals in society is possible.

Measurements are used for more than purely personal, scientific, or communication 
EGYPIIAN ROYAL CUBIT OF AMENHEIEP I (CIS5O B.C.)

1ै.
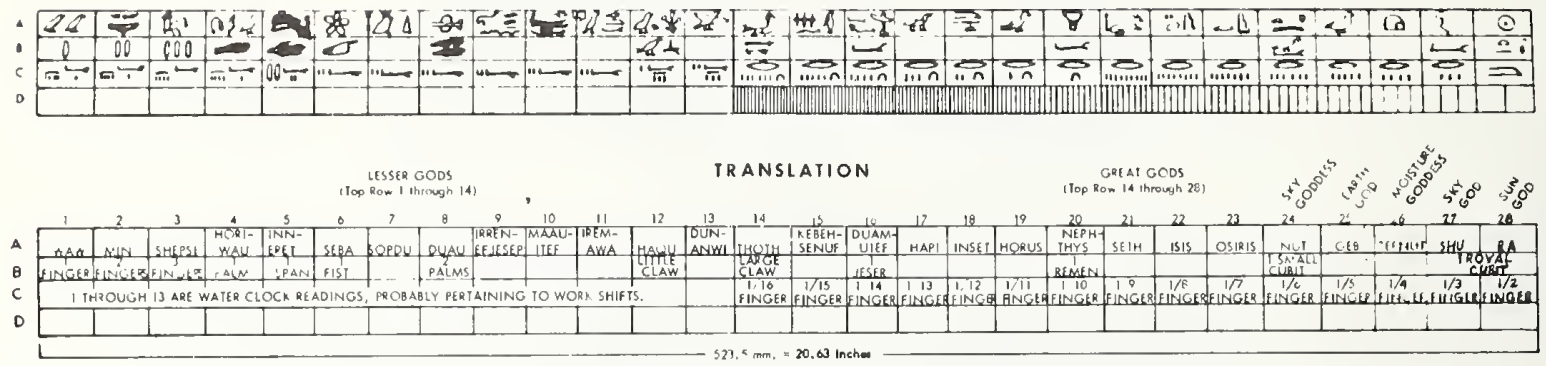

Figure 2. Egyptian Royal Cubit. Five thousand years ago, the Egyptians laid the foundation for all this is embraced by modern linear dimensional control. They produced the first master standard of linear measurement, the Cubit, meaning forearm. This standard was equivalent to the length of the forearm of the Pharaoh, about 20.63 inches 1 ong, and was known as the Royal cubit. This master was subdivided by scribed lines which divided the cubit into two spans, six palms and 24 digits or finger breadths. The digits, in turn, were divided into halves, thirds, quarters, and down to sixteen parts. The Royal Cubit Master was made of black granite and placed in the custody of the royal architect. "Working" cubit sticks made of wood were duplicated from the Royal Cubit and used by artisans in building the Great Pyramid, tombs, and temples [32].

reasons. From time immemorial, goods and services have exchanged hands on the basis of physical measurements. From equally ancient times, cheating and confusion have existed. Both are resented. Societies react to suppress them. These reaction mechanisms to enforce honesty and clarity in measurement constitute a sixth major aspect of the measurement process.

\subsection{Concept of a National Measurement System}

In 1967, Dr. R. D. Huntoon wrote [56]:

"Concurrently with the growth and industrialization of this nation, there has developed within it a vast, complex system of measurement which has made possible the very growth that brought the system into being. This llational Measurement System stands today as one of the key elements in a world-wide measurement system that links all major nations together in a consistent, compatible network for communications and trade."

Today, we understand the U.S. National Measurement System to comprise a 11 of the activities and mechanisms--intellectual and operational, technical and institutional-used by this country to produce the physical measurement data needed to create the objective, quantitative knowledge required by our society.

The use of the term system in the phrase "the national measurement system" is appropriate. There is a high degree of functional interdependence among the different elements of the system, and the interactions are numerous, subtle, and complex. The fact that many occur in an automatic or quiet fashion tends to obscure the reality of their existence.

Historically, the word system has been used in discussions of measurements since at least as early as the days of Thomas Jefferson [1] and John Quincy Adams [2]. often, the word has been applied to the array of units and reference standards used for measurement purposes. On the other hand, both the Congressional directive to Adams and his response involved what we today would describe as a systems approach to analysis of the measurement activities in this nation.

The National Measurement System is conceptually similar in nature to a number of other social systems that provide to the individual and to society at large the means for achieving individual and collective goals. In this case, the goals are support to the acquisition of new knowledge of the physical universe, and the benefits that can come from application of such knowledge.

\subsection{Structure of This Report}

In the next section, a model of the National Measurement System is presented, followed by a discussion of its component parts, with special emphasis on the technical and institutional infrastructural elements. The international measurement system is summarized in section 3 , and section 4 discusses the current status and trends of the U.S. national system. Appendices contain background information about the component elements of the system. 


\section{ELEMENTS OF THE SYSTEM}

\subsection{Mode] of the System}

The model of the National Measurement System developed by induction from interim microstudy reports prepared in December 1973 [177-197] and from previous literature on this subject $[56,82,15,43,44,47,54,65,172]$ can be considered to have five major levels:

I. The interlectual foundation is the conceptual system that defines the measurement quantities and units.

II. The basic technical infrastructure provides the tools and techniques and agreements that allow the conceptual system to be reduced to practice.

III. Realized measurement capabilities the ability to measure specified quantities to known precisions and accuracies under defined circumstances - form the heart of the measurement system. Levels I and II are meaningful only as they result in realized measurement capabilities. Levels IV and V can achieve no more than these capabilities a] low.

IV. The dissemination and enforcement network exists to make the realized measurement capabilities available to the ultimate users and to enforce the adequacy of their use where this is called for by law or accepted practice. This network provides the institutional infrastmucture of the system. Since one function of the national measurement system is to allow compatibility in international commerce, both national and international institutions are relevant.

V. The ultimate level in the system consists of the end-use measurements made and used in the "rineasurements market-place". It is this level that all other elements in the systemi exist to support.

Figure 3 is a flow diagram version of the model of the National Measurement System used in this report. Many different paths can be traced through this model to show the interrelationships of the different functiona) elements. Table 2 describes one such traverse. Sections 2.1 through 2.5 below discuss the five major levels of this model.

Other approaches to diagramming the National Measurement System exist. Appendix A contains examples of charts resulting from one such approach in current use in NBS [314].
2.1 Measurement Quantities, Units, and Standards

The measurement system of the United States is founded upon one basic conceptual system of measurement phenomena, quantities and properties, and two systems of measurement units, the "Customary" system based on old English measurement units, and the modernized metric system, the Systéme International (abbreviated SI) (see fig. 4 and App. B) $[232,15,24,66,1,2$, $7,9,13,17,27,28,39,41,42,57,73,79,118,199,219$, $236,260]$.

Standards are maintained by the international and national standards laboratories for only a limited selection of all of the useful measurement quantities. For the numerous derived quantities, whether or not standards are maintained depends upon a number of factors.

(1) The utility of the standard. For example, standards of volume are maintained, but not standards of area. Area can be determined more accurately by a series of linear and angular measurements than it could be determined by comparison of an unknown area with a reference area. Therefore, while measurement of area, e.g., of land, is of great importance, an area standard is of little practical value. In contrast, while volume can be and sometimes is determined by length and geometrical measurements, volumes can be determined far more accurately, as a rule, by comparison of an unknown volume with a precisely standardized one. Further, volume has great technical and commercial importance-among other things, measurement of volume is often used as a surrogate for measurement of mass or amount of matter. The combination of importance and precision of measuremerit makes volumetric standards among the most important of all derived standards.

(2) Some quantities are not easily susceptible of embodiment in a physical standard, speed or velocity for instance. Physical realization of a standard for speed is a conceivable, but not an attractive idea. Since distance and time can both be measured with exceedingly high precision, there is usually little or no attractiveness in the idea of establishing a reference standard for speed. The value of the speed of light is, of course, an important and exceptional case.

(3) Some quantities simply are not needed urgently enough to justify the economic cost of developing and maintaining a physical reference standard. In the radio frequency and microwave spectrum, for instance, absolute power calibrations may be needed at a wide variety of frequencies, but economic constraints prevent the construction of absolute reference standards for every frequency 
Table 2. Traverse of the National Measurement System Model.

The NATIONAL MEASUREMENT SYSTEM consists of a

I. CONCEPTUAL SYSTEM of measurement

phenomena, quantities, and units,

\section{EASIC TECHNICAL INFRASTRUCTURE}

A. Science and knowledge, as recorded in pliblications.

B. Documentary Specifications System of international agreements, laws, engineering standards, mil specs, etc.

C. Instrumentation system of artifact stds. and meas. tools and techniques,

D. Reference data, or

E. Reference materials,

III. REALIZED MEASUREMENT CAPABILITY for specified ranges of quantities, subject to certain conditions and accuracies.

IV. DISSEMINATION AHD ENFORCEMENT NETWORK

A. Pecple, often organized in professional societies, who acquire knowledge by education and from instrumentation suppliers.

What to measure, how, when, and why

is established and recorded by the

Physical realization and implementation is achieved by the

Which can be applied to specific physical systems or materials to generate

which in turn become supporting elements of the technical infrastructure, to create a

This measurement capability is used by a which employs

These people work in an institutional

framework, which consists of

B. Central Standards Authorities,

C. State and Local Offices of Weights and Measures and equivalent agencies;

D. Standards, Calibration, and Testing Laboratories and Services;

E. Regulatory Agencies.

V. ORGANIZATIONAL INPUT-OUTPUT TRANSACTIONS in the Measurements Marketplace,
A. Costs
B. Suppliers with certain capabilities
C. Users with certain needs,
D. Ultimate Benefits

such as the National Bureau of Standards;

plus

plus other

The end effect of all these structural elements is support to the

whereby useful measurements are delivered at certain

by

to

who realize the

of the National Measurement System. 
of interest. Instead, standards are constructed for a limited number of key frequencies, and measurements at intermediate frequencies are made by interpolation.

Figure 5 displays an array of the physical measurement standards of the type maintained by NBS. Appendix C lists the physical reference standards maintained by NBS.

Application of this basic conceptual system of measurement quantities, units, and standards to the real world of useful measurements requires a number of connecting elements in the National Measurement System. For present purposes, these can be most easily sorted into two categories, those that belong to a technical infrastructure and those belonging to the institutional infrastructure. The technical infrastructure comprises all of the technical means or tools needed, the institutional infrastructure contains all of the organizations required to make these tools adequately available at the point of end use.

\subsection{Technical Infrastructure}

The technical means or tools required to make measurements include both physical hardware and intellectual software, e.g., both measurement instrumentation and instruction manuals. The software aspects include documentary specifications, descriptions of measurement techniques, educational materials, reference data, and the basic recorded knowledge of science. Hardware aspects include transfer and working standards, reference materials, and measurement instrumerits.

Since the software and hardware are functionally inseparable, the discussion will focus on the technical "tool" aspects of the structural elements of figure 3 , handling both the software and hareware aspects together. The institutional aspects of these same elements will be discussed shortly.

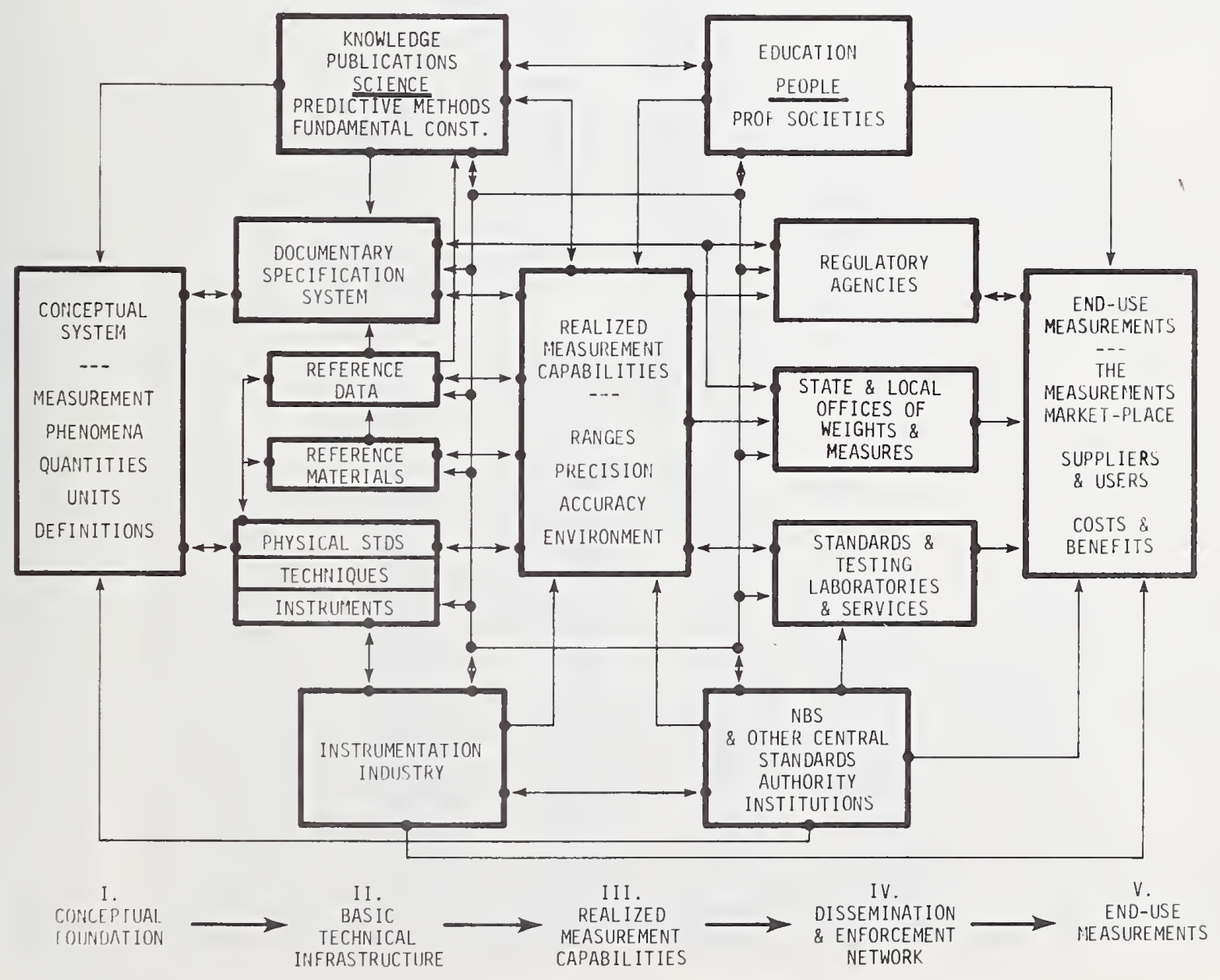

Figure 3. Flow diagram of the National Measurement System. 


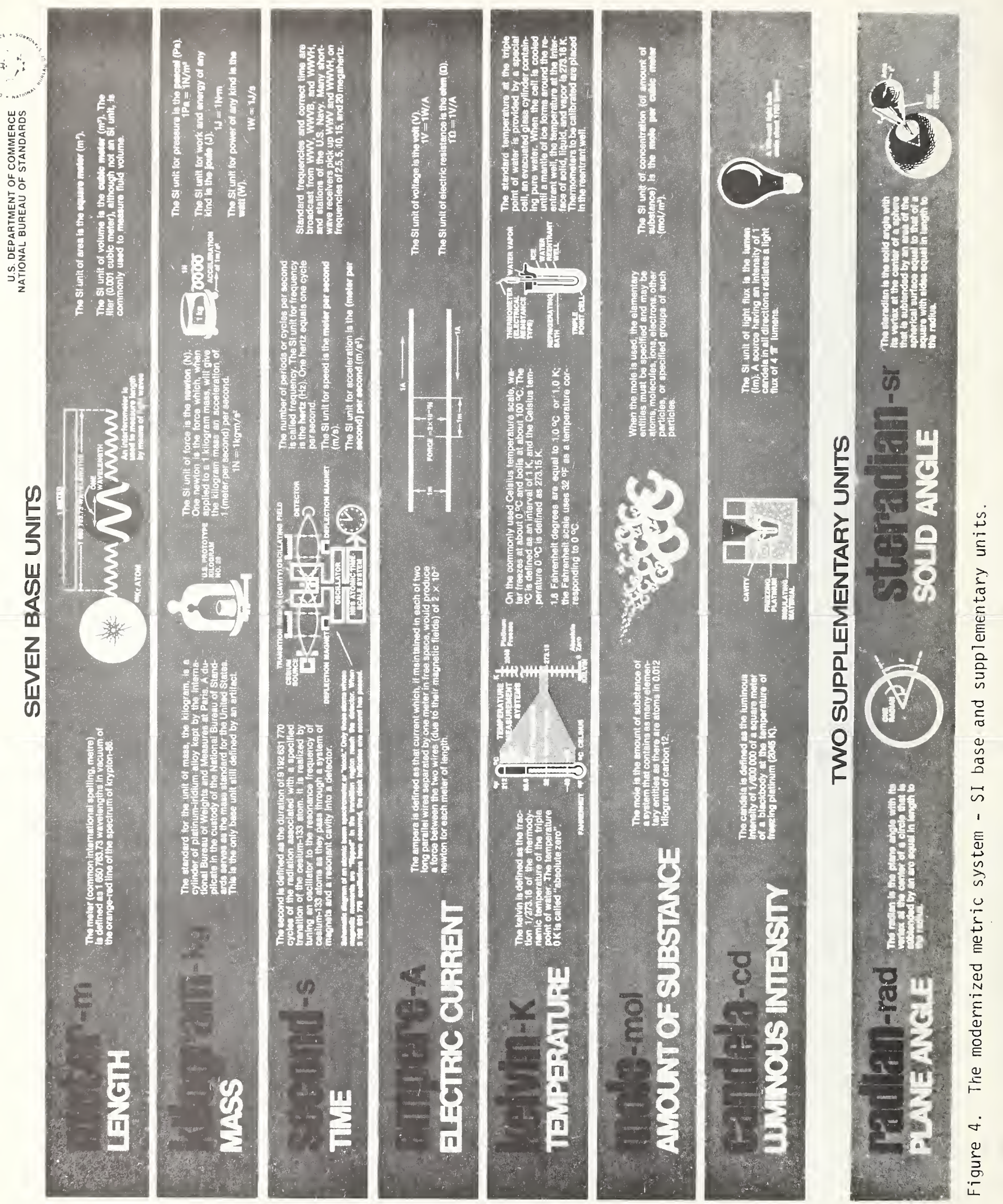




\subsubsection{Documentary Specifications}

Our measurement system both supports and is supported by a documentary specifications system $[109,6,88,95,99,121,128,139,224,251$, $129,279]$. The field of documentary specifications and standardization (broadly interpreted) interfaces with the field of metrolugy and measurement standards in a number of ways:

a. The international basis of the national measurement system is established by an international treaty.

b. The legal basis of the national measurement system is established by the U.S. Constitution and by federal, state, and local laws and ordinances.

c. Engineering standards exist which specify various measurement definitions, instruments, procedures, and processes, i.e., there are engineering standards which apply directly to specification of aspects of the field of metrology itself.

d. Many engineering standards specify test methods, which require metrological capability for their implementation.

e. Many engineering standards are dimensional, design, or process standards, which use convenient multiples of basic measurement units in use in a country as the specified dimensional, design, or process factors.

$f$. Specifications used in procurement and quality control are often very similar to engineering standards, in that they involve or require test methods, which depend on metrological capabilities, and they are phrased in terms of locally accepted measurement units.

Some examples of kinds of documentary standards and specifications upon which the operations of portions of the national measurement system is based include:

\section{A. The Constitution of the United States}

"The Congress shall have the power...To coin money, regulate the value thereof, and of foreign coin, and fix the standard of weights and measures" (art. 1, sect. 8).

\section{B. International Treaties and Conventions}

The Convention of the Metre of May 20, 1875, established the metric system as the international language for physical measurements. It created the international machinery for implementation and evolution of this system. The Convention was ratified by the United States on May 28, 1878. Currently, 43 nations adhere to $i t . \quad[250,9,57,232]$

The International Organization for Legal Metrology (OIML, from its French initials) is a treaty organization not under the United Nations, which was established in 1955. The United States joined it in August 1972. It is concerned for the most part with standards for instruments and measurement techniques involved in legal determinations of quantity and quality. The decisions of the organization have the character of recommendations, not the force of law. However, members of the organization are morally obligated to implement these decisions as far as possible, and this moral obligation is taken seriously.

C. Laws

"Act of 28 July 1866 (14 Stat. 339)--An Act to authorize the Use of the Metric System of Weights and Measures.

"Be it enacted... That from and after the passage of this act it shall be lawful throughout the United States of America to employ the weights and measures of the metric system; and no contract or dealing, or pleading in any court, shall be deemed invalid or liable to objection because the weights or measures expressed or referred to therein are weights or measures of the metric system."

"Act of 3 March 1901, 31 Stat. 1449 (Public Law 177-56 Congress)--An Act to establish the National Bureau of Standards."

"15 U.S.C. 272. Functions of the Secretary The Secretary of Commerce is authorized to undertake the following functions: (a) The custody, maintenance, and development of the national standards of measurement, and the provision of means and methods for making measurement consistent with those standards, including the comparison of standards used in scientific investigations, engineering, manufacturing, commerce, and educational institutions with the standards adopted or recognized by the Government.

(b) The determination of physical constants and properties of materials when such data are of great importance to scientific or manufacturing interests and are not to be obtained of sufficient accuracy elsewhere.

(c) The development of methods for testing materials, mechanisms, and structures, and the testing of materials, supplies, and equipment, including items purchased for use of Government departments and independent establishments.

(d) Cooperation with other governmental agencies and with private organizations in the establishment of standard practices, incorporated in codes and specifications.

(e) Advisory service to Government agencies on scientific and tecknical problems.

(f) Invention and development of devices to serve special needs of the Government...." 


\section{Administrative Regulations}

Mendenhall Order of April 5, 1893 [46]:

"...The Office of Weights and Measures, with the approval of the Secretary of the Treasury, will in the future regard the International Prototype Metre and the Ki logramme as fundamental standards, and the customary units--the yard and the pound--wi11 be derived therefrom in accordance with the Act of July 28, 1866."

\section{E. State and Local Laws and Ordinances}

NBS Handbook 44 [119] is the basic model code that is adopted as the weights and measures law of 50 states, Puerto Rico, and the District of Columbia. The National Conference of Weights and Measures is responsible for the decisions regarding changes in this Handbook.

\section{F. Engineering Standards}

An Engineering Standard is "an engineering practice established by authority or mutual agreement and described in a document, to assure dimensional compatibility, quality of product, uniformity of evaluation procedures, or uniformity of engineering language. Examples are documents prescribing screw thread dimensions, chemical composition and mechanical properties of steel, dress sizes, safety standards for motor vehicles, methods of test for sulphur in oil, and codes for highway signs." [109, p.12] Engineering standards may cover materials, items, features of items, processes, codes, symbols, type designations, definitions, nomenclature, test, inspection, packaging and preservation methods and materials, define and classify defects, and standardize the marking of material, items, parts, and components of equipment, etc.

About 25 percent of the internationally recommended engineering standards in 1969 focused on dimensional specifications, about 15 percent were quality standards, 45 percent dealt with methods of test, and about 15 percent were descriptive standards. Measurement units are important in dimensional specifications since sizes are usually simple multiples or submultiples of the customary measurement units employed in a particular country. The measurement process, but not the measurement language, is important in quality specifications and methods of test [109, p.3].

Engineering standards function in procurement through the medium of specifications. Standards per se disclose or describe the technical features of an item in terms of what it is and what it will do; in contrast, the specification for the same item describes it in terms of the requirements for procurement. As an example of the relationship of specification to standards, a specification for spark plugs would reference the screw thread standard to ensure the interchangeability of that feature of spark plugs produced by different manufacturers. By referencing other documents, additiona? essential interchangeability features and performance characteristics can be established, or they can be established by the text or figures, as appropriate.

There are thousands of commercial and industrial standards in existence. A basic reference source is NBS Special Publication 329, An Index of U.S. Voluntary Engineering Standards [95]. This work and its supplements $[139,251]$ contain more than 30,000 permuted titles covering standards, specifications, test methods and recommended practices published by over 360 technical societies, professional organizations and trade associations. The General Services Administration Index of Federal Specifications and Standards [280] is the basic compendium in its field. It includes over 40,000 specifications and standards.

Between them, the two major international standards bodies (ISO and IEE-see sect. 4) have published through 1974 approximately 2800 Recommendations. It is generally agreed that in a highly industrialized society the total need of national and international standards is of the order of 15,000 to $20,000[99,109]$.

\subsubsection{Measurement Instrumentation}

The heart of any measurement operation is appropriate instrumentation $[19,201,218,237$, 286]. This is the only element in the technical infrastructure of the measurement system that must always be present in any measurement operation if it is to be successful.

The instrumentation categories listed in the annual Guide to Scientific Instruments [272] and in the 1976 Buyer's Guide issue of Instruments and Control Systems [274] have been analyzed and sorted [328]. The goal was to achieve a level of aggregation that approximates the measurement categories of the national measurement system study microstudies (see Fig. 1), one that would be optimally useful in understanding the product output of the instrumentation industry. 
Table 3. Measurement instrumentation categories and suppliers. Instrumentation Category Numbers of:

(code categories in:)

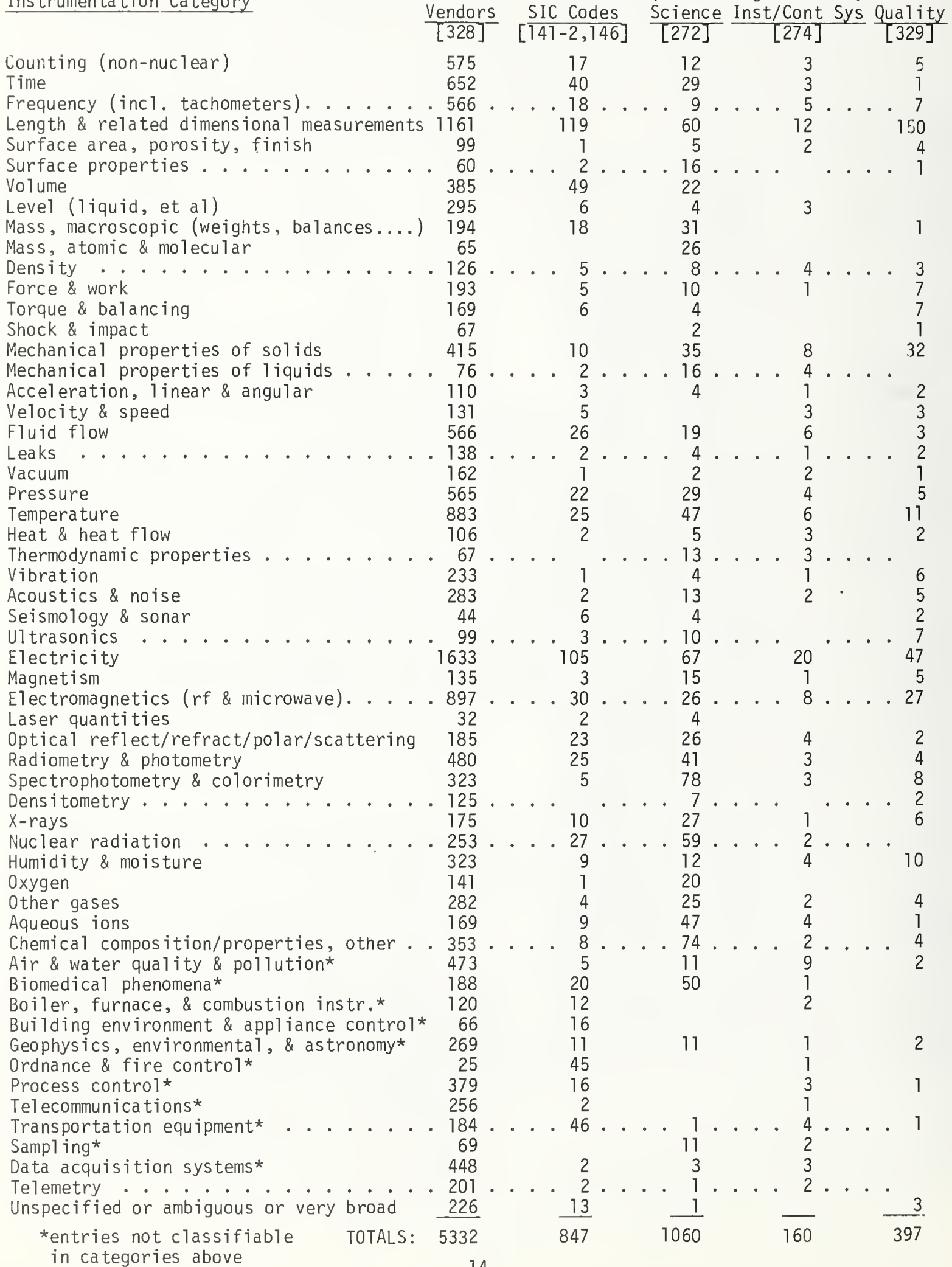


The main instrumentation categories and an approximate count of the number of supplier companies for each category are displayed in table 3 . Note that all measurement instrumentation categories are accounted for, whether or not they were covered during the 1972-75 study by the NBS Institute for Basic Standards; indeed, some are outside either the mission or the technical competence of this Institute. Further, there is some redundancy built into this analysis; specifically, category W "multiparameter measurements" includes instrumentation that could be classified under earlier categories in the sequency, if adequately detailed data were available. Table three also indicates the numbers of specific product categories appearing in the two sources cited, which were aggregated to establish each of the major instrumentation categories.

The final column of numbers in table three defines the counts of Standard Industrial Classification (SIC) measurement product categories which were obtained from analysis of the following sources [328]: U.S. Bureau of Census, Alphabetic List of Manufactured Products, 1963 Census of Manufacturers; A7phabetic List of Manufactured Products (1967 SIC Basis), 1972 Census of Manufacturers [142] Numerical List of Manufactured Products (New (1972) SIC Basis), 1972 Census of Manufacturers [146]; and Office of Management and Budget, Standard Industrial Classification Manua 1, $1972[141]$.

In the language that has grown up with the computer field, measurement instrumentation involves both hardware and software. Both physical apparatus and the techniques by which it can produce the desired results must be available. Therefore, in this discussion, physical instrumentation and measurement techniques will be handled as part of the same subsystem.
The most basic level of physical instrumentation and techniques is that involved in realizing the conceptual definitions of the measurement units. Next is that required to disseminate or transfer the realized units so that they are accessible for reference purposes to those involved in making useful measurements. Finally, there is the working level of instrumentation and techniques which produce the end-use measurement data.

The instrumentation system begins with the equipment and techniques needed to realize the seven base SI units. Of these only one, the kilogram, is defined by an artifact. The others are all defined in terms of physical phenomena or processes, and are realized by physical instrumentation.

A Krypton-86 lamp by means of which the metre is today realized is sketched in figure 6 . One of the primary national frequency standards is shown in figure 7. A schematic diagram of its operating principles is given in figure 8. Figure 9 is a diagram of the experimental realization of the candela, the unit of luminous intensity. A standard voltage reference source is pictured in figure 10 (the volt, while not a base unit, is one commonly maintained for reference standard ; purposes).

Realization of a base unit in a central laboratory is but a first step. In general, the working standards and instruments at the point of end-use-measurement cannot be directly compared against the prototype reference standards or instruments. For one thing, there are simply too many of them. For another thing, the implied intensity of use of the prototype standards is not compatible with maintaining the stability that is one of their most essential features. So, transfer standards, instrumentation, and techniques are required, that allow the connection to be made between the ultimate reference standards and the working end-use instrumentation.

Table 4. Calibration chain example: tire inflation pressure [301]

\section{Operator}

You and I

You and I

Tire gage manufacturer

Tire gage manufacturer

Tire gage manufacturer

Pressure gage manufacturer

Pressure gage manufacturer

Pressure gage manufacturer

National Bureau of Standards
Object/Instrument

Tire

Tire gage

bench standard (Bourdon)

working standard (Bourdon)

plant standard (piston gage)

instrument sold (piston gage)

working standard (piston gage)

plant standard (piston gage)

NBS primary standard

(controlled clearance piston gage)
Required Accuracy Lost

Accuracy In Transfer

1 psi

.3 psi

.1 psi

.03 psi

.01 psi

$100 \mathrm{ppm}$

$70 \mathrm{ppm}$

$50 \mathrm{ppm}$

$30 \mathrm{ppm}$ factor 3

factor 3

factor 3

factor 3

$30 \mathrm{ppm}$

$20 \mathrm{ppm}$

$20 \mathrm{ppm}$ 


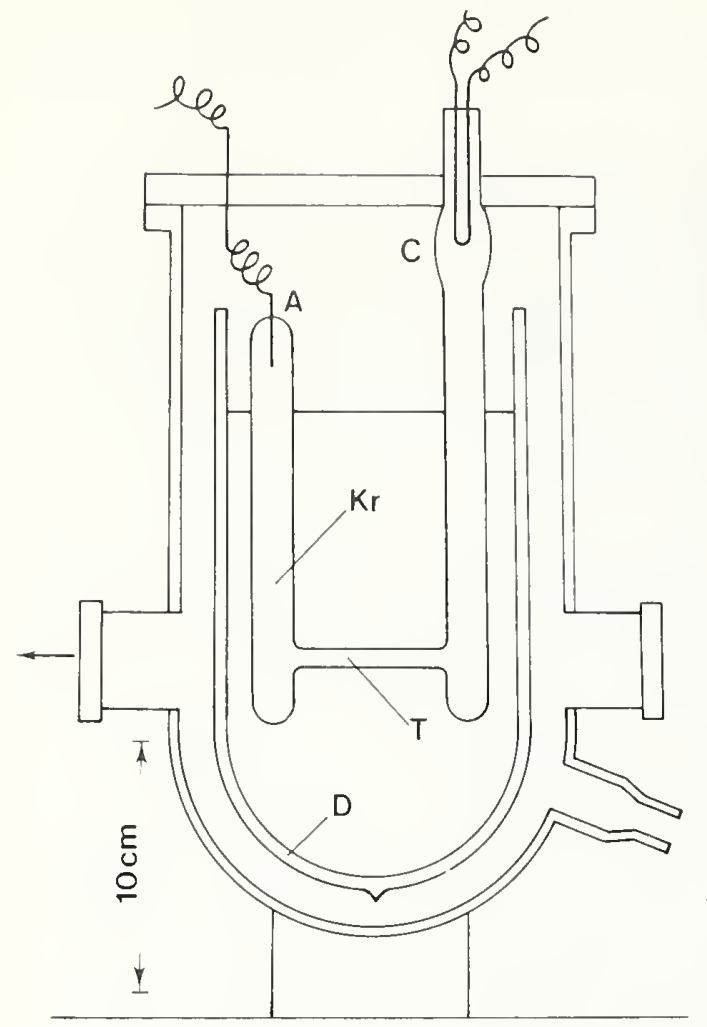

Figure 6. Krypton-86 lamp in its cryostat.

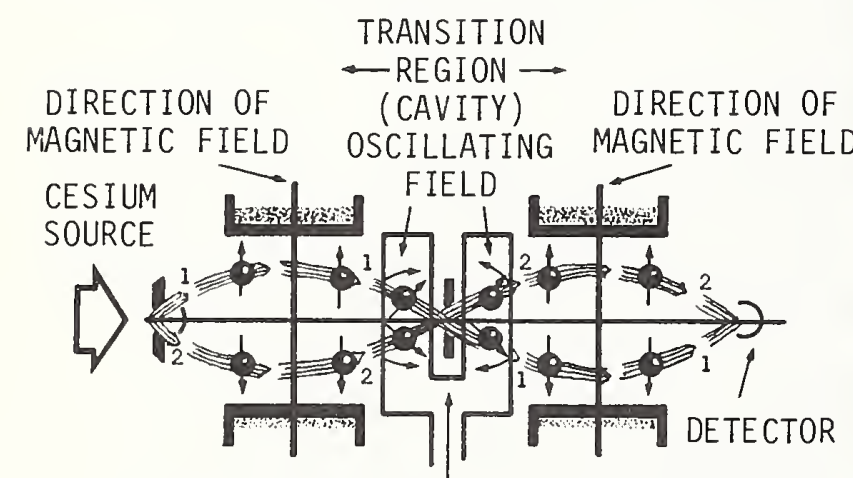

DEFLECTING MAGNET DEFLECTING MAGNET

FROM OSCILLATOR

Figure 8. Schematic of an atomic beam clock.

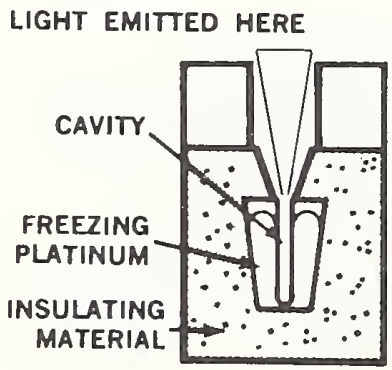

Figure 9. Experimental realization of the candela.

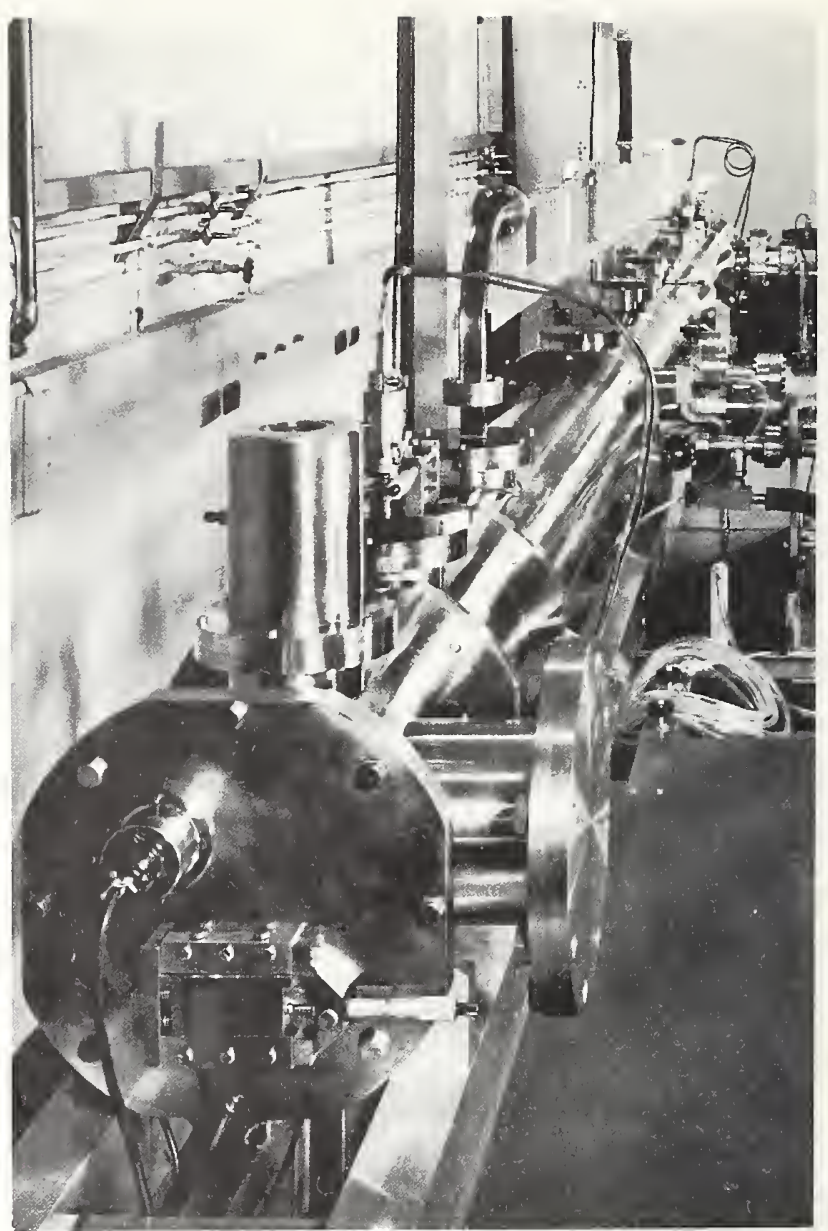

Figure 7. Cesium-beam atomic clock.

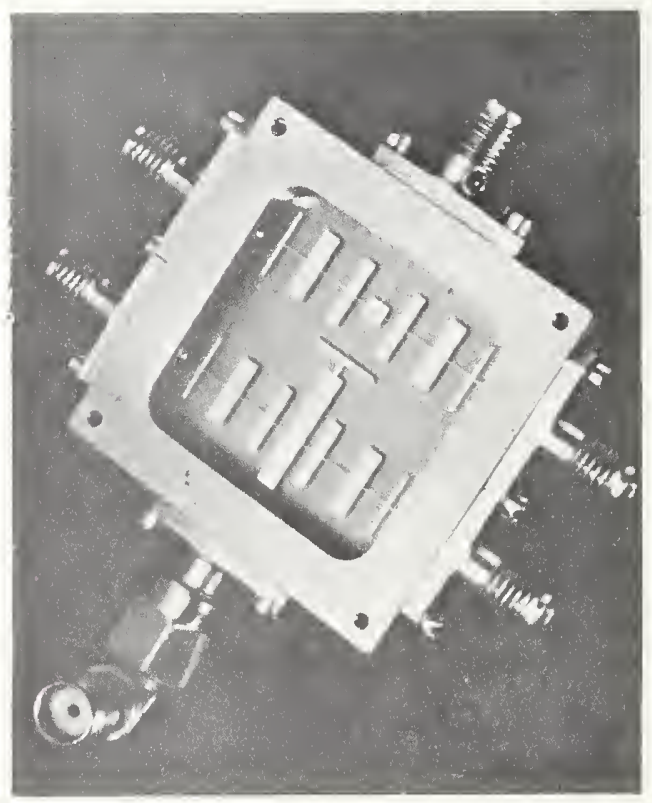

Figure 10. Josephson junction standard voltage source 
Transfer standards must be stable, portable devices, capable of being compared with the reference standards or instrumentation at a central laboratory and with working standards or instrumentation at a number of remote locations. Since, in many cases, a hierarchy of comparisons may be made, with different accuracy requirements at different steps, different kinds of transfer standards nay be appropriate at the different steps. The calibration chain example of table 4 illustrates these points [304].

The calibration of a transfer standard may be against a reference standard which is a physical object very similar to the one being calibrated. This is typically the case for mass. There is no essential difference in kind between the prototype kilogram and mass transfer standards ("weights") or many ultimate end-use mass standards, such as the sets of weights used in chemical laboratories.

In other cases, the transfer standard may be of a very different nature from the reference standard, as in the case of voltage where a bank of standard electrochemical cells is the traveling transfer standard which is compared against the national Josephson junction reference standard. In intermediate cases, the transfer and reference standards may operate on the same physical principle, but be substantially different in design and appearance.

The instrumentation used to compare reference and transfer standards displays an even wider variation in nature than do the standards themselves. Precision balances are used in the case of mass. ETaborate optical instrumentation (fig. 11) is used in the case of length. Complex measuring and comparison systems are used in the case of millimeter wave noise power (fig. 12). Multi-story dead-weight machines (fig. 13) are used to transfer a gravitational force calibration to a proving ring (fig. 14) or load cell which may be only a few inches on a side.

The instrumentation used for end-use measurement and control purposes is even more diverse [328]. Just the members of categovies of instruments listed in various buyers' guides is staggering: over 150 for Instmonents and Control Systems [274] and over 1050 for Science [272]. Over 840 SIC measurement product categories have been identified for the manufacturing industries and more than 200 for non-manufacturing industries [328].

\subsubsection{Reference Data}

One basic function of measurement instrumentation and techniques is to enable the characterization of the properties of matter and materials and of a whole array of fabricated products ranging in complexity from "parts" to "devices" to "equipment" to "subsystems" to "systems". When a given aspect of matter, a given material or a given fabricated product is sufficiently stable, sufficiently well defined, and of wide enough interest, the measurement data that characterize that aspect of matter, material, or fabricated product can become useful as reference data. The existence of reference data takes a substantial load off other aspects of the measurement system. Once these data have been established and made widely available, it is no longer necessary to remeasure the relevant aspects of matter, materials, or fabricated objects every time information is needed about their properties.

The National Standard Reference Data System was established in 1963 by the Federal Council for Science and Technology, as a Federal agency with responsibility to compile, evaluate and disseminate data for the American technical community to use $[50,84$, $137,267]$. The National Bureau of Standards was requested to assume administrative responsibility for this system. The ability of NBS to carry out the program was enhanced by passage of legislation by Congress specifically authorizing this program $[84,267]$. "Standard Reference Data" have been defined to be critically evaluated, quantitative information relating to a property of a definable substance or system. In practice, this means that the program is not concerned with substances of complex or variable composition, for example, concrete, most commercial alloys, or most commercial polymers. Similarly, if the property under consideration is sensitive to the presence of unknown impurities or unknown structural features, that property is not included within the scope of the formal Standard Reference Data system.

Since the data evaluation must necessarily be done by a specialist, and since these experts are located in laboratories a 11 over the country, the National Standard Reference Data System is conducted as a decentralized set of data centers and related activities. Within the National Bureau of Standards, a smal1 program management office coordinates the various activities, allocates funds to individual projects, and takes appropriate action to ensure that produces of the system are adequately available to the technical community in the United States. 


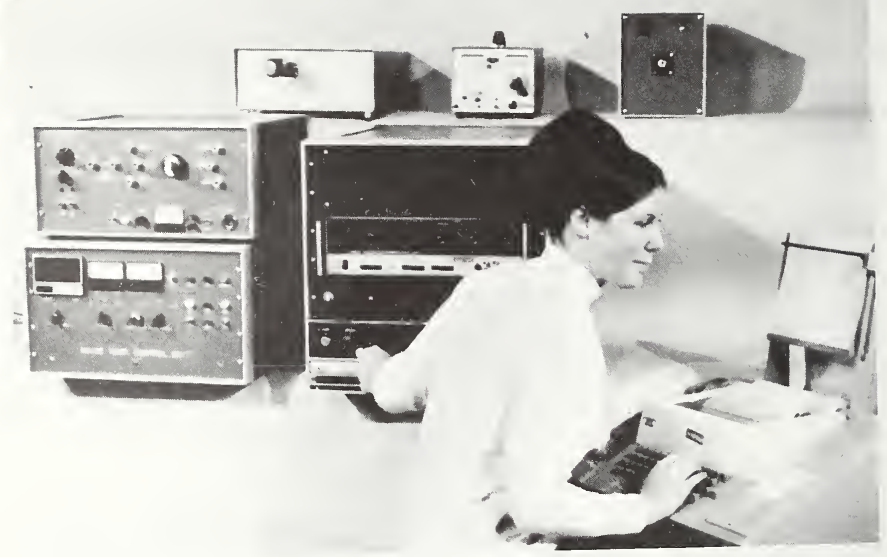

Figure 11.

Figure 12. Automated $\mathrm{Y}$-factor mm-wave noise measurement system. Photoelectric interferometric comparator.
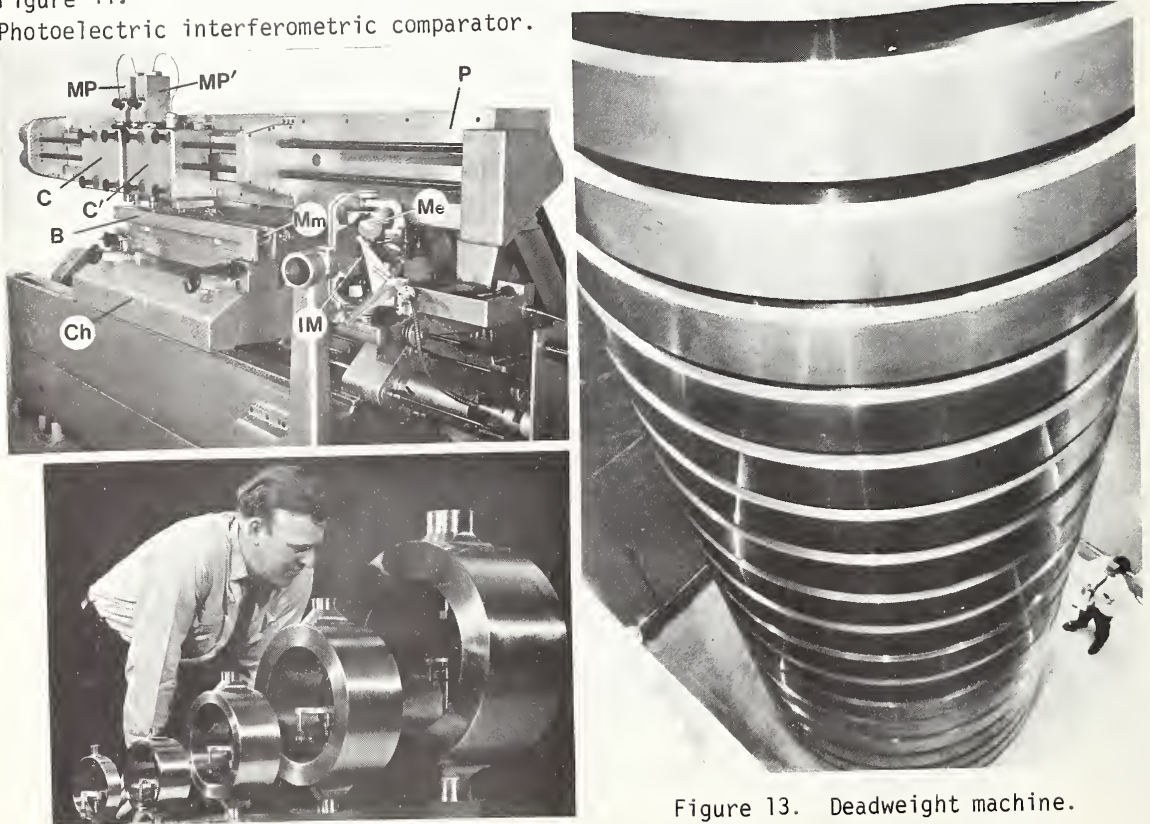

Figure 13. Deadweight machine.

Figure 14. Proving rings. 
Products of the standard reference data centers include:

Classified bibliographies

Indexed bibliographies

State-of-the-art reports

Critical reviews

Compilations of property data

Compilations of critically evaluated data on properties and functions derived from data

Correlations of observations with theory

Compilations of computed properties or functions used in interpretation of experiments.

Appendix D tabulates the published output of the National Standard Reference Data System.

A byproduct of the standard reference data program has been an increase in scientific measurement discipline. During some of the early data studies, it became apparent that perhaps only one paper out of five in a given field could be used as a source of data. For the rest, either the measurement methods used or the printed descriptions were too vague or unreliable to allow the data published in the paper to be used. Substantially, this meant that perhaps 80 percent of the apparently relevant literature was of no value. As a result of the standards set by the publications from the standard reference data system, this situation has significantly improved.

The emphasis in the preceding discussion on standard reference data is not intended to deprecate the importance of reference data of lower precision and more transitory character. The vast bulk of our national engineering activities, particularly in civil engineering, structural engineering, and construction, depends upon the existence of a large body of engineering data concerning the properties of materials and a wide variety of fabricated products. Further, every table of specifications for a commercial product is a table of reference data about that product.

The function of the measurement system in generating reference data is obvious. The fact that such "reusable" data can take a major load off of the routine operations of the measurement system is almost as obvious. Less obvious are the roles that reference data play as a major structural element in the measurement system itself. These roles come in several varieties.

(1) It is often possible to measure the properties of an "unknown" specimen with greater precision or greater ease by comparison of its properties with that of a known material, than it is to measure these properties in an absolute sense. This requires that reference data be available concerning the "known" reference material. An example is the sorting of mineral specimens into different density ranges based on their sinking or floating in a series of liquids of known densities.

(2) The known properties of readily available reference materials may be used to calibrate measurement instrumentation. For example, air bubbled through water held at a known temperature can be used to generate a known humidity atmosphere, for the calibration of humidity meters. This application requires that the reference data regarding water vapor pressure versus temperature be available.

(3) The properties of materials may be used to define the measurement process itself. Units for four of the base SI quantities are defined in this manner: temperature, for which the kelvin is defined in terms of the triple point of water; the candela, which depends upon the luminosity of molten platinum at its freezing point; and length and time, which are defined in terms of data regarding certain atomic transitions. However, it is in the International Practical Temperature Scale (see table 5) in which the interplay between reference data, reference materials, and the foundations of the measurement system becomes most dramatically apparent.

Temperature is defined in theoretical thermodynamic terms, with the size of the unit defined by one arbitrary fixed point, the triple point of water, where ice, water, and pure water vapor coexist in equilibrium. However, theory alone is not very useful for determining how hot it is. It has to be embodied in established data and hardware. The International Practical Temperature Scale is such an embodiment. Reference data have been established for a number of materials, which data represent the closest approximation that is currently feasible to applying the absolute thermodynamic theory to the determination of the temperatures of real materials under defined conditions. These data are then used to establish a practical temperature scale. Use of this practical temperature scale allows enhanced precision in day-to-day temperature determinations. If the practical scale is ever revised because of achievement of greater precision in the reference data base, these revisions can also be applied to measurements made with the current scale, so that their accuracy is further improved. 
Table 5. Frimary fixed points on International Practical Temperature Scale IPTS-68

$\frac{\text { State }}{\text { thermodynamic zero of temperature }}$

$\frac{T_{68}(k)}{0}$

13.81

17.042

20.28

27.102

54.361

90.188

273.16

373.15

692.73

1235.08

1337.58

$\frac{t_{68}\left({ }^{\circ} \mathrm{C}\right)}{-273.15}$
-259.34
-256.108
-252.87
-246.048
-218.789
-182.962
0.01
100.00
419.58
961.93
1064.43

Figure 15 tells a similar story [158]. Only the optical pyrometers (radiation detection) temperature measuring instruments depend upon absolute physical proeprties that are substantially independent of the particular materials used, as are the length of a meter bar or the mass of a kilogram standard. The rest--thermocouples, resistance thermometers, thermistors, mercury-glass thermometers, and bimetallic devices--depend for their functioning directly upon material properties that vary widely from substance to substance. In some cases, such as mercury-glass or bimetallic thermometers, devices are usually individually calibrated so that the user has no need to be aware of the reference data regarding material properties. For others, especially thermocouples and resistance thermometers, the user may be reading an electrical value and converting it into temperature by consulting a table of reference data for the material system that he is employing.

\subsubsection{Reference Materials}

Reference materials represent another facet of the national measurement system $[240,83,87$, $111,131,235,241]$, one both distinct from and closely related to reference data. Reference materials complement and supplement reference data. The very concept of reference material implies the existence of reference data regarding that material, and many kinds of reference data describe properties of substances that could be used as reference materials.

Taken in its broadest sense, the word material can include any physical object. Reference materials may be materials of measured composition, measured properties, or measured dimensions, or materials that when acted upon produce specific and measured effects. From this

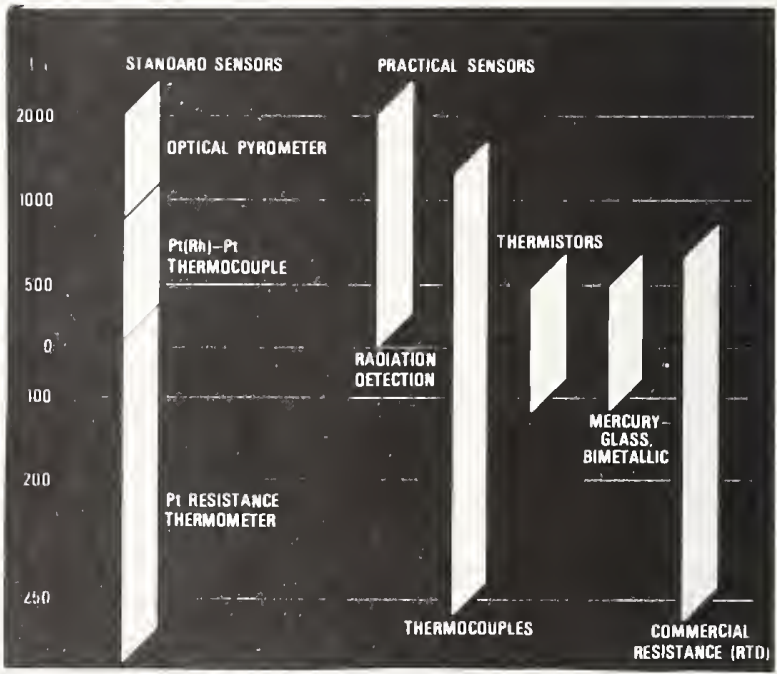

Figure 15. Temperature measurement sensors

point of view, there are few physical reference standard or measurement techniques that do not involve reference materials, and some physical reference standards, such as those for density, are reference materials.

Some reference materials, such as highly pure water or high purity hydrogen, can be prepared by the user. Others can be purchased from commercial sources. However, the uncertainties associated with preparing and characterizing reference materials are sufficiently great that there is a substantial need for standard reference materials (SRM's) prepared and characterized in the most definite possible manner. The National Bureau of Standards and other national standards laboratories often function as sources for such standard reference materials [240] (see table 6). 
Table 6. Table of Contents from catalog of NBS standard reference materials [252].

GENERAL INFORMATION .

PREPARATION AND AVAILABILITY OF STANDARD REFERENCE MATERIALS: Ordering, Terms, Domestic Shipments, Foreign Shipments

CHEMICAL COMPOSITION STANDARDS

Steels (chip form): plain carbon, low alloy, high alloy, stainless, tool

Steels (granular form)

Steels (solid form): special ingot irons and low alloy, stainless, specialty, high-temperature alloys, tool ..... Steelmaking Alloys ........... Cast Irons (chip form) . . . . . . . Cast Steels, White Cast Irons, Ductile Irons and Blast Furnace Irons (solid forms)..

Nonferrous Alloys (chip form): aluminum, cobalt, copper, lead, magnesium, nickel, nickel oxide, selenium, tin, titanium, zinc, zirconium ..........

Nonferrous Alloys (solid form): copper, lead, nickel, tin, titanium, zinc,

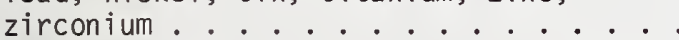

Gases in Metals . . . . . . . .

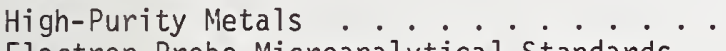

Electron Probe Microanalytical Standards

Primary, Working, and Secondary Standard Chemicals ...........

Microchemical Standards . . . . . .

Clinical Laboratory Standards . . . . .

Biological Standards .........

Environmental Standards: analyzed gases, analyzed liquids, analyzed solids, permeation tubes, trace elements in fossil fuels

Forensic Standards . . . . . . . . Hydrocarbon Blends ........ . . 35

Metallo-Organic Compounds ...... . 36

Fertilizers........... . . 36

Ores . . . . . . . . . . 37

Cements .............. . . 38

Minerals, Refractories, Carbides, \& Glasses 38

Trace Element Standards........ 40

Nuclear Materials: Special nuclear materials (plutonium assay, plutonium isotopic, uranium assay, uranium isotopic), Neutron density standards, Fission track glass standards............ Isotopic Reference Standards . . . . . 43

PHYSICAL PROPERTY STANDARDS . . . . . . . 44

Ion activity Standards: $\mathrm{pH}$ standards, $\mathrm{PD} \cdot 44$ standards, ion selective electrodes . . . 44

Mechanical and Metrology Standards: coating thickness, glass, elasticity, density, polymer . . . . . . . . . . . . .

Heat Standards: Superconductive thermometric fixed point devices, Freezing points (defining fixed points, determined reference points), Melting points, Calorimetry (combustion, solution, heat source, enthalpy and heat capacity), Differential themal analysis, Vapor pressure, Thermal conductivity, Thermal expansion, Thermocouple materials
Magnetic Standards: magnetic susceptibility Optical Standards: Spectrophotometry (color standards for spectrophotometric tristimulus integrator systems, glass filters, liquid filters, quartz cuvette), Thermal emittance, Reflectance, Refractive index

Radioactivity Standards: Alpha-particie standards; Beta-particle and gamma-ray gas standards; Alpha-particle, beta-particle, gamma-ray, and electron-capture solution standards; Contemporary standard for carbon-14 dating laboratories; Environmental standards; Low energy photon sources; Gamma-ray "point-source" standards; Radium gamma-ray solution standards; Radium solution standards for radon analysis; Radioactivity standard reference materials currently not in stock

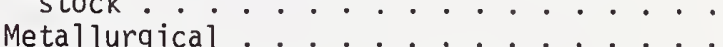
Mellallurgical. . . . . . . . . . 6 Mossbauer .............. 61 X-ray Diffraction . . . . . . . . 61

Permittivity .. . . . . . . . . 62

Reference Fuels . . . . . . . . . 62

Resistivity . . . . . . . . . 62

ENGINEERING TYPE STANDARDS

Standard Rubber and Rubber-Compounding Materials

Reference Magnetic Tapes . . . . . . . .

Sizing Standards: glass spheres for particle size, turbidimetric and fineness (cement)

Color Standards: the ISCC-NBS centroid color charts; paint pigment; 1ight-sensitive

papers; 1ight-sensitive plastic chips . . 64

$X$-ray and Photographic Standards . . . 65

Surface Flammability Standards . . . . 65

Smoke Density Chamber Standards . . . . 65

Water Vapor Permeance . . . . . . . . 66

Internal Tearing Resistance Paper . . . . 66

Tape Adhesion Testing standard . . . . 66

RESEARCH MATERIALS: High-Purity Materials, SEM Resolution Test Specimen, Phosphors

GENERAL MATERIALS: Hydrogen in Steel, Nickel and Vanadium in Residual 0i1, Absorbent Clay (ASTM D2007)........... 68

COMPUTER PROGRAMS FOR METRIC CONVERSION . . 68

OTHER SERVICES OF THE NATIONAL BUREAU OF STANDARDS: Calibration and Test Services, Standards Information Services, Standard Reference Data, Technical P,ublications.

GUIDE FOR REQUESTING THE DEVELOPMENT OF STANDARD REFERENCE MATERIALS

\section{INDEXES}

Alphabetical Index ...... . . 73 Numerical Index to SRM Certificates . . 80
54

\section{5}

8

1


The 1975 NBS price list for Standard Reference Materials 1 ists some 892 items [275]. of these, over 650 are bulk materials, whose utility and properties are either substantially unaffected by or can be readily calculated after subdivision. An example of the former is SRM $43 \mathrm{~h}$ Zinc, freezing point standard, and of the latter, SRM 4963 Radium solution standard, $50 \mathrm{\mu g}$ Ra.

Approximately 100 more can be described as "two-dimensional" bulk materials, such as glass optical filters or specimens with coatings of various kinds. Another seventy or so are of value for physical properties that depend upon specimen dimensions, such as thermal expansivity or conductance, emittance, and magnetic susceptance, or else involve properties that limit the ability to subdivide the materials usefully--such as those associated with single crystal specimens or samples of beads.

The remaining 50 or so standard reference materials are basically physical reference standards as discussed earlier in this report. About half are radiation sources, in the gray area between "materials" and "devices." The rest are physical measurement standards or devices, or even computer software packages, made generally available to the public through the SRM marketing mechanism. Examples include SRM's 932 Quartz cuvette for spectrophotometry; 933 and 934 Clinical laboratory thermometers; 1001 X-ray step tablet; 1010a Microcopy test chart; 1600 Tape, magnetic, secondary standard, cassette; and 2106 ISCC-NBS color charts.

The significant point for present purposes is that measurement instrumentation, measurement techniques, physical reference standards, standard reference materials, and standard reference data form a continuum in the technical infrastructure of the measurement system. Each element complements and supplements all of the others, and any or all may be needed in any given measurement situation.

\subsubsection{Predictive Methods}

One more element needs to be added to the technical infrastructure continuum of the previous paragraph, namely predictive methods, i.e., theoretical models which will alow prediction of measurement results for circumstances in which the volume of experimental measurement data needed is so large or the experimental conditions so inaccessible, that it is not technically or economically feasible to actually generate measurement data. These models are useful for both extrapolation and interpolation [322].

While predictive methods could be shown as a separate structural element (see fig. 3 ) in the formal model of the measurement system, they are at this time encompassed as part of the block labelled "science."

\subsubsection{Fundamental Constants}

In all of our fundamental theories there are a certain few parameters which characterize the fundamental particles and interactions that we find in nature. These are the fundamental physical constants $[12,39,93,112,205]$. The precise determination of the numerical values of these constants has long been and remains one of the principle objectives of experimental science, and one of the greatest driving forces toward increased accuracy and precision in the measurement system. These parameters are the quantitative link between our most basic theories and the physical reality that we wish them to describe. The progress of our understanding of the physical world is therefore very much intertwined with the advance of the art of precision measurement and its application to the determination of the fundamental constants.

There is an essential connection between the fundamental constants and our choice and definition of the base units in our scheme of physical measurement. Moreover, scientific invention and discovery continue to provide us with new opportunities for strengthening these connections.

Ideally, we want our measurement system to be based on aspects of nature that are invariant with time and place and that can be reliably and independently reproduced in different laboratories. We want the measurement system to be independent of reference to artifacts whose continued existence and longterm stability is a matter of fundamental uncertainty. The fundamental constants appear to be the true invariants of nature, and therefore represent the ideal basis for a measurement system.

In fact, both length and time are now defined in terms of atomic transitions, and are therefore conceptually closely connected with the fundamental constants related to these transitions. The volt is now maintained by use of the relationship between voltage phenomena in superconducting tunnel junctions and electromagnetic frequencies, the proportionality factor involving the fundamental constant, $2 \mathrm{e} / \mathrm{h}$. The definition of the candela involves the fundamental constant relating temperature and the emission of radiant energy.

The fundamental constants are often used to calculate desired quantities from measurements actually made of some other quantities. This is particularly true in the case of length, where the speed of light is often used to convert time interval measurements into length measurements. Examples include laser ranging of the moon and terrestrial surveying, radar and radionavigation systems. 
Similarly, the most precise method of realizing a known force consists of utilizing the action of the terrestrial gravitational field on a known mass. This requires precise knowledge of the local acceleration of gravity, determined in an absolute manner by means of measurements of length and time. The fundamental Newtonian gravitational constant enters into determinations by earth scientists of the mass, mean density, and mass distribution of the earth.

As our measurement capabilities evolve, it is becoming apparent that it may become desirable to define certain fundamental constants as fixed numbers relating what were previously independent units. In particular, it is becoming technically feasible to define the speed of light as an arbitrary number (in the last several decimal places), so that one standard could serve as either the time standard or the length standard, with the relation between time and length being the defined constant $c$. Doing so could allow the limitations in convenience, stability, precision, and accuracy of the present Krypton length standard to be avoided, and could eliminate some current aspects of confusion in relating length measurements based on the transit time of light and those based on the wavelength of specific spectroscopic lines.

It is possible to determine certain fundamental constants by basically independent and different measurement paths, involving substantially different combinations of measurement units. Intercomparison of the resulting independent values can provide insight not only into the precision with which the constants themselves are known, but also into the consistency and accuracy of realization of the different measurement units.

Precision determination of the fundamental constants often requires close access to the national measurement reference standards. As a result, the national reference standards laboratories, such as NBS, often can play a unique role in this field of science: as custodians of national measurement standards, they can perform experiments in this field that are not practical in other laboratories, and, indeed, performance of such scientific research is one of the obligations that these laboratories have to the world of science.

The forcing-factor effect of this kind of research often leads to improvements in measurement methods that can then be applied quite widely. A current NBS example involves the improvement of silicon density standards in order to allow a higher precision determination of Avogadro's number. These silicon density standards appear adequate to meet all foreseeable density standard needs for years to come, and represent a solution to the longstanding inadequacies associated with the use of water for this purpose (inadequacies due in large part to the basic variability in the isotopic composition of water).

The fundamental constants thus play a subtle but key role in the measuremtnt system. They enter into the definition of the basic conceptual system, they are of substantial importance in the realization of measurement capabilities, and as one of the most demanding areas of scientific measurement, they are a driving force for advances in the state of the measurement art. In principle, an additional structural element could be added to figure 3 , labelled fundamental constants. For present purposes, however, it seems adequate simply to handle them as part of the central scientific portion of the system.

\subsubsection{Science and People}

The central core of the measurement system consists of knowledge or science and of the people who employ it. In newly developing or simple measurement areas, this element often suffices to hold the system together quite adequately, without the need for any formal technical or institutional infrastructures.

The necessary structural elements of this portion of the system are substantially the same in kind as for any technical field. Publication mechanisms are needed to record and disseminate knowledge. Academic education and training are necessary. Professional societies support these activities. The only structural element that may be somewhat unexpected is the heavy education and training role played by the instrumentation industry in connection with its sales efforts; for many aspects of the measurement system, the primary burden of providing such education and training as does exist, is borne by the instrumentation industry.

Historically, metrology and mathematics (and logic) developed in parallel to meet basic human needs. Civil engineering came into existence for similar reasons, and was inseparably connected with applied mathematics and metrology. Mathematical, metrological, engineering, and craftsmanship capabilities interacted with each other through the ages, each enhancing the others. The rise of experimental science at the end of the Middle Ages drew upon them heavily. The development of experimental science and the new fields of engineering became the driving force for the 
evolution of metrology from its ancient weights-and-measures-and-clocks role into a comprehensive ability to characterize quantitatively the physical world around us.

Today, metrology, science, engineering, and technology form a highly interdependent knowledge complex. Advances on the frontiers of science result from or depend upon advances in measurement capabilities. Advances in measurement capabilities result from exploitation of advances in science, engineering, and technology.

Among recent developments in science and technology that are of major importance in metrology are the following:

(1) The development of nuclear transmutation and isotope separation technology during World War II allowed the production of the isotopically pure electrical discharge light sources that have allowed the redefinition of the meter from being based on a physical artifact to being based on a wavelength of light.

(2) The development of microwave technology during World War II led to the development of microwave resonance techniques that have led to the definition of the second in terms of an atomic transition. Furthermore, unlike the case of length measurements for which the absolute atomic definition of the meter is physically realized in only a very few laboratories around the world, atomic clocks and frequency standards are eminently practical devices in wide use.

(3) The development of computer technology based on semiconductor phenomena is allowing man to be replaced as a vital link in the measurement observation and calculation process. It is making possible measurement capabilities that man could never achieve with his unaided observational and calculational powers.

(4) The laser is profoundly changing the physical basis for many measurements. Laser ranging on retroflectors placed on the moon is allowing experimental determination of the drift of the continents. Laser and computer controlled machine tools are drastically changing the field of precision machining. Capabilities in precision spectroscopy have been increased by orders of magnitude.

(5) The superconducting tunnel junction ("Josephson junction") is providing links between frequency measurements and other basic phenomena, which suggests that some day frequency may be the only basic measurement pa- rameter. Today, the U.S. national legal voltage standard is based upon the Josephson effect. Temperature can be determined and controlled in a similar manner. Length can already be defined more precisely through the speed of light in terms of the time or frequency standard, than it can be defined directly. There is promise that mass and the mole can be related to length by definition of the kilogram in terms of the number of atoms of silicon contained in a given volume of a highly perfect crystal of semiconductor grade silicon. Luminous intensity is currently based on length and temperature measurements.

Today, every scientific, technical, engineering, or trade society or association has an interest in the quantities, units, and methods of measurement. A number of professional societies and trade associations exist directly as part of and in support of the measurement system; among them are:

-American Society for Quality Control

-American Watchmakers Institute

-American Watch Workers Union

-Gasoline Pump Manufacturers Association

- Instrument Society of America

- Metric Association, Inc.

- National Conference on Weights and Measures

- National Conference of Standards Laboratories

- National Committee on Radiation Protection and Measurement

-Precision Measurements Association

- Scale Manufacturers Association

-Scientific Apparatus Makers Association

The measurement system is critically dependent upon the adequacy of the knowledge possessed by those making the measurements. As a result of this dependence, much negative leverage potential exists in the system; lack of knowledge leads to poor measurements plus lack of awareness of their poor quality. The poor measurement data can result in misinformation, erroneous conclusions, and mistaken actions.

The educational system in the field of measurements consists of a widely diffused collection of coincidental efforts plus a very small number of focussed programs. In elementary education, measurement skills are taught as a coincidental adjunct of the teaching of science. Metrology as such, is taught in only a very few formally defined programs in this country. 


\subsection{Realized Measurement Capabilities}

The pivotal level in the whole measurement system is that of realized measurement capabilities $[19,20,22,24-27,33,36,37,41,51,66,67$, $72,86,94,119,140]$. The capabilities of end users and of the dissemination and enforcement network institutions rest upon, exploit, and apply a specific, achieved, limited, measurement capability. Inversely, the conceptual and technical infrastructural levels have meaning only as they lead to an actual capability to measure, and as one moves from the basic conceptual and technical levels out into the field of making useful measurements, limitations in measurement capabilities steadily increase.

The primary limitations of measurement capabilities can be stated in terms of the ranges over which a parameter can be measured; of precision or repeatability of a measurement; of accuracy of measurement, the degree of agreement with a theoretical "absolute" truth; of environmental sensitivity of all of the above, with special emphasis on adverse conditions; and of cost, of the equipment or measurement, in money and in time.

The vastness of this subject--given the large number of measurement quantities studied and the fact that many discussions of it have been published by NBS and others in the past--renders it unprofitable to attempt any extensive summary of realized measurement capabilities in this report. Table 7 is presented to give an indication of the best that can be done in fields of measurement of interest now. Achieved measurement precisions and accuracies range from a few parts in 1013 for time and frequency to approximately one percent in such fields as radiometry and photometry.

\subsection{Institutional Infrastructure}

The institutions (organizations) that currently play a major role in the national measurement system are the documentary standardization institutions and the instrumentation industry in support of the technical infrastructure, the central measurement standards authorities in support of all aspects of the system, the state and local offices of weights and measures in the enforcement of honest weights and measures in commercial transactions, the standards and testing laboratories and services in dissemination of industrial technological measurement capabilities, and the technical regulatory agencies in connection with regulations requiring measurements for their establishment and enforcement.

\subsubsection{Standardization Institutions}

Standardization institutions operate at the international, national, industrial, technical, company, and local governmental levels. With few exceptions, these organizations in the United States are non-governmental, and the standards issued are used voluntarily by industry and government [88, $99,109,121,128,129,291,308]$.

The main international body in the area of industrial and commercial standards is the (non-treaty) International Organization for Standardization (ISO) whose main function is to develop international cooperation in standardization activities. ISO is comprised of national standardization bodies from 69 countries. Its prime objective is to promote the development of world-wide standards with a view of facilitating international exchange of goods and services. From the work of thousands of technical experts around the world emerge the ISO Recommendations, which serve to promote freer international trade by helping to reduce the differences between various national standards. IEC, the International Electrotechnical Commission, became affiliated with ISO in 1947 and today has 41 member countries.

There are also regional organizations. The Pan American Standards Commission (COPANT) operates in the Western Hemisphere. The International Commission on Rules for Approval of Electrical Equipment (CEE), the Economic Commission for Europe (ECE), and the Committee for the Coordination of European Standards in the Electrical Field (CENEL) are concerned with standardization in Europe.

In the field of metrology, the General Conference of Weights and Measures promotes international standardization of the scientific or basic technical aspects of the field, while the International Organization for Legal Metrology promotes standardization of the legal aspects of metrology--laws, instruments, procedures (see section 3 ).

At the national level, the United States has a single standards organization that coordinates the development and publication of industrial and commercial standards, known as the American National Standards Institute (ANSI). Its principal function is to act as a clearing-house to coordinate the work of standards development in the private sector, which is currently being carried on by some four hundred different organizations (see Appendix E). Through its procedures, timely development of standards is made possible, duplication and overlap are minimized and a 
Table 7. Realized measurement capabilities.

Measurement Quantity

Time and frequency:

NBS- 5

Commercial Cs beam devices

Length:

$\mathrm{Kr}-86 \mathrm{lamp}$, NBS

NBS end-std. calib.: $25 \mathrm{~cm}$

Geodetic surveying

Surface Finish:

Mass:

International comparisons Class M laboratory weights Commercial test weights

volume: Laboratory use

Density: NBS

Force:

NBS deadweight standards, corrected for air buoyancy Working calibration standards

Vibration: NBS

Fluid Flow:

Air flow, NBS

Pipelines, liquid and gas

Water, open conduits

$$
\begin{gathered}
\text { Estimated } \\
\begin{array}{c}
\text { Accuracy } \\
\text { (Parts per unit) } \\
1-2 \times 10^{-13} \\
1 \times 10^{-11}
\end{array}
\end{gathered}
$$

$$
\begin{array}{r}
1-2 \times 10^{-9} \\
3 \times 10^{-7} \\
3 \times 10^{-3} \\
1 \times 10^{-6} \\
2.5 \mathrm{~nm}
\end{array}
$$

$$
\begin{array}{r}
2-3 \times 10^{-9} \\
5 \times 10^{-6} \\
1 \times 10^{-4} \\
5 \times 10^{-4} \\
5 \times 10^{-6}
\end{array}
$$

$2 \times 10^{-5}$

$1 \times 10^{-5}$

$5 \times 10^{-5}$

$1 \times 10^{-2}$

$1.5 \times 10^{-3}$

$1-3 \times 10^{-2}$

$5 \times 10^{-2}$

Pressure:

NBS standards

Military maintenance stds.

$$
3-6 \times 10^{-5}
$$

$1 \times 10^{-4}$

Temperature:

Water triple point

Commonly used sensors

$1 \times 10^{-6}$

$1 \times 10^{-5}$

to $5 \times 10^{-4}$

Humidity:

NBS

Commercial humidity meters

$1 \times 10^{-3}$
$1 \times 10^{-2}$

Moisture: In grain

up to $2 \times 10^{-1}$

Thermodynamic properties

of fluids:

to $\begin{array}{r}1 \times 10^{-4} \\ 5 \times 10^{-3}\end{array}$

Cryogenics:

Pressure transducerscommercial

Tempera ture--commercial

Flow--NBS research facility

$5-70 \times 10^{-2}$
$10^{-4}$ to $10^{-2}$

$1 \times 10^{-3}$
Measurement Quantity

Electricity

DC voltage, NBS

RMS voltage, $10 \mathrm{kHz}$, NBS

Capacitance, NBS

Resistance, NBS

Estimated

Accuracy

(Parts per unit)

$1 \times 10^{-7}$
$2 \times 10^{-5}$
$1 \times 10^{-7}$
$8 \times 10^{-8}$

Electromagnetics

Impedance

Attenuation

Phase delay

Power

Voltage

Noise

Field Strength

Medical U1trasonics: power

$1 \times 10^{-3}$

to $2 \times 10^{-1}$

$5-10 \times 10^{-3}$

$1-10 \times 10^{-2}$

$10^{-4}$ to $2 \times 10^{-1}$

$5-300 \times 10^{-2}$

$3-20 \times 10^{-2}$

$5 \times 10^{-2}$

Acoustics:

Sound pressure, NBS

Noise exposure, commercial

$3-30 \times 10^{-2}$

Radiometry and photometry:

NBS

Field workers

$1-5 \times 10^{-2}$
$5-10 \times 10^{-2}$

Spectrophotometry:

Transmittance, NBS

Reflectance, NBS

$3 \times 10^{-4}$
$5 \times 10^{-3}$

Far ultraviolet radiometry:

Detectors, NBS

Sources, NBS

$6-10 \times 10^{-2}$
$5-10 \times 10^{-2}$

Optics:

Resolution limits

Optical density

Lens diopters, NBS

10001 ines per $\mathrm{mm}$

$5 \times 10^{-3}$
$10^{-4}$

Lasers:

Frequencies, NBS

Power and energy, NBS

$10^{-10}$ to $10^{-9}$
$1-7 \times 10^{-2}$

Physical properties of atoms and molecules:

Energy levels

Atomic hyperfine separation

Cross sections, electrons

Cross sections, a toms/ions

Oscillator strengths

Electron drift velocity

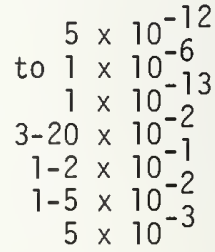

Surface composition: $0.1 \%$ of an atomic layer $0.1 \mu \mathrm{m}$ lateral resolution

Ionizing radiation: NBS 
neutral forum is provided to consider and identify the need for standards. Through its recognition by such international and nontreaty standardsization bodies as ISO, IEC, and COPANT, as the National Standards body of the USA, ANSI serves as the focal point for organizing USA participation in international standardization.

Standards for materials are the province of American Society for Testing and Materials (ASTM). ATI ASTM technical committees are directed to submit all standards under their jurisdiction for adoption by the American National Standards Institute as national standards.

A major example of industry standards becoming international standards is found in those of the American Petroleum Institute, API [298]. The principal activities of this Institute are simplification, standardization and improvement of equipment and methods used by the petroleum industry. As a result of the work of API, the American petroleum industry standards have become world-wide standards. As part of this API standardization system, NBS maintains the API Grand Master Gages against which essentially all hardware unique to this industry is ultimately checked, world-wide.

The Federal Government is also a major contributor of standards and specifications. Its specifications for purchasing are only mandatory for the federal government, but many, such as military specs, are adapted for industrial use.

The Department of Defense's (DOD) "Defense Standardization Program" provides uniform definitions of the technical requirements for parts, equipment, and systems in which the various elements of the DOD have a common interest. The principal product of this program has been the development of nearly 40,000 specifications and standards defining the technical requirements of the DOD. It couples the enormous Defense Department budget, approximately 100 billion dollars, directly to the National Measurement System, since it requires that the length, density, capacity, electrical values, and other physical properties of every item be traceable to the national artifacts at NBS via industry's quality control system.

The General Services Administration [280] issues five types of Federal Standards for items employed by the Federal Government:

1) Supply Standards

2) Test Method Standards

3) Material Standards

4) Engineering Standards

5) Procedural Standards.

The National Bureau of Standards has long been interested in promoting documentary standardization as well as uniform physical measurements. Its role has been that of a central catalytic agent and monitor of the standardization efforts of the nation.

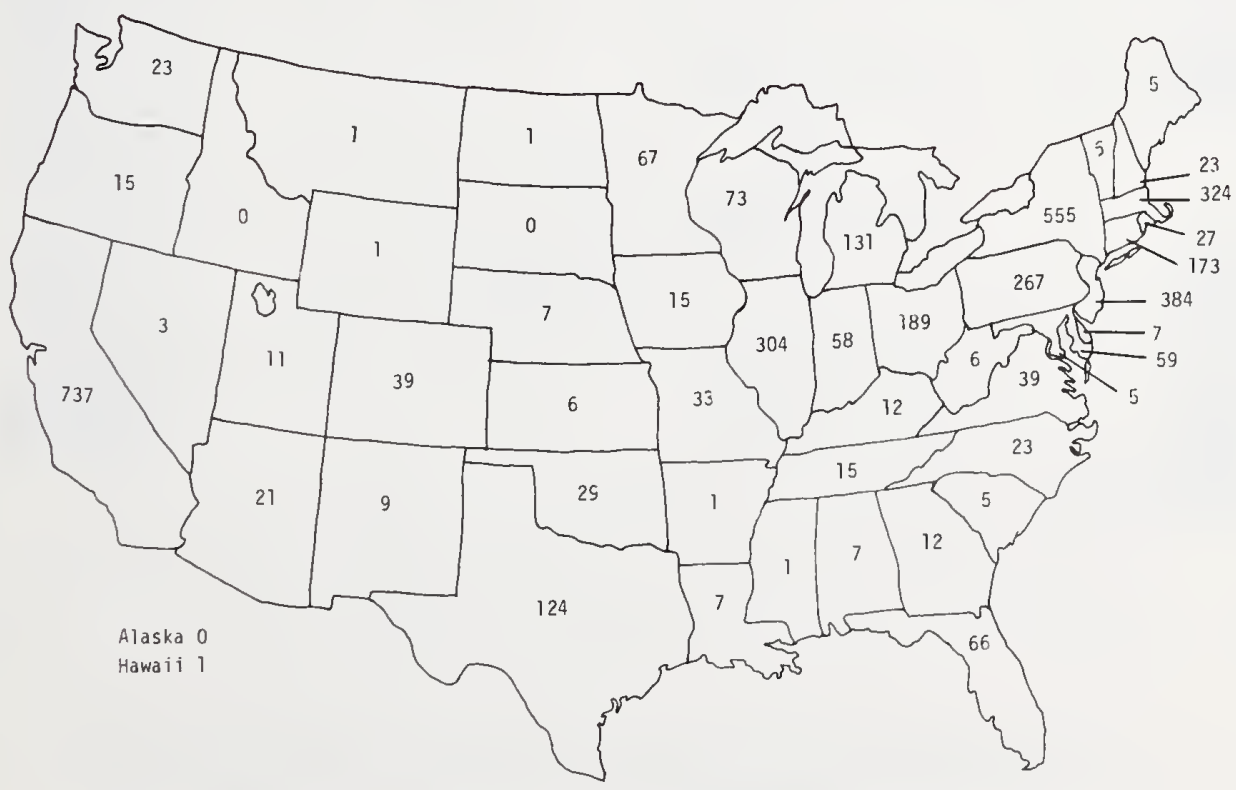

Figure 16. Location of measurement and control instrumentation companies. 


\section{MEASURING, ANALYSIS AND CONTROL INSTRUMENTATION INDUSTRIES EXPENDITURES AND SALES}

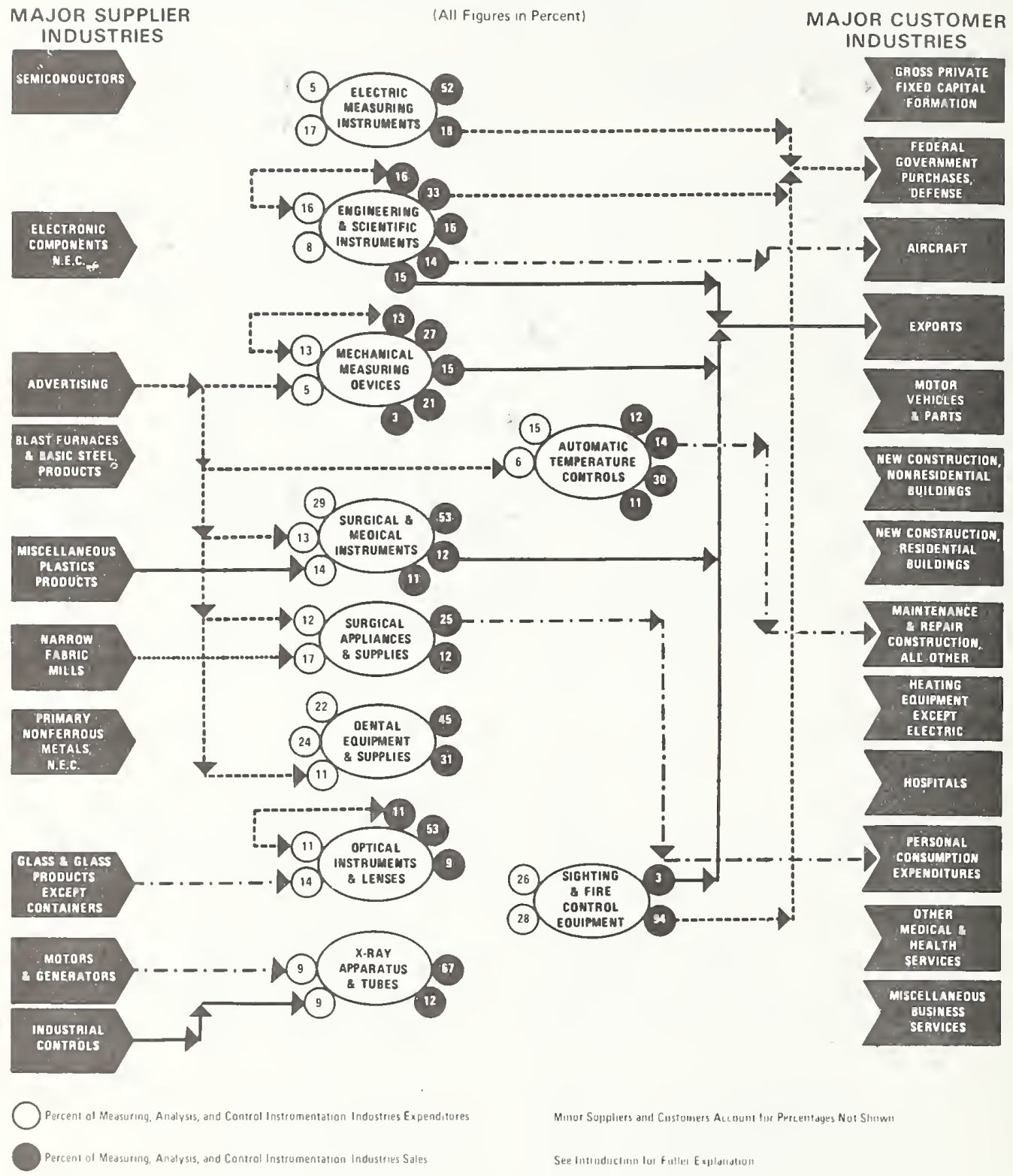

Figure 17. Measuring, analysis and control instrumentation industries expenditures and sales [237]. 


\subsubsection{The Instrumentation Industry}

The product scope of the instrumentation industry has been discussed in section 2.2.2 and summarized in table 3 . The number of companies in this industry is large. Over 4000 companies (or divisions or subsidiaries of large corporations) are known to NBS as sources of measurement instruments. The geographical distribution of these organizations is shown in figure 16.

Most of these companies are small. Some are corporate giants. There appears at least in a preliminary look at the industry to be less economic eoncentration in it than in any other high technology field. This appears to be due to the wide variety of instruments needed and the multitude of highly specialized economic niches available for smal1, competent companies. Indeed, some of the leading organizations in precision measurement instrumentation are small businesses by current industrial standards.

A study in some depth of this industry is currently in progress as part of the continuing study by NBS of the national measurement system; this study is the source of table 3 [328]. Data from another Department of Commerce look at this industry [237] are shown in figures 17-18 and tables 8-11.

\subsubsection{State and Local Offices of Weights and Measures}

The legal responsibilities for enforcement of justice in the use of weights and measures in our domestic commercial marketplaces lie with the state and local offices of weights and measures (see figure 19) $[13,28,46,119,202-4,212,284]$. These agencies combine a basic technical capability, a regulatory function, and a police investigative and citation authority.

The National Conference of Weights and Measures is the central coordinating body for the operating agencies in this field. Its paid staff and executive secretariat are provided by the NBS Office of Weights and Measures. The mission of this conference is quoted in the box on this page [202]. A prime function of this organization is the promotion of a uniform set of weights and measures laws in this country. The vehicle in which the model code is embodied is NBS Handbook 44 [119] (see table 12). The current working interests of the Conference and $i$ ts members can be seen by consideration of the conference titles covered during six recent years (table 13).

Historically, weights and measures officials acted as "sealers" who put their seal of approval for accuracy on the length, weight, and volume measures used in commercial transactions. As the evolution of science and technology increased the scope of the substances involved in commercial transactions, such as through the provision of water, gas and electricity by the public utilities, the scope of the weights and measures official also increased.

Weights and measures officials also have historically been involved in matters of taxation. The most obvious point of contact has been in the customhouse at a port of entry for imported goods. Customs duties based on the amount of goods imported require measurement of those goods. Inconsistencies among customhouses and lack of agreement between

The Mission of

The National Conference on Weights and Measures is

(a) to provide a national forum for the discussion of all questions related to weights and measures administration as carried on by regulatory officers of the States, Commonwealths, Territories, and Possessions of the United States, their political subdivisions, and the District of Columbia;

(b) to develop a consensus on model weights and measures laws and regulations, specifications, and tolerances for commercially-used weighing and measuring devices, and testing, enforcement, and administrative procedures;

(c) to encourage and promote uniformity of requirements and methods among weights and measures jurisdictions; and

(d) to foster cooperation among weights and measures officers themselves and between them and all of the many manufacturing, industrial, business, and consumer interests affected by their official activities. 
Table 8. 1974 Profile, instruments for measurement, analysis and control [237]

\begin{tabular}{|c|c|c|c|c|c|}
\hline $\begin{array}{l}\text { industry shipments }(\$ \text { million) } \\
\text { f establishments } \\
\text { as a percent of product shipments }(000)\end{array}$ & $\begin{array}{l}3811 \\
1,391 \\
721 \\
43 \\
17 \\
4.4\end{array}$ & $\begin{array}{l}3821 \\
2,060 \\
817 \\
72 \\
35.5 \\
6.4\end{array}$ & $\begin{array}{l}3822 \\
880 \\
129 \\
44 \\
5.4 \\
\text { n.a. }\end{array}$ & $\begin{array}{l}3825 \\
2,204 \\
622 \\
70 \\
21.9 \\
9.3\end{array}$ & $\begin{array}{l}3832 \\
800 \\
482 \\
25 \\
17.2\end{array}$ \\
\hline $\begin{array}{l}\text { Value of product shipments (current dollars) } \\
\text { Value of exports (current dollars) } \\
\text { Value of imports (current dollars) } \\
\text { Employment. }\end{array}$ & $\begin{array}{r}4.8 \\
4.2 \\
12.2 \\
-1.0\end{array}$ & $\begin{array}{l}4.8 \\
12.7 \\
25 \\
1.3\end{array}$ & $\begin{array}{l}6.0 \\
8.1 \\
\text { n.a. } \\
1.4\end{array}$ & $\begin{array}{r}8.1 \\
14.4 \\
20.2 \\
1.7\end{array}$ & $\begin{array}{l}6.1 \\
22.0 \\
19.8 \\
0\end{array}$ \\
\hline
\end{tabular}

Table 9. Instruments for measurement, analysis and control: projections 1974-80 (value of shipments in millions of dollars) [237]

SIC

Code

Indus try

$\begin{array}{lll}\text { Percent } & & \text { Percent } \\ \text { Increase } \quad 1980 & \text { Increase } \\ \text { 1973-74 } & & 1974-80^{2}\end{array}$

3811 Engineering and Scientific Instruments_-...- 1,391

3823,24,29 Measuring and Controlling Instruments 2,060

3822 Automatic Environmental Controls..........- 880

3825 Instruments to Measure Electricity......-.- 2,204

3832 Optical Instruments and Lenses............- 800

13

11

2,500

10.3

5

3,400

8.7

20

1,500

9.3

20

5,000

14.6

$23 \quad 1,500 \quad 11.0$

Table 10. Medical and dental instruments and supplies: projections 1974-801

(value of shipments in millions of dollars) [237]

\begin{tabular}{|c|c|c|c|c|c|}
\hline $\begin{array}{l}\text { SIC } \\
\text { Code }\end{array}$ & Industry & 1974 & $\begin{array}{l}\text { Percent } \\
\text { Increase } \\
1973-74\end{array}$ & 1980 & $\begin{array}{l}\text { Percent } \\
\text { Increase } \\
1974-80^{2}\end{array}$ \\
\hline $\begin{array}{l}3693 \\
3841 \\
3842 \\
3843\end{array}$ & $\begin{array}{l}\text { Value of industry shipments--total. } \\
\text { X-ray apparatus and tubes- } \\
\text { Surgical and medical instruments. } \\
\text { Surgical appliances and supplies } \\
\text { Dental equipment and supplies. }\end{array}$ & $\begin{array}{r}3,960 \\
550 \\
1,145 \\
1,760 \\
505\end{array}$ & $\begin{array}{l}11 \\
13 \\
12 \\
10 \\
12\end{array}$ & $\begin{array}{r}6,880 \\
1,060 \\
2,045 \\
2,840 \\
935\end{array}$ & $\begin{array}{r}9.6 \\
11.6 \\
10.0 \\
8.3 \\
12.8\end{array}$ \\
\hline
\end{tabular}

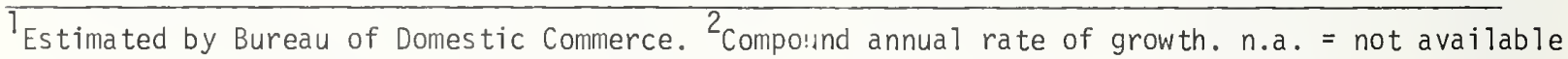

Table 11. 1974 Profile -- X-ray apparatus and tubes [237]

SIC Code

3693

Value of industry shipments (\$M)

Number of establishments ........

Total employment (thousands).....-

Exports as a percent of product shipments

Imports as a percent of apparent

compound annual average rate of 550 growth 1967-74 (percent):

value of product shipments

(current dollars)..........-

32.3

24.6

value of exports

(current dollars)_..-_-_- 19.9

value of imports

(current dollars).........-

Employment..........-..-.-.

Major producing areas......... North Central Region

Figure 18. Instruments show variable trends. [237]

\section{Instruments show variable trends}

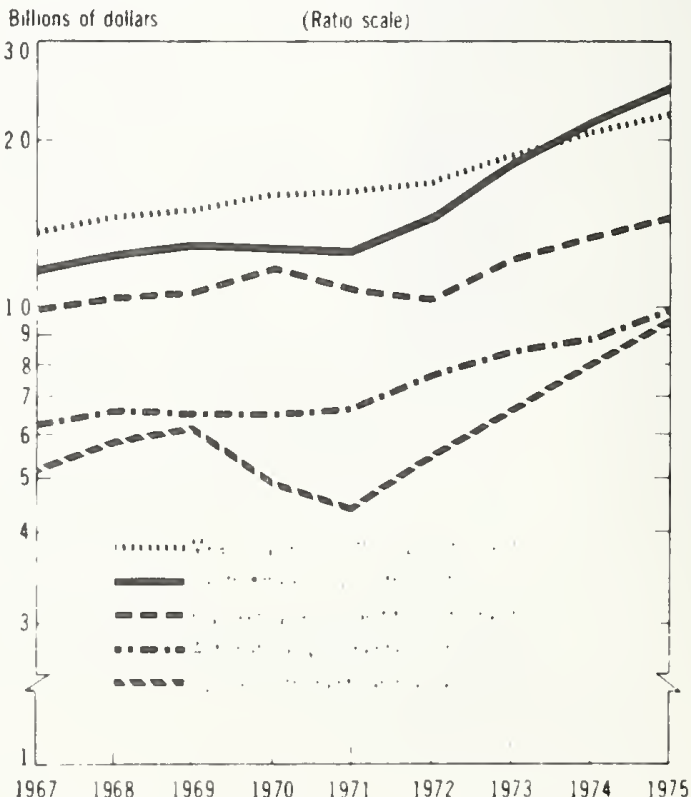


merchant and customs officials cause frictions. Indeed, it was such problems that stimulated the earliest systematic look in the United States at the National Measurement System and the first steps to correct the obvious deficiencies $[1,2]$.

Table 12. Outline of Contents of NBS Handbook 44 , U.S. Specifications, Tolerances, and Other Technical Requirements for Commercial Weighing and Measuring Devices [119]

Introduction:
1. Source
2. Purpose
3. Handbook Amendments
4. Replacement Sheets
5. System of Paragraph Designation
6. Classification of Requirements
7. Using the Handbook

Fundamental Considerations:

1. Uniformity of Requirements

2. Tolerances for Commercial Equipment

3. Testing Apparatus

4. Inspection of Commercial Equipment

5. Correction of Commercial Equipment

6. Rejection of Commercial Equipment

7. Tagging of Equipment

8. Records of Equipment

9. Sealing of Equipment

10. Rounding off Numerical Values

Individual Codes:

General

Scales

Belt-Conveyor Scales

Weights

Liquid-Measuring Devices

Vehicle-Tank Meters

Liquified Petrolwum Gas Lisuid-Measuring Devices

Liquified Petroleum Gas Vapor-Measuring Devices

Cryogenic Liquid-Measuring Devices

Liquid Measures

Vehicle Tanks Used as Measures

Farm Milk Tanks

Measure-Containers

Milk Bottles

Graduates

Linear Measures

Fabric-Measuring Devices

Wire and Cordage-Measuring Devices

Taximeters

Odometers

Timing Devices

Dry Measures

Berry Baskets and Boxes

Append ix:

General Tables of Weights and Measures
Today, with the prevalence of the sales tax for many commercial transactions, the adequacy of measurements for tax purposes covers many commodities undreamed of two hundred years ago. Equity in taxation, rather than equity in trade, has in some cases been the primary stimulus for expansion of the weights and measures enforcement aspect of the National Measurement System, and has even been a primary driving force for substantial innovations in metrology at the National Bureau of Standards. The story of cryogenic flow-metering of liquid nitrogen is an outstanding example [269].

Table 13. National Conference on Weights and Measures--Titles of non-routine sessions, $1970-75[96,126,145,211,253,292]$

1975: New Measurement Partnerships \& Opportunities

Meeting with Consumers

National \& International Standards

1974: Metric Conversion

Metric Plans, Programs and Problems Net Weight--Policy and Procedures

1973: Measures for Progress

Universal Product Code in the Grocery Industry

Digital Designs in Weighing Systems

Dynamic Weighing in the Railroad Industry

Gasol ine Measurement and Marketing

Weighting on the Mail

Net Quantity--Direction and Determinations

Management Assistance for Weights and Measures Progress

New Approach in Weights and Measures Operations: Pilot Program and Development of Dallas Department of Consumer Affairs

Consumer Protection in Minnesota

1972: Forum on Liaison for the Benefit of $\mathrm{Clients}$ and Consumers

Forum on Managing to Keep Pace with the Consumer Movement

Forum on Consumer Concerns in the Marketplace

Forum on Technological Developments to Aid Consumers

1971: Forum on Management

Forum on Merchandising

Forum on Measurement

1970: Forum on Packaging and Labelling

Forum on Weighing Technology

Forum on Measuring Technoiogy

Forum on Organization and Management 


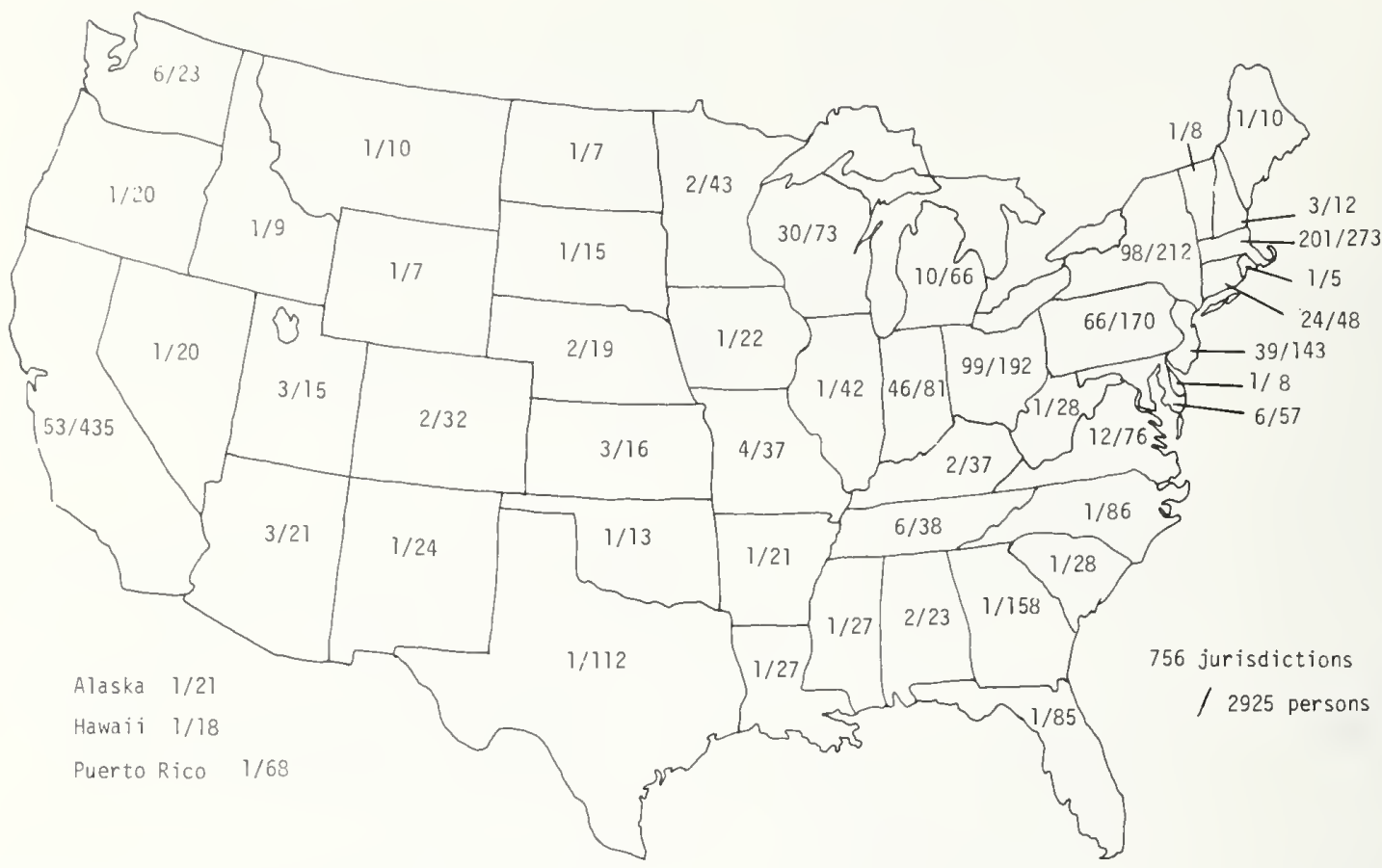

Figure 19. Location of weights and measures governmental jurisdictions and personnel $[212,284]$

\section{WHAT IS NCSL?}

NCSL is a continuing, nonprofit laboratory-oriented organization to promote cooperative efforts toward solving the common problems faced by standards laboratories in their organization and operation. It was established in 1961 under the sponsorship of the National Bureau of Standards. Its membership consists of academic, scientific, industrial, commercial, or governmental laboratories concerned with the measurement of physical quantities, the calibration of standards and instruments, and the development of standards of practice. It provides liaison with technical societies, trade associations and educational institutions interested in these activities.

NCSL pursues its goals through joint voluntary action in:

1. Holding conferences, workshops, seminars, and meetings for presentation of papers and discussions pertaining to technical and managerial problems, operating practices, and policies for standards laboratories.

2. Collecting and disseminating information about current practices for the organization, operation, and evaluation of measurement standards and calibration laboratories.

3. Preparing and disseminating source material and recommendations for preferred technical procedures and operating practices.

4. Providing a medium of interchange of information relative to deficiencies or advances in calibration techniques and laboratory instrumentation.

5. Collecting, analyzing, and disseminating pertinent statistical information related to the scope, growth trends, operation, and management of measurement standards and calibration activities.

6. Assisting measurement standards and calibration laboratories in arranging measurement agreement audits. 
State weights and measures officials have been expanding their scope in other respects, also. One of these is a simple extension of their historical role, in the field of prepackaged goods. By providing an official, legal, accepted weights and measures quality control function to local manufacturers, as for instance to a local brewer, or to a candy bar manufacturer, these manufacturers can gain nation-wide acceptance of their products as containing true weight or volume, so that their products do not have to undergo weights and measures inspections in every state or every local jurisdiction. The economic benefits to the consumer, to the manufacturer (every sample taken for weights and measures inspection costs him money), and to the taxpayers in all of the states, are obvious.

The most notable example of expansion of scope is into the broad areas of consumer protection. The weights and measures field is one in which governments have always acknowledged their consumer protection responsibilities, at least in theory, although often not too effectively in practice. With the recent surge in governmental activity in consumer protections, weights and measures offices both have expanded their concept of their traditional role, and have formed the nuclei of new departments of consumer protection. Creation of the Dallas Department of Consumer Affairs is a striking example [211]. All parties involved appear to have benefitted (except those merchants perhaps intent upon defrauding the public): the consumer, the honest merchant and manufacturer, the city administration, the consumer protection interests, the weights and measures staff, weights and measures enforcement per se, and the taxpayer, since the case is persuasive that he is getting more for his tax dollar after this expansion in scope than before.

Appendix $F$ contains excerpts from recent annual reports by weights and measures officials, selected to give the flavor of the full scope of their activities today.

\subsubsection{Standards and Testing Laboratories and Services}

Standards and testing laboratories and services provide physical standardization services to specific portions of the National Measurement System. Standards or calibration laboratories are a specialized type of testing laboratory, which tests measurement equipment and renders reports on its functioning (calibration reports); they may also undertake preventive or restorative maintenance [19, $49,75,140,223-4,277,293,309]$. Testing laboratories per se are sources of final end-use measurement data on the items that they test. There is a third distinct category of institution here, that can be described as a standords service prototypes for this category are the service organizations that keep the clocks at airport terminals showing the right time [177].

The National Conference of Standards Laboratories (NCSL) is the central organization in the standards $1 a b$ field $[277,309]$. I ts mission is described in the box on page 32 . NBS provides the central secretariat for this organization. Figure 20 shows the locations of NCSL members.

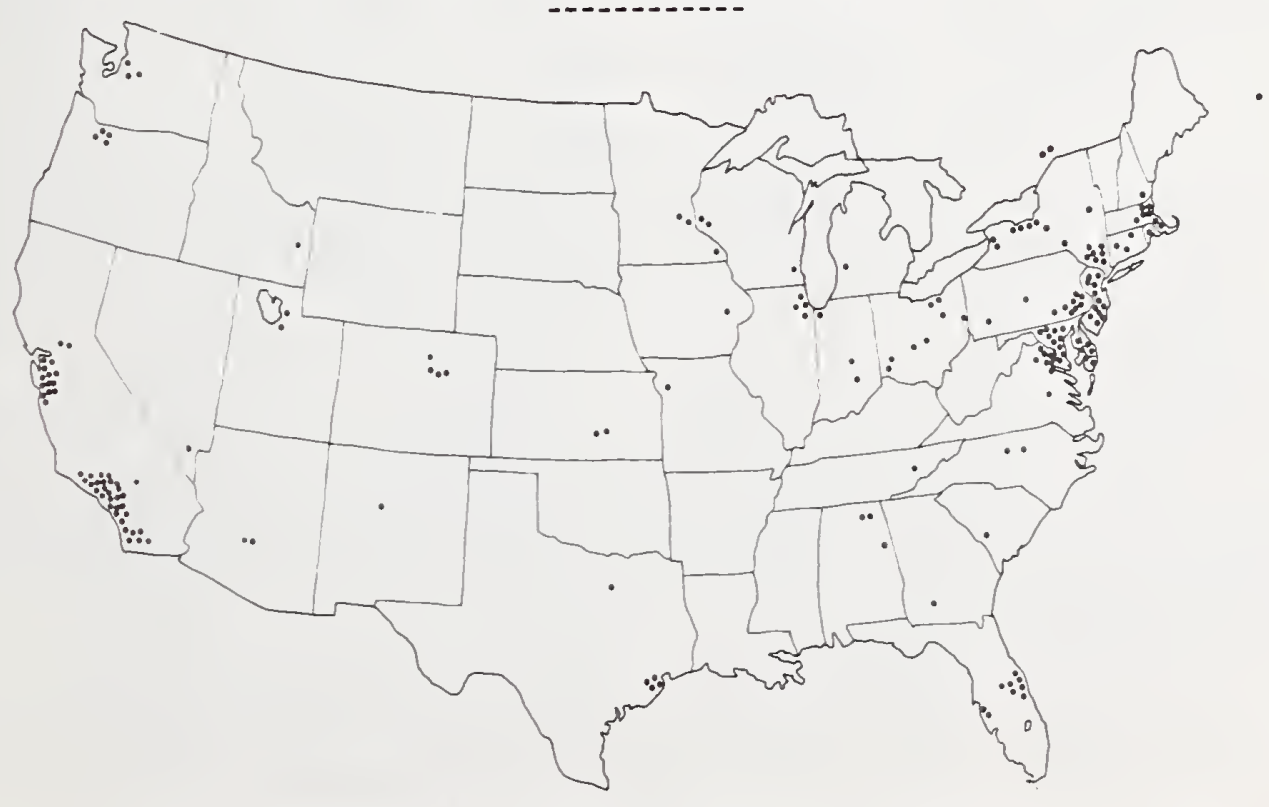

Figure 20. Location of members of National Conference of Standards Laboratories. 


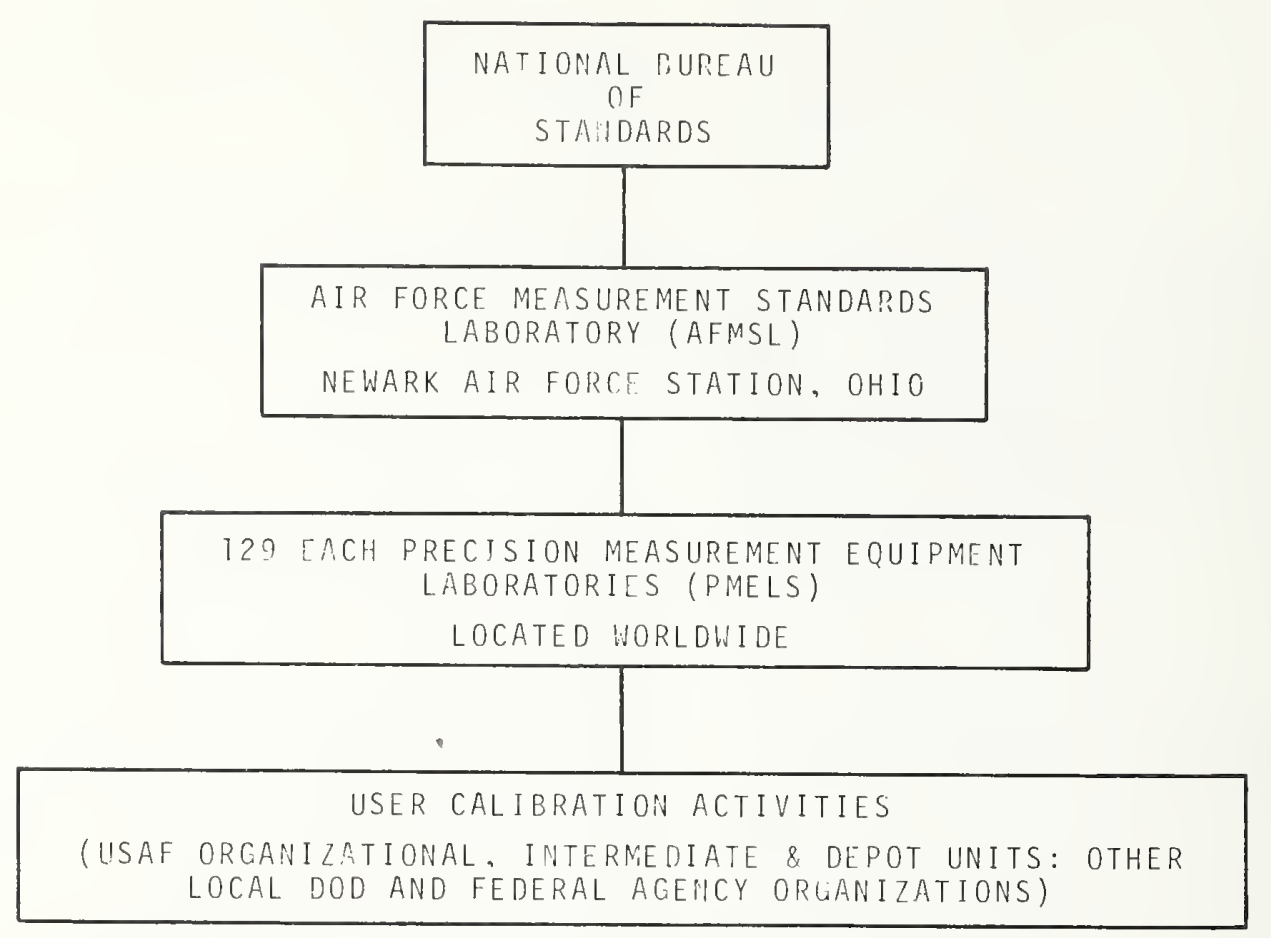

Figure 21. Air Force measurements standards system.

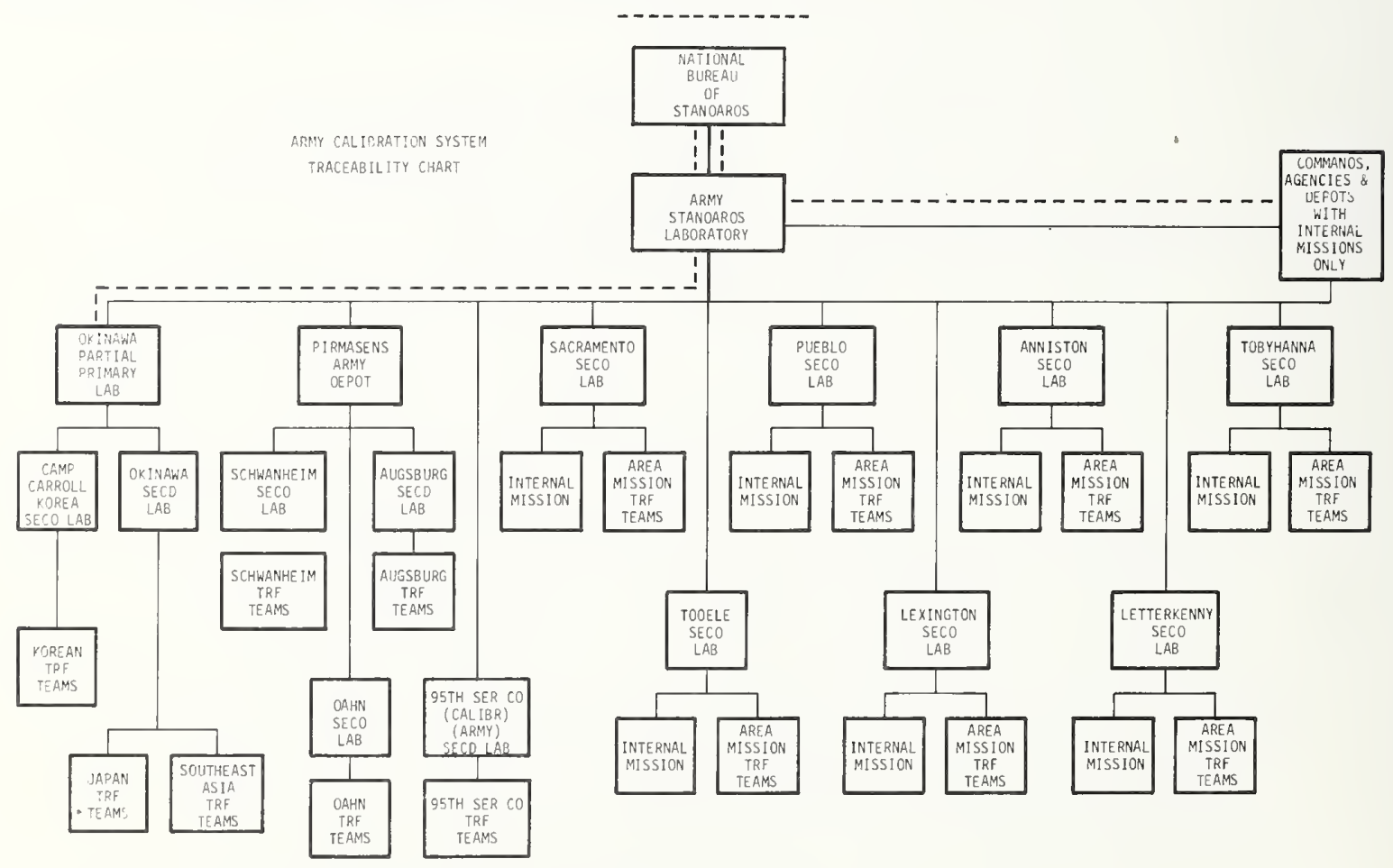

Figure 22. Army calibration system traceability chart. 
The most highly developed standards laboratory networks are in the Department of Defense (DOD). These laboratories are arranged in a formal hierarchy, with the National Bureau of Standards being the topmost unit in the DOD hierarchical chain. The structures for the three armed services and the Energy Research and Development Agency (ERDA) are shown in figures 21-24. In the case of ERDA, most or all of the member laboratories are run by private contractors.

The procurement specifications of the Department of Defense require that all comparisons of equipment construction and performance with the specifications be based upon measurements "traceable" to the Nationa 1 Bureau of Standards. As a result, the aerospace and ordnance companies typically have well established standards laboratories that are fully equivalent to those in the military itself. A number of these organizations are of a very high professional caliber, able at least in limited areas, to match NBS fully in applied metrological science.

The major instrumentation companies have highly qualified standards laboratories, as an intrinsic requirement for doing business. A number of independent standards labs also exist, providing service to all comers for a fee. High-technology companies, particularly in communications and electronics, tend to have standards laboratories. However, a significant number of these laboratories are associated with educational institutions and some of the older industrial technologies. Appendix G contains a summary of the known standards laboratories as recognized by NCSL and a check-list description of their capabilities.

Historically, the standards laboratories have operated completely independently of the state and local offices of weights and measures. However, in some states, notably California, recognition is developing of the existence of a state measurement system that includes many governmental interests in addition to those of the traditional weights and measures field, such as in the areas of health and safety associated with nuclear power plants, medicine, and occupational hazards. Recognition is developing that the standards laboratories within the state can play a significant role as part of the state measurement systems. Needed talents often already exist, and do not have to be created anew.

Another trend that will increasingly affect the organizations working in this field is that toward establishment of formal laboratory accreditation systems. The Department of
Commerce has recently instituted a National Voluntary Laboratory Accreditation Program, in response to pressures both domestic and international in origin $[283,308,310,311]$. One manifestation of the domestic pressures has been repeated proposals in Congress of legislation to establish compulsory laboratory accreditation programs. The basic phenomenon at work is the growing feeling that neither our national interests nor those of international trade can tolerate continuation of the current state of affairs in which there is no reliable way to ascertain the degree of reliability of measurement, calibration, or test data generated by calibration and testing laboratories. As discussed below in section 4.2, the increasing complexity and degree of integration of human society, both nationally and internationally, means that confusion is becoming increasingly intolerable regarding the validity of the basic measurement data about the physical universe which is needed to allow our industrial society to function. Some sort of laboratory accreditation system appears to be one unavoidable answer to these concerns.

\subsubsection{Regulatory Agencies}

With the development of modern technology and the increase in the complexity of society, more and more regulatory roles have been assumed by the formal governmental structure. The Interstate Commerce Commission (established in 1887) represented the first major move in the U.S. to regulate through governmental action a natural monopoly, run by the private sector, based on innovations in technology. The Food and Drug Administration (established in 1907) extended the concept of governmental regulation to include formal protection of the interests of the public and consumers from the pressures of a caveat emptor and Zaissez faire marketplace. Actions during the 1960's extended the Federal government regulatory role in areas such as the protection of the environment and of workers from occupational hazards.

Table 14 lists many of the Federal regulatory agencies, aside from those of a purely financial or traditional law-enforcement nature. Some, such as the Food and Drug Administration, the Environmental Protection Agency, and the Nuclear Regulatory Commission, work in highly technical fields and need a particularly high level of both general technical and measurement competence. A11 of them, from time to time, require significant precision in difficult measurements to do their jobs. 


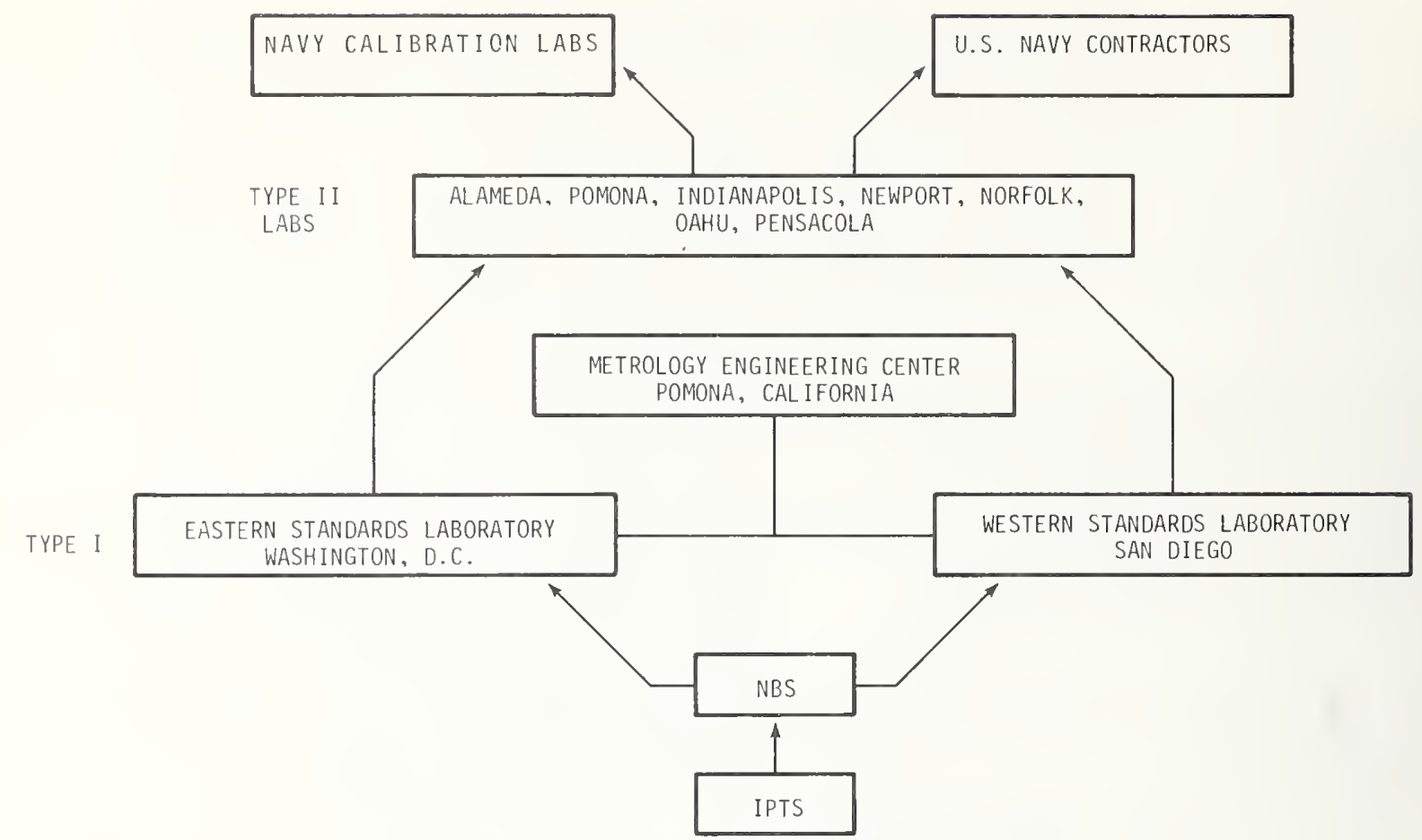

Figure 23. United States Navy temperature calibration chain.

\section{NATIONAL MEASUREMENT SYSTEM SUBSYSTEM}

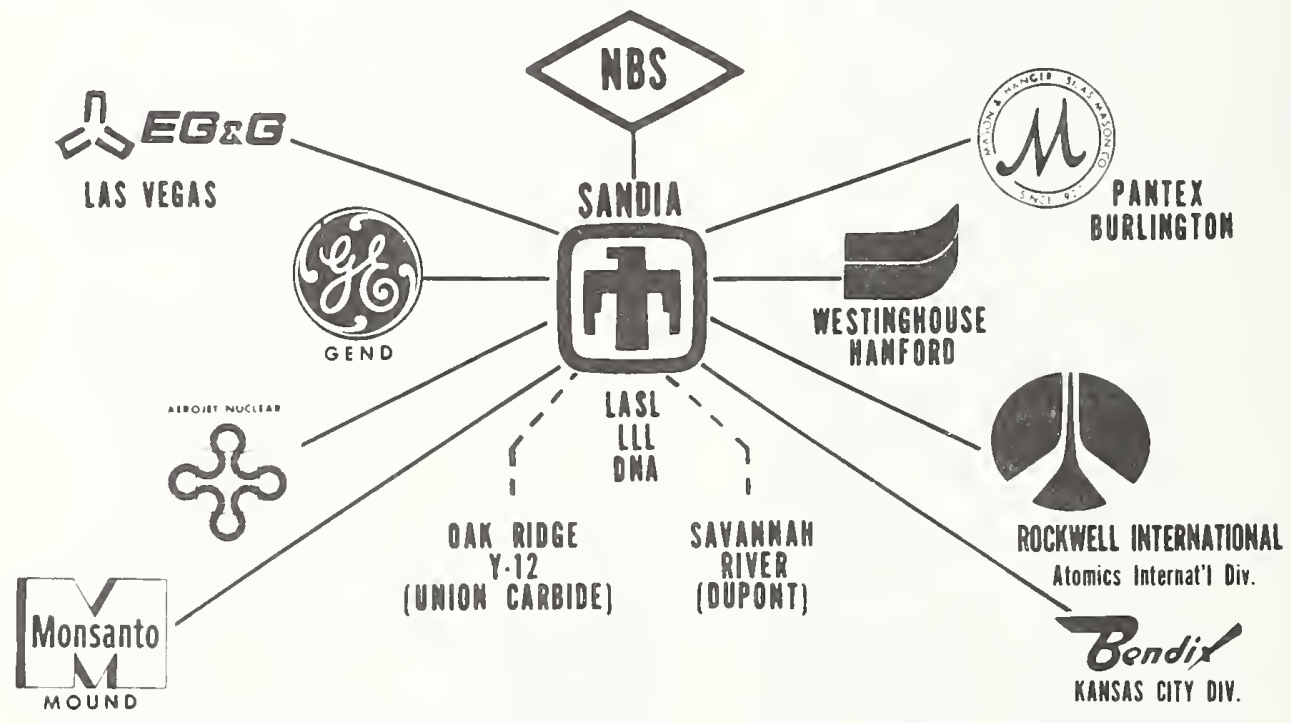

\section{\$9.7 MILLION EXPENDED tO MAINTAIM MEASUREMEMT TRANSFER CAPABILITIES \\ TOTAL EXPENDITURES OF SUBSYSTEM: $\$ 1.29$ BILLION}

Figure 24. Energy Research and Development Administration National Measurement System Subsystem. 
Table 14. Federal regulatory agencies.

Bureau of Alcohol, Tobacco, and Firearms Civil Aeronautics Board

Coast Guard

Consumer Product Safety Commission

Environmental Protection Administration

Federal Aviation Administration

Federal Communications Commission

Federal Power Commission

Federal Trade Commission

Food and Drug Administration

Interstate Commerce Commission

lining Enforcement and Safety Administration

National Highway Traffic Safety Admin.

Nuclear Regulatory Commission

Occupational Safety and Health Admin.

Securities and Exchange Commission

Actions of the regulatory agencies have a mojor impact on the measurement system, since promulgation of regulations requires a measurement capability that allows the necessary knowledge to be obtained and sound decisions to be made in such areas as the feasibility of enforcement; enforcement by the regulator requires comparison of actual conditions with the prescriptions of the regulations, and this often requires measurement; compliance by the regulatee similarly requires an ability to measure; and adjudication requires measurements that will stand up in court.

\subsubsection{The National Bureau of Standards}

The National Bureau of Standards is the primary authoritative central measurement standards institution in the United States $[13,38,46,52,80,81,94,115-6,127,132,217,242$, $261,273,286,288,289]$. However, our u1 timate central standards authority, both by treaty and by domestic decision, is a supranational organization, the International Bureau of Weights and Measures (BIPII from the initials of its French name) [250] (see section 4.). Domestically, only three other organiaztions today have a significant national measurements standards role in the areas of physical measurement covered by the current study: The U.S. Naval Observatory is responsible for establishing astronomical time of day [294].

The Geological Survey provides a central calibration service for aerial cameras [301]. The Coast Guard is effectively the central measurements standards authority with respect to tankships for liquified natural gas [269].

\subsubsection{The Present--Scope of NBS Services}

The National Bureau of Standards provides:

(1) The central basis for the U.S. National Measurement System, for physical, material, and technological measurements, and coordination of that system with those existing internationally.

(2) Standards for Federal use and involvement with computer science and technology.

(3) Technological innovation in selected fields (e.g., building technology, electronics and cryogenics).

(4) Direct technical assistance to other agencies, public and private.

(5) Technical (especially measurement) responsiveness to national needs (e.g., fire safety, general public health and safety, environmental quality, energy, national defense).

(6) Scientific leadership in missionrelated areas.

(7) Reimbursable measurement services (e.g., calibrations, measurement assurance programs, consulting).

(8) Technical data, including standard reference data.

(9) Standard reference materials.

(10) Coordination of and support to measurement-related or standardization activities at the state and local levels or in the private sectors, or in the developing countries (working with other Federal government agencies).

(11) Technical information services, including education and general consultation and advice.

Item (1), of course, pervades this whole report. Items (2) and (3) go beyond its scope. Other items need further discussion at this point.

\section{A. Measurement Services}

The most basic and indespensable services that the National Bureau of Standards provides to the National Measurement System are the calibration and related measurement services that provide to the system access to the national standards of physical measurement. These services are described in a "catalog", NBS Special Publication 250, "Calibration and Test Services of the National Bureau of Standards" [94]. Briefly, they can be summarized here as:

Calibration services

Measurement Assurance Program

Consultation and advice

other 
NBS has established reference standards not only for the SI base units but also for many derived quantities and their multiples and submultiples (see Appendix C). Such reference standards, or equivalent working standards, are used to calibrate laboratory and plant standards for other organizations. Accuracy is maintained by stability checks, by comparison with the standards of other national and international 1 aboratories, and by exploration of alternative techniques as a means of reducing possible systematic error.

Calibrations by NBS in its laboratories for many types of instruments and ranges of physical quantities are described in the itemized service schedules of Special Publication 250 [271] (see Appendix H, NBS Calibration Activity Summary). Upon request, special measurements not 1 isted in SP 250 may be made. These might involve unusual physical quantities, upper or lower extremes of range, higher levels of accuracy, fast response speeds, short durations, broader ranges of associated parameters, or special environmental conditions.

Measurement assurance programs are oriented toward calibration of a client's complete measurement system, not simply the calibration of a particular instrument or standard [130]. Typically, such a program involves provision to the client of an "unknown" check standard, which the client then proceeds to calibrate, using his equipment and personnel. By analysis of the data generated during such processes, NBS can provide the client information regarding the performance of his total measurement system for the measurement quantity involved.

In a similar program NBS assists in the evaluation of state and local weights and measures laboratories.

In areas of its special competence, NBS offers consulting and advisory services on various problems related to measurement, e.g., details of design and construction, operational aspects, unusual or extreme conditions, methods of statistical control of the measurement process, automated acquisition of laboratory data, and data reduction and analysis by computer. Suggestions will be offered on measurement techniques and on other sources of assistance on calibration or measurement problems when the Bureau's own equipment and personnel are unable to undertake requested work.

Other services include:

(1) Tests of measuring instruments to determine compliance with specifications or claims when the evaluation is critical in national scientific or technical operations and when suitable facilities are not available elsewhere.

(2) Referee tests in important cases when clients are unable to agree upon the method of measurement, the results of tests, or the interpretation of these results.

(3) Educational courses and seminars. To enhance the competence of standards laboratory personnel, NBS at irregular intervals conducts several group seminars on the precision measurement of specific types of physical quantities. Training is provided for weights and measures personnel in the states.

(4) Standard time and frequency broadcasts.

\section{B. Technical data}

Ready-made, usable measurement results constitute the second most vital channel of support to the physical measurement system, and a vital mode of suuport for the whole range of science and technology in this country.

The objective of the National Standard Reference Data System is to provide a base of reliable data on physical and chemical properties required in industry, universities, and government $R$ and $D$ institutions $[50,84]$. The program operates through a series of projects at NBS and elsewhere in which data are retrieved from the world literature, evaluated by experts, reconciled as necessary, and prepared for publication. The primary output consists of tables of evaluated data and critical data reviews published on a regular basis in the Journal of Physical and Chemical Reference Data and other channels. The annual output of evaluated data is typical1y 1500-2000 pages, representing the distillation of the useful quantitative results from 5000-10,000 individual experimental investigations. Other output includes bibliographies and data indexes, translations of Russian data compilations, and computer programs for handling data in various formats. In addition, data are supplied in response to specific inquiries, both for isolated property values and for more extensive compilations directed at a particular application (see Appendix D) $[137,267]$.

\section{Standard Reference Materials}

Most uses of reference materials lie in the areas of chemical and material measurements that are outside of the scope of the physical measurements considered in this report. However, as noted in section 2.2.4, reference materials are an integral and essential part of the national system for physical measurements. The aspects of the 
NBS Standard Reference Material program that are of particular importance to the areas of physical measurements of primary interest in this study were adequately discussed in that section.

\section{Coordination Services}

As the central agency in the U.S. National Measurement System, NBS provides a number of services which serve to coordinate that system. The oldest of these, antedating the establishment of NBS, is the Office of Weights and Measures [46].

The role of the NBS Office of Weights and Measures is to provide leadership and those technical resources that will assure accuracy of the quantities and quantity representations in all commercial transactions for all buyers and sellers in the United States, and to promote a uniform national weights and measures system [203]. In fulfilling its mission, the Offices of Weights and Measures engages in a wide range of activities. Foremost is the assistance offered to the States in the following areas:

Laws and Regulations

Standards and Laboratories

Testing Equipment and Procedures

Measurement Studies

Packaging Practices

Technical Training

Information Dissemination

Conferences and Meetings

The NBS Office of Measurement Services provides similar support to the standards and calibration laboratories of the nation, and manages the calibration services program of the NBS Institute for Basic Standards [94].

The Standards and Applications Division of the NBS Institute for Applied Technology provides a central focal point for domestic standardization activities, while the Office of International Standards under the Associate Director for Information Programs provides a similar function in the international field [261]. Together, they serve as the focal points for contact and control for NBS participation with national and international standards organizations. They provide access to the Standards Information Center, which is a library of more than 85,000 standards. They publish general and specific indices of engineering and related standards. They handle inquiries from governmental agencies and industry on the availability and source of international, national, foreign national, industry, state, and federal governmental standards. The
Office of International Standards represents the U.S. officially with the International Organization for Legal Metrology.

The Office of International Relations coordinates NBS ${ }^{\prime}$ intermational interactions, and serves as a focal point for NBS support to the measurement systems abroad, especially those of the developing nations $[121,261]$.

\section{E. Information Services}

Technical information is a principle product of the National Bureau of Standards [261]. The basic goal of the technical information services program is to ensure that the results of work at NBS are provided, through appropriate media, to all interested users and to disseminate other information to which NBS has access because of its central role in the national measurement system and its participation in the development of science and technology. The activities which NBS conducts in pursuit of this goal include the following:

Documentation, reference, and general information services.

Operation of specialized technical information centers closely associated with laboratories working in specialized fields.

Organization of, and provision of, facilities for symposia, technical meetings, and specialized training courses.

Research and development in information sciences.

Provision of consulting and advisory services by members of the NBS technical staff.

\subsubsection{Alternate Sources for Services Provided by NBS}

Historically, the National Bureau of Standards has served the Nation by performing three primary roles, related respectively to:

I. Measurements

II. Standardization

III. Technological development

These will be discussed in inverse order.

As a rule, many alternative sources exist today for NBS in the field of technological development. Industrial research matured following World War II and today is fully capable of developing virtually all of the technology needed by industry. Industry is enlightened and motivated to do what it needs. Governmental research has also matured since World War II, and similar statements are valid here, also. 
The NBS role in technology development became much more sharply focussed with the reorganization of the Bureau following the Baker report in 1953 on the proper role of the National Bureau of Standards. Historically, it is clear that the Bureau's early major involvement in industrial and technological research was necessary for the times (the first 30 years of this century) and for three major wars. With the Baker report and the transfer from NBS of major involvement in military technology in 1953, the issue was effectively settled that, as a general rule, there are satisfactory alternate sources to NBS in fields of technological development [46].

In the field of standardization, the primary actual or potential alternate sources to NBS for the services it renders are the Department of Commerce's Office of Product Standards, the American National Standards Institute and its affiliated organizations, the non-profit research institutes, the universities, and the professional societies. NBS has far from a monopoly in this field. Its role continues, because the subject of standardization has a close functional connection with the field of physical measurements, and the high technology end of the field clearly benefits from being associated with an active, high technology organization that is neutral among the competing technological and commercial interests.

In the field of measurements, as a rule no effective alternative sources exist. If NBS did not exist, it would have to be invented. These points are best made service area by service area:

(a) Calibration services. At the highest level, there is no alternative source, without reinventing one or more National Bureaus of Standards, since only one agency can have custody of the national physical reference standard for a given quantity. Any other approach would be equivalent to a decision that we should have two Supreme Courts.

At more routine levels, there are many alternative sources of supply, (see Appendix G), and there could be more, if economic barriers could be overcome. The present trend toward measurement assurance programs, self-calibration techniques, laboratory accreditation, and the like should serve to make alternatives to the Bureau's calibration services more viable. This trend may not lessen the total Bureau work load in the measurement services area, but it will convert it from providing routine services to an active quality control operation, which will be far more challenging intellectually and far more effective in assuring the nation the measurement system that it needs.

(b) Technical data. The Bureau has two major roles here, generation of technical data and management of the Standard Reference Data Program. The alternative sources of technical data are many, primarily the universities, the non-profit research institutes, the industrial laboratories, and other governmental laboratories. The NBS role in data generation is restricted to the fields of data that cannot be obtained with adequate precision elsewhere and for which the NBS measurement expertise is particularly relevant.

Management of the National Standard Reference Data System was entrusted to NBS only after it had become apparent that private sector agencies could no longer adequately handle the job, and that there was no more effective alternative governmental agency available. In principle, the job could be given back to the National Academy of Sciences/National Research Council, or to the National Science Foundation. Much of the work is, of course, done on contract by organizations independent of NBS. On the other hand, the philosophy of precision that dominates NBS is essential in this program, and it would appear that the program could not benefit by being placed in another agency.

(c) Standard Reference Materials. In principle, private organizations could provide the standard reference materials needed by this country. Some, in fact, are supplied now by commercial vendors and many are prepared commercially and then analyzed and certified by NBS. Often, however, alternative sources for operating this program would suffer from the lack of immediate access to national standards and the large pool of materials measurement expertise that exists in NBS, and from a lack of a tradition of precision.

(d) Coordination Services. It is hard to see alternative sources to NBS except by reinventing NBS. The NBS role historically has been to be a catalytic agent, bringing organizations into existence, and then withdrawing as they become selfperpetuating. The National Council on Radiation Protection and Measurements is an outstanding example of an organization created by NBS that today has only minor ties to it. 
(e) Technical information services; direct technical assistance to other agencies, public and private; and technical responsiveness to national needs. When such work is dominantly based upon measurement expertise or other direct mission competence uniquely possessed by NBS, there are, by definition, no reasonable al ternative sources. When this work bears no close connection with NBS measurement expertise (or other unique mission competence, in fields outside the scope of this study), then there are usually many potentially satisfactory alternative sources. Similarly, when such work offers a unique opportunity for NBS to become intimately aware of real-life measurement problems, it is of unique value to NBS. When it simply exploits NBS' capabilities and does not regenerate them in any significant sense, it is of little, no, or negative value to NBS.

\subsubsection{NBS Funding and Staffing}

NBS funds come from the following four primary sources:

(1) The working capital fund, which is augmented from time to time by Congressional appropriations.

(2) Congressional appropriations for annual operating budgets.

(3) Funds transferred from other agencies, public or private, to cover non-routine technical services.

(4) Funds that reimburse NBS for the costs of its normal, "advertised", routine technical services.

The NBS working capital fund is used to provide long-term working capital for investment in equipment, standard reference material inventories, and similar purposes. The fund is regenerated by depreciation charges and by the sale of standard reference materials.
The NBS annual operating budgets are funded from three sources: direct appropriation by Congress, reimbursement for routine services, and funds transferred from other agencies, public of private, to cover the costs of special technical services. In FY 75 , the approximate percentages from the three sources were $55 \%, 6 \%$, and $39 \%$. The primary sources of the transferred funds for recent years are shown in figure 25 . The FY 75 budget is given in table 15. The NBS staffing pattern is displayed in figure 26 [261].

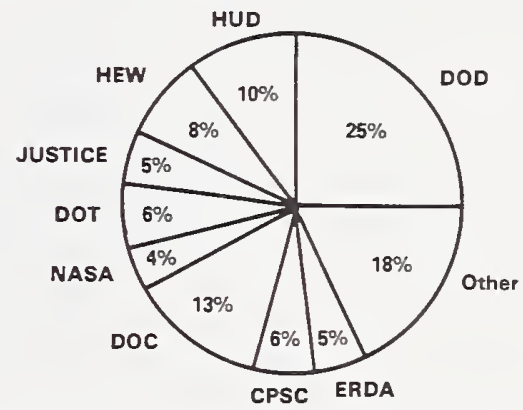

Figure 25. Other agency funding sources.

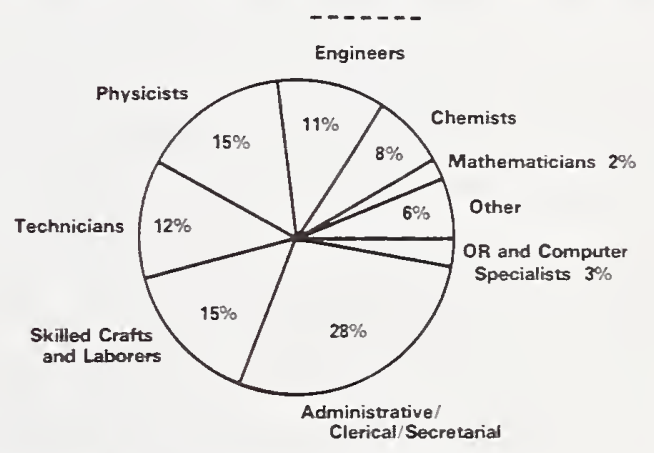

Figure 26. Composition of staff.

Table 15. NBS funding by program (amount in millions) [261]. Appropri- Reimburse-

Program Area $\begin{array}{lll}\$ & \text { ments } & \text { Total } \\ \$ & \$ & \$\end{array}$

Provide a National System for Physical Measurement

Provide Services to Improve Use of Materials

Provide Services to Improve the Application of Technology

Experimental Technology Incentives Program (ETIP)

Improve the Application of Computer Technology

Supporting Nontechnical Services for Other Agencies

TOTAL, NBS, FY 1975 (Actual)

$\begin{array}{rrrrrr}24.5 & 40 & 11.4 & 25 & 35.9 & 33 \\ 16.0 & 26 & 9.6 & 21 & 25.6 & 24 \\ 10.7 & 21 & 19.0 & 37 & 29.7 & 28 \\ 2.7 & 5 & -- & -- & 2.7 & \\ 5.1 & 8 & 4.7 & 10 & 9.8 & 9 \\ -- & -- & 2.9 & 7 & 2.9 & \\ \overline{59.0} & -100 & \frac{17.6}{100} & \frac{106.6}{100}\end{array}$

'Includes \$2.1 million transferred to NBS for work supported by the National Fire Prevention and Control Administration, which NBS performs under Section 18 of the Federal Fire Prevention and Control Act of 1974. 
Table 16. Direct measurements transactions matrix for IBS Study of National Measurement System.

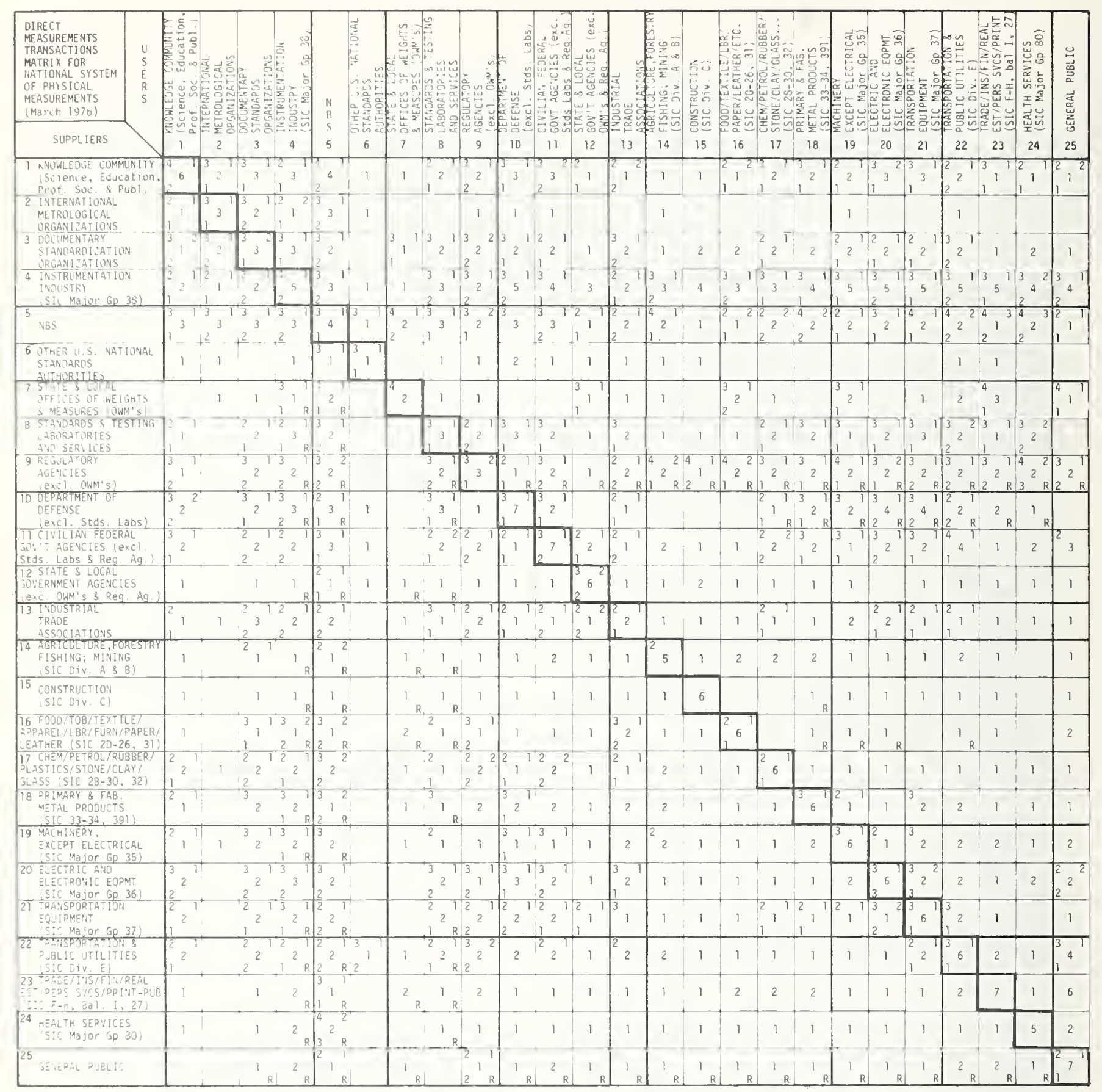

KEY TO MATRIX ENTRIES

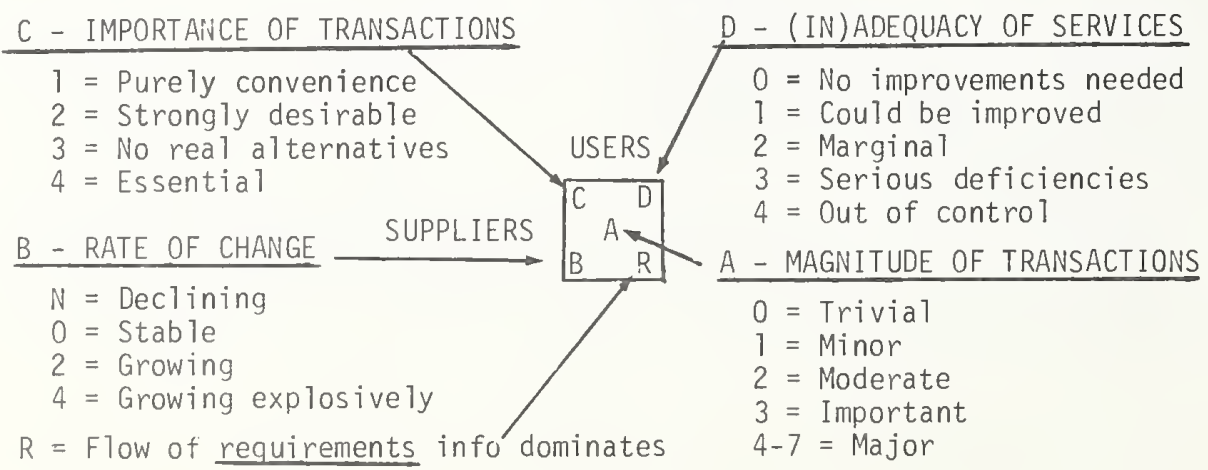




\subsubsection{Evaluation Panels and Visiting Committee}

The National Bureau of Standards has a long-established mechanism for evaluation of its programs, which consists of an array of evaluation panels managed by the National Academy of Sciences. Normally, these panels are continuing institutions, with rotating menbership, the normal term being three years, each panel corresponding to an NBS divisionlevel organizational unit. Institute-level panels include the chairmen of all of the Institute's division-level panels.

The evaluation panels have been involved with the National Measurement System Study from its beginning. Panel members have reviewed the reports of this study.

A Visiting Committee was established by the NBS Organic Act, for the purpose of evaluating the work of the Bureau, reporting to the responsible cabinet-level officer. The evaluation panels have no such legal standing, nor any legal connections with the Visiting Committee. Nevertheless, clearly established communication channels exist between the two mechanisms, so that systematic observations by evaluation panels can and do get channeled directly to the Secretary of Commerce.

2.5 The Measurements Market-Place: The Direct Measurements Transactions Matrices

The fifth level in the national measurement system model consists of the "measurements market place" in which the end-use measurement activities occur. The technique that has been chosen for displaying these activities is a measurement transactions matrix, which displays the direct interactions among the various suppliers and users of measurement information, data, goods, and services [302].

The following categories appear to encompass a 11 of the kinds of goods and services that are involved in these transactions:

A. End-use measurement data

B. Reference data

C. Other measurement services (e.g., calibrations or time \& frequency broadcasts)

D. Reference materials

E. Measurement instrumentation and its associated software

$F$. ileasurement how-to information

E. Measurement requirements specifications (e.g., laws, regulations, documentary standards)

H. Measurement needs information

I. Money to pay for the above.

Attention was focused on the functional information, goods, and services involved in the transactions. The last item, money, was ignored as a direct entry in these matrices.

Al1 institutional sectors of the system have been included in the transactions matrices so that only part of a matrix describes enduse measurements. Every defined sector is entered as both a supplier and a user, so that the flow of measurement needs information from the users to the suppliers of measurement goods and services can be entered. The diagonal elements define the measurement goods and services generated within a given sector that are consumed by that same sector, either within a given organization or by others; these diagonal elements contain the vast bulk of the measurements made in our society.

For simplicity, zeros have been suppressed in the matrices, so that a blank data entry location means zero, with the following exception: When the only data entry is for the central magnitude quantity, the blank entries for all of the other numerically coded quantities mean simply that no estimates have been made for them.

Table 16 is the master supplier-user matrix for the whole system, as seen by this study of the National Measurement System. Table 17 summarizes NBS ouputs to the various user sectors in the fields of physical measurement covered by this 1972-75 study of the National Measurement System.

The supplier-user sectors have been adequately identified in table 16. Sectors 1-9 and 13 are primary supplier sectors, and sectors 1,4 , and 9-25 are primary users. Sectors 4 and 14-24 are based on Standard Industrial Classification (SIC) Codes [141]. These codes are used in a straightforward fashion, except that: Major group 39 "miscellaneous manufacturing industries" activities are informally associated with those non-miscellaneous groups most nearly similar technically. Standard sector 23 includes only those parts of SIC division I not elsewhere accounted for. SIC 27, printing and publishing, is grouped in sector 23 with the technically similar activities of division I; SIC division J, public administration, is covered in the various governmental sectors. A yes-no summary of the users of NBS services has also been developed (see Appendix J).

There is a rather inevitable bias in the transactions matrices that probably magnifies the apparent importance of the user sectors with which the NBS Institute for Basic Standards is most familiar. All approaches indicate that the Government sectors are of first-rank importance. From here on, the indicators diverge. The high technology industries that are major users of NBS services, and that place major demands on innovation in the measurement system, show up high in these matrices, even though their absolute expenditures on measurements are a minor part of the country's total $[173,200,218]$. In contrast, such areas as retail and wholesale trade that expend trmendous sums in measurement-related activities, make only modest demands on NBS for service. 
Table 17. Direct measurements transactions matrix for outputs of NBS.

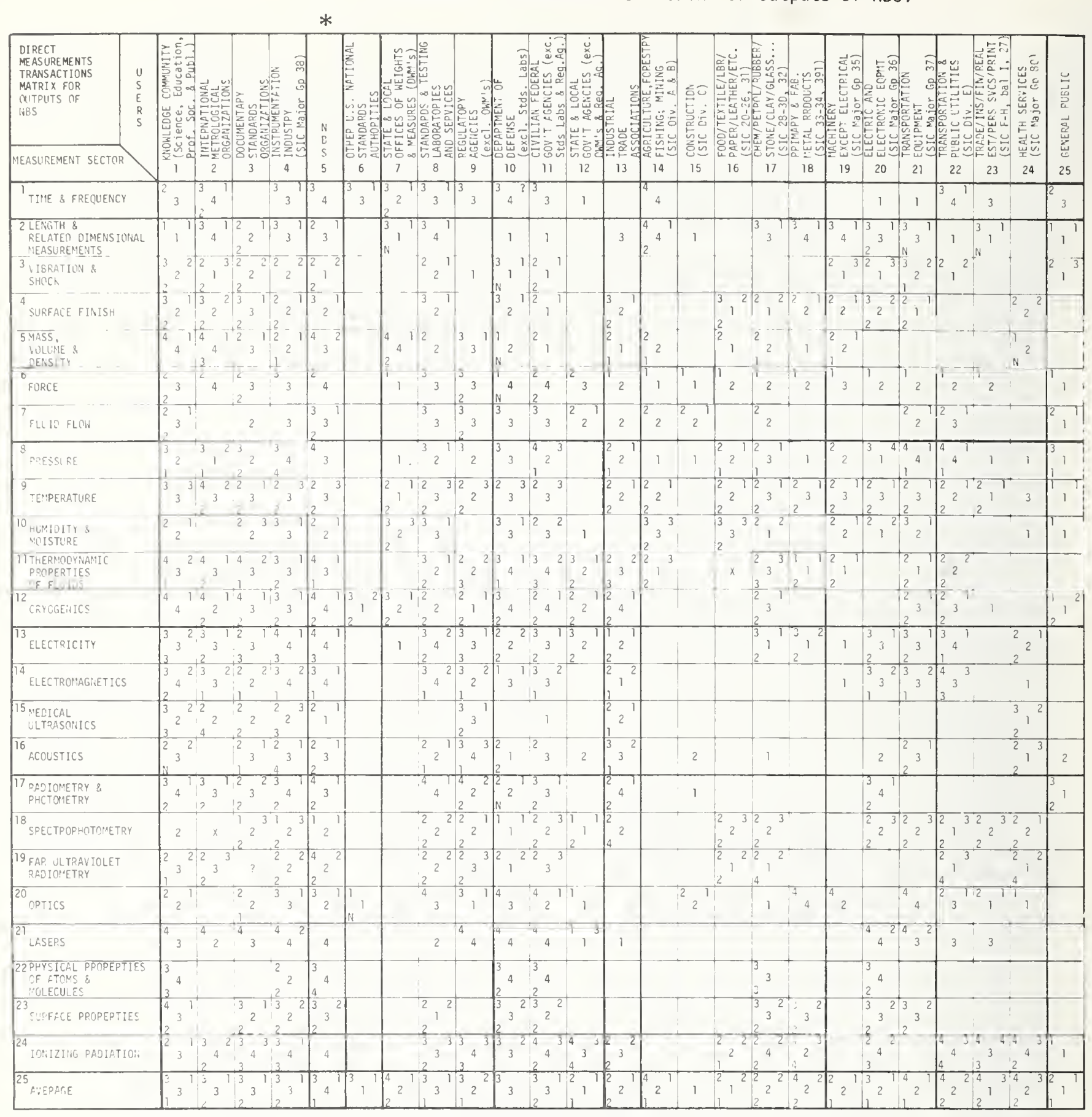

KEY TO MATRIX ENTRIES

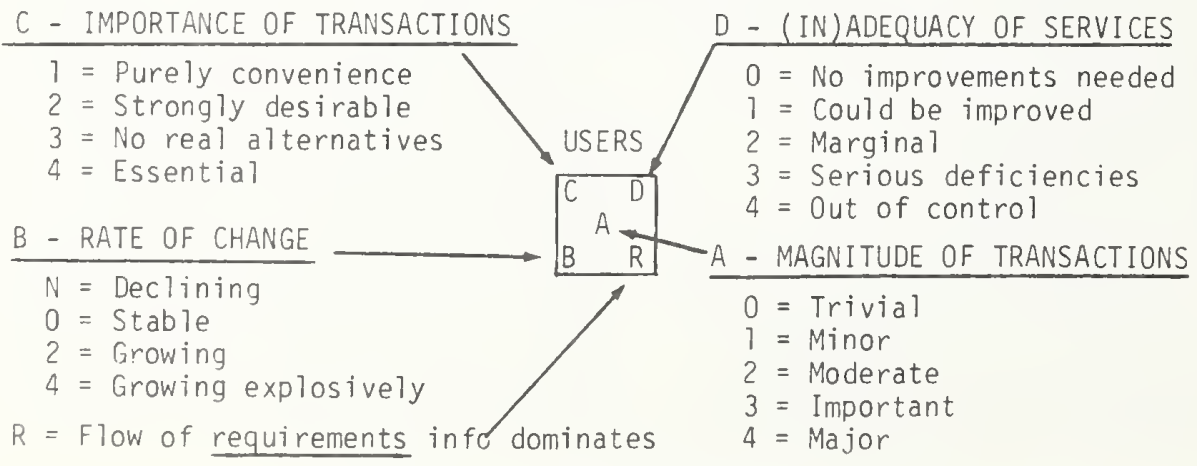

? = Inknown, $X=$ Not studied, Blank $=0$ 


\section{THE INTERNATIONAL CONTEXT}

The U.S. National Measurement System is part of an international measurement system The international system exists primarily to carry compatibility in measurements beyond national borders, and also functions as a mechanism for sharing of information and of effort to reduce the burdens borne by individual measurement systems or laboratories.

Figure 27 displays a model of the International Measurement System structure. The model includes

- the national measurement systems $\left(N_{1}, N_{2} ..\right)$,

- the supranational sector where everything is common to all nations and national interest is completely suppressed (central circle), - the "co-national" portion that represents cooperative efforts for their mutual benefit by groups of national measurement systems (intermediate band),

- the "bilateral" portion of the system which represents one-to-one relations between national measurement systems acting in their frank self-interest (outer band). The supranational portion represents organizations and people (including some international civil servants) that are the source of agreements, definitions, and physical reference standards which are unique, accepted by all, non-political in nature and which act as the central tie point for the acnievement of compatibility of all measurement systems. National systems (notably national standards laboratories) contribute their efforts and inputs to this portion by, for example, participation in working groups or submission of draft documents and ideas.

Once internationally accepted definitions and standards related to the SI base quantities are made available, it is possible for a national laboratory to generate independently the derived units of measurement. An example of such a unit is the milliwatt (power) at $10 \mathrm{GHz}$ (a microwave frequency). The same process is followed within other national measurement systems to arrive at almost the same units; small errors in fabrication or measurement and variations in techniques employed make inevitable small but often significant differences. One of the main functions of the "co-national" portion of the international measurement system is to identify these differences, find their bases, and, where possible, reconcile them. Any number of national measurement systems

(usually through their national standards laboratories) can usefully participate in any standards coordination and evaluation effort.

The international dissemination of information concerning measurement techniques and new results in measurement research also

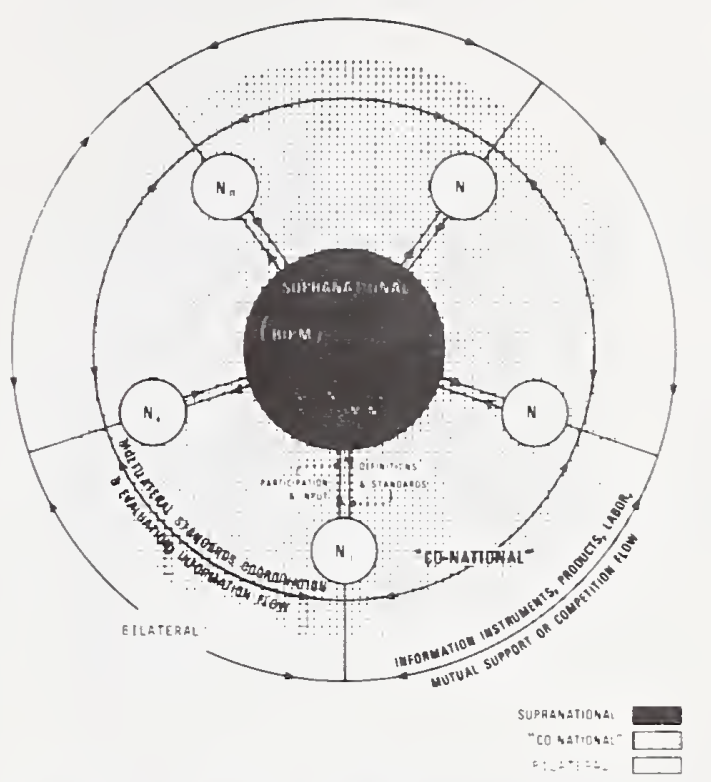

Figure 27. Model of the international measurement system [190].

falls substantially into the "co-national" portion of the international measurement system. National laboratories can profit considerably in many areas from each other's experience and outputs because they often have the only efforts within their own countries to reach certain measurement and standards objectives. In this respect a real community of specialized technical interest often lies only in the "co-national" area and is virtually absent within any one national measurement system.

The "bizateraz" portion of the international measurement system probably involves many more different activities than either the supranational or the "co-national". Many of these are small or one-time affairs, some are quite substantial. Included are the flow of information between one national system and another, and of measuring instruments and manufactured products with measurement content, and of labor by measurements people. The flows may be unidirectional, often truly bilateral, and sometimes multilateral as the result of a concatenation of bilateral interactions.

The information flow is typically in the form of technical papers, reports, plans, or data. A second important channel is the visitor to or from another system and the guest-worker who comes from one system into the other. Attendance at the national technical meetings in one system by scientists from another is a third channel. Some of these mechanisms are based on formal bilateral agreements, many are entirely ad hoc and based on personal contacts. 
The export of measuring instruments produced witinin one systeli to another is a very important component of the international measurement system. The measurement systems of some smaller nations depend almost conipletely on this mechanism, but even the technologically advanced nations often use each other's iristruments.

Measurements on high technology products manufactured for export also form part of the international measurement system. The point is the question of satisfying the specifications and standards of the importing national measurement system with measurements made in the exporting system.

Mutual support in the "bilateral" area tends to take the form of cooperative measurement research projects in which different nations contribute what they can toward a cominon objective. Contributions are normally not identical.

Competition in the international measurement system is somewhat harder to document. Still, it exists, especially in the area of international engineering standards where nations vie with each other to have their national standards adopted as international standards. In the field of physical standards, national standards laboratories sometimes compete to produce an output first or best and others seek to catch up or copy. one reason for this is that the reputation and image of a national measurement laboratory are important because they reflect on the technological capability of the nation to produce sophisticated instruments and products that will be internationally sought.

The International Bureau of Weights and Measures was established by the Convention of the Metre, of May 20, 1875. It is located in a tiny international enclave, at Sevres, France, near Paris. The initial essential mission of the international bureau was to construct and preserve the definitive standard meter and kilogram, to compare them with the national standards which were to be furnished to the various countries, and to improve procedures of measuring in order to advance progress in all fields of metrology. In subsequent years, assignments of BIPM extended into other areas such as thermal, electric, photometric and ionizing radiation fields. Today, it functions to advance the most basic parts of the conceptual and technical infrastructures of the international measurement system, and promotes coordination and harmony among the measurement systems of the different nations of the world.

The supreme authority governing the International Bureau of Weights and Measures is the General Conference of Weights and

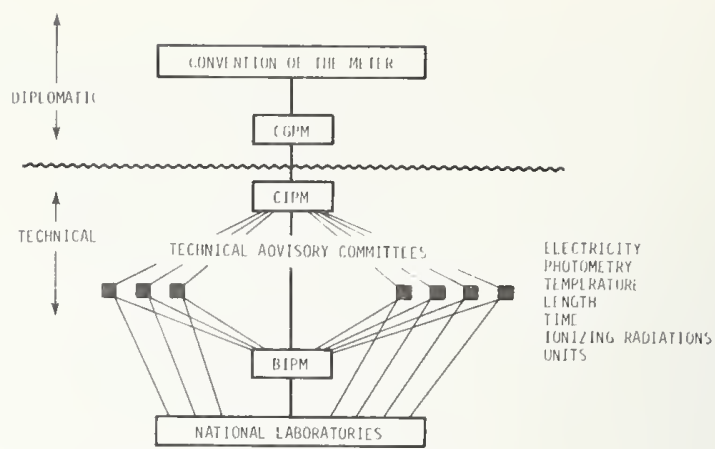

CGPM: GENERAL CONFERENCE OF WEIGITS ANO MEASURES
CIPM: INTERNAT IOFAL COMMITTEE OF WEIGHTS AND MEASURES
GIPM: INTIRNATIONAL BUREAII OF WEIGHTS AND MEASURES

Figure 28. International coordination of measurement standards [71].

Measures (CGPM). It consists of delegates from all of the countries belonging to the Convention of the Metre and meets at least every six years. The International Committee of Weights and Measures, composed of eighteen members, acts for CGPM between conferences to look after scientific and administrative matters. A series of consultative committees have been established under the International Committee, each charged with a particular field of measurement, each drawing on the leading experts in the world in its field (see fig. 28.).

Other supra-national organizations function in specialized parts of the international measurement system. In particular, BIPM shares responsibility in the area of time and frequency with BIH, the International Time Bureau, which is also located near Paris. In the field of legal metrology, the area covered by the offices of weights and measures in this country, the primary international coordinating body is OIML, the International Organization for Legal Metrology.

The International Organization for Standardization (ISO) and International Electrotechnical Commission (IEC), although primarily documentary standardization bodies, also have a significant effect on the international physical measurements system. Other, more specialized bodies have an even more direct role. In particular, the International Commission on Radiation Units and Measurements develops documentary standards that are of major importance in defining the international radiation measurement system. All of the major international technical organizations have substantial effects on the international measurement system: the International Unions of Pure and Applied Physics and Pure and Applied Chemistry, the International Telecommunications Union and its consultative committees; the International Scientific Radio Union (URSI); and others. 


\section{IMPACT AND TRENDS OF MEASUREMENT SYSTEM}

\subsection{Impact of Measurements}

\subsubsection{Functional, Technological, and Scientific Applications}

This subject was touched upon in a general fashion in section 1., Functions of Measurement. Table 1 presented there is the outline for the present discussion.

The functions of measurements, including those in science and technology, involve all of the uses made by human beings of knowledge of the physical universe. Since science deals with the advancement of knowledge, the uses of measurements in that field set a pattern often followed in other fields. For this reason, it is useful to observe the functions of measurement in scientific activities, as an initial entry into the general subject.

Science consists of the human mechanisms for acquiring knowledge in an organized fashion, and of the organized body of knowledge thus acquired.

The most basic use of measurement by science is to describe what is or was. Understanding is built upon these descriptions.

The utility of science, and the ultimate test of any understanding developed by it, depends upon an ability to predict what will be. Predictions of the future are based upon measurements of the past and present.

Science originates with the individual. It becomes significant to the race when communicated. Measurements provide a language to communicate the knowledge and understanding developed by science.

The development of science does not proceed on a purely random basis. Measurements provide knowledge that allows the scientist to decide among alternate courses of action.

Scientists plan courses of action, some of which may be very elaborate. Control of the preplanned process is essential. Measurements are used to control.

Science studies the uncontrollable as well as the controllable. When the uncontrolled does occur, the scientist must be prepared to respond, to react. Measurement of what is, allows the scientist to react, when the events he is seeking do occur.
The uses of measurements in the world of science are, then:
to describe,
to predict,
to communicate,
to decide,
to control,
to react,

in dealing with what is, was, or will be in the physical universe. This set is believed to be complete.

Of this set of six descriptors, two are most fundamental: To communicate and to decide. In the broadest sense of the words, these can encompass the other four. Nevertheless, it seems useful for most purposes to restrict the meanings of "to communicate" and "to decide" to the narrower meanings implicit in the discussion above, and to use the total set of six infinitives for most purposes when discussing the functions of measurements.

It is now instructive to consider the application of these six infinitives to the areas of personal 1 ife, society, and technology.

In the personal life of the individual, the infinitive "to describe" can be translated into the noun, knowledge: "My automobile weighs a nominal 3630 pounds and gives me 19 miles per gallon at 55 miles per hour".

The individual is also concerned with prediction of the future: "Our porch thermometer reads 2 degrees above freezing now, at 6 p.m. The weather is clear and windstill. It is sure to freeze tonight."

Some of the simplest communications between individuals depends upon the availability of a measurement capability: "What time is it?"

Many decisions depend upon measurement data: "Should I take time to stop to get gas?"

Our personal actions are often determined--initiated--by measurements. "The alarm clock just went off."

We use measurements to warm us of the occurrence of uncontrolled, unplannable events: "The oil pressure gage just dropped to zero. I'd better stop and find out what's wrong."

Measurement activities also play many roles in contributing to the efficiency com? fairness of our society.

The "to describe" dimension shows up in the use of measurements to develop data bases for social use, such as in all kinds of maps and charts, e.g., those used for navigation in the coastal waterways. 
Many aspects of public planning and jor'tcisting are heavily dependent upon measurement activities. The meteorological data generation system is one of the largest formal measurement subsystems in our society, and it exists to provide a basis for weather prediction.

Communication applications of measurements pervade all of the social applications, by the very definition of the word "social". Perhaps the purest form of communication occurs in the use of measures to define lani ownership and political boundaries.

Just as communication aspects tend to show up everywhere in the social uses of measurements, so do the decision dimensions of measurements. Perhaps the purest occurrence of the decision dimension occurs in the use of measurements in the judicial provess: "You will pay to this woman the damages prescribed by the jury, because it has concluded that the evidence of the measurements shows that you were indeed driving in a reckless and negligent manner and that you were responsible for the accident in which she was seriously injured."

closely related are equity in trade and tuxation, and the payment of wages (and the like) on a time basis.

Measurements are used for policing and for regulation in our society. "Pull over. You were doing 70 miles per hour in a 55 mile per hour zone.

Measurements are used for hazard warning: "Take cover! Weather radar has picked up tornado funnels advancing on us at 25 miles per hour!"

The same set of six basic functions of measurement show up in the implementation of techrology. It is convenient to use a single industry--petroleum--as a source of specific examples.

To describe finds its purest embodiment, perhaps, in the area of resource location, such as geophysical prospecting for oil.

To predict translates into such terms as engineering design, as in the design of liquified natural gas tankers.

To conmunicate can translate into interchangeability, as in the fact that the threads on oil drilling hardware are interchangeable for equipment originating anywhere in the free world.

To decide can be correlated with quality assurance function: "Is this lot of gasoline of an acceptable octane rating?

To control translates directly into procese control, as in refinery operations.

To respond or react can be translated into fault diamosis, as in detecting the existence of and locating leaks in pipelines.
The significance of measurements varies among the different fields of science and technology. The descriptive/observational fields of science--such as anatomy and taxonomy in biology historically, at least, have made few demands on the measurement system. Such observational fields as astronomy have made immense demands on the system. Experimental physical science is founded upon a measurement capability. Today, there are very few frontiers in any field of science that are not dependent in a major way on the existence and advancement of precision measurement capabilities. Resolution of detailed problems even in taxonomy, for instance, may today depend upon precision biochemical measurements.

In the field of technology, the older areas such as leather tanning and brick manufacturing make few exacting demands on the measurement system. While one of the oldest of al1--metal working--makes some of the most exacting demands, it is the newer physical technologies that usually pose the most difficult measurement requirements--electronics and nucleonics, to name two outstanding examples.

\subsubsection{Economic Considerations}

The National Measurement System is part of the information sector of our economy [225, 316]. It cuts across al1 other economic and technological systems in our society. Every sector of our economy owns measuring instruments, employs labor for the purpose of making measurements, and uses the results of measurement activities. Every technology, every means of production, depends upon measurement activities of one sort or another $[47,98]$.

In the broadest sense of the phrase, the national measurement system consists of al1 of the mechanisms used by our society to obtain the objective, quantitative knowledge needed for its functioning. However, for present purposes, two major categories of quantitative knowledge are excluded: Knowledge of the kind of subjective human phenomena that can be determined quantitatively only by such means as polling or voting, and those quantitative determinations of subjective value that are made by the fiscal pricing system or some analog or substitute for it. Operationally, we are here dealing only with the national system for quantitative physical measurements.

The national system for physical measurements plays a pervasive role in our economy. It accounts for perhaps 6 percent of our gross national product $[173,200,218]$. It is a significant consumer of economic resources. It generates essential economic benefits $[307,327]$. 
The system deals with both public and private goods. The private goods aspects include the overwhelming majority of the costs. The cost of a butcher weighing out meat is clearly a private expense between seller and buyer. The cost of measurements made during the production of an automobile engine is clearly a private cost to the auto manufacturer. The cost and benefits of a piece of measurement instrumentation reside with the purchaser who needs, controls, and uses the instrument.

Public goods aspects of the measurement system can be characterized as market enabling, market failure, and public market.

The market enabling aspects of the system relate to the fact that it is essential both in enabling our markets and in allowing the production of many of the goods traded in them. Few markets as we know them could exist without the measurement system. And this system does not exist as a matter of spontaneous creation, any more than does our present monetary system. Actions are required to generate and maintain an infrastructure for the system, which actions benefit the whole society in such a manner that there is no feasible way to recover costs other than by taxation, which means governmental action.

Market failure aspects can come in from several directions. The classical one is that markets usually fail to provide adequate incentive to the sellers to promote social efficiency and to alleviate social frictions in commercial transactions. The rule of the unregulated market place is caveat emptor, "let the buyer beware!" The public goods aspect of fair weights and measures overrides the private goods drive on the part of the sellers to cheat when they think they can get away with it.

Another aspect of market failure stems from the importance of the information part of the national measurement system infrastructure. Since much of this information either usually cannot be retained as the exclusive property of the originator, or has such public goods aspects to it that it should not be so appropriated, the economy will tend to underinvest in the development of such information unless a public subsidy is provided.

The public market aspects come from the fact that the national measurement system functions to deliver information needed for many governmental regulatory, decisionmaking, or operational purposes. The uses of such information may be either coincident- ally or inherently public. The use by the military of measurement information in the maintenance of its equipment inventory is no different in kind than similar uses in the private sector. On the other hand, measures of the quality of air throughout a metropolitan region inherently have primarily a public goods value, at least at this time.

On any time scale that we wish to consider, a measurement system is a "must" for the functioning of our human society, just as is a monetary or a transportation system. If through some means any of these systems should be seriously disrupted, major social disruptions would result, that would (and do) require prompt corrective action. It is of little usefulness to try to establish in an absolute quantitative sense the value of such "musts."

How much of any of these systems--measurement, monetary, transportation--is optimum, is quite another question, and for such questions the concepts of marginal economics can be applied, albeit not necessarily easily [76]. Economic "externalities" and other complications are often involved. When costs and benefits are not neatly localized and clearly calculable, cost/benefit analyses and decisions become difficult.

Detailed economic discussions are inappropriate here. Such questions are dealt with in other reports in this series $[307,327]$.

\subsection{Trends of the National Measurement Sys tem}

The major trends of the system can be described under the following headings:

\author{
Increased complexity \\ Increased integration \\ Improved quality control \\ Improved information resources \\ Automation \\ Metrication \\ Science
}

\subsubsection{Increased Complexity of the National Measurement System}

The confluence of three major driving forces inevitably dictates that the measurement system will increase in complexity, in all dimensions. Its total scope will widen. Its internal structure will grow. Its meaning for society will expand.

The three major driving forces are (a) the ever-increasing scope of science and technology, (b) the development of the infornation economy, and (c) the challenge of mastering the ever-growing complexity of our 
society as a whole. Implications for the measurement systems of the first factor are discussed frequently in this report and do not need elaboration at this point. The latter two factors, however, require some discussion here.

The Information Economy. Figure 29 summarizes an analysis of the American economy performed by Mr. Mark Porat while at the Institute for Conmunication Research of Stanford University $[225,316]$. Briefly, Mr. Porat adopted a not unusual concept, namely that there was a significant component of the American econony that could best be described by the term "Information Sector", and then set out to see just how important this sector was to the economy. He proceeded to look at what actually do, rather than what their vipritizations are thought to do. The question was, what is the ultimate significant output from this particular kind of job? Outputs were classified into four categories:

(1) Provision of data, information, or knowledge, or of physical products whose only real value lies in the data, information, or knowledge that they transmit or allow to be created.

(2) Provision of physical services, such as restaurant meals, health care, or most transportation.

(3) Provision of manufactured products whose utility is inherent in the product as a physical object and not in any use of the product to transmit or generate data, information, or knowledge, including products resulting from the extraction of resources from the earth and oceans.

(4) The provision of food and other products of agriculture and fishing.

The major conclusions that follow from iMr. Porat's analysis of the data is that the much-heralded explosion in recent years of the service sectors of the economy is all concentrated in the information sector except for a small net effect due to the large increase in the health-care sector. Further, approximately half of all American workers are found in the information sector, a fraction so large that a saturation effect appears to be taking place: the economy simply can't afford any more (see figure 29).

The National Measurement System is, of course, inherently part of the information sector of the economy. Since the information sector depends for its operation upon the availability of raw data, and the measurement system is one of the major sources of raw data, the measurement system has probably

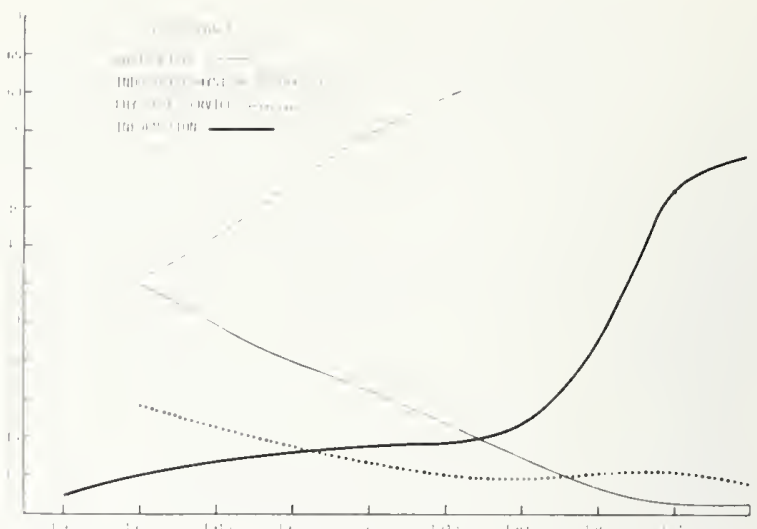

Figure 29. Composition of U.S. labor force, $1860-1980$.

shared some of the growth of the information sector during the last 10-15 years. Of more importance are the effects of the interaction of the newer information technologies-automatic data processing, in particular-with the measurement system, and of the inevitable pressures toward economy and efficiency and complexity that are implied by "saturation" of the economy with information sector workers. At the very least, such pressures will increase the importance of an ability of the measurement system to deliver exactly the data needed when it is needed, with exactly the required quality, no more, no less. Doing so inevitably increases aspects of complexity of the measurement system.

Social complexity. The need to manage the ever-growing complexity of our society is probably the greatest single driving force affecting the measurement system today. The general factors involved here were discussed by Daniel E. Noble in 1971 durinc; a symposium entitled "The next twenty years--the promise and the challenge." The following is quoted from his paper, "The Challenge of Intelligent Decision-Making [97]:

"I suggest to you that our present permeating sense of alienation, confusion, and frustration should have been expected. There should be no mystery about the exponential growth curve we have been following..., or about the stagnation, frustration, and confusion which result when the curve flattens out and we find ourselves in an environmental state of equilibrium brought about by the saturation of the growth-supporting forces. While the saturation includes 1 imitations upon the availability of power and resources, the primary factor is the degradation of the quality of control and decision-making 
induced by the saturation of our information processing facilities. The crowding into the cities with the attendant prodigious rise in interdependance and interaction among all of the systems, subsystems and the people, the rise of high speed transportation, high speed printing systems, and high speed communications systems of all kinds, and the information inundation which makes it impossible to select from the flood the relevant information needed for our decision-making processes, all contribute to the saturation of our 'communications' channels.

"In other words, we have created a very high information 'noise level' and the noise level in turn fosters alienation, frustration, confusion, and the stagnation of effective decision-making processes.... We have overloaded the information processing capabilities of our brains and of our filing cabinetmemory systems and procedural structures, so that we are suffering from a very high 'noise level' in all of the social, political, and economic areas of our culture... We have three choices: 1) we can continue in a state of confusion... down to disaster; 2) we may adjust to a static state of equilibrium...; 3) we can use our brains and marshal all the forces of science and technology to desaturate our culture and, by the introduction of new step-function forces of change, create a fresh new exponential growth curve which will revitalize our total cultural growth over the next fifty years...

"We may characterize the industrial revolution as a major concentration upon the development of muscle power extension systems of a 11 kinds. These muscle power extension developments, which created machinery for heavy work, for intricate work, and for redundant work, also created high speed transportation, communications, printing, and distribution systems of prodigious efficiency. The emphasis was upon orders-of-magnitude increase in man's muscle power, muscle efficiency, and labor productivity. The cultural configurations changed sharply from a farming economy to an industrial economy, and from rural living to urban living....

"Education has been the key to the expansion of the new power of the individual and to the new freedom of choice for the individual but, admittedly, an opposing force has been constantly increasing in its limiting negative effect upon the individual freedom of today. This force (the real villain of the piece) which, with some poetic license, might be called 'complexity', has been increasing steadily in nearly all areas of our cultural patterning until the organizational structures and procedural systems erected to combat complexity are in danger of becoming self-defeating. They have become so procedurally complex that they control the people who are supposed to be controlling the functioning of the system....

"We are now faced with the increasingly important job of rescuing man from the very complexities he has created. Since the primary cause of the present dilemma is the low speed, low efficiency and poor productivity of man's information processing systems, we must make monumental use of high speed electronic brain extension systems. As man has revolutionized his environmental structures through the application of muscle power extension systems, so in the next fifty-year period, he must revolutionize his total culture (including the social, economic, and political elements) through the application of brain extension systems....

"Without the introduction of radically new techniques for processing information, our modern culture is headed for saturation, stagnation, and collapse; it will perish under the weight of its own rising complexity. As the man/machine symbiotic muscle power relationship has prodigiously extended man's labor efficiency, so the introduction of electronic brain extension systems will extend man's capacity for processing information and enable him to rationalize the flood of information that now confuses our decisionmaking efforts. A new brain extension culture must supplant the muscle extension culture...."

The implication of Dr. Noble's thes is for the National Measurement System is simply that our culture can no longer afford the complexity introduced by poor, inadequate, or excessive measurements. The measurement system provides the foundation of data about the physical universe that allows the industrial system and uciety to function. Confusion about these data introduces confusion and complexity at the most fundamental level. The overwhelming social driving force for reduction of social complexity means that confusion in the physical measurements data base will become increasingly intolerable. We must have the data we need, with the reliability we need. We can no longer afford to guess about the validity and adequacy of our fundamental data. 


\subsubsection{Increased Integration of the liational Measurement System} systell is essential to improve its ability to provide most economically and effectively the measurement data required by our society. While integration itself implies an increase in complexity, it can on the net reduce complexity if it brings enough order out of chaos in a sufficiently simple manner.

Three primary arenas exist for integration of the measurement system. In the federal government, vast new areas of measurement responsibility have developed during a very few years, in the newer regulatory areas relating to health, safety, and protection of the environment. New needs have arisen in the older economic areas, as a result of the increased pressure of international standardization, a recurring balance of payments deficit, lagging productivity in the economy, and general economic malaise. However, the benefits of pooling measurements needs and of responding in an integrated manner are only casually perceived by the agency managers involved, for the most part. A new initiative similar to the National Conference of Weights and Measures or the National Conference of Standards Laboratories could be in order, perhaps a Federal Council on Measurement Operations. A moderate extension of current NBS efforts could lead to the creation of such a coordinating group.
Increased integration of the measurement

It meets only for action. Some results to date have included moves to allow private standards laboratories to undertake calibrations for the state and local weights and measures operations on a fee basis; the motivation was simply to tap into well established expertise that already existed in the state, with established ties to NBS. Not surprisingly, this committee early uncovered numerous duplications of effort. On the other hand, it early became clear that it was essential to avoid any appearance of having the offices of weights and measures take over the measurement regulatory functions of other departments of the state government. In California the interested departments include agriculture, health, transportation, water resources control, and others. Functions of the Advisory Committee include looking at "exotic" areas, new needs, and identification of problems. It provides a clearing-house for measurement science $R$ and $D$ and for inventorying measurement needs and expertise. It is finding that people from the different agencies and localities can be inspired to work together, and that its own job is immensely satisfying to its members.

Similarly, the explosion in the need for measurements for technological regulation. suggests that a "National Conference on Regulatory Metrology" could well be in order. This would involve state, Federal, and local governmental agencies, private industries, and private public interest groups.

\subsubsection{Improved Quality Control in the National Measurement System} where the state governments are becoming aware of the substantial expansion of state regulatory measurement activities and of the benefits of approaching a 11 of the formal measurement system involvements of the state government in an integrated manner. Historically, state and local governments functioned only at the commercial weights and measures level. Today, they are also functioning in the fields of environmental pollution control and of health and safety, particularly in connection with the regulation of the use of ionizing radiation and in the enforcement of occupational safety and health. Increasing miscellaneous needs also arise, such as the calibration of radar speed measuring instruments for state highway patrol use.

The State of California has taken a lead in moving toward integration of its state measurement system, by the establishment of a Measurements Advisory Committee with the responsibility of looking at and formalizing the existence of a California State Measurement System. ${ }^{+}$This Measurement Advisory Committee includes representatives from industry, the cities, and the state government.
Improvement of the quality of any operation requires determination of the quality of $i$ ts output and of feedback of this information to those responsible for the output. Historically, except in the weights and measures enforcement field, few mechanisms existed in the national measurement system to permit quality assurance or control with respect to its functioning. The orientation of NBS was to make it possible for good measurements to be made by the end-use levels of the system, but little was done to assure that adequate measurements were in fact made, or even to provide mechanisms to allow anyone to know what quality was in fact being achieved, much less control it.

Today, improvements in the quality of the output of the national measurement system are being pursued along two lines. One is

Unpub 1 ished presentation by W.F. Cowan at a Workshop on Study and Improvement of State Measurements Systems, NBS, Githersburg, Md., Jan 14-15, 1975. 
the historical orientation of enabling good measurements to be made. Specific programmatic efforts in this area include laboratory accreditation programs; extension of the concept of measurement traceability to NBS; and provision of new calibration services, standard reference materials, and standard reference data. All of these establish a potential for the production of good measurements, but they do not establish that good end-use measurements are in fact made

The second approach is a true quality control approach of determining the quality of the output and feeding it back to the input. It includes the NBS-sponsored Measurement Assurance Programs (MAP's) [130] the measurement audit packages used by the Department of Defense [91], cooperation by state offices of weights and measures with manufacturers of pre-packaged commodities to assure the measurements quality of their products, and shifts in the operating philosophy of the state and local offices of weights and measures.

The Measurement Assurance Program concept originated over ten years ago as a "selfcalibration program" in the mass measurement area [52]. The term "self-calibration" meant that a user who has an instrument requiring calibration will arrange to do it himself using a technique provided by the central laboratory. Self-calibration was seen then to have obvious advantages of providing an evaluation of the users' measurement techniques as well as his instruments. In late 1965 it was decided to develop a self-calibration program in the mass measurement area as a pilot study. By 1967, it was evident that a considerable amount of innovation was required, in philosophy as well as in procedural detail. Philosophical$1 y$, this self-calibration program required NBS to consider the ability of the organization to use its own standards, and to face up to the fact that it might not know what an NBS calibration really meant at the point of end use. It became obvious that lack of attention to the problems of demonstrating measurement consistency independent of 1ocation (an automatic by product of self-calibration) was a failure to assume responsibility for the role of standards in our society. In 1970, the quality assurance aspects of this"self-calibration" program came to the fore, and the term "measurement assurance program" was coined to describe the expanding program in this field. An NBS Measurement Assurance Program provides to its participants standards, techniques, and data analys is services which allow the participants to know how well their measurement processes work under the conditions prevailing during the Measurement
Assurance Program. If the results are inadequate, a participant can effect the changes needed in his measurement system until adequacy is achieved [130].

Measurement audit packages perform functions similar to the measurement assurance programs. These packages are designed to test the measurement abilities of the technicians and laboratories involved. They consist of a collection of hardware whose properties are known to the auditor but not the auditee. The deftness and precision with thich the auditee is able to determine the properties measures his measurement competence [91].

The expansion of scope of state and local weights and measures operations into cooperation with manufacturers in assuring the measurement quality of pre-packaged goods has been discussed earlier in section 2.4.3. There has been a parallel shift in philosophy to transfer of the burden of measurement responsibility from the inspecting agency to the measurer. In 1962 a law became effective in the State of Wisconsin which contained a provision that allowed weights and measures officials to test devices as often as necessary to obtain compliance with the law [96]. It removed the mandatory provision for placing seals on approved devices and left such marking or sealing up to the discretion of the weights and measures official. Under this law, a "Selective Testing Program" was implemented to return to the user the responsibility of selecting, maintaining, and using his weighing and measuring equipment correctly. As one part of the program, the weights and measures officials collect statistics for many of the devices tested. These statistics tell which retailers are doing a good job and which ones a poor one in maintaining their equipment. As a result, enforcement efforts can be focused where they will do the most good, and the retailers doing a good job are rewarded by being able to put their resources where they are productive--in maintaining their equipment in good condition --rather than in dealing with the weights and measures officials on a frequent basis.

\subsubsection{Improved Information Resources for the National Measurement System}

One major internal result of the National Measurement System study has been a broad awareness of the need of more "how-to" measurement information at all levels of the system. In field after field, it became apparent that NBS could increase the system effectiveness more by the generation of such publications than by almost any technical improvements in $i$ ts own laboratories. Development of such 
publications is underway in a number of areas. Notable are the "metrology guides" of the Electromagnetics Division, two of which have so far been issued $[214,215]$, the "self-study manual" [285] being developed in the field of radiometry and photometry, and the "user's manual" pub1 ished by the Time and Frequency Division [315]. A long range goal of the NBS Institute for Basic Standards is a "National Measurement System" series of books which will contain factual and how-to information about all aspects of the sys tem.

\subsubsection{Automation of Measurements}

The application of automatic data taking and processing techniques to the field of measurement is having a revolutionary impact. Briefly, the machine is augmenting man's brain power in the field of measurements, along the lines discussed philosophically by $D r$. Noble in his essay cited in section 4.2.1. The measurement process is no longer 1 imited by the limitations of man's brain: its ability to get bored, to get confused, to make unpredictable mistakes, its difficulty in dealing with simultaneous complexity--many different things or too much all at once. The most significant impact of automation occurs when it augments man or goes beyond his limitations.

Among the obvious benefits of automation of the measurement process are speed (simply doing what a person has previously done or could reasonably do, only faster) and cost (often a direct result of speed). Somewhat less obvious are reliability (the machine can be inherently more reliable than man, and it can be inherently easier to reliably monitor that reliability), and the machine's ability to master complexity in memory processes and computation: The machine can remember complex correction conditions and complex data reduction instructions and apply these reliably, rapidly, at low cost, in a manner that a human being finds impractically difficult. Further, then is the machine's adaptive capablitity: it can determine in real time the appropriate corrections and computational processes for the measurement being made. In addition the machine is able to make inherently better measurements than a man can ever make, simply because it can do so many things so fast, that drift effects that have long plagued precision measurements either simply vanish or can be determined and corrected out.

In a similar vein, the computation can follow the transients of the measurement process and extrapolate to a steady state, without having to wait for the steady state to exist. Implicit in all of this latter discussion is the fact that the machine can control the measurement process in real time, to optimize that process and its results. The machine controls the measurement process, senses the raw measurement data, computes meaningful data output, and feeds back the results into the control function to optimize the ultimate product.

The ultimate revolutionary impact of automation on the measurement system is due to the synergistic or compounding effect of all of the advantages that the "brainmachines" offer. Any one by itself may be of relatively minor importance, but the net effect of the whole array is truly astounding. Another approach to the same point can be gotten by following the logic that says that a man can do anything that a computer can do, it just normally takes a little longer, and he is more likely to make (obscure) mistakes, and he has to spend some time correcting his mistakes. This is true, but ultimately, the argument breaks down ("a man can do anything a computer can") because it takes so much time and energy to correct the mistakes made in correcting the mistakes made in correcting the mistakes... made in the original computation, that no man or group of men can work long enough to get the job done in the massive, complex calculations that computers make in minutes today. When this phenomenon is tied in with the problems of drift in the measurement process, it becomes clear that machines can in fact make measurements that an unaided man can never do.

Often, automation (computers) has been employed in the measurement process as simply a replacement for man, and only a few of the ultimate benefits have been achieved. However, major exceptions exist:

A. In the mid-1960's, computer controlled $X$-ray crystallography machines became avai1able that could do in hours and days the work that previously took weeks and months.

B. Automated radio-frequency and microwave measurement techniques are allowing measurements to be made that were previously impossible. The machines can make measurements so rapidly at a given frequency, and apply all necessary correction factors, that is is now possible to obtain measurement results as a function of frequency with the data points spaced closely enough to reveal many new features of equipment performance, with each datum point possessing an accuracy equal to the best of the old, laborious, manual single-frequency measurements. Another way to state this point is to note that it is now possible to obtain the equivalent of "swept" measurements (data taken while the frequency is being continuously changed) without any sacrifice of precision 
or accuracy relative to fixed frequency measurements. On the purely economic side, these machines are allowing far more information to be obtained about devices being calibrated than with the previous manual techniques, far more rapidly, at a lower total cost.

\section{c. The NBS automated noise-factor meas-} urement techniques developed a few years ago illustrate another major benefit of automation: Because measurements could now be made in hours and days that formerly took weeks and montins, the creativity of the scientists working in this area was unleashed. Ideas that were formerly dismissed without experimentation--because it would simply take too long to try them out and cost too much--can now be tested in hours or days--and they are tested. Thus automation is not a depressant to creativity, it is a powerful stimulant.

D. Numerically controlled machine tools and automated factories using tham provide another example. Because dimensional instructions can be developed by computer and fed to the machines by computer, the whole production process can be (and has been in some cases) revolutionized. Limitation of the number of different varieties of product produced is no longer essential to productivity. Every job can be a custom job, with very little or no increase in cost. The measuring equipment automatically measures the dimensions appropriate for the job, and the product gets made.

E. On a "trivial" or primitive scale, automation has been with us in the measurement field for decades, in the form of control instrumentation that senses the environment, compares the result with a control setting, and then automatically takes the action that it has been set to do.

\subsubsection{Metrication}

As the U.S. Metric Study $[98,99-110,113]$ and developments since 1971 clearly show $[226,231$, $234,238,245,248,281,290]$, a major trend in the U.S. measurement system is toward substantially increased use of the metric system. In the words of the report of that study [98]:

"Many times in the last two centuries, the Congress considered the merits of adopting the metric system as America's primary language of measurement. Each time, action was postponed, often because the metric system was not then in use by our major trading partners abroad. Now, with every other major nation converted to metric or committed to conversion, this obstacle has been removed."
"The U.S. Metric Study concludes that eventually the United States will join the rest of the world in the use of the metric system as the predominant common language of measurement. Rather than drifting to metric with no national plan to help the sectors of our society and guide our relationships abroad, a carefully planned transtiton in which all sectors participate voluntarily is preferable."

"The basis for the conclusion that the U.S. will eventually be metric lies in the findings of the Study that America is already metric in some respects; that we are becoming more so; and the that the great majority of businessmen, educators and other informed participants in the Study reported that increased use of the metric system is in the best interests of America. They also believe that it is better for the nation to move to metric by plan rather than by no plan at all."

"On the basis of all the factors that were considered, the Study concludes that it would be best for the nation to change to metric under a coordinated program that provides for flexibility and encourages the various sectors of society to deal with their particular problems voluntarily. Within this framework, these sectors would work out their own timetables and programs, dovetailing them with those of other sectors."

In his letter of transmittal to the Congress, the Secretary of commerce recommended [98]:

"-That the United States change to the International Metric System deliberately and carefully;

- That this be done through a coordinated national program;

- That the Congress assign the responsibility for guiding the change, and anticipating the kinds of special problems described in the report, to a central coordinating body responsive to all sectors of our society;

-That within this guiding framework, detailed plans and timetables be worked out by these sectors themselves;

- That early priority be given to educating every American schoolchild and the public at large to think in metric terms;

- That immediate steps be taken by the Congress to foster U.S. participation in international standards activities; That in order to encourage efficiency and minimize the overall costs to society, the general rule should be that any changeover costs shall "lie where they fall";

-That the Congress, after deciding on a plan for the nation, establish a target 
date ten years ahead, by which time the U.S.will have become predominantly, though not exclusively, metric;

-That there be a firm government commitment to this goal."

Congress responded to these recominendations by passing two pieces of legislation [28 290]. The Education Amendments of 1974, P.L. 93-380 authorized a Metric Education Program to be managed by the U.S. Office of Education. The Metric Conversion Act of 1975, P.L. 94168, declared "a national policy of coordinating the increasing use of the metric system in the United States," and established "a United States Metric Board to coordinate the voluntary conversion to the metric system."

Aside from the fundamental fact of metric conversion itself, the main impacts on the measurement system of metrication appear to be the following:

A. A substantial emphasis on metrology and metrication in education, primarily at the elementary, vocational, and continuing adult educational levels. As a result of the focus on metrication, there will also be a renewed emphasis on metrology per se. Today, metrology is dominantly a stepchild in the educational system of arithmetic, the vocational arts and the sciences. If the leaders in metrological education can have a significant influence on the general educators and publishers as they respond to the needs of education for metrication, then the whole educational basis of the measurement system could be profoundly strengthened.

B. Publicity about metrication can also be highly supportive of the essential role of the measurement system. The national awarenes of the important role of measurements can be substantially increased. The awareness at the measurement-related worker level almost inevitably will be increased.

c. Housecleaning: As a result of metrication, many obsolete tools, instruments, practices, and procedures will be swept away and replaced, where appropriate, with a metric version.

D. Instrumentation: A minor but significant increase in the sales volume of the instrumentation industry should occur, as any inherently essential new metric instrumentation is bought and as marginally obsolete "customary unit" equipment is retired somewhat earlier than would otherwise have happened. However, the major impact would appear to be in the repair. maintenance, and recalibration service industry in the instrumentation field, where it appears that the work force may need to expand substantially in order to handle the task of converting useful existing equipment from reading in customary units to reading in metric units. A side benefit of this expanded service effort is that the total array of instrumentation in the field is likely to be in better working order at the end of any formal changeover period than it is at the beginning, simply because more of it will have received much more thorough attention during this process.

It is important to note that the only measurement units affected directly by metrication are length, mass, temperature, and their derivatives. Time, electrical, photometric, and chemical units are not directly affected. Therefore, not all parts of the instrumentation industry will be affected by metrication.

Costs and benefits are hard to assess quantitatively. Clearly, the conversion will not be made without some costs, at least the mental effort of planning the conversion. clearly, also, the measurement system will be stronger after the conversion.

\subsubsection{Science}

As discussed in sections 2.2.6 and 2.2.7, scientific developments during the past 35 years have put us in a position to nearly realize the dream of the founders of the metric system, of a universal system for physical measurements founded on natural law, fundamental constants, and a single material constant of nature. The single material constant would be a microwave transition of the cesium atom. The key developments include:

Microwave technology, essential for the cesium frequency standard.

Nuclear science and technology, and the ability to create monoisotopic chemical species.

The laser.

Superconductivity, especially the superconducting tunnel junction (Josephson junction).

Semiconductor science and technology, with special emphasis on high purity silicon.

Computer and "brain-power extension" technologies.

It appears that all of the essential scientific components for a "new metrology" are in hand, and that the next quarter century will be devoted to completing and solidifying the revolution that began over a quarter of a century ago. 


\section{SUMMARY}

Measurement is essential for obtaining objective knowledge about the physical universe. We use this knowledge for communication and control in many aspects of our lives: on the personal level, in science and technology, in industry and commerce, in governmental regulation. The measurement data used by our society are generated by the National Measurement System, which comprises the totality of the activities and mechanisms employed for this purpose. These activities and mechanisms can be usefully discussed as either technical or institutional: It takes both tools and people working in an organized fashion to get the job done. The technical tools include the basic conceptual system of measurement quantities, units and standards; physical standards, instrumentation and operating instructions; reference data and reference materials; documentary agreements concerning a 11 of the above; and a basic core of knowledge or science. The institutional mechanisms in this country include the National Bureau of Standards, state and 1ocal offices of weights and measures, standards and testing laboratories and services, governmental regulatory agencies, documentary standardization institutions, and the instrumentation industry. A1l of these depend upon a central core of competent, educated people. The major trends of the system are toward increased complexity, increased integration, improved quality control, improved information resources, automation, metrication, and consolidation of a major metrological revolution based on the scientific developments of the past 35 years. 

These charts are a simplified picture of how NBS actions affect users' problems in physical measurements, through various agencies and institutions. Each series for one techical area is typically composed of four charts:

(1) FIELD PROBLEMS -- in square boxes -- meas urement problems as users see them -- and USERS -in ovals -- identified user groups with an economic or safety stake in the solution of the problems.

(2) MEASUREMENT DISSEMINATION/CALIBRATION HIERARCHY. Arrows proceeding downward indicate the flow of instruments and services, from instrument manufacturers to measurement laboratories, to their use on the problems. Crossing these arrows are boxes which illustrate NBS impacts such as calibration services, measurement assurance programs (MAP's), standard reference materials (SRM's), and maintenance of base standards.

(3) VOLUNTARY/DOCUMENTARY STANDARDS SYSTEM. Arrows proceeding upward from user groups depict the flow of aspirations and technical expertise through industrial and professional associations, to the standards-writing groups. The output of these (larger arrows) flows to international bodies, or into adoption by regulatory agencies. Key NBS memberships and leverage points are indicated in boxes.

(4) REGULATORY/MANDATORY CONTROL SYSTEM. Downward arrows go from regulatory agencies to the problems which they regulate, or from mandatory control groups to the area in which work is impermissible wi thout their sanction. Important NBS functions, needed for implementation or compliance, are highlighted in boxes.

The total NBS impact for any technical area is the sum of all the "NBS-impact" boxes for the last three kinds of charts. In most cases, this impact is too detailed to present well in a single chart.

For present purposes, charts have been selected from the total set available [3]4] to depict the interactions for the six SI base quantities whose units are maintained by the NBS Institute for Basic Standards, plus ionizing radiation. These charts are a result of the first pass by this Institute at using these concepts to describe its program, and are expected to evolve into more definitive forms with future iterations.

$$
\text { -...-. }
$$

\section{NBS TECHNICAL PROGRAMS}

\section{AFFECT}

FIELD PROBLEMS SUCH AS

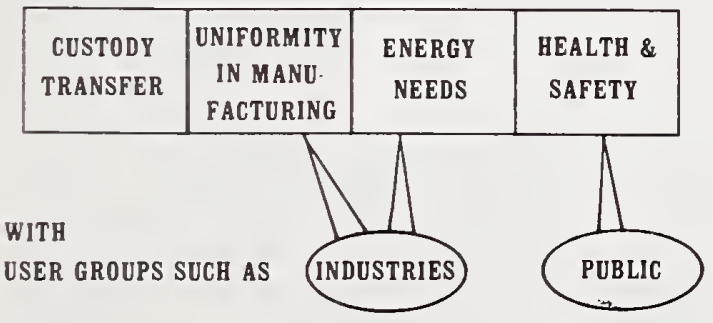

\section{MEASUREMENT \\ DISSEMINATION/CALIBRATION HIERARCHY}

B.I.P.M

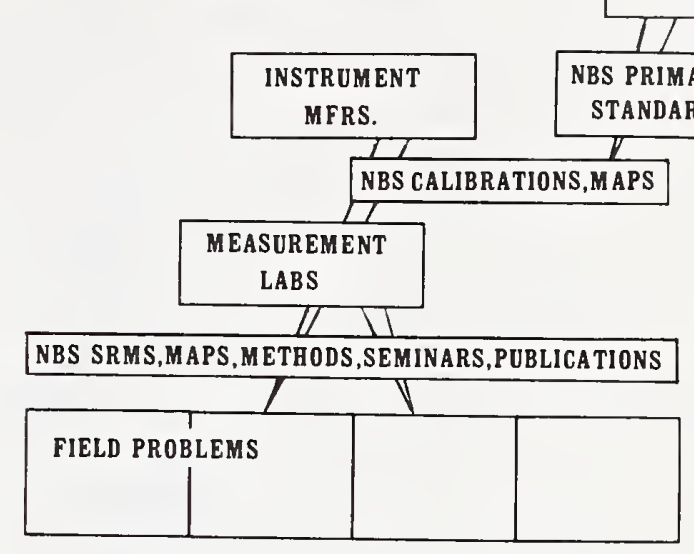

T

VOLUNTARY/DOCUMENTARY STANDARDS SYSTEM

DOCUMENTARY OUTPUT

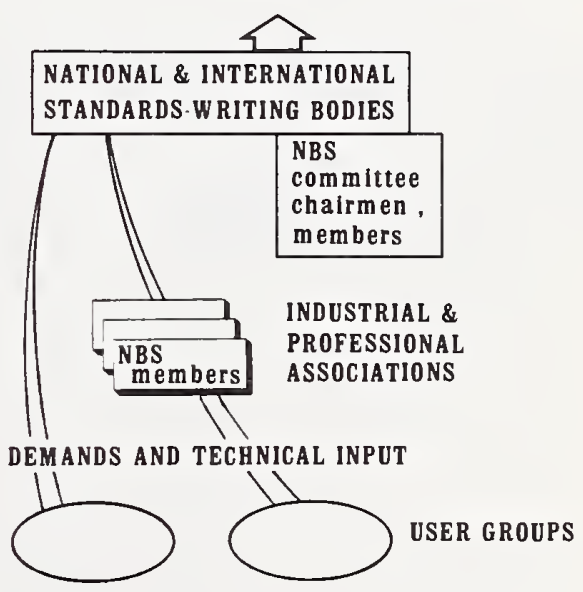

REGULATORY/MANDATORY CONTROL SYSTEM

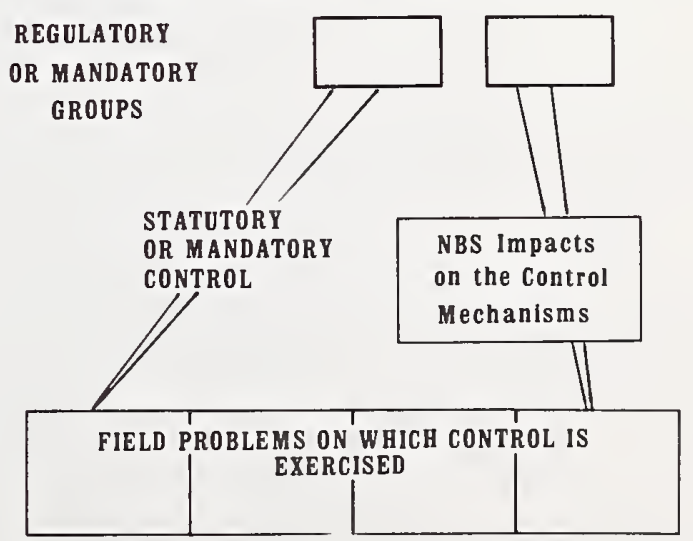


The major field problems are shown in the central block of the "measurement dissemination" diagram. "m. " luy is of concern to almost everyone. Telephone companies receive some 5 billion calls per year for the time, and NBS some 2 million. stiui minizition can be a life-and-death matter for approximately 5000 U.S. ships and boats depending upon it as a primary means of navigation, and many more use it for backup. Precision fredemands are steadily growing, in such areas as control of the electric power distribution system and the functioning of sophisticated telecommunications systems. Military demands are the prime driving force for improved position-location s......s. System design goals of 10 foot accuracy translate into 10 rianosecond time measurements. Loran and Omega systems are currently operational, and initial phases of the multi-billion dollar Global Positioning System are underway.

Major user groups are shown in the ovals at the bottom of the measurement dissemination diagram. The general public uses coarse time-of-day information for setting household clocks and personal watches. Most of these clocks maintain their accuracy because the electric power companies watch their frequency rather closely. The electric power somanies need accurate time and frequency information themselves to control power flow in their systems. As a result of the boom in the solid-state watch business, jewelers now need to check and service watches with rate accuracies of better than a part per million--for this they need NBS services, and many do use WWV. Telecommunications, historically a primary demand area for accurate frequency, is still one for commercial broadcasters, ham radio operators, and some of the newest areas of telephony. Transportation uses this technology for navigation and position location, and for scheduling. Both commercial airliner and FAA control center station clocks are set with reference to WWV, as often as each eight-hour shift. Private aircraft are beginning to use electronic navigation systems, and the boat owner is a continuing user. The military has always been a key figure in time and frequency measurement systems, with needs in such areas as accurate position location and precisely synchronized "time-ordered communication systems." Astronomy, the original supplier of precise time data, is not often a user.

other parts of science and technology are also key users; for instance, seismologists use WWVB signals to date events in remotely located strongmotion sensors, and the NASA space program depends heavily on accurate time and frequency.

Measurement Hierarchy: The final authority in the world for time is the International Time Bureau (BIH), which uses input from atomic clocks and frequency standards operating in various labs all over the world. NBS uses an ensemble of commercial atomic clocks and two primary frequency standards to maintain time scales which both support BIH and also serve as references for NBS dissemination services. Of these services, the most well-known are the radio stations WWV and WWVB in Colorado and WWVH in Hawaii. These radio stations serve a very large number of users direct7y, and an even greater number indirectly, through commercial telephone time-of-day services or through standards laboratories which, for example, calibrate TV broadcast frequencies. NBS also calibrates routinely the TV network color subcarrier, and commercial equipment to use this calibrated signal is readily available. The NBS telephone service has been previously mentioned. The U.S. Naval observatory has a large bank of atomic clocks, used to provide input to BIH and dissemination services to the military; it steers the phase of certain military and navigation broadcasts and provides time-of-day announcements on certain Navy stations. Because of the close coordination and cooperation between NBS and USNO, the NBS services are totally acceptable with in the military and are endorsed by USNO as important to the DOD in efficiently meeting military time and frequency requirements.

Voluntary Standards Structure. The center of control is the CCIR (International Radio Consultative Committee). The CCIR is formally only advisory to the International Telecommunications Union (ITU) under the U.N. In practice, the CCIR resolutions have virtually the force of international law in that no country goes counter to these resolutions. Thus, this system, while formally voluntary, is operating so powerfully as to be almost not "voluntary". This situation reflects the fact that time and frequency are so important internationally that close coordination and cooperation are in everyone's best interest. NBS is well represented on the CCIR.

Mandatory Standards. The Department of Transportation is the enforcing authority of the Uniform Time Act. The FCC regulates most of the telecommunications system, and depends upon NBS for accurate frequency information. The internationally accepted definitions of time, time interval, and frequency are handled by the organizations of the treaty of the meter. NBS participates on the Consultative Committee for the Definition of the Second (CCDS). Within the DoD, the U.S. Naval Observatory is the central authority for precise time and frequency matters. 
TIME \& FREQUENCY

MEASUREMENT DISSEMINATION
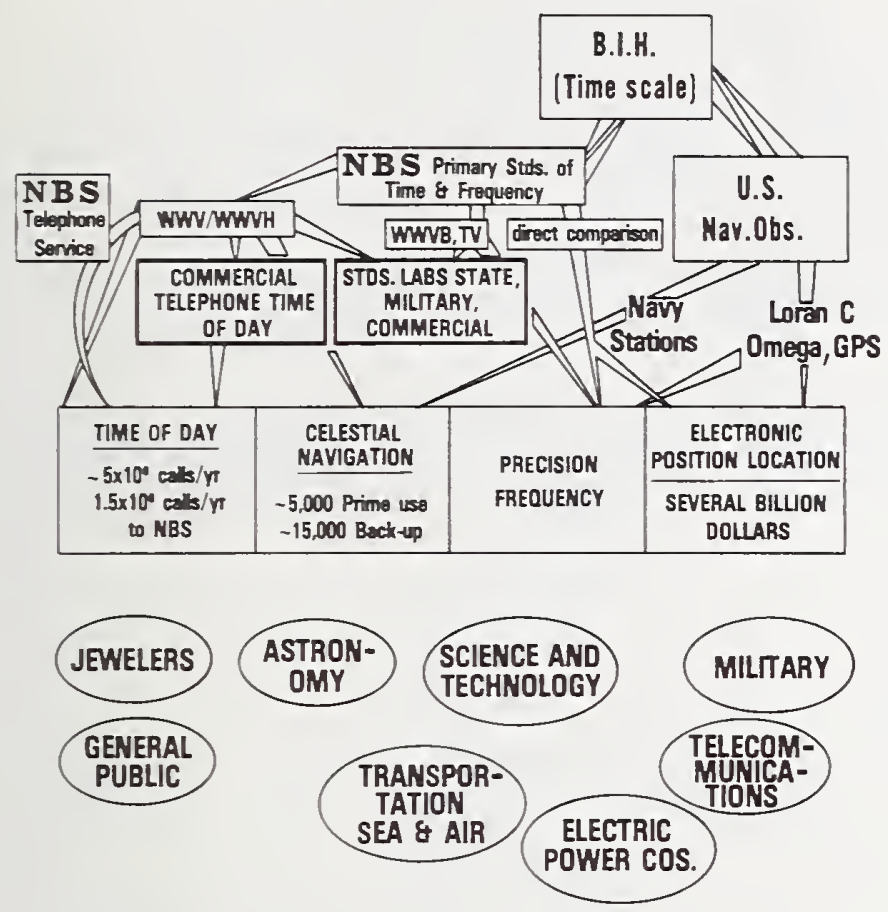

TIME \& FREOUENCY VOLUNTARY STANDARDS SYSTEM

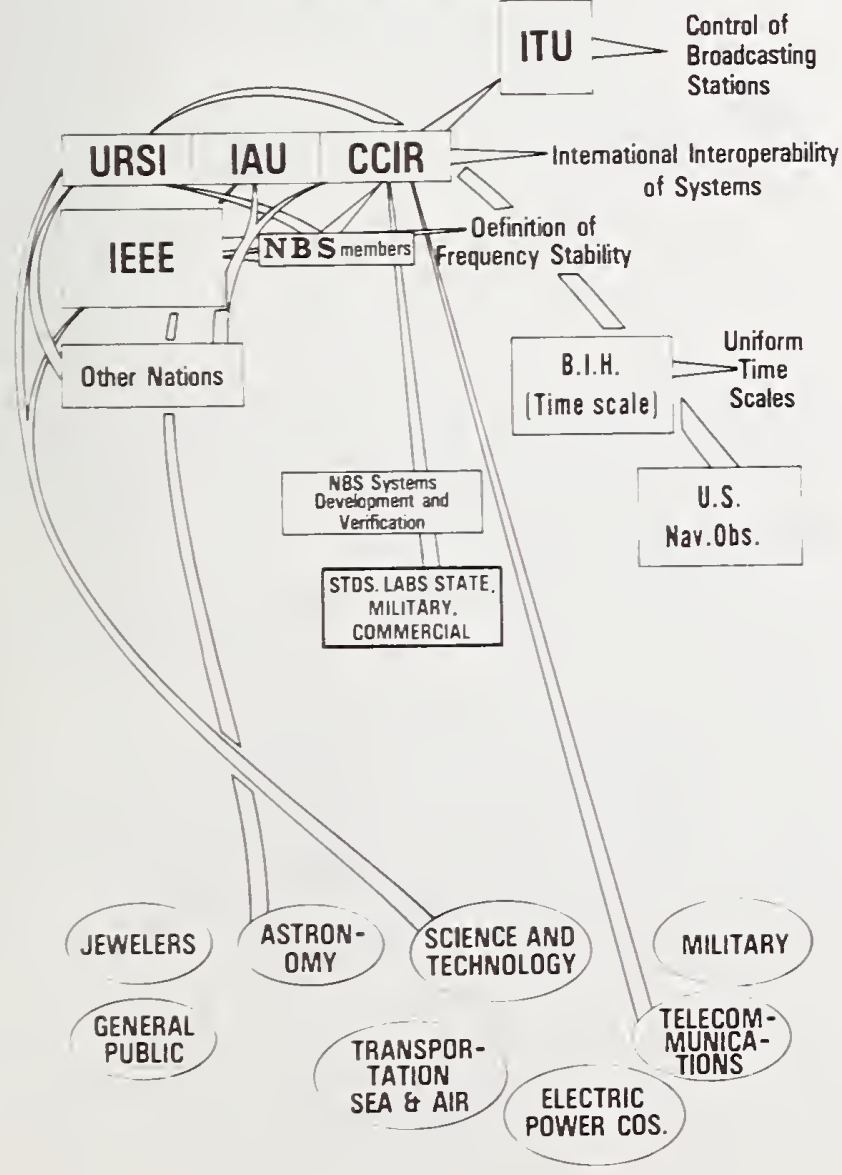

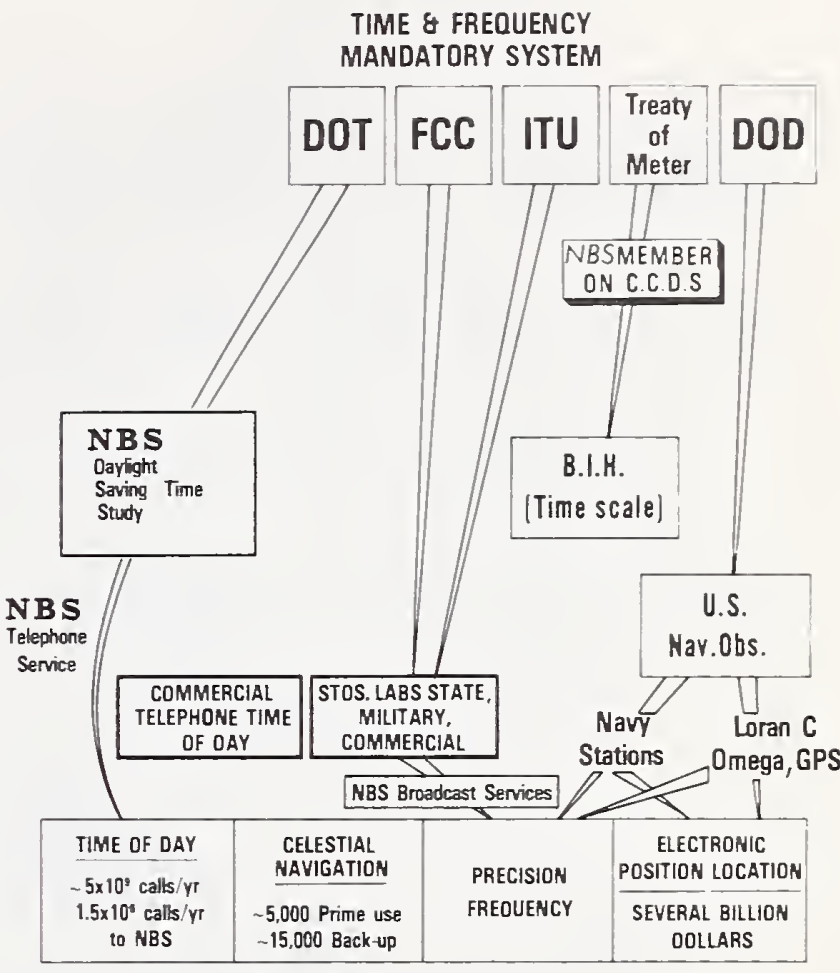

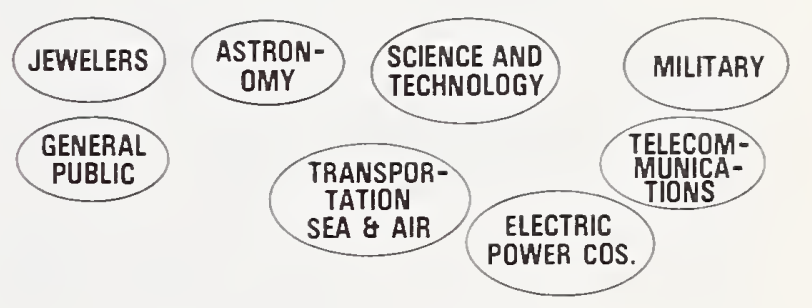

TIME AND FREQUENCY GLOSSARY

B. I. H. - Bureau International de 1 'Heure WIV, WWVH, WWVB - NBS broadcast stations

TV - NBS precision monitoring of TV network color carrier frequencies

U. S. Nav. Obs. - U. S. Naval Observatory, Washington, D. C.

Loran C - low frequency navigation system Omega - world-wide long-range navigation system GPS - proposed global positioning system, using satellites

ITU - International Telecommunications Union URSI - International Radio Scientific Union IAU - International Astronomical Union CCIR - International Radio Consultative Committee IEEE - Institute of Electrical and Electronic Engineers

DOT - Department of Transportation

FCC - Federal Communications Commission

DOD - Department of Defense

CCDS - Comite Consultatif pour la Definition de Seconde (technical comrittee supportive of B. I. H.) 
LENGTH AND DIMENSIONAL MEASUREMENTS

FIELD PROBLEMS AND USERS

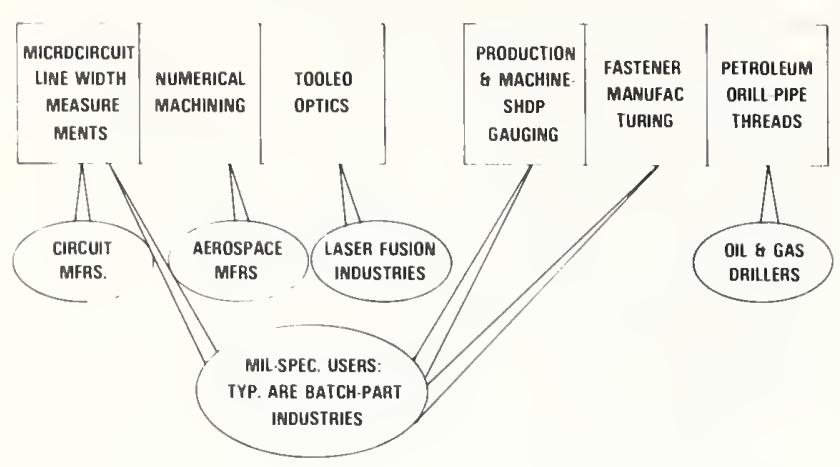

LENGTH AND DIMENSIONAL MEASUREMENTS MEASUREMENT DISSEMINATION

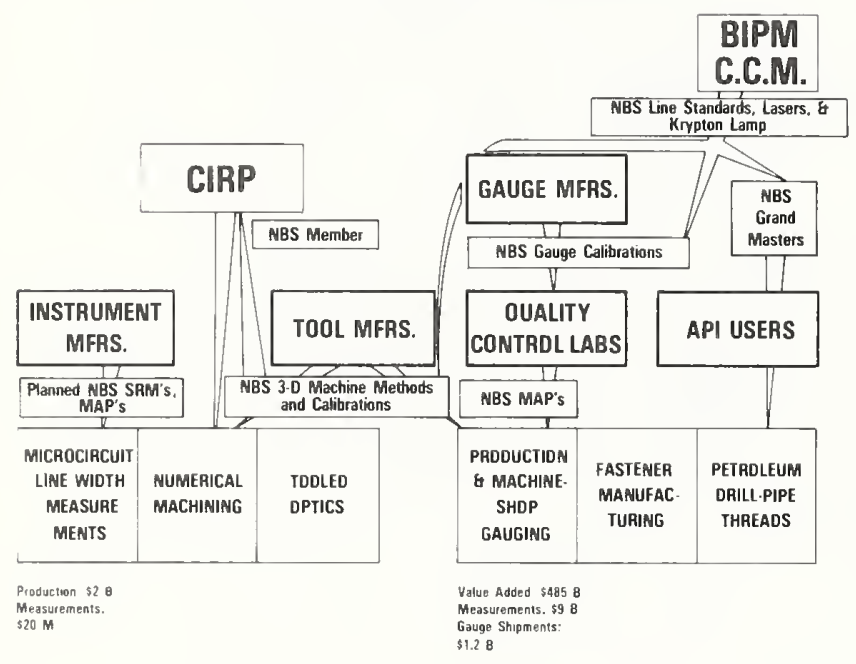

LENGTH AND DIMENSIDNAL MEASUREMENTS DDCUMENTARY STANDARDS

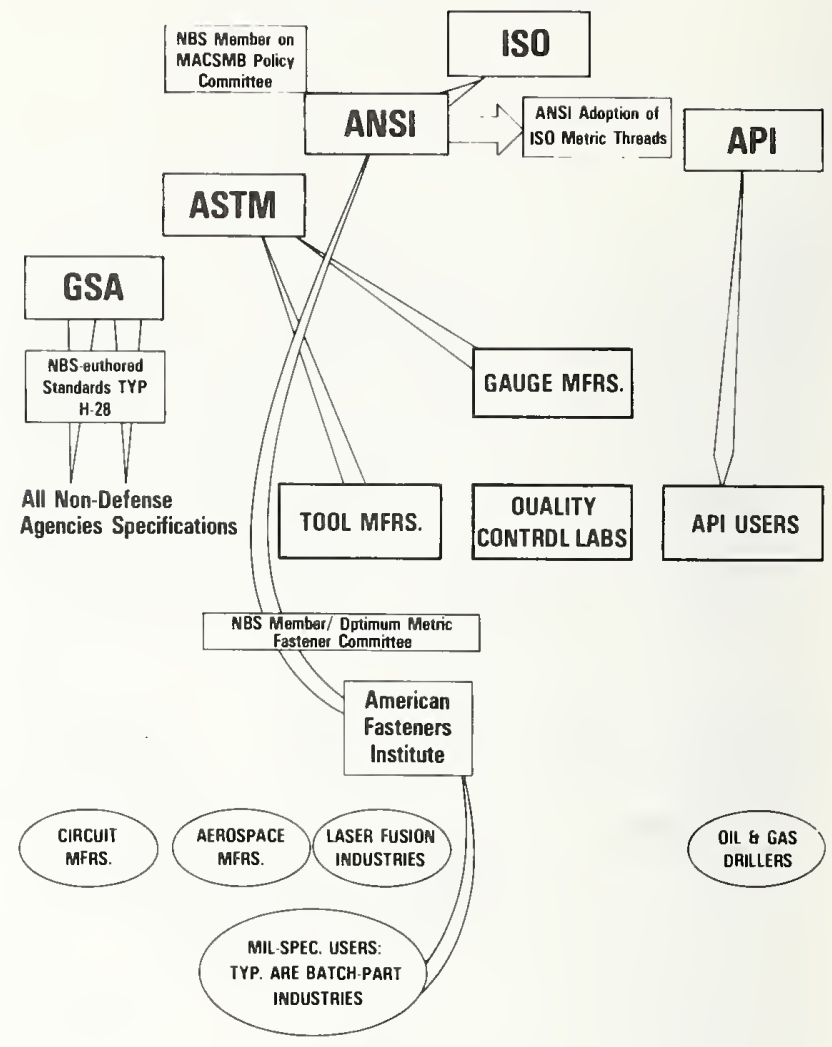

LENGTH AND DIMENSIONAL MEASUREMENTS GLOSSARY

CIRP - International Institute for Production

Engineering Research

BIPM - Bureau International des Poids et Mesures

C.C.M. - Comite Consultatif du Metre (advisory to BIPM)

SRM - Standard Reference Material

MAP - Measurement Assurance Program

API - American Petroleum Institute

GSA - General Services Administration

ASTM - American Society for Testing and Materials

ANSI - American National Standards Institute

ISO - International Standards Organization

MACSMB - a senior policy committee of ANSI 

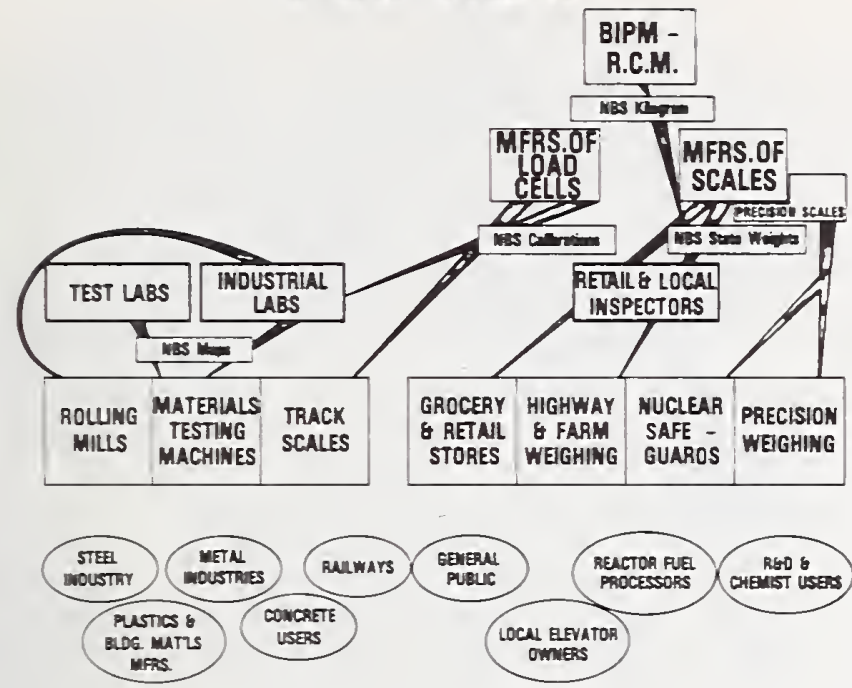

MASS \& FORCE

VOLUNTARY-DOCUMENTARY SYSTEM

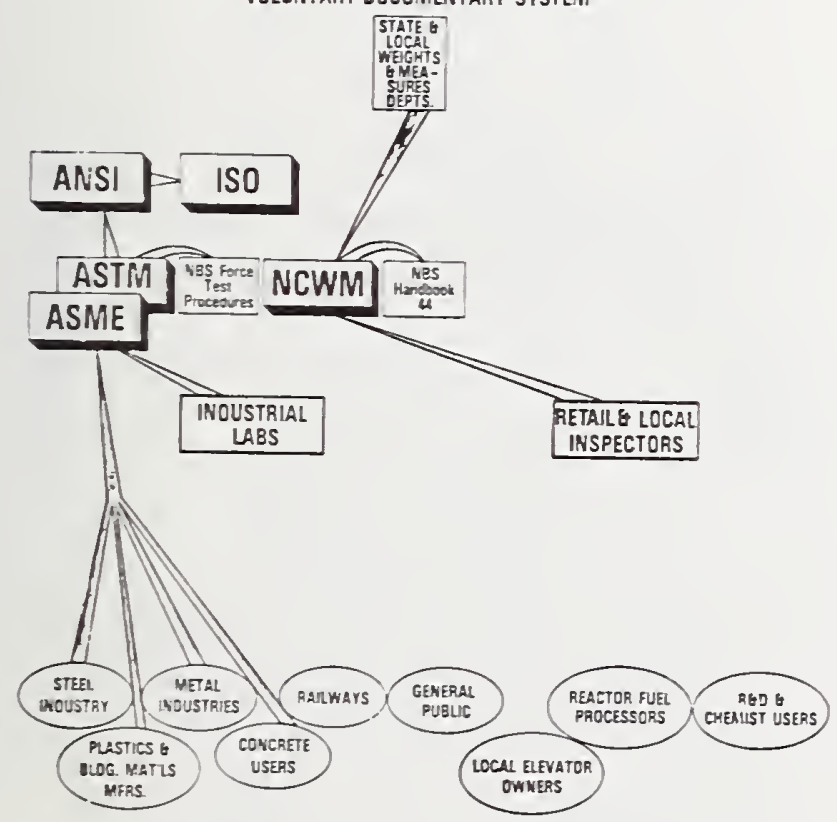

MASS \& FORCE

REGULATORY-MANOATORY SYSTEM

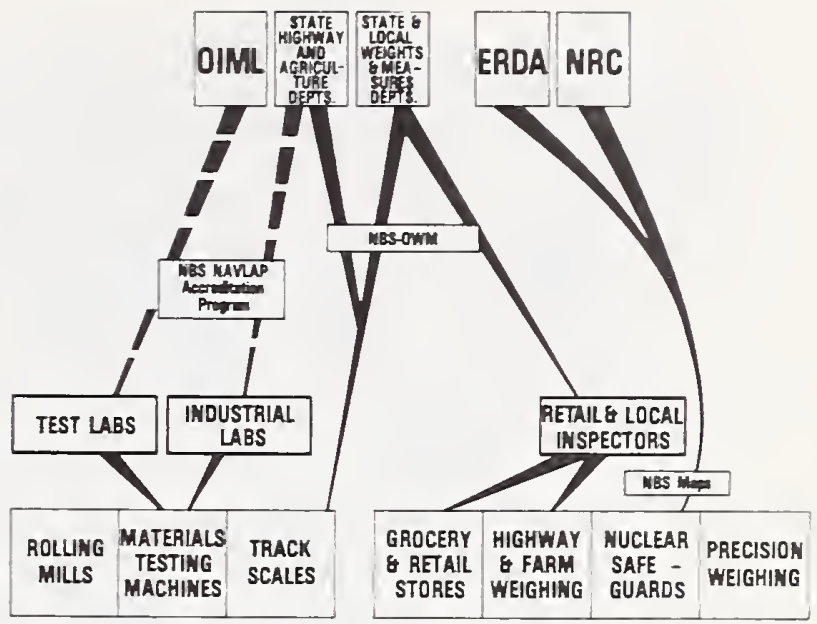

MASS AND FORCE GLOSSARY

ASTM - American Society for Testing and Materials ANSI - American National Standards Institute ISO - International Standards Organization ASME - American Society of Mechanical Engineers

NCWM - National Conference of Weights and Measures OIML - International Organization of Legal Metrology NAVLAP - National Voluntary Laboratory Accreditation Program

OWM - Office of Weights and Measures

ERDA - Energy Research and Development Administration

NRC - Nuclear Regulatory Commission 
TEMPER A T URE

FIELO MEASUREMENT PROBLEMS AND USERS

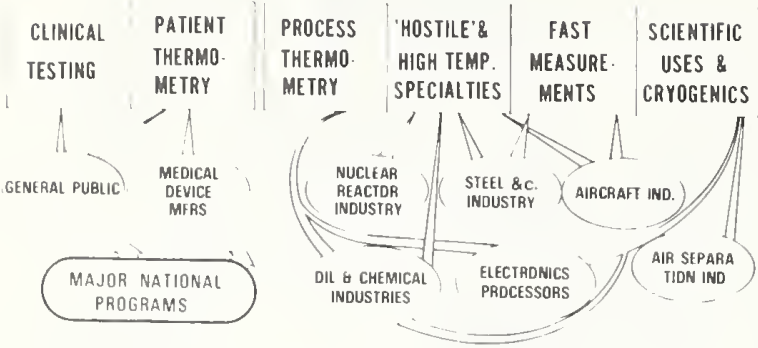

TEMPERATURE MEASUREMENTS CALIBRATIDN HIERARCHY

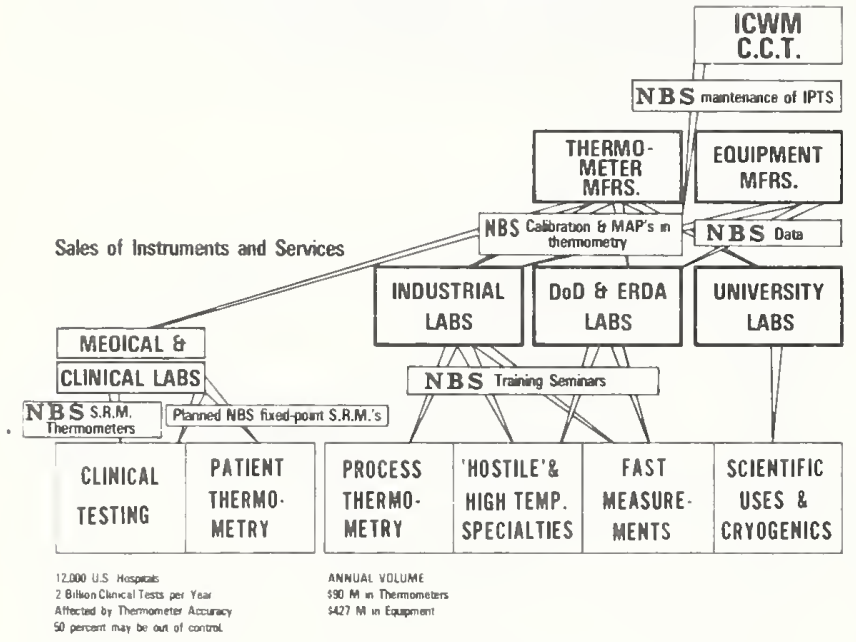

TEMPERATURE VDLUNTARY STANDARDS SYSTEM

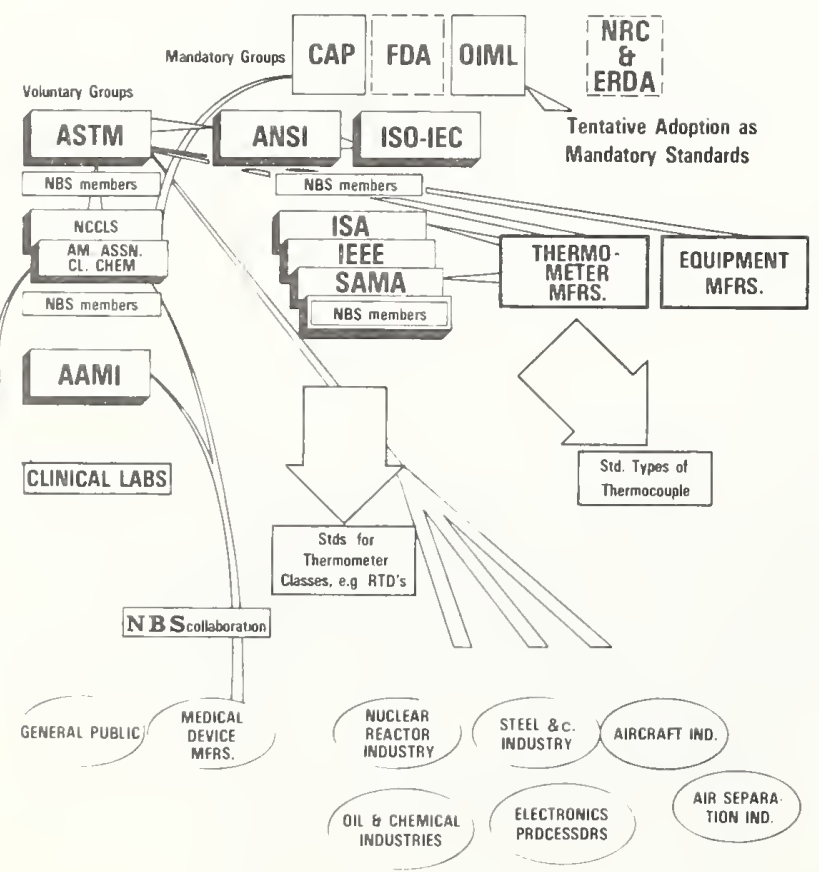

TEMPERATURE MANDATORY STANDARDS

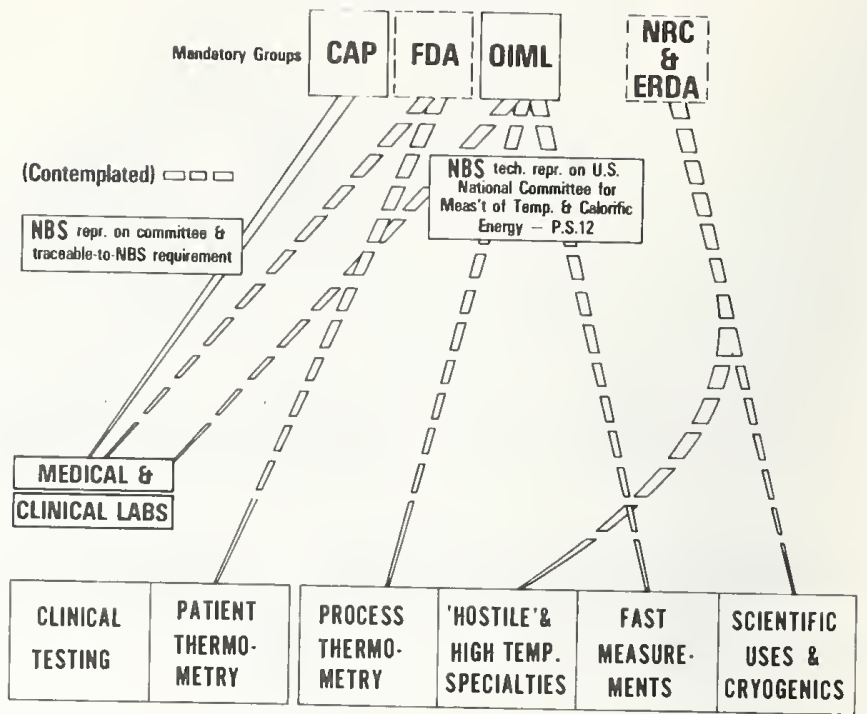

\section{TEMPERATURE GLOSSARY}

ICWM - International Committee of Weights and Measures (supervisory to BIPM)

CCT - Comite Consultatif de Thermometrie - (advisory to ICIM)

IPTS - International Practical Temperature Scale MAP - Measurement Assurance Program SRM - Standard Reference Material CAP - College of American Pathologists

FDA - Food and Drug Administration OIML - International Organization of Legal Metrology NRC - Nuclear Regulatory Committee ERDA - Energy Research and Development Administration ASTM - American Society for Testing and Materials ANSI - American National Standards Institute ISO-IEC - International Standards OrganizationInternational Electrotechnical Commission NCCLS - National Committee for Clinical Laboratory Standards

Am. Assn. Cl. Chem. - American Association for Clinical Chemistry

AAMI - American Association for Medical

Instrumentation

ISA - Instrument Society of America

IEEE - Institute of Electrical and Electronic Engineers

SAMA - Scientific Apparatus Makers Association RTD - Resistance Thermometer Device P.S. - Pilot Secretariat 
ELECTRIC POWER

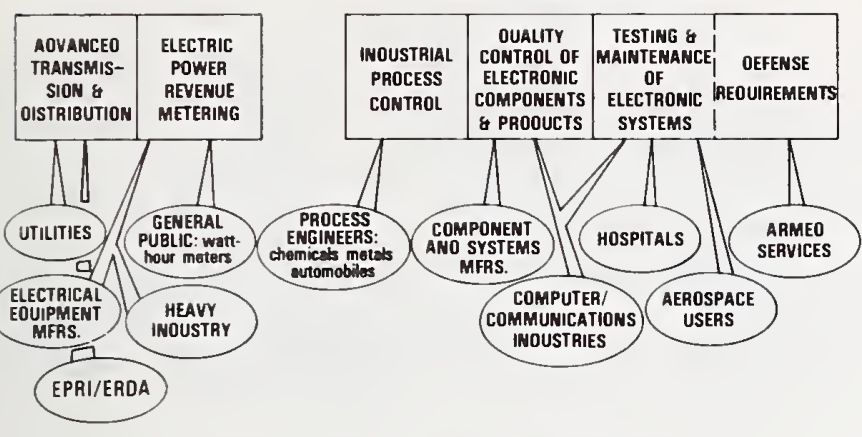

ELECTRICAL QUANTITIES

MEASUREMENT DISSEMINATION

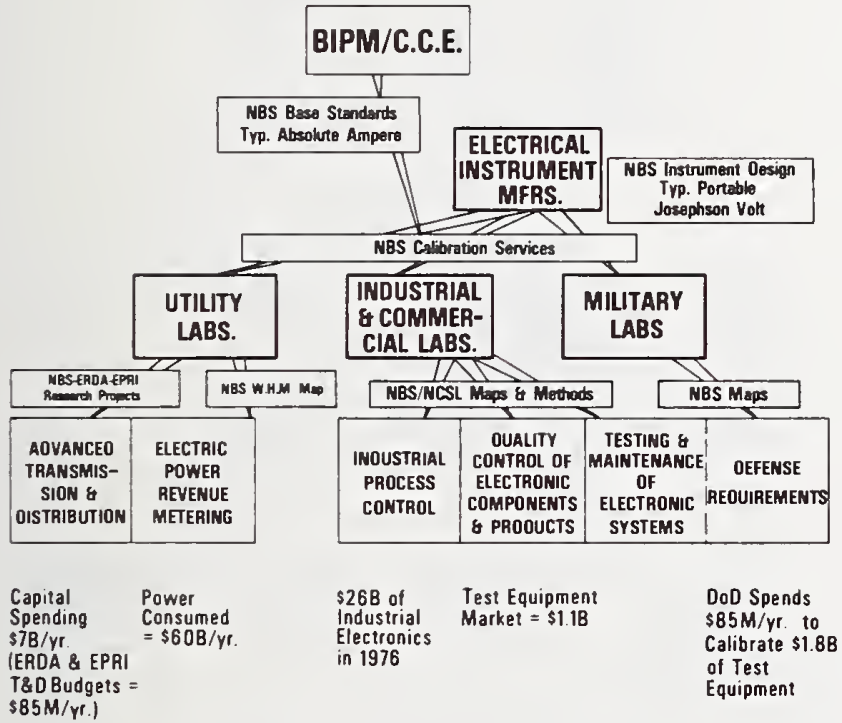

ELECTRICAL QUANTITIES REGULATORY CONTROL

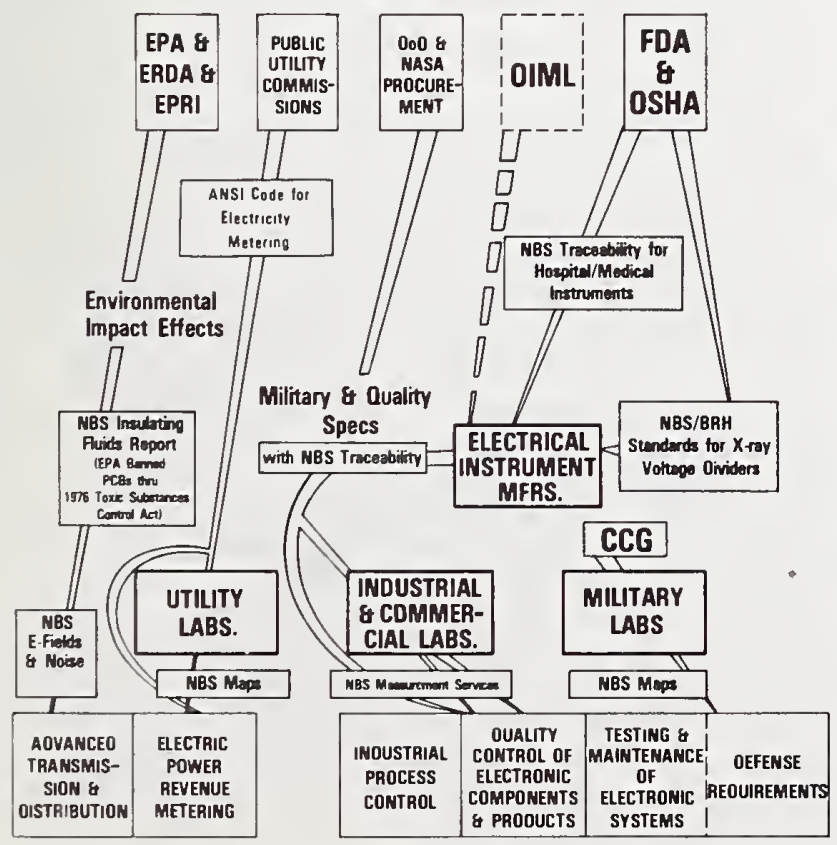

ELECTRICAL QUANTITIES VOLUNTARY-DOCUMENTARY SYSTEM

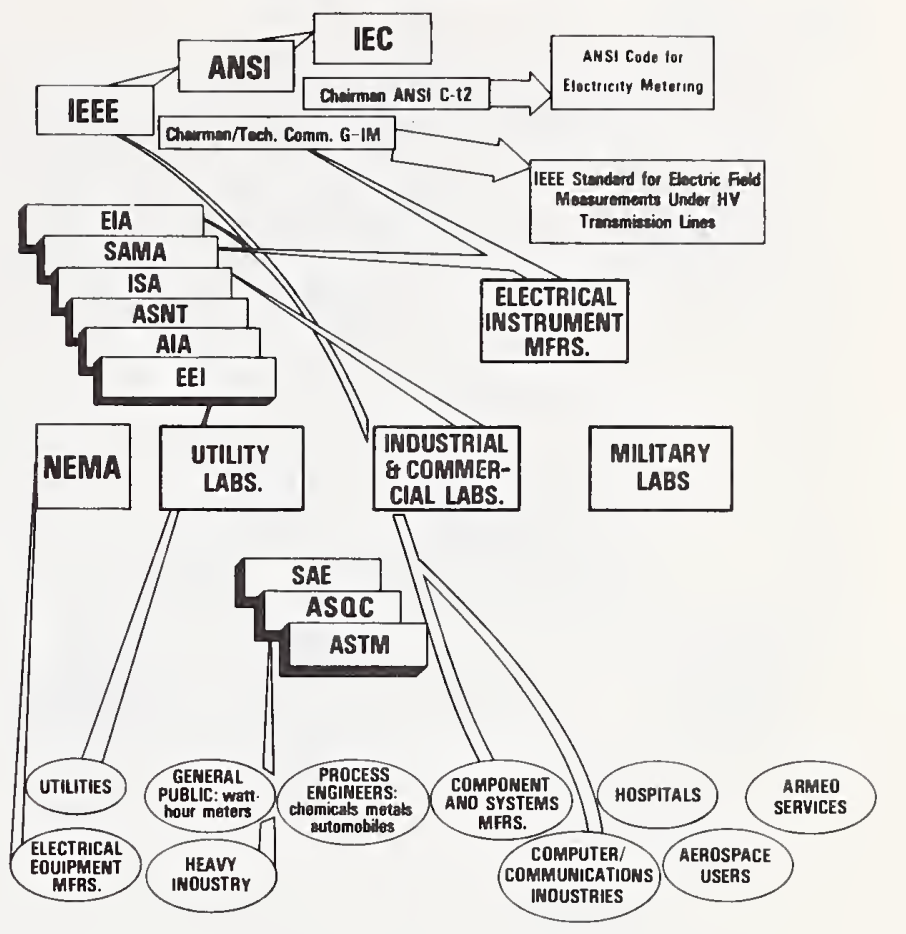

\section{ELECTRICAL QUANTITIES GLOSSARY}

EPRI - Electric Power Research Institute

ERDA - Energy Research and Development

Administration

BIPM - Bureau International des Poids et Mesures

C.C.E. - Comite Consultatif d'Electricite (adv. BIPM)

W.H.M. - Watthour Meter

MAP - Measurement Assurance Program

NCSL - National Conference of Standards Laboratories

DOD - Department of Defense

IEEE - Institute of Electrical and Electronic Engineers

ANS I - American National Standards Institute

IEC - International Electrotechnical Commission

Tech. Comm. A-IM - Technical Committee of the IEEE

Group in Instrumentation and Measurement

EIA - Electronics Industry Association

SAMA - Scientific Apparatus Makers' Association

ISA - Instrument Society of America

ASNT - American Society for Non-Destructive Testing

AIA - Aerospace Industries Association

EEI - Edison Electrical Institute

NEMA - National Electrical Manufacturers' Association

EPA - Environmental Protection Administration

NASA - National Aeronautics and Space Administration

OIML - International Organization of Legal Metrology

FOA - Food and Drug Administration

nSHA - Occupational Safety and Health Administration

PCB - Polychlorobiphenyl (insulating fluid)

$B R H$ - Sureau of Radiologal Health

CCG - Department of Defense Calibration Coordination Group 


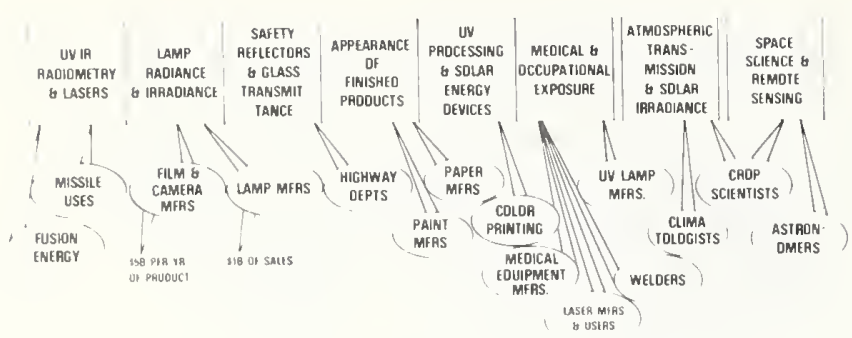

RAOIOMETRY

VOLUNTARY STANOAROS SYSTEM

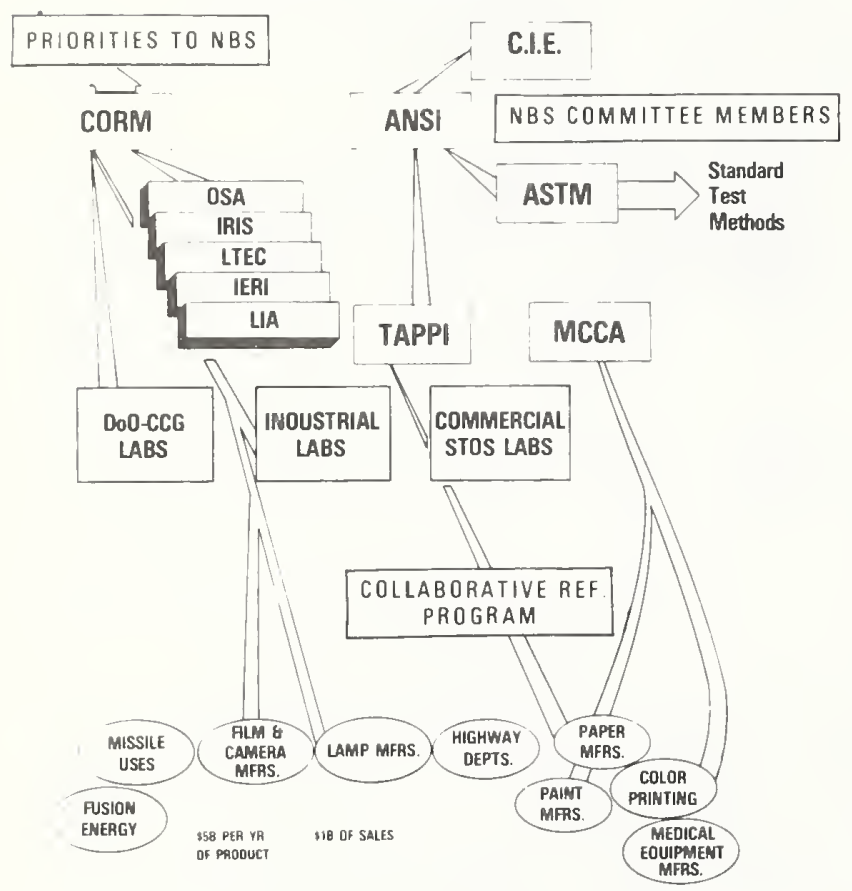

RADIOMETRY

REGULATORY SYSTEM

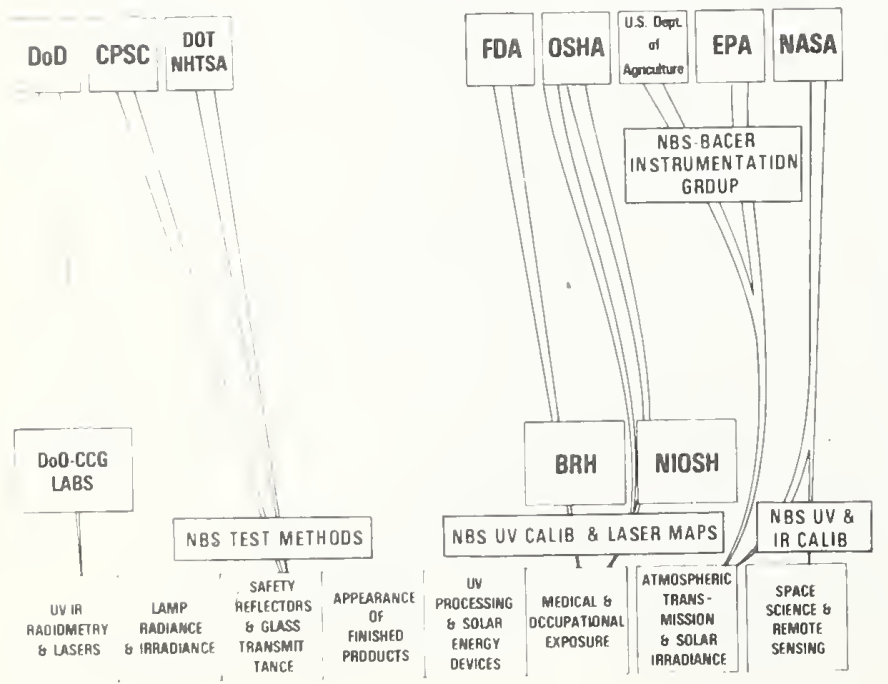

\section{RADIOMETRY LASER AND ULTRAVIOLET EXPOSURE}

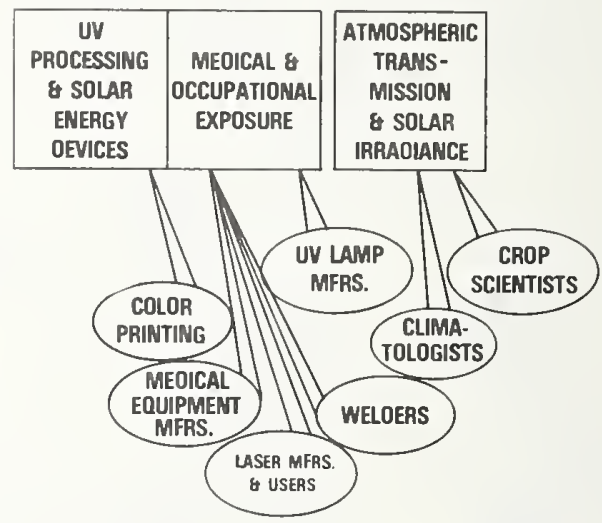

RADIOMETRY GLOSSARY

UV - Ultraviolet

$I R$ - Infrared

BIPM - International Bureau of Weights and Measures CCPR - Comite Consultatif de Photometrie et Radiometrie (consultative to BIPM)

DOD-CCG - Department of Defense Calibration Coordination Group

BRH - Bureau of Radiological Health

NIOSH - National Institute of Occupational Safety and Health

NASA - National Aeronautics and Space Administration SRM's - Standard Reference Materials

CORM - Council for Optical Radiation Measurements C.I.E. - International Commission on Illumination ANSI - American National Standards Institute ASTM - American Society for Testing and Materials TAPPI - Trade Association of the Pulp and Paper Industry

MCCA - Manufacturers Council on Color and Appearance

OSA - Optical Society of America

IRIS - Infrared Information Symposium

LTEC - Lamp Testing Engineers' Conference

IERI - ITlumination Engineering Research Institute

LIA - Laser Institute of America

CPSC - Consumer Product Safety Commission

DOT/NHTSA - Department of Transportation/National Highway Safety Administration

OSHA - Occupational Safety and Health Administration

EPA - Environmental Protection Administration

BACER - Biological and Climatic Effects Research Program 


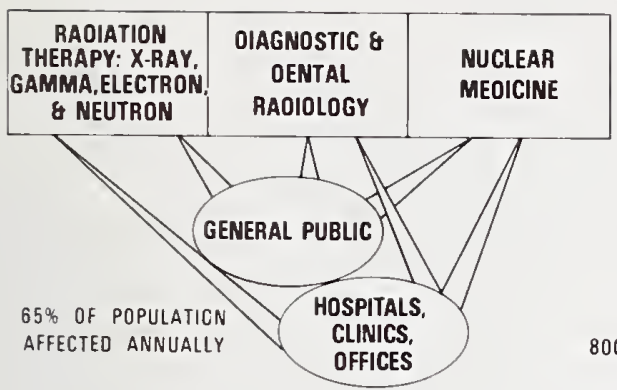

MEOICAL RADIATION MEASUREMENT CALIBRATION

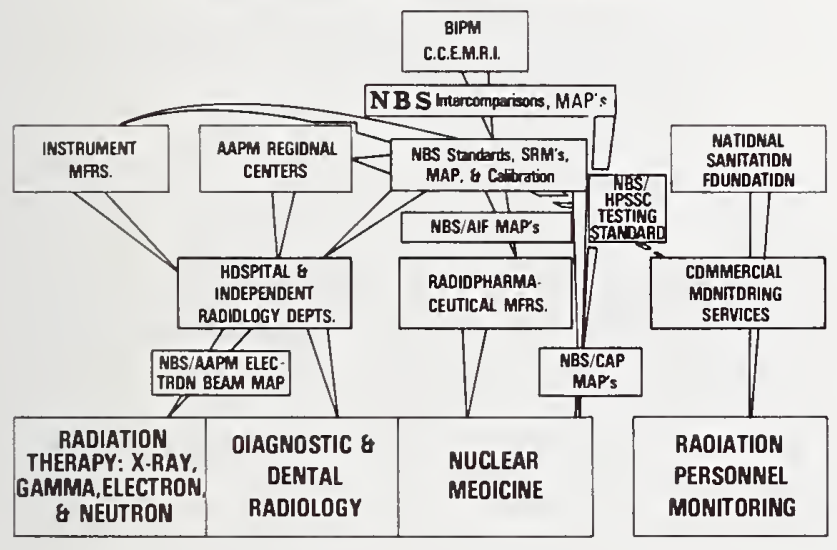

MEDICAL RADIATIDN: DOCUMENTARY STANDARDS SYSTEM

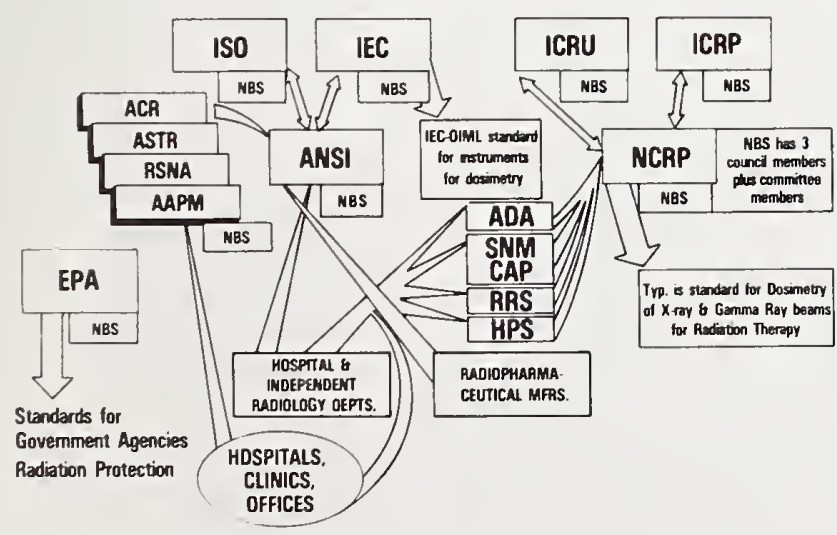

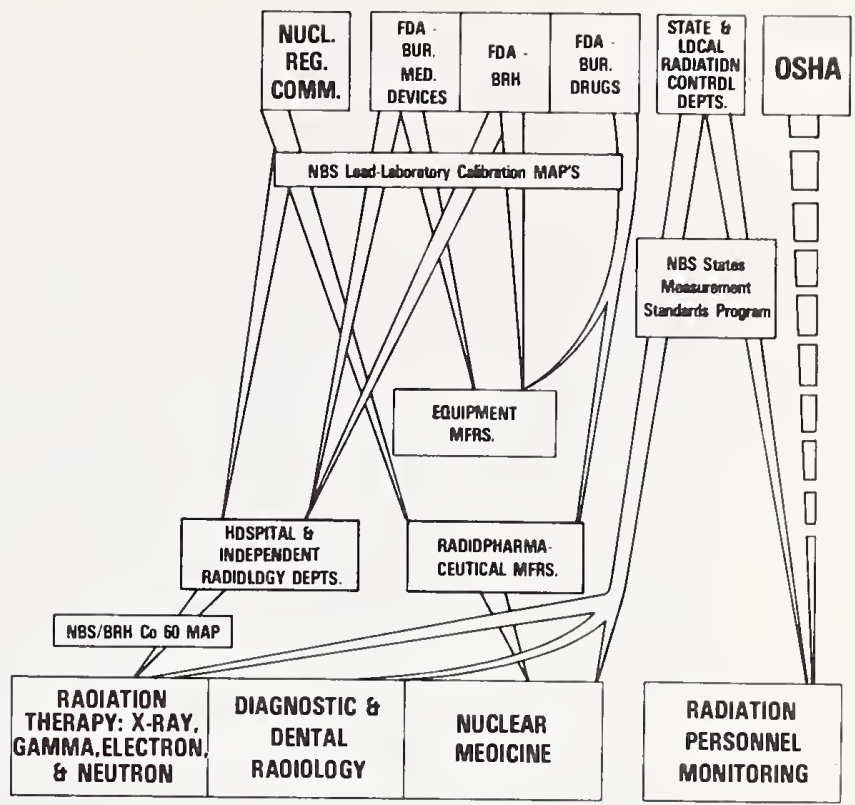

\section{MEDICAL RADIATION GLOSSARY}

BIPM - International Bureau of Weights and Measures C.C.E.M.R.I. - Comite Consultatif pous les Etalons de Mesure des Rayonnements Ionizants (advisory to BIPM)

MAP's - Measurement Assurance Programs

AAPM - American Association of Physicists in Medicine

SRM - Standard Reference Material

AIF - Atomic Industrial Forum

HPSSC - Health Physics Society Standards Committee

CAP - College of American Pathologists

ISO - International Standards Organization

IEC - International Electrotechnical Commission

ANSI - American National Standards Institute

ICRU - International Commission on Radiation Units and Measurements

ICRP - International Commission on Radiological Protection

IICRP - National Council on Radiation Protection and Units

ACR - American College of Radiology

ASTR - American Society of Therapeutic Radiologists

RSNA - Radiological Society of North. America

OIML - International Organization for Legal Metrology

EPA - Environmental Protection Administration

ADA - American Dental Association

SNI.1 - Society for Nuclear Medicine

RRS - Radiation Research Society

HPS - Health Physics Society

Nucl. Reg. Comm. - Nuclear Regulatory Commission

FDA - Food and Drug Administration

Bur. Med. Devices - Bureau of Medical Devices

BRH - Bureau of Radiological Health

Bur. Drugs - Bureau of Drugs

OSHA - Occupational Safety and Health Administration (Department of Labor)

MAP's - Measurement Assurance Programs

Co60 - Cobalt 60 (gamma-ray Radiotherapy Source) 


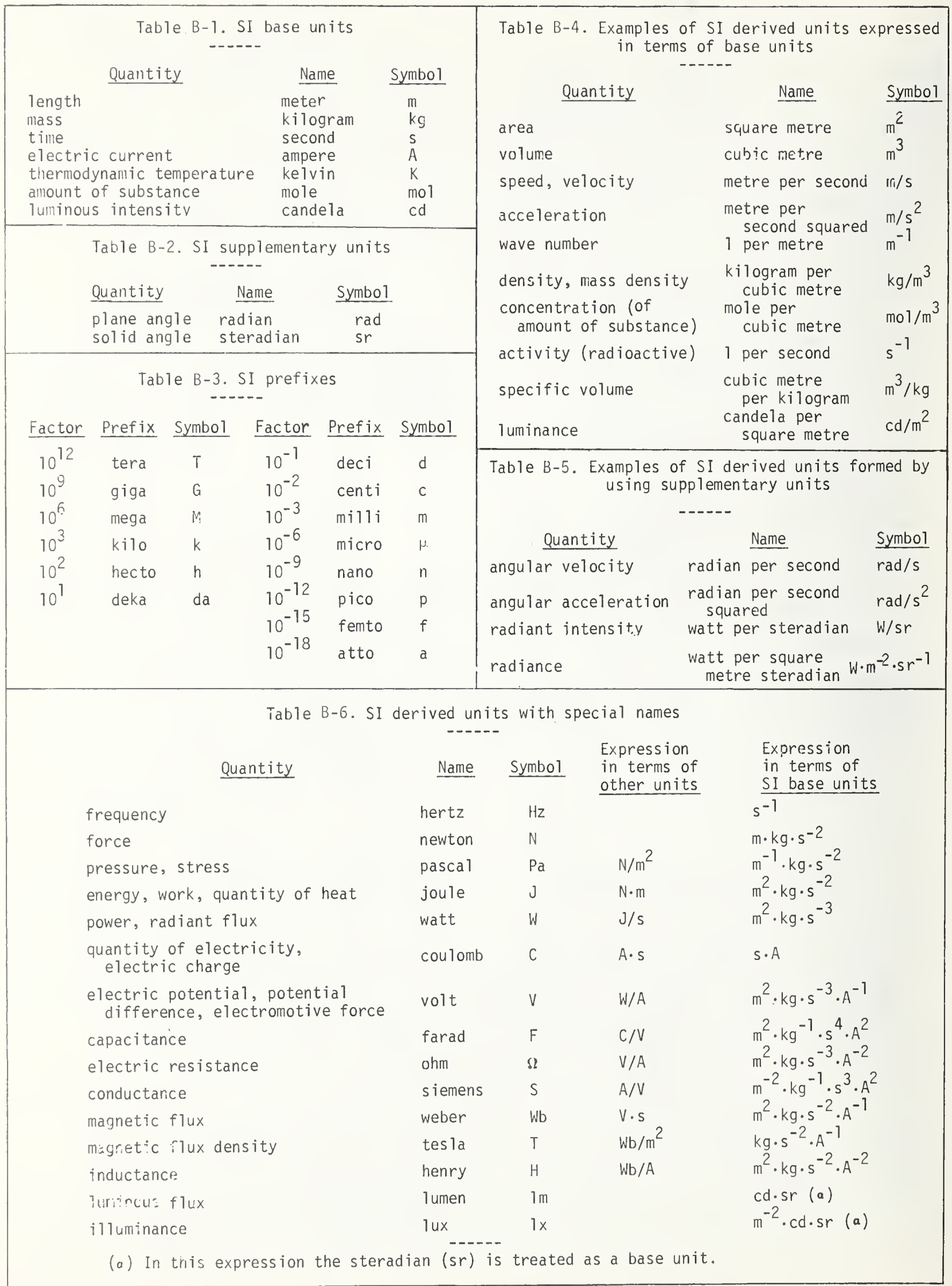




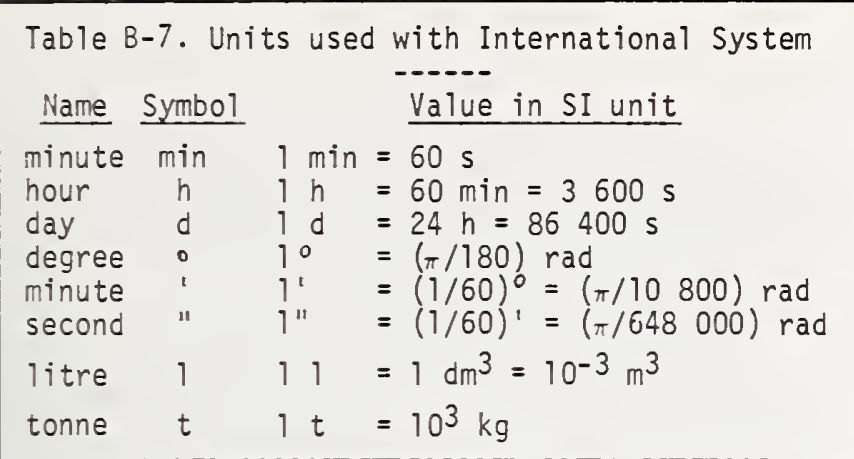

Table B-8. Units used with International system whose values in SI units are found experimentally

\begin{tabular}{lc}
\multicolumn{1}{c}{$\frac{\text { Name }}{\text { electronvolt }}$} & $\frac{\text { Symbol }}{\mathrm{eV}}$ \\
unified atomic mass unit & $u$ \\
astronomical unit & (see def'nc) \\
parsec & pc
\end{tabular}

Definitions:

(a) 1 electronvolt is the kinetic energy acquired by an electron in passing through a potential difference of 1 volt in vacuum; $1 \mathrm{eV}=1.60219 \times 10^{-19} \mathrm{~J}$ approximately.

(b) The unified atomic mass unit is equal to the fraction $1 / 12$ of the mass of an atom of nuclide $12 \mathrm{C} ; \mathrm{l}=1.66053 \times 10^{-27} \mathrm{~kg}$ approximately.

(c) This unit does not have an international symbol; abbreviations are used, for example AU in English. The astronomical unit is the length of the radius of the unperturbed circular orbit of a body with negligible mass moving round the Sun with sidereal angular velocity of $0.01720209895^{\circ}$ radian per day of 86400 ephemeris seconds. In the system of astronomical constants of the International Astronomical Union the value adopted for it is: $1 \mathrm{AU}=149600 \times 106 \mathrm{~m}$.

(d) 1 parsec is the distance at which 1 astronomical unit subtends an angle of 1 second of arc; we thus have approximately, $1 \mathrm{pC}=206265 \mathrm{AU}$ $=30857 \times 1012 \mathrm{~m}$.

Figure B-1. Metric conversion card [228].

\section{$30857 \times 1012 \mathrm{~m}$.}

U. S. DEPARTMENT OF COMMERCE

'Satunal Bureau of Standards NBS Special Publication 365 METRIC CONVERSION CARD Approximate Converion:

\begin{tabular}{|c|c|c|c|c|}
\hline$m b o$ & When You Kno & Multiply by & To Find & Symbol \\
\hline & & LENGTH & & \\
\hline & inches & 2.5 & centirseter & \\
\hline & feet & 30 & centimeters & $\mathrm{cm}$ \\
\hline$y d$ & yards & 0.9 & meters & \\
\hline & miles & $\frac{1.6}{1.5 \mathrm{~A}}$ & kilometen & $\mathrm{km}$ \\
\hline & square inches & 6.5 & square centimeter & $\mathrm{rB} \mathrm{cm}^{2}$ \\
\hline $\mathrm{ft}^{\mathrm{3}}$ & square feet & 0.09 & square meters & $\mathrm{m}^{3}$ \\
\hline$y d^{3}$ & square yarda & 0.8 & squa re meten & $\mathrm{m}^{2}$ \\
\hline & square miles & 2.6 & square kilometers & $\mathrm{km}^{2}$ \\
\hline \multirow{2}{*}{\multicolumn{5}{|c|}{ MASS (weight) }} \\
\hline & & & & \\
\hline \multirow[t]{3}{*}{ al } & ounces & 28 & grams & 8 \\
\hline & $\begin{array}{l}\text { pounds } \\
\text { short tons }\end{array}$ & 0.9 & $\begin{array}{l}\text { Gilograms } \\
\text { tonnes }\end{array}$ & $\mathrm{kg}$ \\
\hline & - 20001 & & & \\
\hline
\end{tabular}
nautical mile knot

àngs trom

are

hectare

barn ${ }^{2}$

bar

standard

atmosphere

$\mathrm{ga}^{3}$

curie ${ }^{4}$

röntgen 5

$\operatorname{rad}^{6}$

Name Symbol Value in SI units

Units to be used with International System for a limited time

$$
\begin{array}{ll} 
& 1 \text { nautical mile }=1852 \mathrm{~m} \\
& 1 \text { nautical mile per hour }= \\
& (1852 / 3600) \mathrm{m} / \mathrm{s} \\
\AA & 1 \mathrm{~A}=0.1 \mathrm{~nm}=10^{-10} \mathrm{~m} \\
\mathrm{a} & 1 \mathrm{a}=1 \mathrm{dam}=10^{2} \mathrm{~m}^{2} \\
\text { ha } & 1 \mathrm{ha}=1 \mathrm{hm}^{2}=10^{4} \mathrm{~m}^{2} \\
\mathrm{~b} & 1 \mathrm{~b}=100 \mathrm{fm}^{2}=10^{-28} \mathrm{~m}^{2} \\
\mathrm{bar} & 1 \mathrm{bar}=0.1 \mathrm{MPa}=10^{5} \mathrm{~Pa} \\
\text { atm } & 1 \mathrm{~atm}=101325 \mathrm{~Pa} \\
\mathrm{Ga} 1 & 1 \mathrm{Gal}=1 \mathrm{~cm} / \mathrm{s}^{2}=10^{-2} \mathrm{~m} / \mathrm{s}^{2} \\
\mathrm{Ci} & 1 \mathrm{Ci}=3.7 \times 10^{10} \mathrm{~s}^{-1} \\
\mathrm{R} & 1 \mathrm{R}=2.58 \times 10^{-4} \mathrm{c} / \mathrm{kg} \\
\mathrm{rad} & 1 \mathrm{rad}=10^{-2} \mathrm{~J} / \mathrm{kg}
\end{array}
$$

${ }^{1}$ The nautical mile is a special unit employed in marine and aerial navigation to express distances. 2The barn is a special unit employed in nuclear physics to express effective cross sections.

${ }^{3}$ The gal is a special unit empioyed in geodesy \& gegphysics to express acceleration due to gravity. The curie is a special unit employed in nuclear physics to express activity of radionuclides.

${ }^{5}$ The röntgen is a special unit employed to express exposure of $X$ or $Y$ radiations.

The rad is a special unit employed to express absorbed dose of ionizing radiations. When there is risk of confusion with the syilbol for radian, rd may be used as symbol for rad. 
APPENDIX C. NBS NATIONAL MEASUREMENT REFERENCE STANDARD ARTIFACTS, INSTRUMENTS \& FACILITIES ${ }^{\dagger}$

\section{1. Time and Frequency}

Frequency standards: NBS-4 and NBS-6. Time standard: NBS clock ensemble.

Standards services:

Television calibration

Telephone

Radio station broadcasts: WWV, WWVB, WWVH, WWVL (experimental)

Services available:

Time of day - voice, BCD code

One-second ticks

Standard frequencies

Carrier: $2.5,5,10,15,20$, $25 \mathrm{MHz}$

Audio: $100,440,500,600 \mathrm{~Hz}$

UT1 corrections

\section{C.2. Length \& Related Dimensional Measurements}

\section{C.2.1 Absolute standards}

Hel ium lamps (3)

Cadmium lamps (2)

Mercury lamps (2)

Lamb-dip stablized He-ile lasers (4)

Iodine-stabilized He-Ne laser (1)

Zeeman split stabilized He-Ne lasers (5)

\section{C.2.2 Multidimensional comparator: Moore $5 z$}

\section{C.2.3 End standards}

Steel gage blocks:

4 8-piece sets, 5-20 inches

1 8-piece set, $125-500 \mathrm{~mm}$

2 120/121-piece sets, $0.01-4$ inches

2 121/122-piece sets, $0.5-100 \mathrm{~mm}$

1 28-piece set, 0.01-0.09 inch

1 18-piece set, $0.0101-0.019$ inch

1 18-piece set, 0.0501-0.059 inch

1 4-piece set, 1-4 inches

1 10-piece set, 0.20001-0.2001 inch

2 88-piece sets, 0.05-4 inches

Chrome carbide gage blocks:

1 18-piece set, 0.0501-0.059 inch

1 4-piece set, 1-4 inches

Tungsten carbide gage blocks:

1 82-piece set, $0.05-4$ inches

Cervit gage blocks:

281 -piece sets, $0.05-4$ inches

Step blocks: 1

+In Spring 1976

\section{C.2.4 Line standards}

Prototype meter bar

$60 \mathrm{~m}$ bench standard, for steel tapes

\section{C.2.5 American Petroleum Institute thread gages}

Cable drilling connections: 14

Rotary connection gages: 38

Extreme line casing plugs: 9

\section{C.2.6 Angle standards}

Angle blocks: Set NBS-25 (16)

Set NBS-7 (16)

Polygons: 1 12-sided

Indexing tables: 2 7-inch

Angle generator: 1, range 1000 seconds

Pentaprisms: 2

\section{C.2.7 Other dimensional standards}

$60^{\circ}$ Thread wires: 2 sets of 51

$60^{\circ}$ Metric thread wires: 2 sets of 29

$29^{\circ}$ Acme best wires: 2 sets of 22

290 Acme flush: 1 set of 22

$29^{\circ}$ Acme worm flush: 1 set of 22

Gear wires: 1.44 series, set of 13

1.68 series, set of 23

1.728 series, set of 22

1.92 series, 2 sets of 26

Bal1 plates: 2

Plug gages: 2 sets of $16,0.05$ or $1 / 16$ to 1 inch.

Ring gages: 5 masters, $0.125-1$ inch Optical flats: 9 masters, 3-16 inches Balls (sphieres): 2 sets of $31,1 / 16-1$ inch 1 set of $25,1-25 \mathrm{~mm}$

\section{C.3. Surface Finish}

Computerized surface roughness mea suring instrument (re ANSI B46.1).

C.4. Mass

Prototype kilograms $K_{4}$ and $K_{20}$

Nichrome kilograms $\mathrm{N}_{1}$ and $\mathrm{N}_{2}$

$10,000,20,000$, and $30,000 \mathrm{~Tb}$ stainless steel disc weights

C. 5. Volume

$1,5,30,50$, and 100 gallon provers

C.6. Density

Silicon single crystals (4)

Master hydrometers (about 250) 


\section{C.7. Force}

7 deadweight machines for applied forces from $44.5 \mathrm{~N}$ to $4.45 \mathrm{MN}$

Load cells, 4.45 (3) and 13.3 (4) MN capacity, extend force standards range to $53.4 \mathrm{MN}$

\section{C.8. Vibration}

Vibration exciters, $2 \mathrm{~Hz}$ to $10 \mathrm{KHz}$ (3) Interferometer (1)

C.9. Shock

Shock accelerometer comparator, 50-5000 g peak, $0.5-40$ ms half sine

C. 10. Fluid Flow

\section{C.10.1 Air flow facilities, velocity}

Dual test section wind tunnel, $82 \mathrm{~m} / \mathrm{s}$ $\max , 45.7 \mathrm{~m} / \mathrm{s} \max$. with adjustable pressure gradient

Low velocity wind tunnel, $0.05-15 \mathrm{~m} / \mathrm{s}$

Unsteady flow wind tunnel, $27.4 \mathrm{~m} / \mathrm{s}$, fluctuations $0.1-25 \mathrm{~Hz}$ at max. amplitude of $50 \%$ mean flow

\section{C.10.2 Air flow facilities, volume flow- rate}

Constant volume collection tank, $1400 \mathrm{l} / \mathrm{s}$ max. at $100 \mathrm{kPa}$ and $20^{\circ} \mathrm{C}$

Bell type prover, $0.1-251 / \mathrm{s}$ at $100 \mathrm{kPa}$ at $20^{\circ} \mathrm{C}$

Mercury sealed piston prover, $1-250 \mathrm{ml} / \mathrm{s}$ at $100 \mathrm{kPa}$ and $20^{\circ} \mathrm{C}$

\section{10.3 Water flow facilities, velocity}

Open-circuit water tunnel, $2.5 \mathrm{~m} / \mathrm{s} \max$.

C.10.4 Water flow facilities, volume and mass flowrates

Tilting open channel, $280 \mathrm{l} / \mathrm{s} \max$.

Collection in weight tank, $630 \mathrm{~kg} / \mathrm{s} \max$.

\section{C.10.5 Liquid hydrocarbon flow facilities,} mass flowrate

Collection in weight tanks, 12.5 and $100 \mathrm{~kg} / \mathrm{s} \max$.

\section{10.6 Cryogenic fluid flow metering facilities}

Atmospheric gases - liquid $\mathrm{N}_{2}$ and $\mathrm{A}$ : $0.00126-0.0126 \mathrm{~m}^{3} / \mathrm{s}$, at $0.0125-1.9 \mathrm{MPa}$, 64-114 K.

Liquified Natural Gas: 0.00126-0.0126 $\mathrm{m}^{3} / \mathrm{s}$, at $100 \mathrm{kPa}-1.38 \mathrm{MPa}, 80-150 \mathrm{~K}$
C.11. Pressure

Controlled clearance piston gages:

$7 \times 10^{8}-3 \times 10^{9} \mathrm{~Pa}, 0.2 \%$ F.S. accuracy

$3 \times 10^{8}-4 \times 10^{8} \mathrm{~Pa}, 0.01 \%$

$3 \times 10^{6}-3 \times 10^{8} \mathrm{~Pa}, 0.006 \%$

$1 \times 10^{5}-4 \times 10^{6} \mathrm{~Pa}, 0.003 \%$

$2 \times 10^{8}-1 \times 10^{9} \mathrm{~Pa}, 0.02 \%$ (under construction)

Piston and die: $1 \times 10^{9}-5 \times 10^{9}, 1 \%$

Hg melting line: $1 \times 10^{5}-7 \times 10^{8}, 0.04 \%$

$\mathrm{Hg}$ U-tube manometer: $1 \times 10^{4}-2 \times 10^{5}$, $0.003 \%$

Vacuum-backed piston gage: $2 \times 10^{3}-1 \times 10^{5}$, $0.003 \%$

U1 trasonic $\mathrm{Hg}$ manometer: $1 \times 10^{-1}-1 \times 10^{4}$, $0.05 \%$ (tent.)

U1trasonic oil manometer: $1 \times 10^{-3}-1 \times 10^{2}$, $0.1 \%$ (tent.)

IR laser interferometric manometer: $1 \times 10^{4}-3 \times 10^{5}, 0.0005 \%$ (under construction)

\section{C.12. Temperature}

Triple point of water cells (12)

Platinum resistance thermometers (12)

Platinum-rhodium thermocouple thermometers (6)

Freezing point cells: gold, silver, zinc, tin (3 each)

Superconducting fixed point devices (2)

C. 13. Humidity

Primary standard: gravimetric hygrometer

Precision generators: Two-pressure; two-temperature (low frost-point)

\section{14. Electricity}

\section{C.14.1 Resistance}

Thomas (NBS) one-ohm standard resistors (5)

At $10^{-5}$ ohm: Commercial high current standards--1 Wolfe, 1 Reichsanstalt

At $10^{-4}$ ohm: 1 Wolfe, 1 Reichsanstalt

At $10^{-3}$ ohm: 1 Wolfe, 1 Reichsanstalt

At $10^{-2}$ ohm: 3 Reichsanstalt

At $10^{-1}$ ohm: 3 Reichsanstalt

At $10^{\circ}$ ohm: 2 Reichsanstalt, 1 Thomas (NBS) standard resistor

\section{C.14.2 Precision apparatus}

2 Universal ratio sets, commercial, NBS-specified

1 Dunfee-Dziuba (NBS) volt ratio standard Two-stage (NBS) inductive voltage divider One-stage (commercial) inductive voltage divider 


\section{14.3 Impedance}

cutknsky (NBS) calculable capacitor

\section{14.4 Voltage}

Denenstein-Finnegan (NBS) AC Josephson effect apparatus

\section{C.14.5 AC-DC transfer standards}

12 single-junction Evanohm thermoelements, commercial, NBS specified

2 multi-junction Evanohm thermoelements, commercial, NBS specified

\section{14.6 Transformers}

Voltage: Petersons (NBS) high voltage current comparator bridge

Current: 2 Souders (NBS) two-stage transformers

\section{C.14.7 High voltage and energy}

3 Park (NBS) D.C. high voltage dividers Hillhouse (NBS) high voltage capacitor

\section{C.15. Electromagnetics}

Impedance: 21 precision coaxial air transmission lines

Reflection coefficient: 8 precision waveguide sections $(4-40,55-65 \mathrm{GHz})$

$30 \mathrm{MHz}$ attenuator

$30 \mathrm{MHz}$ phase shaft reference standard

Set of 6 microcalorimeters for power, $10 \mathrm{MHz}-75 \mathrm{GHz}$

Sampling oscilloscope (20 ps transition time), for pulse generator and 2-port network transition times, and impulse generator spectrum amplitude

Pulse delay: precision, adjustable, coaxial air transmission line

Waveform of voltage and current: reference waveform generator

(100 ps transition time)

Thermal noise sources:

Coaxial: $3 \mathrm{MHz}$ at $77 \mathrm{~K}$

$3 \mathrm{MHz}$ at $373 \mathrm{~K}$

$30-60 \mathrm{MHz}$ at $77 \mathrm{~K}$

$30-60 \mathrm{MHz}$ at $373 \mathrm{~K}$

$1 \mathrm{GHz}$ tunable at $77 \mathrm{~K}$

$1 \mathrm{GHz}$ tunable at $373 \mathrm{~K}$

$10 \mathrm{MHz}-12 \mathrm{GHz}$ at $77 \mathrm{~K}$

Waveguide: $8-13 \mathrm{GHz}$ at $1200 \mathrm{~K}$

$12-18 \mathrm{GHz}$ at $1200 \mathrm{~K}$

$50-75 \mathrm{GHz}$ at $1200 \mathrm{~K}$

2.6-4 GHz at $692 \mathrm{~K}$

Electric field strength: 2 dipole antennas, 30-400 \& 300-1000 $\mathrm{MHz}$

Magnetic field strength: $10 \mathrm{~cm}$ 10op antenna, $30 \mathrm{~Hz}-30 \mathrm{MHz}$
Material properties, $1 \mathrm{MHz}-10 \mathrm{GHz}$ :

2 quartz test rods

1 quartz test disk

1 glass test rod

1 glass test disk

Antenna measurement facilities:

15 and $60 \mathrm{~m}$ extrapolation ranges, for gain and polarization, $0.5-75 \mathrm{GHz}$

Near field scanning range, for radiation pattern, polarization, and gain, 1-75 GHz

Automatic network analyzer facility, for power, attenuation, and complex impedance, $100 \mathrm{MHz}-18 \mathrm{GHz}$

C.16. Medical Ultrasonics

Total beam power calorimeter

Set of 5 standard transducers

\section{C.17. Acoustics}

2 WE type 640 AA microphones Acoustic anechoic chamber Acoustic reverberation chamber

\section{C.18. Radiometry and Photometry}

Gold point blackbody (3)

Variable temperature blackbodies

( 1 each, $100-600^{\circ} \mathrm{C}$ and -50 to $100^{\circ} \mathrm{C}$ )

Facility for International Practical Temperature measurements above $1064^{\circ} \mathrm{C}$

Facility for automated spectral calibrations (FASCAL, spectral radiance and spectral irradiance measurements)

Cryogenic blackbody calibration facility

Luminous intensity standard lamps (NBS 839 group - 8 lamps)

Luminous flux standard lamps (NBS 526 group - 5 lamps)

Photodetector characterization facility

Electrically-based radiant power measuring instrument

\section{19. Spectrophotometry}

Reference transmittance spectrometer Directional incidence, hemispherical collector

Retroreflectance reference instrument

Gloss measurement instrument

\section{C.20. Far U1traviolet Radiometry}

Standard sources: Synchrotron radiation (SURF) Plasma blackbody Hydrogen wall-stabilized arc Deuterium lamps (4)

Standard detectors: Windowless photodiodes (5) Windowed diodes (8) Ion chamber 
C.21. Optics

Inverse square bar

Transmission transfer densitometers (2)

Reflection densitometer

Wavefront shearing interferometer

Scanning microdensitometers (4)

C.22. Lasers
C series calorimeter
$\mathrm{Kl}$ series calorimeter
K2 series calorimeter
$Q$ series calorimeter
$B B$ series calorimeter

\section{C.23. Ionizing Radiation}

Free air (3) and cavity (set of 8 ) ionization chambers for $x$-rays and ${ }^{137} \mathrm{Cs},{ }^{60} \mathrm{Co}$

Graphite calorimeters (2) for high energy electrons

Thin-film calorimeter for intense photon fields

Radium-beryllium photo-neutron source

Californium-252 spontaneous fission neutron source

Thermal neutron flux density standard

P-2 ionization chamber for high energy photon fluence

Faraday cage for high energy electron beam current measurement

Monoenergetic neutron beam facility

Cobalt-60 irradiation facility

Cesium-137 irradiation facility

Intermediate-energy standard neutron field (ISNF)

Uranium-235 fission neutron spectrum standard field

Response-energy calibrated ionization chambers and solid state detectors for radioactivity (12)

SUMMATION:

Approximately 2200 items

of 170 different types,

for about 90 different quantities. 
APPENDIX D. NATIONAL STANDARD REFERENCE DATA SYSTEM PUBLICATIONS.

A key-word-in-context technique has been employed in generating the list below, to provide rapid, illustrative access to the substantive content of the publications of the National Standard Reference Data System available in the spring of 1976. To avoid excess length, this list has been abridged from a comprehensive list, by choosing only one entry for each bibliographic item.

The sources of the publications, of use in identifying them on the formal publication lists, are shown in abbreviated form in parenthesis following the permuted title listings. The key to the abbreviations is this:

ASM: American Society for Metals

COM: A translation from the Russian

ICRA: International Copper Research Association

JCPDS: Joint Committee on Powder Diffraction Standards

JPCRD: Journal of Physical \& Chemical Reference Data

JPCRD-S: Supplement to the Journal of Physical \& Chemical Reference Data

Activity Coefficients of Strong Electrolytes in Aqueous Solutions from 0 to $100^{\circ} \mathrm{C}$. Theoretical Mean (NSRDS-NBS 24)

Activity Coefficients of Uniunivalent Electrolytes in Water at $25^{\circ} \mathrm{C}$. Osmotic Coefficients and Mean (JPCRD 15)

Air and Air Components. Thermophysical Properties of (TT70-50095)

Air and Its Components. Thermophysical Properties of Liquid (TT69-55092)

Alcohols. Physical and Thermodynamic Properties of Aliphatic (JPCRD-S1)

Ammonia as an Ideal Gas. Thermodynamic Properties of (NSRDS-NBS 19)

Argon from the Triple Point to $300 \mathrm{~K}$ at Pressures to 1000 Atmospheres. Thermodynamic Properties of (NSRDS-NBS 27)

Astrophysica 1 Interest. Partial Grotrian Diagrams of (NSRDS-NBS 23)

Atmospheric Chemistry. Chemical Kinetic and Photochemical Data for Modelling (NBSTN 866)

Atmospheric Chemistry. Survey of photochemical and Rate Data for Twenty-Eight Reactions of Interest in (JPCRD 27)

Atomic Spectra, Atomic Energy Levels and Multiplet Tables Si II, Si III, Si IV. Selected Tables of (NSRDS-NBS 3, Sec. 1)

Atomic Spectra, Atomic Energy Levels and Multiplet Tables, Si I. Selected Tables of (NSRDS-NBS 3, Sec. 2)

Atomic Spectra, Atomic Energy Levels and Mu1tiplet Tables C I, C II, C III, C IV, C V, C VI. Selected Tables of (NSRDS-NBS 3, Sec. 3)

Atomic Spectra, Atomic Energy Levels and Multiplet Tables, N IV, N V, N VI, N VII. Selected Tables of (NSRDS-NBS 3, Sec. 4)
JR: JILA Report

LBL: Berkeley Particle Data Group, Lawrence Berkeley Laboratory

NBSIR: NBS Internal Report

NBSM: NBS Monograph

NBSTN: NBS Technical Note

NSRDS-NBS: NSRDS-NBS Series

Atomic Spectra, Atomic Energy Levels and Mu1tiplet Tables, N I, N II, N III. Selected Tables of (NSRDS-NBS 3, Sec. 5)

Atomic Spectra, Atomic Energy Levels and Multiplet Tables, H I, D, T. Selected Tables of (NSRDS-NBS 3, Sec. 6)

Atomic Spectra in the Range $15 \AA$ to $25000 \AA$. Reference Wavelengths from (JPCRD 56)

Band Gaps in Elemental and Binary Compound Semiconductors and Insulators. Compilation of Energy (JPCRD 22)

Bimolecular Gas Reactions. Tables of (NSRDSNBS 9)

Binding Energies in Atomic Negative Ions. (JPCRD 68)

Bond Dissociation Energies in Simple Molecules. (NSRDS-NBS 31)

Calcium, A Critical Data Compilation. Atomic Transition Probabilities, Vol. II. Sodium Through (NSRDS-NBS 22)

Carbon Monoxide between 1060 and $1900 \AA$. Atlas of the Observed Absorption Spectrum of (JPCRD 4)

Carbon Monoxide. The Band Spectrum of (NSRDSNBS 5)

Carbonates. High Temperature Properties and Decomposition of Inorganic Salts, Part 2 (NSRDS-NBS 30)

Charge Exchange. Theory of (Wiley)

Collision Cross Sections at Low Energies - A Critical Review. Total Electron-Atom (RMP)

Collision Integrals and Second Virial Coefficients for the $(m, 6,8)$ Intermolecular Potential Function. Tables of (NSRDS-NBS 47)

Combustion Products, Vol. 1, Computation Methods. Thermodynamic and Thermophysical Properties of (TT74-50019) 
Combustion Products, Vol. II, Oxygen-Based Propellants. Thermodynamic and Thermophysical Properties of (TT74-50032)

Combustion Products, Vol. III, Oxygen- and fir-Based Propellants. Thermodynamic and Thermophysical Properties of (TT75-50007)

Cooper and Copper Alloys, Part I. Volume and Surface Self-Diffusion in Copper. Diffusion in (JPCRD 36)

Cooper and Copper Alloys, Part II. CopperSilver and Copper-Gold Systems. Diffusion in (JPCRD 52)

Copoer and Copper Alloys, Part III. Diffusion in Systems Involving Elements of the Groups IA, IIA, IIIB, IVB, VB, VIB, and VIIB. Diffusion in (JPCRD 61)

Copper and Some of Its Binary Alloys. Selected Thermodynamic Values and Phase Diagrams for (ICRA)

Cooper and Its Inorganic Compounds. Thermodymanic Properties of (ICRA)

Cooper. Elastic Properties of Metals and Alloys, II (JPCRD 57)

Critical Points. An Analysis of Coexistence Curve Data for Several Binary Liquid Mixtures Near Their (JPCRD 31)

Critical Region of Magnetic Solids. Analysis of Specific Heat Data in the (JPCRD 18)

Cross Section Data, Part I. Compilation of Low Energy Electron Collision (JR-6)

Cross Section Data, Part II. Compilation of Low Energy Electron Collision (JR-7)

Cross Section Data, Part III: Total Scattering; Differential Elastic Scattering, Low Energy Electron-Collision (AD)

Cross Section Data for Atoms, Atomic Ions, and Diatomic Molecules: I. Experimental Data. Electron Impact Ionization (RMP)

Cross Section Data for Modeling Gas Discharge Lasers. Compilation of Electron Collision (JR-13)

Cross Sections at Low Energies - A Critical Review. Total Electron-Atom Collision (RMP)

Cross Sections. Atomic Form Factors, Incoherent Scattering Functions, and Photon Scattering (JPCRD 67)

Cross Sections, Attenuation Coefficients, and Energy Absorption Coefficients from $10 \mathrm{keV}$ to $100 \mathrm{Gev}$. Photon (NSRDS-NBS 29)

Cross Sections for Molecules of Astrophysical and Aeronomic Interest. Critical Review of Ultraviolet Photoabsorption (NSRDS-NBS 38)

Crystal Data, Determinative Tables, Third Edition, Volume 1. Organic Compounds. (NBS/JCPDS)

Crystal Data, Determinative Tables, Third Edition, Volume 2. Inorganic Compounds. (NBS/JCPDS)

Crystal Structure Transformations in Binary Halides. (NSRDS-NBS 41)

Crystal Structure Transformations in Inorganic Nitrites, Nitrates and Carbonates. (NSRDSNBS 53)
Crystal Structure Transformations in Inorganic Sulfates, Phosphates, Perchlorates, and Chromates (NSRDS-NBS 56)

Dielectric Constant of Inorganic Solids. Compilation of the Static (JPCRD 28)

Diffusion Coefficients. Gaseous (JPCRD 1)

Dipole Moments for Molecules in the Gas Phase. Selected Values of Electric (NSRDS-NBS 10)

Elastic Properties of Metals and Alloys. I. Iron, Nickel, and Iron-Nickel Alloys. (JPCRD 34)

Electric Conductivity of Ferroelectrics. (TT70-50180)

Electrolytic Conductance and Conductances of the Halogen Acids in Water (NSRDS-NBS 33)

Electron Impact on Atoms and Diatomic Molecules. Resonances in (NSRDS-NBS 50)

Electron in Alcohols. Selected Specific Rates of Reactions of the Solvated (NSRDS-NBS 42)

Electron. Selected Specific Rates of Reactions of Transients from Water in Aqueous Solution, I. Hydrated (NSRDS-NBS 43)

Electron, Supplemental Data. Selected Specific Rates of Reactions of Transients from Water in Aqueous Solution. Hydrated (NSRDS-NBS 43, Supplement)

Electron Swarm Data. A Survey of (JPCRD 69)

Electrons in Dielectric Liquids. Drift Mobilities and Conduction Band Energies of Excess (NSRDS-NBS 58)

Energy Levels as Derived from the Analyses of Optical Spectra, Vol. I. ${ }^{1} \mathrm{H}$ to ${ }^{23} \mathrm{Y}$; Vol. II. ${ }^{24} \mathrm{Cr}$ to ${ }^{41} \mathrm{Nb}$; Vol. III. ${ }^{42} \mathrm{Mo}$ to ${ }^{57} \mathrm{La}$, ${ }^{12} \mathrm{Hf}$ to ${ }^{89} \mathrm{AC}$. Atomic (NSRDS=NBS 35)

Ethylene on Metallic Catalysts. Hydrogenation of (NSRDS-NBS 13)

Evaporation and Condensation Coefficients of Simple Substances. Selected Values of (JPCRD 3)

Ferroelectrics. Electric Conductivity of (TT70-50180)

Freon-22. Thermophysical Properties of (TT7050178)

Fundamental Constants. The 1973 Least-Squares Adjustment of the (JPCRD 37)

Hardness Data. Handbook of (TT70-50177)

Heats of Combustion and Heats of Formation of Organic Compounds Containing the Elements $\mathrm{C}, \mathrm{H}, \mathrm{N}, \mathrm{O}, \mathrm{P}$, and $\mathrm{S}$. Selected Values of (JPCRD 6)

Heavy Particle Collisions. Dissociation in (Wiley)

Heavy Particle Collisions. Excitation in (Wiley)

Heavy Water, Thermophysical Properties. (TT7050094)

Helium ("He I). Energy Levels of Neutral (JPCRD 26)

Helium 4 from 2 to $1500 \mathrm{~K}$ at Pressures to $10^{8} \mathrm{~Pa}$. Thermodynamic Properties of (JPCRD 40)

Helium. Thermodynamic and Thermophysical Properties of (TT70-50096) 
High-Pressure Calibration: f Critical Review (JPCRD 55)

High Pressures. Behavior of the Elements at (JPCRD 55)

High Temperature Properties and Decomposition of Inorganic Salts, Part 1. Sulfates (NSRDS-NBS 7)

High Temperature Properties and Decomposition of Inorganic Salts, Part 2. Carbonates (NSRDS-NBS 30)

High Temperature Properties and Decomposition of Inorganic Salts, Part 3. Nitrates and Nitrites (JPCRD 11)

High Temperature Properties and Decomposition of Inorganic Salts, Part 4. Oxy-Salts of the Halogens (JPCRD 51)

Hydrogen Atom. Selected Specific Rates of Reactions of Transients from Water in Aqueous Solution, I I (NSRDS-NBS 51)

H-Atom Transfer in the Liquid Phases: Chlorine Atom, Alkyl, Trichloromethyl, Alkoxy, and Alkylperoxy Radicals. A Critical Review of (JPCRD 58)

Hydrogen. Properties of Liquid and Solid (TT70-50179)

Hydroxyl Radical. A Critical Review of the Gas-Phase Reaction Kinetics of the (JPCRD-6)

Hydroxyl Radical in Aqueous Solutions. Reactivity of the (NSRDS-NBS 46)

Impact Excitation of Atoms. Electron (NSRDS-NBS 25)

Impact Ionization Cross-Section Data for Atoms, Atomic Ions, and Diatomic Molecules: I. Experimental Data. Electron (RMP)

Impact. Theory of the Ionization of Atoms by Electron (RMP)

Index to NSRDS Data Compilations. Property (NSRDS-NBS 55)

Infrared Reference Spectra. Coblentz Society Evaluated; Vol. 6, 1000 Spectra; Vol. 7, 1000 Spectra; Vol. 8, 1000 Spectra; Vol. 9, 1000 Spectra; Vol. 10, 1000 Spectra; Vol. 11, 1000 Spectra; Cumulative Coblentz Indices

Ion-Molecule Reactions (Wiley)

Ionization of Atoms by Electron Impact. Theory of the (RMP)

Ionization Potentials and Ionization Limits Derived from the Analyses of Optical spectra. (NSRDS-NBS 34)

Ionization Potentials, Appearance Potentials and Heats of Formation of Gaseous Positive Ions. (NSRDS-NBS 26)

Ionization Potentials for Lanthanide and Actinide Atoms and Ions. Ground Levels and (JPCRD 54)

Ions. Ionization Potentials, Appearance Potentials and Heats of Formation of Gaseous Positive (NSRDS-NBS 26)

Iron, Fe I through Fe XXVI. Energy Levels of (JPCRD 64)

KiN Interactions - A compilation. (LBL-55)

Methane. Thermophysical Properties of Gaseous and Liquid (TT70-50097)
Microwave Spectra of Molecules of Astrophysical Interest, 1. Formaldehyde, Formamide, and Thioformaldehyde. (JPCRD 14)

Microwave Spectra of Molecules of Astrophysical Interest, II. Methylenimine. (JPCRD 17)

Microwave Spectra of Molecules of Astrophysical Interest, III. Methanol. (JPCRD 23)

Microwave Spectra of Molecules of Astrophysical Interest, IV. Hydrogen Sulfide. (JPCRD 24)

Microwave Spectra of Molecules of Astrophysical Interest, $V$. Water Vapor. (JPCRD 45)

Microwave Spectra of Molecules of Astrophysical Interest, VI. Carbonyl Sulfide and Hydrogen Cyanide. (JPCRD 46)

Microwave Spectra of Molecules of Astrophysical Interest, VII. Carbon Monoxide, Carbon Monosulfide, and Silicon Monoxide. (JPCRD 47)

Microwave Spectra of Molecules of Astrophysical Interest, VIII. Sulfur Monoxide. (JPCRD 48)

Microwave Spectral Tables, Diatomic Molecules. (NBSM70-I)

Microwave Spectral Tables, Line Strengths of Asymmetric Rotors. (NBSM70-II)

Microwave Spectral Tables, Polyatomic Molecules with Internal Rotation. (NBSM70-III)

Microwave Spectral Tables, Polyatomic Molecules without Internal Rotation. (NBSM70-I I I)

Microwave Spectral Tables, Spectral Line Listing (NBSM70-V)

Microwave Spectral Tables I. Diatomic Molecules. (JPCRD 53)

Molecular Energies and Properties. Compendium of ab-initio Calculations of (NBSTN 438)

Molten Salts: Vol. 1. Electrical Conductance, Density, and Viscosity Data. (NSRDS-NBS 15)

Molten Salts: Vol. 2, Section 1. Electrochemistry of Molten Salts: Gibbs Free Energies and Excess Free Energies from EquilibriumType Cells. (NSRDS-NBS 28)

Molten Salts: Vol. 2, Section 2. Surface Tension Data. (NSRDS-NBS 28)

Molten Salts: Volume 3, Nitrates, Nitrites, and Mixtures, Electrical Conductance, Density, Viscosity, and Surface Tension Data. (JPCRD 10)

Molten Salts : Volume 4, Part 1. Fluorides and Mixtures, Electrical Conductance, Density, Viscosity, and Surface Tension Data. (JPCRD 41)

Molten Salts: Volume 4, Part 2. Chlorides and Mixtrues, Electrical Conductance, Density, Viscosity, and Surface Tension Data. (JPCRD 71)

Multiplet Table of Astrophysical Interest, Revised Edition, Part I. Table of Multiplets; Part II. Finding List of All Lines in the Table of Multiplets. A (NSRDS-NBS 40) 
Multiplet Tables, C I, C II, C III, C IV, C V, C VI. Selected Tables of Atomic Spectra, Atomic Energy Levels and (NSRDS-NBS 3, Sec. 3)

Multiplet Tables, H I, D, T. Selected Tables of Atomic Spectra, Atomic Energy Levels and (NSRDS-NBS 3, Sec. 6)

Multiplet Tables, N I, N II, N III. Selected Tables of Atomic Spectra, Atomic Energy Levels and (NSRDS-NBS 3, Sec. 5)

Multiplet Tables, N IV, N V, N VI, N VII. Selected Tables of Atomic Spectra, Atomic Energy Levels and (NSRDS-NBS 3, Sec. 4)

Muliplet Tables, Si I. Selected Tables of Atomic Spectra, Atomic Energy Levels and (NSRDS-NBS 3, Sec. 2)

Multiplet Tables, Si II, Si III, Si IV. Selected Tables of Atomic Spectra, Atomic Energy Levels and (NSRDS-NBS 3, Sec. 1)

National Standard Reference Data System Plan of Operation (NSRDS-NBS 1)

Neon, Argon, and Xenon 136 in the 1.2-4.0 ism Region. First Spectra of (JPCRD 33)

Nitrogen Including Liquid and Vapor Phases from $63 \mathrm{~K}$ to $2000 \mathrm{~K}$ with Pressures to 10,000 Bar. Thermodynamic Properties of (JPCRD 39)

$\overline{N N}$ and $\overline{N D}$ Interation - A Compilation. (LBL-58)

$\overline{N N}$ and $\overline{N D}$ Interactions (above $0.5 \mathrm{GeV} / \mathrm{C}$ ) A Compilation. (UCRL-20000/NN)

Nucleation of Liquids from the Vapor. Selected Values of Critical Supersaturation for (JPCRD 2)

Osmotic Coefficients and Mean Activity Coefficients of Uniunivalent Electrolytes in water at $25^{\circ} \mathrm{C}$. (JPCRD 15)

Oxygen $\left(0^{3} \mathrm{P}\right)$ with Organic Compounds in the Gas Phase. Rate Constants for the Reactions of Atomic (JPCRD 32)

Oxygen Species. Gas Phase Reaction Kinetics of Neutral (NSRDS-NBS 20)

Oxygen. The Spectrum of Molecular (JPCRD 8)

Parahydrogen from the Triple Point to $100 \mathrm{~K}$ at Pressures to 340 Atmospheres. Thermodynamic and Related Properties of (NBSM-94)

Particle Properties. Review of (LBL-100)

$n$-Pentane and Methane-n-Pentane. Phase Behavior in Binary and Multicomponent Systems at Elevated Pressures: (NSRDS-NBS 32)

$\pi N$ Partial-Wave Amplitudes. (UCRL-20030/ $\pi N$ )

$\pi N$ Two-Body Scattering Data I. A User's Guide to the Lovelace-Almehed Data Tape. (LBL-63)

$\pi+p, \pi+n$, and $\pi+d$ Interactions - A Compilation; Parts I and II. (LBL-53)

Radiation Chemistry of Ethanol: A Review of Data on Yields, Reaction Rate Parameters, and Spectral Properties of Transients. (NSRDS-NBS 48)

Radiation Chemistry of Gaseous Ammonia. The (NSRDS-NBS 44)

Radiation Chemistry of Nitrous Oxide Gas. Primary Processes, Elementary Reactions, and Yields. (NSRDS-NBS 45)
Radiation. Yields of Free Ions Formed in Liquids by (NSRDS-NBS 57)

Radiolysis of Methanol: Product Yields, Rate Constants and Spectroscopic Parameters of Intermediates. (NSRDS-NBS 54)

Rate Constants for the Reactions of Atomic Oxygen $\left(0^{3} \mathrm{P}\right)$ with Organic Compounds in the Gas Phase. (JPCRD 32)

Rate Constants for Various Gas Phase Reactions. Evaluated Chemical Kinetic (JPCRD 19)

Rate Constants of Gas Phase Reactions, Reference Book. (COM 72-10014)

Re-entry Flow Fields in the Atmosphere. A Review of Rate Constants of Selected Reactions of Interest in (NBSTN 484)

Rotational Energy Levels and Rotational Line Intensities in Diatomic Molecules. The Calculation of (NBSM-115)

Rotor: Transformation Coefficients from Symmetric to Asymetric Bases and Expectation Values of $P_{Z}^{2}, P_{Z}^{4}, P_{Z}^{6}$. Tables for the Rigid Asymmetric $Z$, $Z$ (NSRDS-NBS 12)

Silicate Systems, Vol. I. Binary Systems, Second Revised Edition. Handbook of Phase Diagrams of (TT71-50040)

Silicate Systems, Vol. II. Metal-0xygen Compounds in Silicate Systems, Second Revised. Handbook of Phase Diagrams of (TT71-500.41)

Space Groups and Lattice Complexes (NBSM-134)

Spectra of Neon, Argon, and Xenon 136 in the 1.2-4.0 $\mu \mathrm{m}$ Region. First (JPCRD 33)

Superconductive Materials. Properties of Selected (NBSTN 724)

Superconductive Materials - 1974 Supplement. Properties of Selected (NBSTN 825)

Surface Ionization. (TT70-50148)

Surface Tension of Pure Liquid Compounds. The (JPCRD 13)

Surfactant Systems. Critical Micelle Concentrations of Aqueous (NSRDS-NBS 36)

Thermal Conductivity of Selected Materials. (NSRDS-NBS 8)

Thermal Conductivity of Selected Materials, Part 2. (NSRDS-NBS 16)

Thermal Conductivity of the Elements. (JPCRD 7)

Thermal Conductivity of the Elements: A Comprehensive Review. (JPCRD-S2)

Thermal Properties of Aqueous Uniunivalent Electrolytes. (NSRDS-NBS 2)

Thermochemical Tables, Second Edition. JANAF (NSRDS-NBS 37)

Thermochemical Tables, 1974 Supplement. JANAF (JPCRD 50)

Thermochemical Tables, 1975 Supplement. JANAF (JPCRD 60)

Thermodynamic and Transport Properties of Ethylene and Propylene. (NBSIR75-763)

Thermodynamic Properties and Isomerization of n-Butane and Isobutane. Ideal Gas (JPCRD 70)

Thermodynamic Properties of Binary Alloys. Selected Values of the (ASM) 
Thermodynamic Properties of Copper, Silver, and Gold from 0 to 300K. Critical Analysis of the Heat-Capacity Data of the Literature and Evaluation of (NSRDS-NBS 18)

Thermodynamic Properties of Eight Chloroand Fluoromethanes. Ideal Gas (JPCRD 42)

Thermodynamic Properties of Ethane and Propane. Idea Gas (JPCRD 30)

Thermodynamic Properties of Ethylene and Propylene. Ideal Gas (JPCRD 62)

Thermodynamic Properties of Geological Substances. Handbook of (TT73-53051)

Thermodynamic Properties of Ruthenium, Rhodiulli, Palladium, Iridium, and Platinum from 0 to 300K. A Survey of the Literature Data on Osmium. Critical Analys is of Heat-Capacity Data and Evaluation of (JPCRD 44)

Thermodynamic Properties of Six Chloroethanes. Ideal Gas (JPCRD 43)

Thermodynamic Properties of Six Fluoroethanes. Ideal Gas (JPCRD 65)

Thermodynamic Properties of the Eight Bromoand Iodomethanes. Ideal Gas (JPCRD 66)

Thermodynamic Properties of the Elements. selected Values of the (ASM)

Thermodynamic Properties, Table for the First Thirty-four Elements in the Standard Order of Arrangement. Selected Values of Chemical (NBSTN 270-3)

Thermodynamic Properties, Tables for Elements 35 through 53 in the Standard Order of Arrangement. Selected Values of Chemical (NBSTN 270-4)

Thermodynamic Properties, Tables for Elements 54 through 61 in the Standard Order of Arrangement. Selected Values of Chemical (NBSTN 270-5)

Thermodynamic Properties, Tables for the Lanthanide (Rare Earth) Elements (Elements 62 through 76 in the Standard Order of Arrangement.) Selected Values of Chemical (NBSTN 270-7)

Thermodynamic Properties, Tables for the Alkaline Earth Elements (Elements 92 through 97 in the Standard Order of Arrangement). Selected values of Chemical (NBSTN 270-6)

Thermophysical Properties of Gases and Liquids, No. I (TT69-55091)

Thermophysical Properties of Matter and Substances, Volume 2. (TT72-52001)

Thermophysical Properties of Matter and Substances, Volume 3. (TT73-52009)

Thernophysical Properties of Matter and Substances, Volume 4. (TT73-52029)

Transition Metal 0xides, Crystal Chemistry, Phase Transition, and Related Aspects. (NSRDS-NBS 49)

Transition Probabilities for Ba I and II. Critically Evaluated (NBSTN 474)

Transition Probabilities for Forbidden Lines of the Iron Group Elements. (A Critical Data Compilation for Selected Lines.) Atomic (JPCRD 20)
Transition Probabilities for Scandium and Titanium (A Critical Data Compilation of Allowed Lines). Atomic (JPCRD 63)

Transition Probabilities, Vol. I, Hydrogen Through Neon. Atomic (NSRDS-NBS 4)

Transition Probabilities, Vol. II, Sodium Through Calcium, A Critical Data Compilation. Atomic (NSRDS-NBS 22)

Unimolecular Reactions. Kinetic Data on Gas Phase (NSRDS-NBS 21)

Vibrational Data of Atomic and Molecular Ions Doped in Alkali Halide Crystals. Electronic Absorption and Internal and External (NSRDS-NBS 52)

Vibrational Frequencies, Consolidated Volume I. Tables of Molecular (NSRDS-NBS 39)

Vibrational Frequencies, Part 5. Tables of Molecular (JPCRD 5)

Vibrational Frequencies, Part 6. Tables of Molecular (JPCRD 21)

Vibrational Frequencies, Part 7. Tables of Molecular (JPCRD 25)

Vibrational Frequencies, Part 8. Tables of Molecular (JPCRD 49)

Viscosity and Thermal Conductivity Coefficients for Dense Gaseous and Liquid Argon, Krypton, Xenon, Nitrogen and 0xygen. The (JPCRD 59)

Viscosity and Thermal Conductivity Coefficients of Dilute Argon, Krypton, and Xenon. The (JPCRD 35)

Viscosity and Thermal Conductivity Coefficients of Dilute Nitrogen and Oxygen. The (JPCRD 38)

Viscosity and Thermal Conductivity Coefficients of Gaseous and Liquid Fluorine. The (JPCRD 16)

$X$-Ray Emission Spectra of Metallic Solids: Critical Review of Selected Systems. Soft (JPCRD 29)

$X$-Ray Wavelengths and X-Ray Atomic Energy Leve1s (NSRDS-NBS 14)

YN Reactions. A Compilation of (UCRL-20000/YN) 
Acoustical \& Board Products Association Acoustical Society of America

Adhesive \& Sealant Council

Air-Conditioning \& Refrigeration Institute

Air Diffusion Council

Air Moving \& Conditioning Association, Inc.

Air Pollution Control Association

Air Transport Association of America

Alumina Ceramic Manufacturers Association

The Aluminum Association

American Alliance for Health, Physical

Education \& Recreation

American Academy of Pediatrics

American Association of Advertising Agencies

American Association of Cereal Chemists

American Association of Hides, Skins and

Leather Merchants

American Association of Medical Milk

Commissions, Inc.

American Association of Petroleum Geologists

American Association of Poison Control Centers

American Association of State Highway and

Transportation Officials

American Association of Textile Chemists and

Colorists

American Bankers Association

American Bleached Shellac Manufacturers

Association

American Boat \& Yacht Council, Inc.

American Boiler Manufacturers Association

American Bottled Water Association

American Bureau of Shipping

American Chemical Society

American Concrete Institute

American Concrete Paving Association

American Conference of Governmental

Industrial Hygienists

American Congress on Surveying and Mapping

American Crystallographic Association

American Dehydrators Association

American Dental Association

American Die Casting Institute, Inc.

American Dry Milk Institute, Inc.

American Feed Manufacturers Association, Inc.

American Fishing Tackle Manufacturers

Association

American Foundrymen's Society, Inc.

American Gas Association

American Gear Manufacturers Association

American Gem Society

American Gum Importers Laboratories, Inc.

American Home Lighting Institute

American Industrial Hygiene Association

American Institute of Architects

American Institute of Baking

American Institute of Chemical Engineers

American Institute of Steel Construction, Inc.

American Institute of Timber Construction
American Insurance Association

American Iron \& Steel Institute

American Ladder Institute

American Leather Chemists Association

American Library Association

American National Standards Institute, Inc.

American Nuclear Society

American 0il Chemists' Society

American Paper Institute

American Petroleum Institute

American Pharmaceutical Association

American Plywood Association

American Public Health Association, Inc.

American Public Works Association

American Railway Engineering Association

American Society for Nondestructive Testing

American Society for Quality Control

American Society for Testing \& Materials

American Society of Agricultural Engineers

American Society of Brewing Chemists

American Society of Cinematographers

American Society of Electroplated Plastics

American Society of Enologists

American Society of Heating, Refrigeration \& Airconditioning Engineers

American Society of Lubrication Engineers

American Society of Mechanical Engineers

American Society of Photogrammetry

American Society of Safety Engineers

American Society of Sanitary Engineering

American Sod Producers Association

American Speech \& Hearing Association

American Spice Trade Association

American Stone Importers Association

American Textile Machinery Association

American Textile Manufacturers Institute, Inc.

American Trucking Associations, Inc.

American Vacuum Society, Inc.

American Water Works Association, Inc.

American Wax Importers and Refiners

Association, Inc.

American Welding Society, Inc.

American Wood-Preservers' Association

American Wood Preservers Bureau

Anti-Friction Bearing Manufacturers Association, Inc.

Archery Manufacturers Organization

Architectural Aluminum Manufacturers

Association

Architectural Woodwork Institute

Asbestos Textile Institute

Asphalt Emulsion Manufacturers Association

Asphalt Roofing Manufacturers Association

Associated Air Balance Council

Associated Cooperage Industries of America, Inc.

Associated General Contractors of America

Associated Locksmiths of America, Inc. 
Associated Master Barbers and Beauticians of Allerica

Association for the Advancement of Medical Instrumentation

Association of American Feed Control

officials, Inc.

Association of American Railroads

Association of Bedding and Furniture Law Officials

Association of Edison Illuminating Companies Association of Home Appliance Manufacturers Association of Iron \& Steel Engineers Association of Official Analytical Chemists Association of Official Seed Analysts Association of Petroleum Re-Refiners

Audio Engineering Society, Inc.

Baking Industry Sanitation Stds. Committee

Barley and Malt Institute

Barre Granite Association

Battery Council Internationa 1

Bicycle Manufacturers Association of America

Billiar Congress of America

Biological Stain Commission

Book Manufacturers' Institute

Brass and Bronze Ingot Institute

Brick Institute of America

Builders Hardware Manufacturers Association

Building Officials \& Code Administrators, Inc.

Building Owners \& Managers Association International

Cal ifornia Redwood Association

Can Manufacturers Institute

Canvas Products Association, International

Cast Bronze Bearing Institute

Cast Iron Soil Pipe Institute

Caster \& Floor Truck Manufacturers Association

Ceilings \& Interior Systems Contractors Association

Cemented Carbide Producers Association

Chain Link Fence Manufacturers Institute

Chemical Specialities Manufacturers Association

Chlorine Institute, Inc.

Coffee Brewing Center

Commercial Refrigerator Manufacturers Association

Composite Can \& Tube Institute

Compressed Air \& Gas Institute

Compressed Gas Association, Inc.

Concrete Reinforcing Steel Institute

Construction Industry Manufacturers Association

Construction Specifications Insitute

Contractors Pump Bureau

Conveyor Equipment Manufacturers Association

Cooling Tower Institute

Cooper Development Association

Cordage Institute

Corn Refiners Association

Cosmetic, Toiletry \& Fragrance Association, Inc.

Crane Manufacturers Assoc. of America, Inc.
Cultured Marble Institute

Dairy \& Food Industries Supply Association, Inc.

Diamond Core Dri11 Manufacturers Association

Diaper Service Accreditation Council

Diesel Engine Manufacturers Association

Door \& Hardware Institute

Door Operator \& Remote Control Manufacturers Association

Dry Color Manufacturers Association

Edison Electric Institute

Electrical Apparatus Service Association, Inc.

Electronic Industries Association

Entomological Society of America

Essential 0il Association of the USA, Inc.

Expanded Shale, Clay, \& Slate Institute

Expansion Anchor Manufacturers Institute

Expansion Joint Manufacturers Association

Facing Tile Institute

Factory Mutual System

The Fertilizer Institute

Fibre Box Association

Fir and Hemlock Door Association

Flat Glass Marketing Association

Flax Development Committee

Floor \& Vacuum Machinery Manufacturers Association

Fluid Controls Institute, Inc.

Forging Industry Association

Gas Processors Association

General Aviation Manufacturers Association

Glass Tempering Association

Gravure Technical Association, Inc.

Grocery Manufacturers of America, Inc.

Gummed Industries Association

Gypsum Association

Gypsum Roof Deck Foundation

Hardwood Dimension Manufacturers Association

Hardwood Plywood Manufacturers Association

Hearing Aid Industry Conference, Inc.

Heat Exchange Institute

Helical Washer Institute

Hoist Manufacturers Institute

Home Ventilating Institute

Hydraulic Institute

Hydronics Institute

Illuminating Engineering Society

Indiana Limestone Institute of America, Inc.

Industrial Fasteners Institute

Industrial Silencer Manufacturers Association

Industrial Gas Cleaning Institute, Inc.

Industrial Perforators Association

Industrial Truck Association

Institute of Electrical and Electronics

Engineers, Inc.

Institute of Environmental Sciences

Institute of High Fidelity, Inc.

Institute of Makers of Explosives

Institute of Printed Circuits

Institute of Scrap Iron \& Steel, Inc.

Institute of Traffic Engineers

Instrument Society of America

Insulated Power Cable Engineers Association 
International Air Transport Association

International Association of Plumbing and Mechanical Officials

International Association of Wall and Ceiling Contractors

International Commission on Radiation Units and Measurements

International Conference of Building Officials

International Fabricare Institute

International Mobile Air Conditioning Association, Inc.

International Municipal Signal Association

International Nonwovens and Disposables Association

International Society for Terrain-Vehicle Systems, Inc.

Investment Casting Institute

Joint Industrial Council

Juvenile Products Manufacturers Assoc., Inc. Laundry \& Cleaners Allied Trade Association

Lead Industries Association

Library Binding Institute

Linen Supply Association of America

Magnetic Materials Producers Association

Manufactured Housing Institute

Manufacturers Standardization Society of the

Valve \& Fittings Industry

Manufacturing Chemists' Association

Maple Flooring Manufacturers Association

Marking Device Association

Material Handling Institute

Mechanical Power Transmission Association

Metal Building Manufacturers Association

Metal Cookware Manufacturers Association

Metal Ladder Manufacturers Association

Metal Lath Association

Metal Powder Industries Federation

Metal Tube Packaging Council of North America

Mi11 Mutual Fire Prevention Bureau

Monorajl Manufacturers Association

Mo-Sa $i$ Institute

MTM Association for Standards \& Research

Narrow Fabrics Institute

National Accreditation Council for Agencies

Serving the Blind \& Visually Handicapped

National Agricultural Chemicals Association

National Association of Architectural

Metal Manufacturers

National Association of Broadcasters

National Association of Chain Manufacturers

National Association of Corrosion Engineers

National Association of Food Chains

National Association of Furniture

Manufacturers, Inc.

National Association of Glue Mfrs., Inc.

National Association of Hosiery Manufacturers

National Association of Insect Electrocutor

Manufacturers

National Association of Metal Name Plate

Manufacturers

National Association of Pattern Manufacturers

National Association of Pipe Coating

Applicators
National Association of Plastic Fabricators

National Association of Plumbing-Heating-

Cooling Contractors

National Association of Recyling Industries, Inc.

National Association of Relay Manufacturers

National Association of Rocketry

National Association of Store Fixture Mfrs.

National Association of Wiping Cloth Mfrs.

National Audio-Visual Association

National Automatic Merchandising Association

National Barrel and Drum Association

National Board of Boiler \& Pressure Vessel Inspectors

National Building Granite Quarries

Association, Inc.

National Cable Television Association

National Cargo Bureau, Inc.

National Clay Pipe Institute

National Coil Coaters Association

National Committee for Clinical Laboratory Standards

National Concrete Masonry Association

National Cottonseed Products Association

National Council on Radiation Protection \&

Measurements

National Crushed Stone Association

National Education Association

National Electrical Contractors Assoc., Inc.

National Electrical Manufacturers Association

National Elevator Industry

National Environmental Systems Contractors Association

National Fertilizer Solutions Association

National Fire Protection Association

National Flexible Packaging Association

National Fluid Power Association

National Forest Products Association

National Hardwood Lumber Association

National Industrial Leather Association

National Institute of $0 i 1$ seed Products

National Knitted Outerwear Association

National Lime Association

National Lubricating Grease Institute

National Machine Tool Builders Association

National Micrographics Association

National Model Railroad Association, Inc.

National Oak Flooring Mfrs. Association, Inc.

National Operating Committee for Standards

in Athletic Equipment

National Paper Box Association

National Particleboard Association

National Pest Control Association

National Printing Ink Research Institute

National Ready Mixed Concrete Association

National Retail Merchants Association

National Rifle Association of America

National Roofing Contractors Association

National Sanitation Foundation

National School Supply \& Equipment Association

National Silo Association

National Soft Drink Association

National Solid Wastes Management Association 
National Soybean Processors Association National Standards Association National Swimming Pool Institute National Terrazzo \& Mosaic Association, Inc. National Wholesale Hardware Association National Pallet \& Container Association National Woodwork Manufacturers Association Northeastern Lumber Manufacturers Assn., Inc. Northern Hardwood \& Pine Mfrs. Assn., Inc. Northern Textile Association Optical Manufacturers Association, Inc. Packaging Institute, Inc.

Paper Converters Association Paperboard Packaging Council Perlite Institute, Inc.

Photographic Society of America

Pipe Fabrication Institute

Plastics Pipe Institute

Plumbing \& Drainage Institute

Porcelain Enamel Institute, Inc.

Portland Cement Association

Power Saw Manufacturers Association

Pressure Sensitive Tape Council

Prestressed Concrete Institute

Pulverized Limestone Association

Rack Manufacturers' Institute

Radio Technical Commission for Aeronautics

Railway Tie Association

Recording Industry Association of America, Inc Red Cedar Shingle \& Handsplit Shake Bureau

Redwood Inspection Service

The Refractories Institute

Resilient Floor Covering Institute

Resistance Welder Manufacturers' Association

Rubber Manufacturers Association

Rubber Reclaimers Association, Inc.

Salt Institute

Scaffolding \& Shoring Institute

Scale Manufacturers Association

Scientific Apparatus Makers Association

Screen Manufacturers Association

Sealed Insulating Glass Manufacturers Assn.

Sheet Metal \& Air Conditioning Contractors National Association, Inc.

Snowmobile Safety \& Certification Committee

Society for Technical Communication

Society of Automotive Engineers, Inc.

Society of Die Casting Engineers, Inc.

Society of Motion Pictures \& Television

Engineers

Society of Naval Architects \& Marine

Engineers

Society of the Plastics Industry, Inc.

Southern Building Code Congress International

Southern Cypress Manufacturers Association

Southern Forest Products Association

Southern Pine Inspection Bureau

Speciality Equipment Manufacturers Assoc.

Specialty Wire Association

Spring Manufacturers Institute

Sprinkler Irrigation Association

Stained Glass Association of America

Steel Bar Mills Association
Steel Deck Institute

Steel Door Institute

Steel Founders' Society of America

Steel Joist Institute

Steel Structures Painting Council

Steel Tank Institute

Steel Window Institute

Stucco Manufacturers Association

Sump Pump Manufacturers Association

Technical Association of the Pulp \& Paper Industry

Test Boring Association, Inc.

Tile Council of America

Tire \& Rim Association, Inc.

Tire Retreading Institute

Truck Body \& Equipment Association

Truck Trailer Manufacturers Association

Truss Plate Institute, Inc.

Tubular Exchanger Manufacturers Assn., Inc.

Ultrasonic Industry Association, Inc.

Underwriters' Laboratories, Inc.

U. S. Department of Commerce

U. S. Golf Association

United States Pharmacopeial Convention, Inc.

U. S. Tennis Court \& Track Builders Assn.

Vacuum Cleaner Manufacturers Association

Vacuum Wood Preservers Institute

Variable Resistive Components Insitute

Vehicle Equipment Safety Commission

Water Pollution Control Federation

Water Quality Association

Water Systems Council

Welded Steel Tube Institute

West Coast Lumber Inspection Bureau

Western Wood Moulding \& Millwork Producers

Western Wood Products Association

Wire Reinforcement Institute

Wood \& Synthetic Flooring Institute of America Wooden Box Institute

Woodworking Machinery Manufacturers of America Writing Instrument Manufacturers Assn., Inc. Zinc Institute 
APPENDIX F. STATE AND LOCAL WEIGHTS AND MEASURES ACTIVITY SUMMARY (EXCERPTS), 1974-1975 [256]

Arkansas.

A two-montin study program was conducted with moisture meters at public grain elevators beginning iovember 1, 1974. After extensive field work the following conditions were found: outdated charts, poor environmental conditions, inaccurate weighing devices (approximately 90 percent were adjusted), and failure to use temperature corrections. All of the preceding are detrimental to correct and accurate moisture determination. Therefore, in addition to moisture meters, charts, operating procedures, and scales are checked. Scales were adjusted when official testing began January 3, 1975.

\section{Colorado.}

We initiated and implemented testing of tuning forks used witn the Doppler radar gun for traffic speed control. Mr. David Allan, Time and Frequency Division, NBS-Boulder, Colorado, gave us expert advice in procedure testing. The basic principle of operation of these guns is tnat the radar signal reflected from a moving vehicle is shifted in frequency by an amount directly proportional to the speed of the venicle relative to the radar gun. We nave tested all of the Colorado Hignway Patrol equipment and equipment in several of our larger cities.

iBS-Boulder recommended an equipment configuration that would be relatively easy to set up, operate, and reassemble (also inexpensive at $\$ 400$ to $\$ 500)$; yet, with sufficient accuracy, it is traceable to the primary frequency referenced and operated by iBS-Boulder. You may readily see assistance in court cases when tuning forks are certified

\section{Florida.}

This nas been a dig year for our computerized nonfood package inspection program. Selective testing of these types of packages has revealed some rather large scale shortages in certain areas. Our inspections indicated over one-half million pounds of charcoal had been snipped into Florida that was short weignt, mucn of it oy more than 10 percent. We also found large quantities of antifreeze/engine coolant to be snort measure. These products were withheld from sale and required to De returned to the packagers. Tney were tnen replaced by the packagers on a one-for-one basis with packages inspected at our metrology laboratory in Tallahassee before distribution. This operation turned out to be very costly for the packagers and very time consuming for our Bureau of Weights and Measures personnel. Our packages inspection program always receives good coverage in the press; and because of the amounts involved, more than usual prominence was given to stories about these two items in all news media.

Our taximeter testing program, which we started several years ago, has proven very effective. The majority of taxi companies now maintain their meters in reasonably good condition, and we find few serious violations. We now have accurately laid out test courses for checking these meters in all major cities of Florida which have taxi fleets. Our testing of odometers on rental cars and trucks is also quite effective, although we occasionally find a new model whose odometer is grossly out of tolerance, apparently because of being equipped with improper gears. We have recently had to reject more than 80 percent of two models tested of a popular brand of rental car for overregistration....

As chairman of the ilational Conference on Weignts and Measures this year, over one hundred presentations on the metric system were made in Florida, as well as other states. These include appearances before professional and technical societies, civic clubs, women's organizations, scnool groups, as well as newspaper interviews, television shows and discussions with members of Congress. It is our sincere hope that the 94 th Congress will enact metric legislation committing this country to planned voluntary conversion programs. Weights and measures officials will have a large responsibility in providing an orderly transition in the marketplace from the customary system of measurement to the metric system. We can play a major part in helping to educate the consuming public to understand this system and appreciate the value of making the conversion.

\section{Georgia.}

A neavy count of non-consumer goods has been getting "stop sale" flags and the commodities have been returned to the processors--particularly because of short weight or short fill. Items include salt blocks, feeds, fertilizers, seeds, pesti- 
cides, detergents for sprays, and packaged nails. Some items involved package counts of several thousand bags or boxes. A review of pachaging systems has been instituted on tnese and other itemis of conmerce to help keep packaging problems to a minimum.

Indiana.

We are pleased also with the success of our iloisture Testing Device Program. Approximately 1,000 devices have been inspected this past year. Of this number, approximately 10 percent have been condenined.

During the past summer, a special project of testing gasoline pump meters was initiated witn the employment of three college students. This program was found to be very significant due to tine number of pumps that had not been tested for several years and were found to be ill a deplorable state. The special project nas Degun again this spring with the use of four CETA employees the Division has employed to continue the testing of gasoline pump meters.

Kansas.

In public relations activities, our annydrous aminonia safety program took on new aspects. Stress was put on an educational program for dealers, farmers, and transport trucking industries in regard to the two hazardous products of propane and anhydrous aminonia. The anhydrous ammonia program which we innerited in 1968 now takes over half of the office time of the Division along with the increasea night educational programs and daily inspections and complaints.

The Uivisioll has had more court cases involving weights and measures personnel and the laboratory this past year. Short weight packaging cases were won on the ability of the inspectors to prove equipment and test weights and measures were accurate. Field men had to prove their ability and background in training for the work. A presentation of certificates, as provided by the Office of Weights and Measures, National Bureau of Standards, showing proof of training was necessary. Traceability was the major factor in completing one of the highway overload cases in McPherson County, Kansas.

\section{ilas sachusetts.}

Current legislation being considered will give the Division of Standards and municipal weights and measures officials the authority to examine and test the operation of automated electronic retail checkout systems.
Such authority will extend to systems whether there is a scale involved or not. Legislative concern was directed to the fact that there should be a monitoring agency to make inspections from time to time to determine whether the advertised or posted price was in agreement with that programmed in the computerized checkout system. This legislation will provide the necessary authority for weights and measures officials to make such inspections.

The Division of Standards is in the process of acquiring a new combination motor-method and research-method octane machine to be utilized in the enforcement of statutes relating to the Motor Fuel Sales Act. This new unit will replace a research-method unit which has been used for many years and must necessarily be retired.

Missouri.

New program emphasis has been given to the bait-and-switch operation. Legal action has been taken against six operations, resulting in four being closed. Fine cooperation has existed between the Weights and Measures Division and the Attorney General's Office.

An additional change in program emphasis is taking place on a joint effort basis between the Division of Water Safety and the Weights and Measures Division. All marinas on our lakes are being inspected on accuracy of the petroleum dispensers and inspection of petroleum in storage tanks. We will completely inspect some 572 marinas during May, June, July, August, and September 1975.

\section{Nebraska.}

There are two problems that stand out as challenges for the Division. One is the problem of high-shrink packaged products. A great deal of time is being spent on research of these various products with cooperation from the industries involved. The second challenge is in the area of uniformity between our neighboring states . The more involved a state becomes in the weights and measures field, the more obvious it is that we must work together to eliminate a problem existing in our State which may also be existing in a neighboring state or any other state in the nation. This is a difficult task due to the different laws and regulations in each state. 
New Jersey.

Investigations of complaints involving faulty water meters disclosed that thousands of utility-type water and electric meters are under our weights and measures jurisdiction. Data is being compiled as to the total number of meters, types, and sizes so that a test program can be formulated.

Initial type approval tests conducted on four manufacturers' parking meters have not yet been completed, pending manufacturing changes and the possibility of code changes to be considered at the 60th National Conference on Weights and Measures.

The investigation of one complaint uncovered large scale short measure deliveries of gasoline to schools, municipal garages, and police departments. This was accomplished by the drivers riding with the tickets in the meters and charging for the last drop for the total deliveries. Two men are facing criminal action in addition to 31 weights and measures violations.

The lumber enforcement section has uncovered a scheme where at least four lumber dealers were substituting southern yellow pine for other designated species, resulting in overcharges of at least 10 percent. There is nothing inherently wrong with yellow pine; however, it is a much cheaper product.

There are at least three current investigations being conducted with federal and state investigative agencies involving short measure deliveries on contracts of federallyfunded programs, one of which is a school lunch program.

New Mexico.

A concerted effort was made this past winter to test all construction material hopper scales in the State. As with all new programs, there was some resistance; but most of the ready-mix concrete, sand, and gravel dealers welcomed our inspection. Rejections ran as high as 50 percent on first inspection in some areas of the State. Major problems involved maintenance of equipment. Most objections raised were on the supposedly restrictive tolerances applied to sand and gravel scales.

Jewelers' scales represent another area of increased activity. These scales, at trading posts as well as jewelry stores, are used to buy and sell turquoise, silver, gold, and otner materials used to make handmade jewelry. Rejection rates were very low for these balances and scales compared to other types of weighing devices.

Package checking activities were extended to two new areas: large packages, such as pet foods, livestock feed, and garden supplies; and petroleum products, especially motor oil. The initial round on large packages uncovered many violations in short fill and labeling. Subsequent inspections found many of these problems corrected. Short fill on motor oil was often found, but not consistently. In other words, quantity control seems to be an area of managerial concern in some firms but not in others.

Virginia.

OUTSTANDING COURT CASES: Top management of a tobacco warehouse in southwest Virginia was found guilty of improper record keeping and for taking more tobacco than represented. Each party was fined $\$ 113.75$ and ordered to pay six farmers for the 145 lbs of tobacco they were shortweighted. Similar charges against the weigher are still pending, but cannot be heard since the defendant is in jail in another state.

A court case against a Richmond beef company was terminated in Virginia's favor when the judge ordered forfeiture of the $\$ 300$ bond and issued an attachment for the manager's arrest.

Top management of a large supermarket chain was convicted and fined $\$ 1,000$ plus $\$ 6.25$ court costs on one charge and was fined $\$ 1,000$ for each of six additional charges. However, the charges were suspended for one year, providing no further violations are found.

A warrant was issued against a service station manager for pouring water into antifreeze. Laboratory tests indicated that the antifreeze being sold by this station contained approximately 33 percent water. The judge found the defendant guilty and fined him $\$ 25$ plus $\$ 6.25$ court costs.

OTHER HIGHLIGHTS: Since Virginia discontinued calibrating vehicle compartments, we have encouraged industries to provide the necessary facilities for performing this service. During the past year another company began calibrating tank compartments. This makes three private businesses now in Virginia that are performing tank calibrations according to the requirements as set forth in National Bureau of Standards 
Handbook 44. We train personnel performing these calibrations and make spot checks to determine if they are following recognized methods as well as performing accurate calibrations.

WURLD'S LARGEST SUBMARINE SANDWICH: On Sunday, March 16, 1975, Inspector G. W. Diggs certified the world's largest submarine sandwich. The sandwich, made by the University of Ricnmond's Student Union, was 796 feet long and weighed 1,370 pounds. The certification was necessary for recognition in the "Guiness Book of World Records."

Wasninyton.

Jur participation in the third Tri-State Weignts and Measures Training Seminar was the niginlight of our training efforts this year. The seminar, with Lyman Holloway of Idaho as nost and Richard W. Smitil of the National Bureau of Standards as training officer, was a very positive meeting. Representatives of area scale firms provided the technical aspect of the day devoted to weighing devices. John Larsen, president of Petroleum Dynamics, Inc. of Los Angeles, provided the technical aspect in the measuring field. Harry Couden from the Oakland office of Safeway gave us a comprenensive overview on prepackaging. It is anticipated that we will make this venture an annual event with an attempt to establish the tnird week in March each year as our meeting date.

One of the interesting surveys in which we participated was that covering cedar shingle and shake products which is a rather extensive industry in our area. We found that the shingle aspect of the industry seemed to be wel1 organized, well supervised, and basically witnout problems. The shake industry, however, was fraught with problems to the point tnat the industry welcomed our activities in cneckmeasuring and inspection at the shake filil level. Our survey resulted in a definite improvement in quality and quantity, as well as serving as a stimulus for better inspection on the part of the inspector serving under the auspices of the industry.

\section{Wisconsin.}

The third year of the LP-vapor meter program indicates a significant increase in compliance. The larger companies have obtained test equipment to begin their own test program, while others have undertaken extensive replacement of meters. Test meters are adjusted in the laboratory and a complete training session is given to company personnel on tne proper testing and adjusting of meters.
The successful prosecution of an LP-gas company has strengthened this enforcenient prograin.

\section{Ventura County, California.}

VARIABLE FREQUENCY OF INSPECTION: This program, reported on at the 1973 National Conference on Weights and Measures, is now in full operation. We now have only 5 inspectors checking devices compared to 7 before. Next year will see us reduce this by 1 more. We have not experienced any decline in devices found out of compliance with the less frequent inspection.

COMPLAINTS: Weights and measures complaints are running 17 percent ahead of last year. In the past 5 years complaints have increased by about 200 percent. This dramatic increase is due to newspaper publicity and our educational programs. More consumers are becoming aware of the Department and the help it can give. Also, consumers today are tired of many fraudulent practices in the marketplace, service stations, and other stores and are quicker to file a complaint. Complaints received by the Consumer Affairs Division are showing the opposite trend and are down 9 percent from last year, which is also due to newspaper publicity and our educational programs. Consumers know how to handle their complaints now and are more knowledgeable in avoiding problem areas. Dollar savings are 36 percent ahead of last year and over $\$ 75,000$ has been returned to consumers since the Division's inception.

Washtenaw County, Michigan.

During this past year, this Department has instituted ten cases in the courts. Of these cases only two resulted in guilty pleas, proving that nothing comes easy any more. One case against a corporation for false advertising has been resolved in a court judgment of guilty. Another case against an oil company for possession and operation of an illegal device has also resulted in a judgment of guilty.

Four cases are still not resolved by the courts. Two are felonies, one in which the president of a small meat processing corporation jumped a $\$ 2,000$ bond and headed west. When efforts to reach him in Bakersfield, California, failed, it was learned that he went to Mexico. One unfinished case concerns the failure of a coin operated car wash to post a sign for the return of money when equipment fails to operate. This case has caused some confusion in the process as it 
invokes Handbook 44 and $i$ ts tie-in with the Michigan law. The judge, at first, was under the impression that this was a federal regulation formulated by federal bureaucrats who had sprung it on the unsuspecting and uninformed business community. He was ready to dismiss the case on advice of defense counsel when we were able to convince him that his suspicions were wrong and that the National Conference on Weights and Measures is, in fact, a wholly democratic commitment by state and local officials.

\section{Birmingham, Al abama}

We are now keeping a percentage record of package condemnations in all our prepack stores. This enables us to concentrate on the stores with the highest percentage records with follow-up inspections. To date, this procedure has worked very well. This enables us to keep our Division inspectors in the area where they are most needed. We are also trying this method of inspection in the testing of motor fuel dispensers.

Dallas, Texas.

The second program involves a new test purchasing program; purchasing advertised products from the retail food stores, with the stores' main offices then buying the products back. We feel this is a very unique program in that we have the full cooperation and backing of the food industry. We agreed with management that we would give the stores the first opportunity to correct any discrepancies we mignt uncover. If they failed to correct the discrepancy, then we would take the necessary steps to insure compliance under the law. Under this program we can purchase any item advertised through any media at any time. We then record the findings as to overcnarges, items not available although advertised, misleading price tags, etc. At the end of the day we return all purchased items to a central location and receive our reimbursement. The management is contacted and the results are discussed. Since the inception of this program we have cut down the complaints of overcharging at the checkout counters, misrepresenting prices, and advertising products that are unavailable.
Philadelphia, Pennsylvania.

NEWSWORTHY ITEMS: The Indiana State Department of Weights and Measures shares some billing in this unusual matter of short measure in a liquid commodity sold to certain members of a profession. The investigation confirmed the complaint for the 16-fluid ounce product; it was found to have shortages from $1 / 8$ to $1 / 4$ fluid ounce! Thus, the users of the commodity could not really give the recipient a full measure of ... embalming fluid. 
This section charts the various calibration capabilities of members and other participating standards laboratories. The information for this section has been transcribed from the questionnaires received from the participating laboratories through February 1976 and should not be construed as an endorsement or rating of the individual laboratories by either THE NATIONAL CONFERENCE OF STANDARDS LABORATORIES (NCSL), or THE NATIONAL BUREAU OF STANDARDS (NBS).

The laboratories are listed in zip code order.

Availability of calibration services is indicated by $(0)$ when limited to parent organization only, $(F)$ when calibration is generally available on a fee basis, and (N) indicates calibration on a no-fee basis (the latter group consists of some State Weights and Measures Laboratories). In the first column, the asterisk (*) indicates that the laboratory is a member of NCSL.

\section{PRIVATE LABORATORIES}

O SERVICE TO PARENT ORGANIZATION ONLY

F CALIBRATION SERVICES AVAILABLE ON A FEE basis

N CALIBRATION SERVICES AVAILABLE ON A NO FEE BASIS

\begin{tabular}{|c|}
\hline LABORATORIES \\
\hline $\begin{array}{l}\text { *EELL NCFTHEAN RESEARCH } \\
\text { * } \text { EENES ELECTRCNICS LIMITEO } \\
\text { \#INSTITUTF TAO FOR NECH. CCNSTR } \\
\text { * CENEFAL ELECTPIC CORRANY } \\
\text { * CENERAL RADIC CCMPANY }\end{array}$ \\
\hline $\begin{array}{l}\text { *FAYTHECN CCNFANY } \\
\text { FCA } \\
\text { NANCIB CC. } \\
\text { HCAEYWELL INC. } \\
\text { * NICRCWAVE ASSCCIATES. INC. }\end{array}$ \\
\hline $\begin{array}{l}\text { \#GAYTRECA CCNPANY } \\
\text { \#LAIV. CF LOWELL RESEARCH FOUNO } \\
\text { TRANSITRCA ELECTFONIC CCFP. } \\
\text { \#AVCC COFP. } \\
\text { \#FCXBCRC CO. }\end{array}$ \\
\hline $\begin{array}{l}\text { FAYTHECA CCN } \\
\text { \&TCNE + WEESTER ENGINEERING CO } \\
\text { CHAFLES STAFK CPAPER LABCRATOR } \\
\text { FAYTHECA CCNFANY } \\
\text { HEWLETT RACKAPO CC. }\end{array}$ \\
\hline $\begin{array}{l}\text { CENERAL CYNAMICS CCPPOFATION } \\
\text { ITEY CCFF. } \\
\text { EFPLEY LAECFATCRY. INC. } \\
\text { *FAYTHECA CCNFANY } \\
\text { KCLLSMAR INST. CC. }\end{array}$ \\
\hline 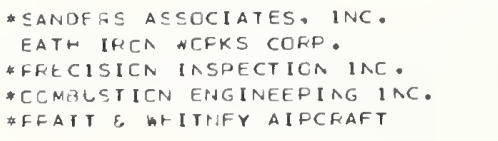 \\
\hline $\begin{array}{l}\text { \#CFNEFAL CYNAMICS CCFFCRATION } \\
\text { *NCCHE SPFCIAL TCCL CO.. INC. } \\
\text { *FEFHIA FLMEF CCFP. } \\
\text { HAKFEL, INC. } \\
\text { \#INCAL SEFVICE CCEP. }\end{array}$ \\
\hline
\end{tabular}

ZIP

01201
01742
01778
01801
01803
01803
01803
01810
01854
01880
01887
02035
02062
02107
02139
02154
02154
02169
02173
02840
02871
03053
03060
04530
06051
06055
06108
06340
06607
06810
06855
06902

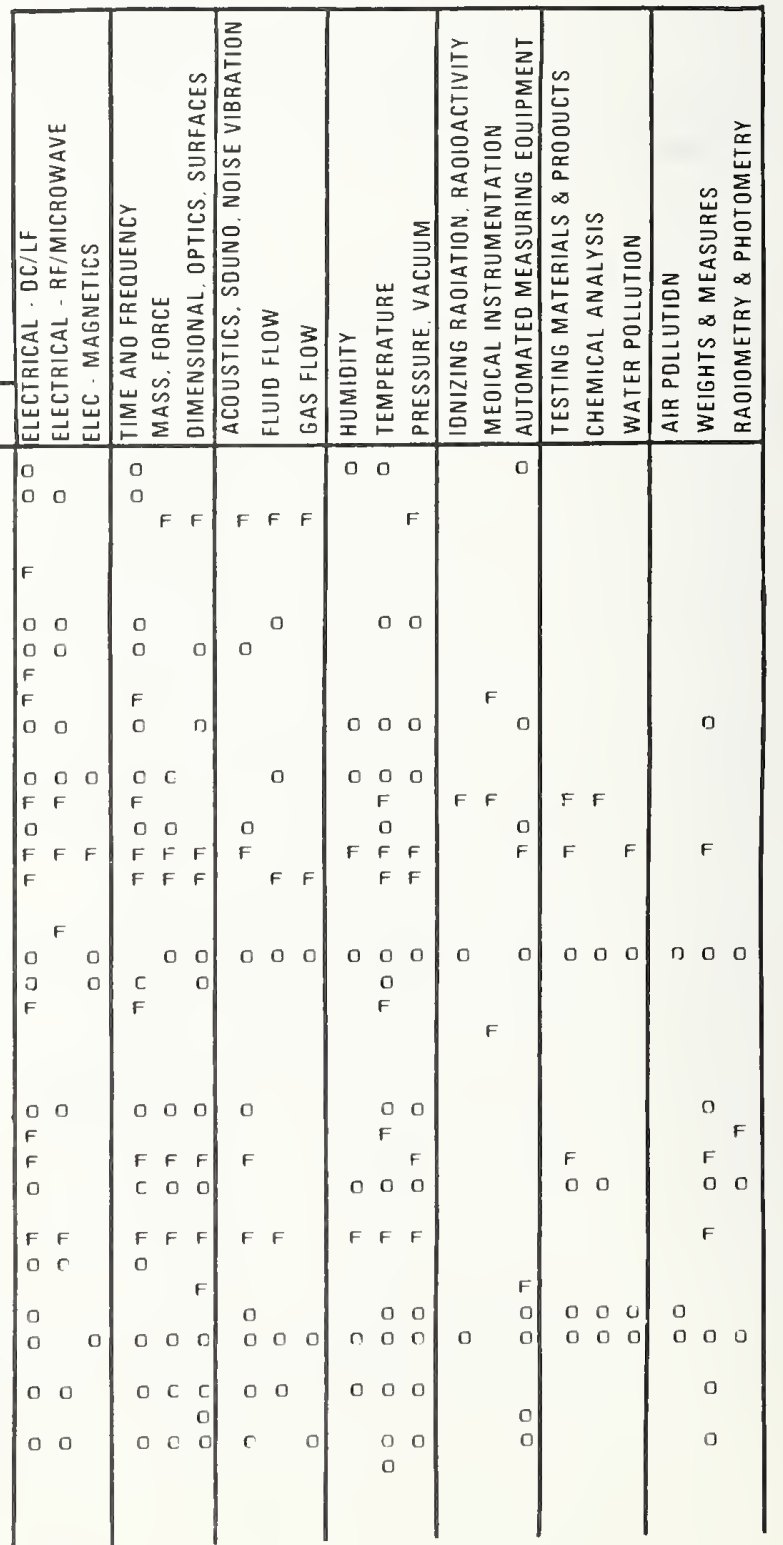


O SERVICE TO PARENT ORGANIZATION ONLY

F CALIBRATION SERVICES aVAILABLE ON A FEE basis

N CALIBRATION SERVICES AVAILABLE ON A NO FEE BASIS

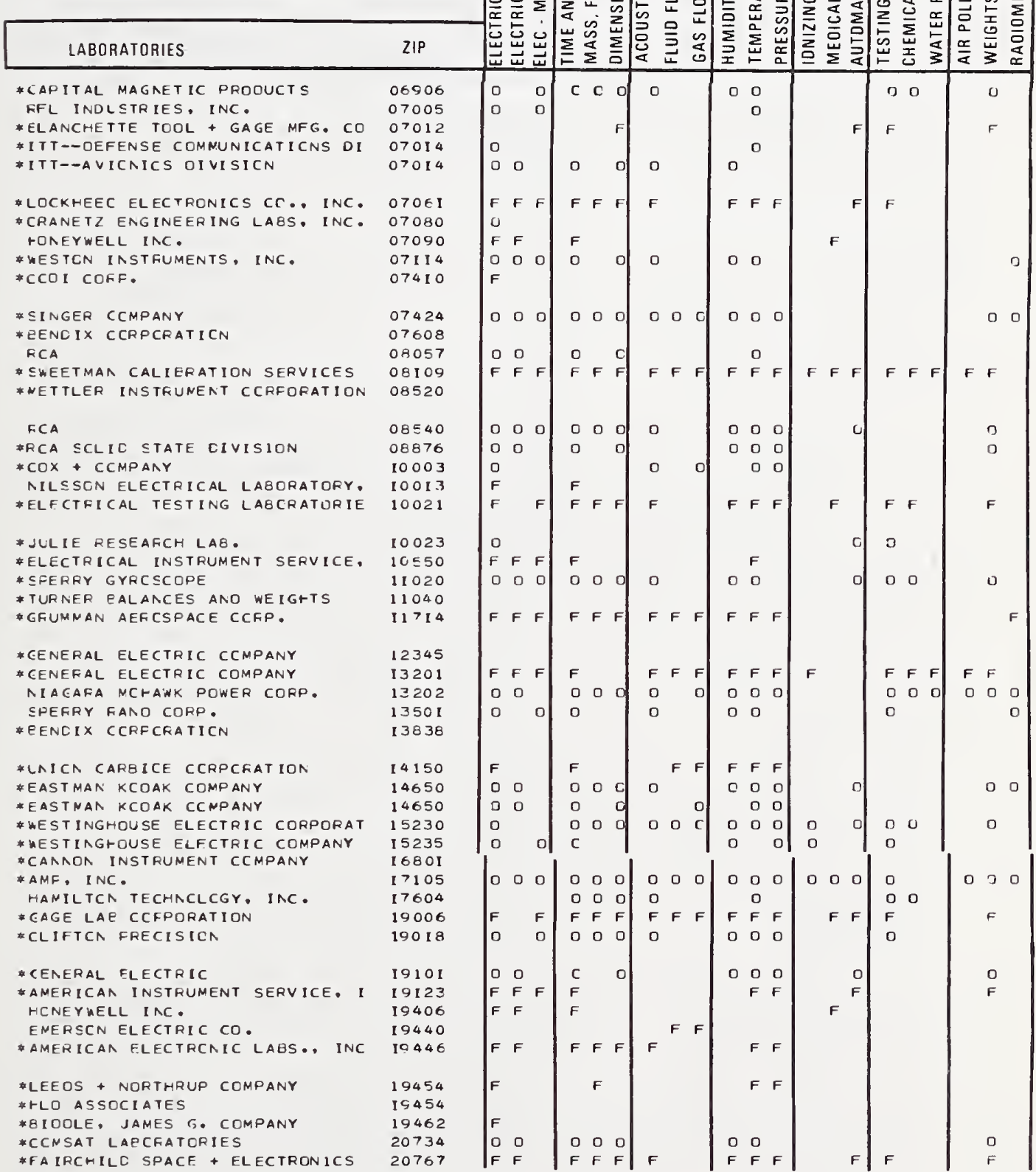


PRIVATE LABORATORIES

O SERVICE TO PARENT ORGANIZATION ONLY

F CALIBRATION SERVICES AVAILABLE ON A FEE BASIS

N CALIBRATION SERVICES AVAILABLE ON A NO FEE BASIS

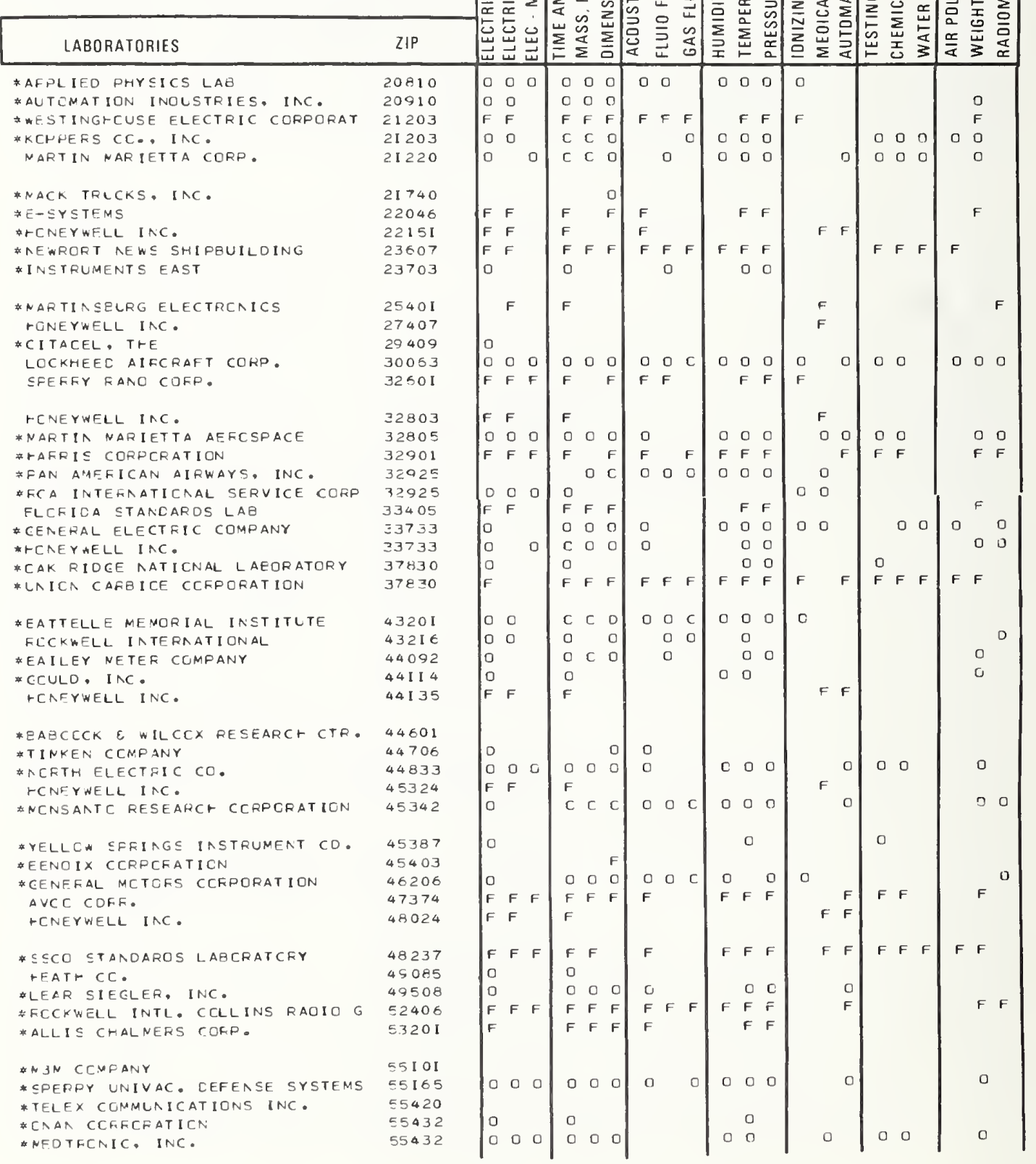


PRIVATE LABORATORIES

O Service to parent organization ONLY

F Calibration services available on a fee basis

N CALIBRATION SERVICES AVAILABLE ON A NO FEE BASIS

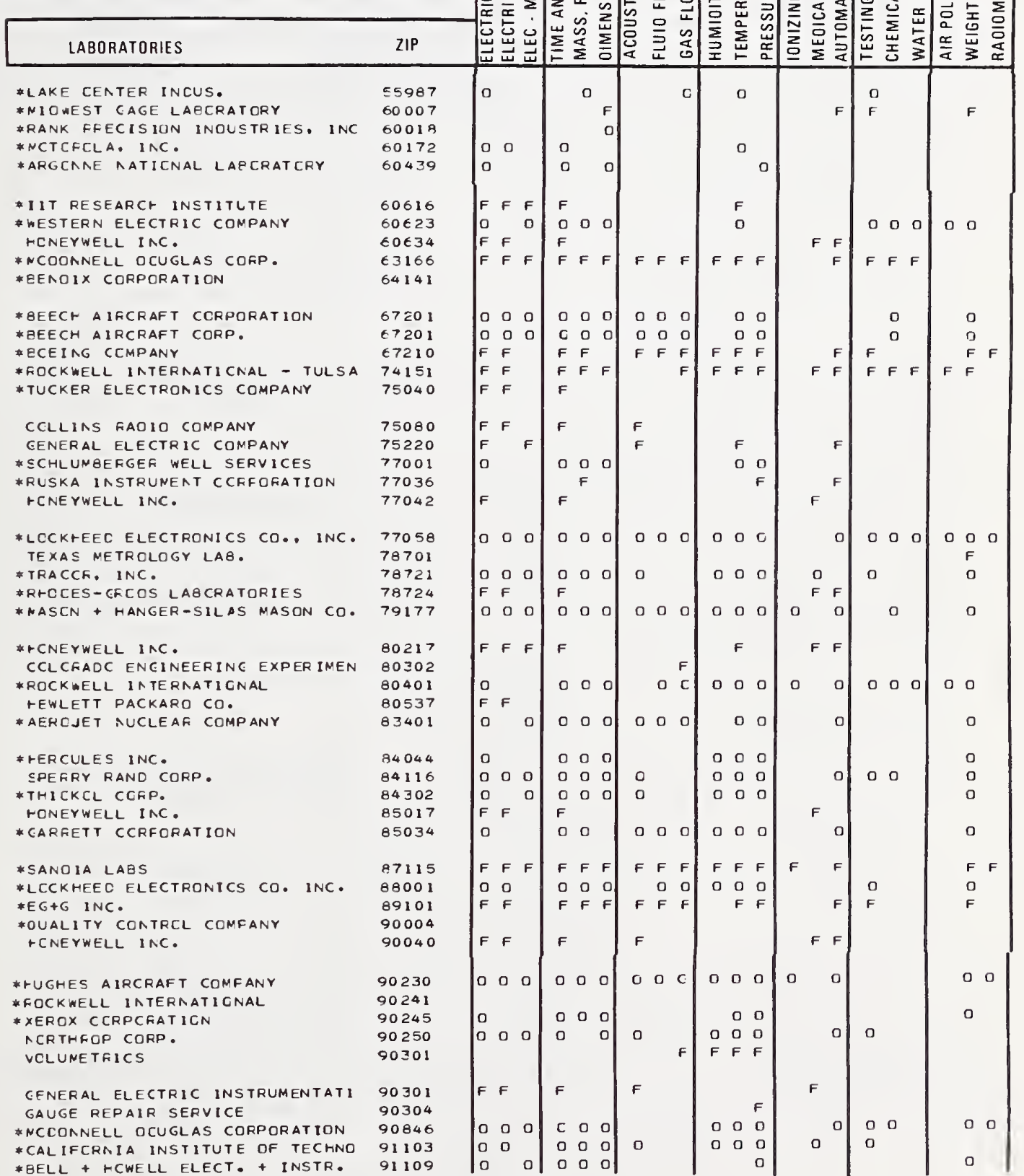




\section{PRIVATE LABORATORIES}

O SERVICE TO PARENT ORGANIZATION ONLY

F CALIBRATION SERVICES AVAILABLE ON A FEE BASIS

N CALIBRATION SERVICES AVAILABLE ON A NO FEE bASIS

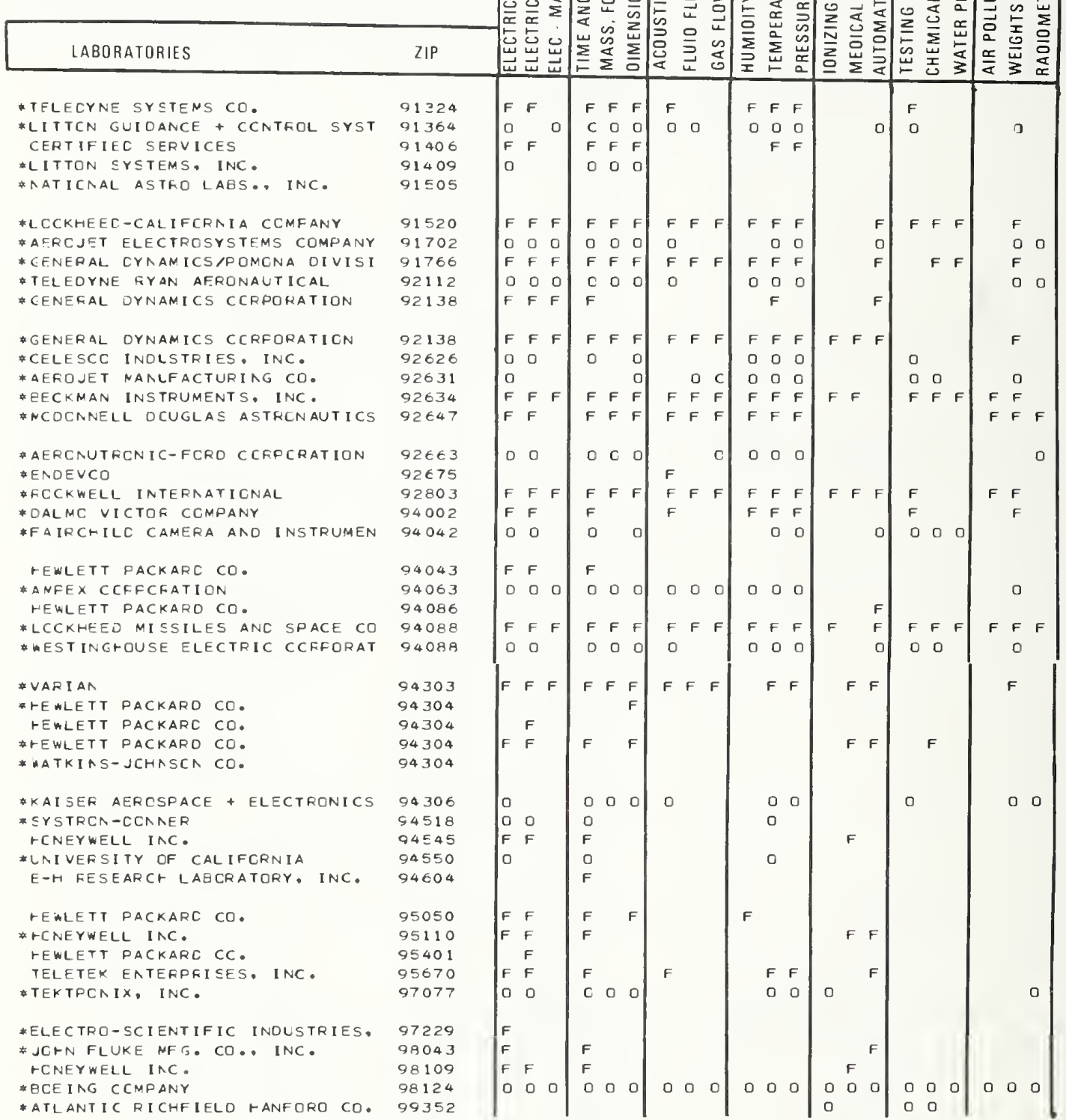


GOVERNMENT LABORATORIES

O SERVICE TO PARENT ORGANIZATION ONLY

F CALIbration SERVICES aVailable ON A FEe basis

N CALIBration SERVICES aVaILAble ON A NO FEe basis

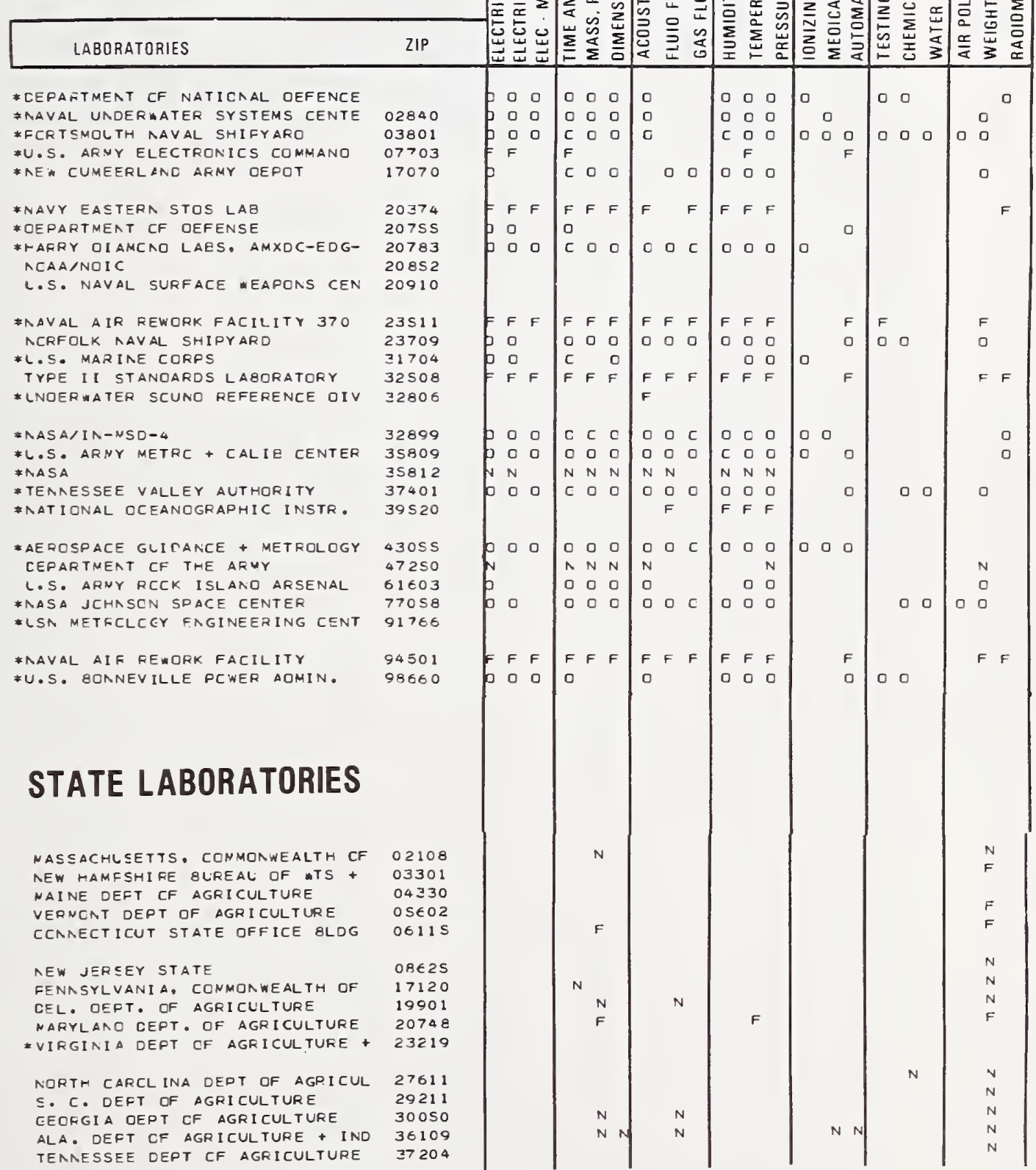




\section{STATE LABORATORIES}

O SERVICE TO PARENT ORGANIZATION ONLY

F CALIBRATION SERVICES AVAILABLE ON A FEE BASIS

N CALIBRATION SERVICES AVAILABLE ON A NO FEE BASIS

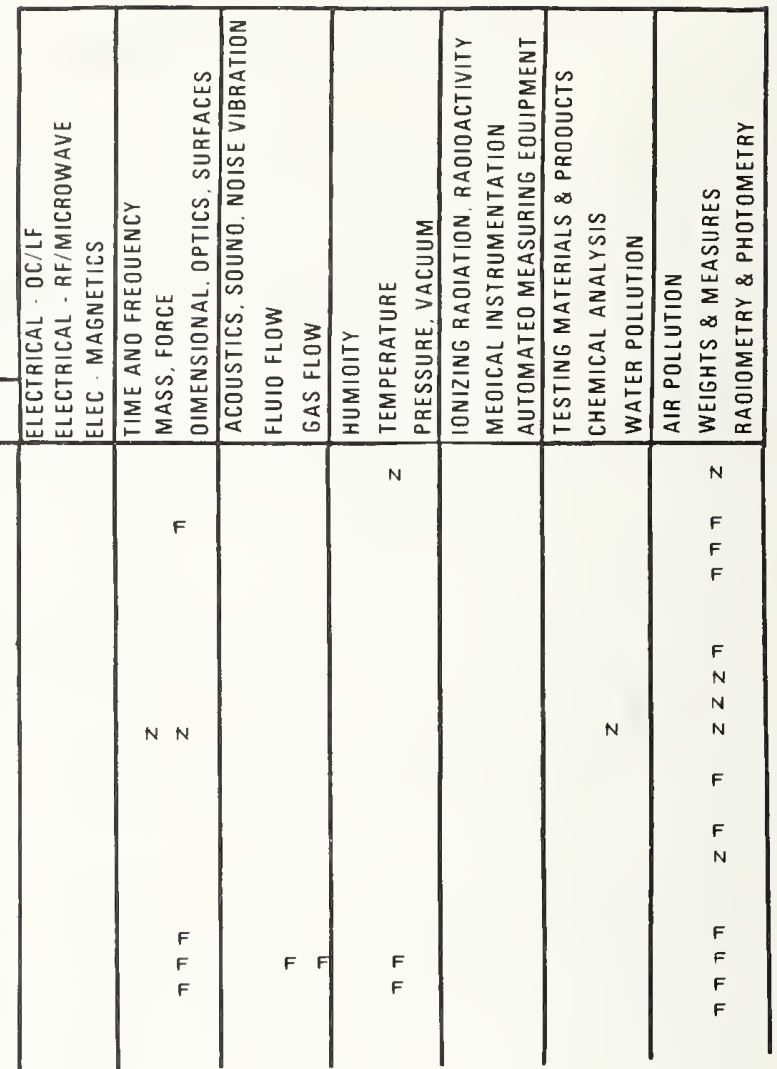


APPENDIX H. INBS CALIBRATION ACTIVITY SUMMARY FOR FISCAL YEAR $1975[255,271]$.

Table H-1. Calibration data for NBS by state

\begin{tabular}{|c|c|c|c|c|c|c|c|}
\hline & & blic & Gov & nment & & tal & \\
\hline & Count & Cost & Count & $\operatorname{Cos} t$ & Count & & $\operatorname{Cos} t$ \\
\hline $\begin{array}{l}\text { Al abama } \\
\text { Alaska }\end{array}$ & $\begin{array}{r}10 \\
0\end{array}$ & $\begin{array}{r}1,267 \\
0\end{array}$ & $\begin{array}{r}260 \\
0\end{array}$ & $\$ 171,366$ & $\begin{array}{r}270 \\
0\end{array}$ & $\$$ & 172,633 \\
\hline Arizona & 43 & 14,493 & 0 & 0 & 43 & & 14,493 \\
\hline Arkansas & 0 & 0 & 0 & 0 & 0 & & \\
\hline Cal ifornia & 613 & 237,805 & 48 & 37,284 & 661 & & 275,089 \\
\hline Colorado & 101 & 33,242 & 2 & 910 & 103 & & 34,152 \\
\hline Connecticut & 116 & 41,463 & 0 & 0 & 116 & & 41,463 \\
\hline Delaware & 2 & 2.60 & 0 & 0 & 2 & & 260 \\
\hline District Columbia & 17 & 7,283 & 80 & 48,700 & 97 & & 55,983 \\
\hline Florida & 81 & 15,344 & 18 & 8,477 & 99 & & 23,821 \\
\hline Georgia & 40 & 16,018 & 1 & 340 & 41 & & 16,358 \\
\hline Hawai i & 1 & 150 & 0 & 0 & 1 & & 150 \\
\hline Idaho & 4 & 1,333 & 0 & 0 & 4 & & 1,333 \\
\hline Illinois & 44 & 14,066 & 4 & 1,174 & 48 & & 15,240 \\
\hline Indiana & 40 & 11,357 & 1 & 417 & 41 & & 11,774 \\
\hline Iowa & 4 & 1,063 & 0 & 0 & 4 & & 1,063 \\
\hline Kansas & 5 & 750 & 0 & 0 & 5 & & 750 \\
\hline Kentucky & 20 & 5,632 & 5 & 3,680 & 25 & & 9,312 \\
\hline Louisiana & 12 & 6,192 & 0 & 0 & 12 & & 6,192 \\
\hline Maine & 5 & 752 & 0 & 0 & 5 & & 752 \\
\hline Maryland & 113 & 81,531 & 30 & 27,692 & 143 & & 109,223 \\
\hline Massachusetts & 197 & 63,040 & 7 & 2,447 & 204 & & 65,487 \\
\hline Michigan & 63 & 16,838 & 0 & 0 & 63 & & 16,838 \\
\hline Minnesota & 87 & 37,387 & 0 & 0 & 87 & & 37,387 \\
\hline Mississippi & 9 & 3,416 & 3 & 1,080 & 12 & & 4,496 \\
\hline Missouri & 82 & 30,690 & 0 & 0 & 82 & & 30,690 \\
\hline Montana & 0 & 0 & 0 & 0 & 0 & & \\
\hline Nebraska & 15 & 5,389 & 0 & 0 & 15 & & 5,389 \\
\hline Nevada & 4 & 1,266 & 2 & 207 & 6 & & 1,473 \\
\hline New Hampshire & 26 & 6,780 & 0 & 0 & 26 & & 6,780 \\
\hline New Jersey & 166 & 37,575 & 46 & 24,842 & 212 & & 62,417 \\
\hline New Mexico & 80 & 41,350 & 3 & 1,244 & 83 & & 42,594 \\
\hline New York & 332 & 139,267 & 0 & 0 & 332 & & 139,267 \\
\hline North Carolina & 57 & 17,598 & 2 & 205 & 59 & & 17,803 \\
\hline North Dakota & 2 & 153 & 0 & 0 & 2 & & 153 \\
\hline Ohio & 204 & 71,440 & 192 & 159,515 & 396 & & 230,955 \\
\hline Okla homa & 17 & 8,651 & 1 & 660 & 18 & & 9,311 \\
\hline Oregon & 12 & 7,771 & 6 & 1,430 & 18 & & 9,201 \\
\hline Pacific Islands & 0 & & 0 & 0 & 0 & & \\
\hline Pennsylvania & 283 & 94,868 & 1 & 1,200 & 284 & & 96,068 \\
\hline Puerto Rico & 1 & 110 & 0 & 0 & 1 & & 110 \\
\hline Rhode Island & 21 & 8,892 & 0 & 0 & 21 & & 8,892 \\
\hline South Carolina & 23 & 6,629 & 0 & 0 & 23 & & 6,629 \\
\hline South Dakota & 0 & 0 & 0 & 0 & 0 & & \\
\hline Tennessee & 69 & 32,125 & 1 & 89 & 70 & & 32,214 \\
\hline Texas & 130 & 36,379 & 49 & 13,597 & 179 & & 49,976 \\
\hline Utah & 12 & 5,024 & 3 & 1,273 & 15 & & 6,297 \\
\hline Vermont & 5 & 974 & 0 & 0 & 5 & & 974 \\
\hline Virginia & 48 & 10,071 & 25 & 19,785 & 73 & & 29,856 \\
\hline Washington & 47 & 40,891 & 4 & 1,717 & 51 & & 42,608 \\
\hline West Virginia & 7 & 1,943 & 0 & 0 & 7 & & 1,943 \\
\hline Wiscons in & 26 & 5,793 & 0 & 0 & 26 & & 5,793 \\
\hline Wyoming & 2 & 208 & 0 & 0 & 2 & & 208 \\
\hline Unzipped Entries & 32 & 12,325 & 3 & 13,481 & 35 & & 25,806 \\
\hline TOTALS & 3,330 & $1,234,844$ & 797 & 542,812 & 4,127 & & 777,656 \\
\hline
\end{tabular}


Table H-2. Summary of calibration data for FY-75.

1.6 Flatness, Straightness \& Roundness $20 \quad 5.1$

Item

1.1 Mass, Volume and Density

1.1A Mass measurement services

1.1B Calibration of reference stds of mass (individual weights or weight sets)

1.1C Mass Measurement Assurance Program

1.1D Railroad track scales

$1.1 \mathrm{G}$ Volume meas. services

1.1H Calibration of reference std volumetric apparatus

1.1P Density meas. services

1.10 Density determinations of liquids or solids

1.1R Reference std hydrometers

1.2 Office of Weights and Measures

1.2A Special weights \& measures services

1.2B Weights \& measures calibration (LP gas provers, class $F$ weights, etc.)

1.2C Device prototype testing (for compliance to handbook 44)

\subsection{Length}

1.3A Special ?ength meas. services

1.3B Linear thermal expansion--solids

1.3C Calibration of gage blocks

1.3D Gage block thermal expansion

1.3E Gage block comparator stylus tip radius

$1.3 \mathrm{H}$ Line stds--40 in. or less long

1.3J Tapes--steel or invar

1.3K Surveying instruments--other

1.3M Sieves

1.3N Haemacytometers

1.3R Precision circles

1.4 Length \& Diameter Dimensional Metrology

1.4A End stds of length

1.4B Step gage stds of length-up to 40 inches

$1.4 \mathrm{C}$ Plug gages

1.4D Measuring wires for threads and gears

1.4E Spherical diameter stds--balls

$1.4 \mathrm{~F}$ Internal diam. stds--ring gages

\subsection{Complex Stds of Length \& Diameter}

$1.5 \mathrm{~A}$ Plain conical plug \& ring gages

1.5B Threaded plug \& ring gages

1.5C API threaded plug \& ring gages

$1.5 \mathrm{D}$ Master gears

1.5E Length \& diameter calipers

1.5F Micrometer screws, dial micrometers

1.5G Penetration needles

1.5H Polariscope tubes

$1.5 \mathrm{~J}$ Two dimensional gages
No. $\frac{\text { Cost }}{(\mathrm{k} \$)}$

$103 \quad 37.9$

1.6A Optical reference planes--flats

$1.6 \mathrm{~B}$ Surface plates \& straight edges

$1.6 \mathrm{~F}$ Roundness stds

1.6G Roundness calibration specimens

$1.6 \mathrm{H}$ Roundness measurements

\subsection{Angular}

$\begin{array}{ll}53 & 21.7\end{array}$

$6 \quad 2.3$

1.7A Angle gage blocks

1.7B Optical polygons

1.7C Angle calipers \& step mirrors

1.7D Wedges

1.7E Cylindrical \& machinist squares

1.7F Rotary \& indexing tables

$20 \quad 6.3 \quad 1.7 \mathrm{G}$ Autocollimating telescopes

1.7H Angle generators

\subsection{Surface Texture}

1.8A Instrument calibration specimens

$1.8 \mathrm{~B}$ Surface roughness measurements

1.9 Image Optics and Photography

1.9A Refractive index

1.9B Optical lens evaluation

$1.9 \mathrm{C}$ step tables

1.9D Microscopy resolution test charts

$1.9 \mathrm{E}$ Lens test

1.9J Special microdensitometer meas. (new FY76)

1.9K\&L Photographic edge calibrations (new FY76)

1.9M Photographic sinusoidal calib.

\subsection{Acoustic Measurements}

2.1A Acoustical meas. services

2.1BC\&D Microphone WE type 640 AA or equivalent

\subsection{H\& I Earphones}

\subsection{Vibration Measurements}

2.2A Vibration meas. services

2.2BCD\&E Vibration pickups

2.2F Shock pickups
$27 \quad 15.1$

$5 \quad 4.4$

$4 \quad 2.4$

16

7.3

0.5

$51 \quad 19.7$

10.7

$\begin{array}{ll}1 & 0.1\end{array}$

$38 \quad 16.0$
10.5

\subsection{Humidity Measurements}

2.3A Humidity meas. services

2.3B\&C Dewpoint hygrometers automatic

2.3D\&E Dewpoint hygrometers manual

2.3F Electric hygrometer

2.3G Coulometric hygrometer

2.3H Aspirated hygrometer

2.3I Pneumatic bridge hygrometer

\subsection{Engineering Mechanics}

\subsection{A Engineering mechanics meas.}

2.4B\&C Services of staff members

1

0.3

\subsection{Calibration of Force Transducers}

2.5AB\&C 100-25.000 lbf

2.5DE\&F 25,001-112,000 1bf

2.5GH\&I $112,001-300,0001 \mathrm{bf}$

2.5 JK\&L $300,001-1,000,0001 \mathrm{bf}$

2.5M $1,000,001-12,000,0001 \mathrm{bf}$ 


\subsection{Fluid Quantity \& Flow Rate Meters}

2.7A Flow rate meas. services

$\underline{53.1}$

2.7C Liquid quantity meter 26.0

2.7D Flow rate meter (direct reading) 13

2.7E Flow rate meter (orifice, nozzles, laminar flow, etc.)

2.8 Hydraulics

2.8A Hydraulic meas. services

2.8B Water current meters

2.9 Aerodynamics

2.9A Aerodynamic meas. services

2.9B Air speed instruments

2.9C Pitot-static tubes

3.1 Resistance Measurements (Electric) 439

3.1A Special resistance meas. services

3.1B Resistance Meas. Assurance Prog. 5 Standard resistors:

3.1C 4 terminal, Thomas types, 1 ohm 97

3. IDE\&F 4 terminal, decimal multiples of $1 \mathrm{ohm}$

3. IG\&H 2 terminal, " " " " " 73

3.1I Four terminal, other

3.1J Two terminal, other

3.1KL\&M Multiple megohm, $10^{6}$ ohm up 51

3.1N\&O Temperature coefficient data

3.1P Pressure coefficient, Thomas-type

3. 1QR\&S For current meas. (shunts) 54

3.1T Adjustable low resistance std 3

\subsection{Precision Apparatus (Electrical)}

3.2A\&B Decade variable resistors

3.2C Hamon devices

3.2D High resistance transfer device

3.2E Precision Wheatstone bridges

$3.2 \mathrm{~F}$ Thermometer bridges

$3.2 \mathrm{G}$ Double ratio set ratio device

$3.2 \mathrm{H}$ Kelvin ratio box, plug type

3.2IJ\&K Ratio device--resistive decade voltage divider

3.2L\&M Direct reading ratio sets

3.2NO\&P Potentiometers

3.2Q\&R Inductive voltage dividers

3.2ST\&U Fixed dc voltage dividers

86 $\quad 31.9$

3.2V\&W Silsbee type divider

3.2X\&Y Measurement Assurance Programs for dc voltage ratio

3.3 Impedance Measurements (Electric)

$\underline{185}$

$\underline{39.5}$

3.3A Special inductance \& capacitance meas. services

3.3B Capacitance Meas. Assur. Prog.

3.3Cã Inductors, fixed, self or mutual

Standard capacitors:

3.3EF\&G Fixed, 3-terminal

3.3H\&I Variable or decade

3.3J Fixed, fused silica dielectric

17.0

18.9

30.6

12.4

0.1

0.5

14.9

10.1

1.5

0.8

0.3

0.8

3.1

0.9

1.0

5.6

0.4

10.2

3.4

5.4

0.1

$174 \quad 36.4$
3.4A Special voltage meas. services

3.4B Volt transfer program

3.4C\&D Std cell calibrations

$\begin{array}{rr}4 & 1.2 \\ 13 & 9.4\end{array}$

3.4E Pt thermometer temp. determination of cells in air enclosures 1

$3.4 \mathrm{~F}$ Std cell calib., unsaturated std cell

3.4GH\&I Solid state voltage reference sources

$3.4 J \& K$ Special handling

$184 \quad 40.8$

0.1

3.4

0.3

20

3.5 Electrical Instruments (AC-DC)

102

3.5A Special dc meas. services

3.5BC\&D RMS ac-dc transfer std

$3.5 \mathrm{~F}$ Ac-dc wattmeters

3.5H 4-terminal ac resistors

36

0.6

3.6 Instrument Transformers \& Comparators

41.7

3.6A Special ac meas. services

3.6BCD\&E Voltage transformers, ratio \& phase angle

3.6G Voltage transformer comparators

3.6PQRS\&T Current transformer, ratio \& phase angle

3.6W\&X Current transformer comparator

1
98

98

$\underline{26.6}$

0.1

26.1

0.4

0.1

3.7 High Voltage \& Energy Measurements

18

25.6

18

2.2

0.9

43

10.7

2.2

3.7A Specialized high voltage meas. services

3.7B Resistors $\&$ resistive dividers

3.70 Watthour meters: Measurement Assurance Program

3.7EFGH\&J Watthour meters

3.7 KLM\&N Kilovoltmeters

3.70 High voltage capacitors \&

capacitance bridges

3.7P Kerr electro-optical, pulsevoltage-measuring systems

3.7Q X-ray machines, pulse-voltagemeasuring systems

3.72 High voltage field calibrations

3.8 Magnetic Measurements

3.8A Magnetic meas. services

3.8BC\&D Normal induction

3.8E\&F Demagnetization

3.8G\&H Permeability

3.8J\& K Magnetic materials, core loss

3.8L\&M Magnetic materials, ac permeability

3.8P\&Q Magnetic testing apparatus

3.8R\&S Area turns of a search coil

3.8T\&U Flux meter calibrations

$3.8 \mathrm{~V}$ Calibration of a std magnet

3.8W Solenoids \& Helmholz coils

81

19.7

$6 \quad 0.6$

1

0.1

\subsection{Dielectric Measurements}

$3 \quad 1.0$

\subsection{A Dielectric constant \& dissipation factor}


$\underline{\text { Item }}$

No. Cost

4.0 ELECTROMAGNETICS: METROLOGY AT RADIO, MICROWAVE AND LASER FREQUENCIES

\subsection{Attenuation (RF \& Microwave)}

4.1A Special calibrations

4.1B\&C Coaxial fixed attenuators

4.1EF\&G Coaxial variable attenuators

4.1H Waveguide below-cutoff (piston) attenuators

4.1I\&J Coaxial fixed directional couplers

4.1 K\&L Coaxial variable directional couplers

4.1M Fixed rectangular waveguide attenuators

4.IN Variable rectangular waveguide attenuators

4.10 Wideband attenuation or gain of coaxial networks

\subsection{Fields (EM) \& Antennas}

4.2A Special calibrations

4.2BC\&D Field strength receivers

$4.2 \mathrm{E}$ Loop antennas

4.2F Dipole antennas

4.2G Antenna gain

$4.2 \mathrm{H}$ Antenna polarization

\subsection{Impedance (RF \& Microwave)}

4.3A Special calibrations

4.3B Capacitance meas., 2 terminal

4.3C Capacitance meas., 3 terminal

4.3D Inductance meas. (high Q)

4.3E Resistance meas. (10w Q)

4.3F Q-standards phase angle, VSWR, reflection coeff., phase angle)

4.2I Reflection coefficient of coaxial terminations (magnitude)

$4.2 \mathrm{~J}$ Reflection coefficient of rectangular waveguide reflectors (mismatches) (magnitude only) reflecting rectangular waveguide ports \& matched loads (magnitude only)

\subsection{Laser Parameters}

4. 4 A Special calibrations

4.4B Measurement Assurance Programs for power and energy

\subsection{Material Properties (Electromagnetic)}

4.5A Special calibrations

4.5BCDE\&G Permittivity measurements

4. $5 \mathrm{H}$ Saturation magnetization std ref. spheres of $\mathrm{Fe} \& \mathrm{Ni}$
4.3G\&H Coaxial impedance (magnitude,

4.3K\&L Reflection coefficient of non-
$184 \quad 116.1$

$\begin{array}{ll}18 & 20.3\end{array}$

$92 \quad 43.4$

$3 \quad 3.1$

$53 \quad 33.4$

21.3

$\begin{array}{ll}16 & 14.7\end{array}$

(new FY76)

$\underline{38} \quad \underline{47.2}$

$16 \quad 40.0$

$12 \quad 1.6$

$3 \quad 1.9$

$7 \quad 3.6$

3.6

$206 \quad 86.5$

$\begin{array}{ll}16 & 16.1\end{array}$

$\begin{array}{ll}7 & 1.4\end{array}$

$33 \quad 7.8$

$31 \quad 18.1$

10.2

$77 \quad 7.3$

$22 \quad 9.7$

21.2

13.2

11.4
$22 \quad 35.1$

4.6A Special calibrations

8.9

4.6B\&C Coaxial noise generators

4.6D\&E Rectangular waveguide noise sources

$11 \quad 17.1$

4.7 Phase Shift (RF \& Microwave) $\underline{9} \underline{13.3}$

4.7A Special calibrations

4.7B Fixed coaxial phase shifter

4.7CD\&E Variable coaxial phase shifter $4 \quad 3.7$

4.7F Coaxial delay lines

4.7G Variable reactangular waveguide phase shifters

4.7H Pulse time delay

9.6

(new FY76)

4.8 Power (RF \& Microwave) $\quad \underline{273} \underline{247.9}$

4.8A Special calibrations $\quad 76 \quad 76.1$

$\begin{array}{llll}4.8 \mathrm{~B} & \text { Coaxial bolometer units } & 70 & 70.6\end{array}$

4.8C Coaxial bolometer-coupler units 3120.2

4.8DE\&F Rectangular waveguide bolometer units

4.8G\&H Rectangular waveguide bolometer-coupler units

4.8I Coaxial peak pulse power meters

$4.8 \mathrm{~J}$ Coaxial \& waveguide pulse power meters at $8.2-12.4 \mathrm{GHz}$

4.8K\&L Coaxial RF calorimeters \& RF power meters

$16 \quad 11.5$

$13 \quad 9.1$

$18 \quad 7.8$

$3 \quad 2.4$

\subsection{Voltage (RF \& Microwave) $\quad 438 \quad 111.7$}

4.9A Special calibrations

4.9B Attenuator-thermoelement vol tmeters

4.9C Thermal voltage converters

4.9D RF millivoltmeters \& RF signal sources

4.9E RF micropotentiometers

4.9F Coaxial peak pulse voltmeters

4.9G Coaxial peak pulse generators

4.9H Impulse generator spectrum amplitude

4.9I Pulse generator risetime

4.9J Low pass filter risetime

(new FY76)

(new FY76)

\subsection{Frequency Measurements}

$9 \underline{9} \quad \underline{10.1}$

5.1A Special time/frequency meas.

$\begin{array}{ll}9 & 10.1\end{array}$ (new FY76)

\subsection{CRYOGENICS}

\subsection{Laboratory Thermometers $\quad 211 \quad \underline{80.6}$}

7.1A Thermometry services $\quad 28 \quad 53.5$

7.1BCDE\&F Laboratory thermometers $142 \quad 23.1$

$\begin{array}{lll}7.1 \mathrm{G} \text { Calorimeter thermometers } & 7 & 1.4\end{array}$

7.1H Beckmann thermometer $\quad 7 \quad 2.2$

7.1 I Preliminary examination $\quad 190.2$

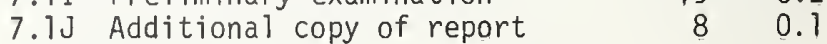


7.2 Thermocouples \& Thermocouple

$$
\text { Materials }
$$

$\underline{194} \quad \underline{33.6}$

7.2A Thermocouple meas. services

7.2B Type $S$ calib. vs. thermocouple

$7.2 \mathrm{C}$ Type $\mathrm{R}$ vs. thermocouple

7.2D\&E Type B vs. thermocouple

$7.2 \mathrm{~F}$ Base metal vs. thermocouple

7.2G Thermocouple materials tested against $P$ t thermoelectric std 10

7.2H Comparison calib., per point

7.2KL\&M Type S vs. metal freezing pts 25

7.2N\&O Portable potentiometer pyrometer indicator

7.2RS\&T Comparison vs. Pt thermoelectric std, with Pt resistance thermometer

$7.2 U$ Type $T$ thermocouple

\subsection{Resistance Thermometers}

7.3A Resistance thermometry meas. services

7.3B\&C Long stem PRT

7.3D Calorimetric type PRT

7.3E\&F Capsule type PRT

7.3G\&H Additional copies of reports

7.3J Measurement Assurance Program

7.3P Germanium resistance thermometer capsule type

7.4 Radiation Thermometry

$56 \quad 25.9$

7.4A Radiation thermometry meas. services

7.4BCD\&E Optical pyrometers

7.4F\&G Ribbon filament. 1 amp

7.5 Basic Radiometric Calibrations

7.5A Radiometric meas. services

7.5BC\&D Spectral radiance std., ribbon filament lamp

7.5E\&F Spect. rad. std, blackbody

7.5GH\&I Spectral irradiance std., quartz-halogen lamp

$7.5 J \& \mathrm{~K}$ Irrad. std, 33 or $144 \mathrm{mw} / \mathrm{cm}^{2}$

$7.5 \mathrm{Y}$ Spectral radiance standard, UV, deuterium arc lamp

7.6 Basic Photometric Calibrations

7.6A Photometric meas. services

7.6BC\&D Luminous intensity std., $100 \mathrm{~W}$ tungsten lamp

7.6E\&F Same, $500 \mathrm{~W}$ tungsten lamp

7.6G\&H Same, $1000 \mathrm{~W}$ tungsten lamp

7.6IJKL\&M Luminous flux stds

\subsection{Radiometric \& Photometric Gage Calibrations}

7.7A Irradiance of $253.7 \mathrm{~nm}$ line of $\mathrm{Hg}$ from low pressure $\mathrm{Hg}$ lamp

7.7BC\&D Color temperature std., airway beacon lamp

7.7E Luminous flux stds, min. lamps

7.7F Luminous directional transmittance std, opal glass

0.5

3.0

0.1

61 34.7

9.2

3.0

3.4

17.4

10

17.4
8.2

5

4.1

$24 \quad \underline{12.8}$

4

2.6

5.2

1.5
7.8 Spectrophotometric Standards

7.8A Spectrophotometric meas. services 8

7.8B Spectral transmittance std, cobalt blue glass

0.2

7.8C Same, copper green glass

7.8D Same, carbon yellow glass

7.8E Same, selenium orange glass

7.8FG\&H Wavelength std, didymium glass

7.8I Same, holmium oxide glass

7.8JK\&L Vitrolite white glass std of diffuse reflectance

\subsection{Pressure \& Vacuum Measurements}

7.9A Special pressure \& vacuum

\section{meas. services}

7.9B Deadweight piston gages

7.9C Controlled clearance piston gages

7.9D Mercurial barometer or manometer

7.9E Pressure gages \& transducers

$7.9 \mathrm{~F}$ Pressure transfer std perf. test

$7.9 \mathrm{~N}$ Vacuum gages

\subsection{Neutron Sources}

8.1A Special meas. services

8. $1 \mathrm{~B} \& \mathrm{C}$ Emission rate in $\mathrm{MnSO}_{4}$ bath

8.1H Thermal neutron dosimeters

8.1P Neutron irradiation of foils

0.8

\subsection{Radioactivity}

8.2A Radioactivity meas. services $\&$ tests

8.2B Radium

8.2C\&D Gamma-ray emitting samples

8.2HI\&J Alpha-particle emitting sample

8.2K Polonium-210 sources

8.2P\&Q Beta-particle emitting samples

\subsection{X- \& Gamma-Ray Meas. Instruments}

$\underline{105}$

8.3A Special meas. services

8.3B\&C Calib. factor for cavity ionization chamber

8.3D\&E

\section{ionization chamber} correction factor for electro-

8.3F\&G meter + ionization chamber

1.5

1.6

2.3

2.7

0.2

0.8

\subsection{Gamma-Ray Sources}

$\underline{45.6}$

8.4A Special meas. services

$8.4 \mathrm{~B} \quad 0.1$ to 3 microroentgen per second at one meter

$8.4 \mathrm{C} 3$ to 20 amma-ray irradiation of passive dosimeters

0.3

14.8

8.40 20 to 60

" 11 " $11 "$

\subsection{Dosimetry in High-Energy Electron Beams}

8.5A Special meas. services

8.5B\&C 4 ferrous-ferric dosimetes

\subsection{Computer Science}

9.1A\&B Magnetic disk calibration

\subsection{Engineering Tests}

9.3 Interlaboratory Testing Programs 


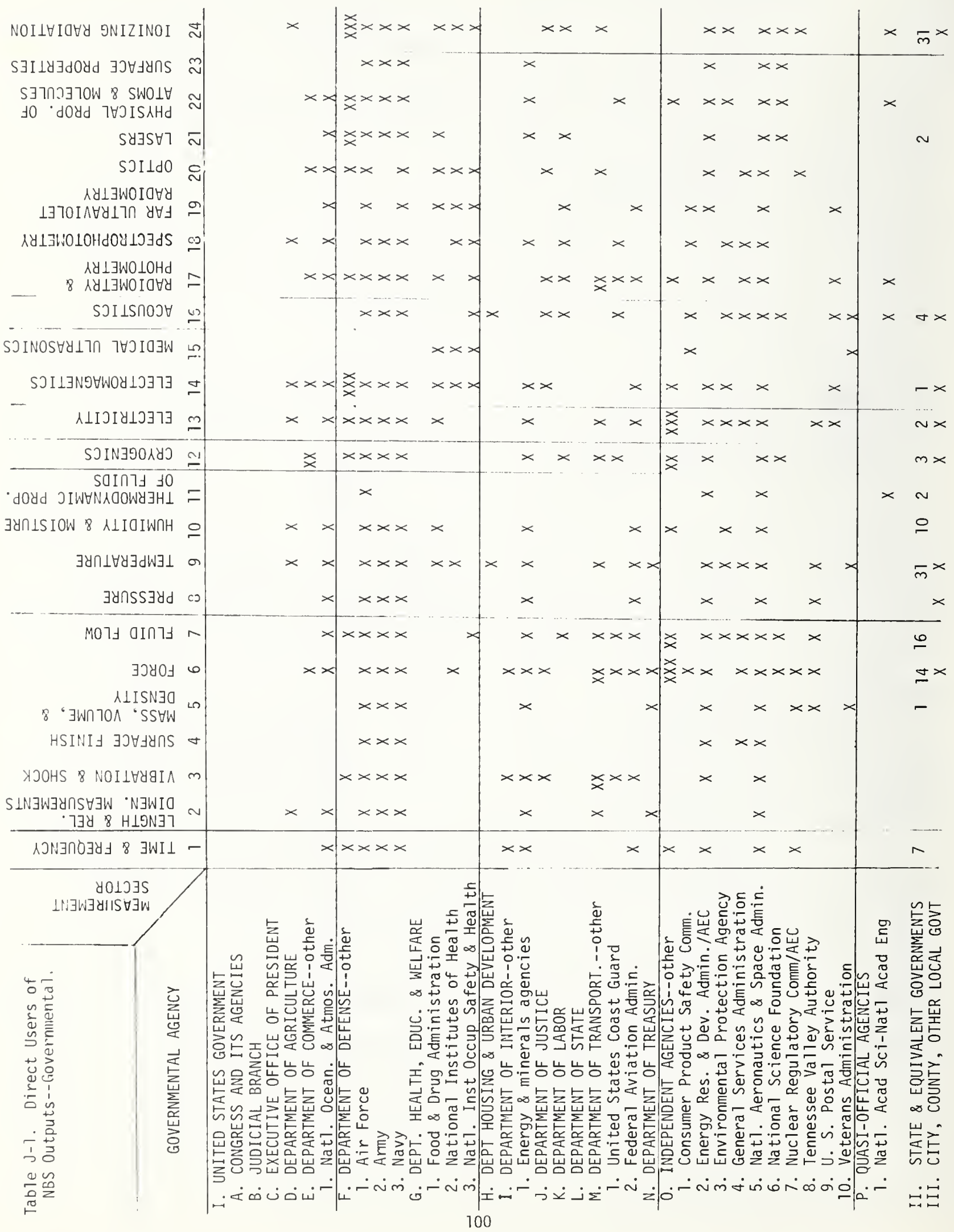


Table J-2. Direct users of NBS Outputs--SIC Major Groups 1-32.

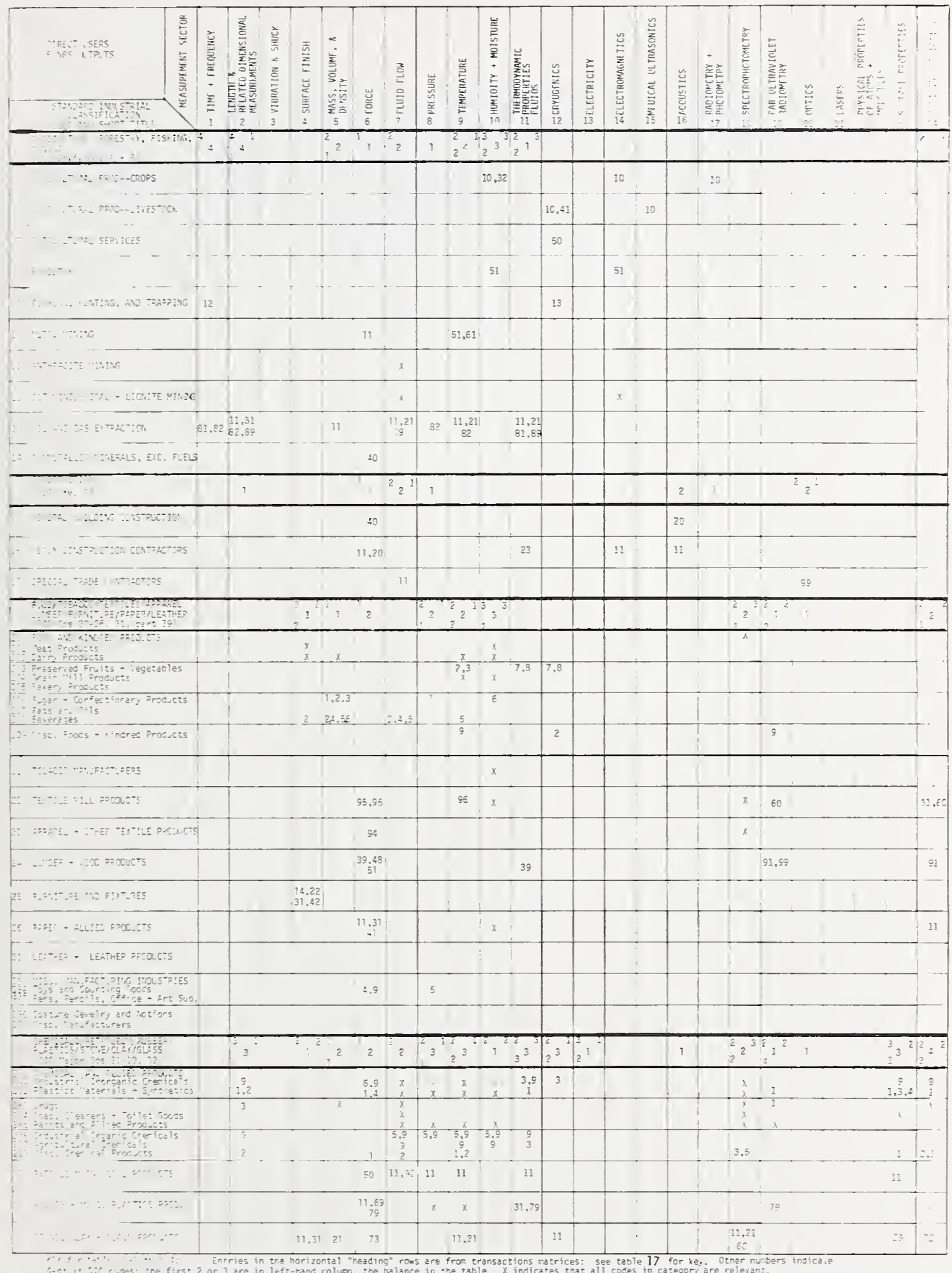


Table J-3. Direct users of NBS Outputs--SIC Major Groups 33-49.

\begin{tabular}{|c|c|c|c|c|c|c|c|c|c|c|c|c|c|c|c|c|c|c|c|c|c|c|c|c|}
\hline 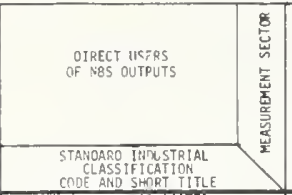 & 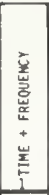 & 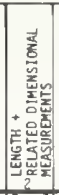 & 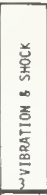 & 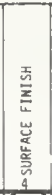 & 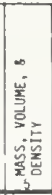 & 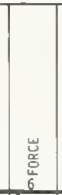 & 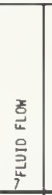 & 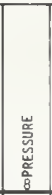 & 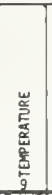 & 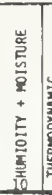 & 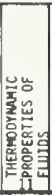 & 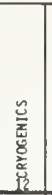 & 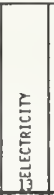 & 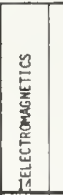 & 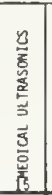 & 舜 & 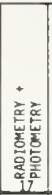 & 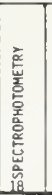 & 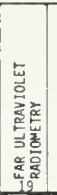 & $气$ & 空 & 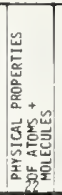 & 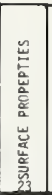 & 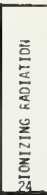 \\
\hline 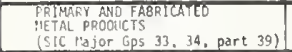 & & $3_{4}^{3}$ & & $\sqrt{2}$ & 1 & 2 & & 1 & 2 & & $\int_{2}^{1}$ & & $2_{2}^{3} 1^{2}$ & & & & & & & 4 & & & $\frac{3}{3}$ & $4^{4}$ \\
\hline 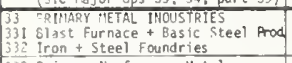 & & $\begin{array}{c}x \\
x \\
x=-1 \\
x\end{array}$ & & $3,5,6$ & & $2,5,6$ & & & $\begin{array}{l}x \\
x \\
x \\
x \\
x\end{array}$ & & $\frac{2}{5}$ & 2 & & & & & & & & $\begin{array}{l}7 \\
x \\
\end{array}$ & & & 2 & \\
\hline 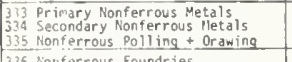 & & 2,9 & & $x$ & & ${ }_{1}^{x}$ & & & $\begin{array}{l}x \\
x \\
x \\
x \\
x\end{array}$ & & & 1,3 & & & & & & & & & & & 3 & ? \\
\hline 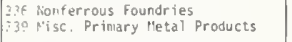 & & & & & & & & & $\begin{array}{l}x \\
x \\
x\end{array}$ & & & 8 & & & & & & & & $\begin{array}{l}x \\
x\end{array}$ & & & & \\
\hline 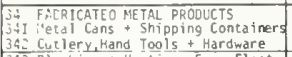 & & $x$ & & & $x$ & & & & & & & & & & & & & & & & & & & \\
\hline 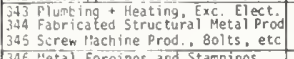 & & {$\left[\begin{array}{c}3 \\
1,3,9 \\
x\end{array}\right]$} & & & & $\begin{aligned} 1 \\
2 \\
-2\end{aligned}$ & & 1 & 3 & 3 & 3 & 3 & & & & 3 & & & & $x$ & & & & 3 \\
\hline 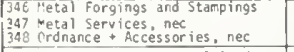 & 3 & & & & & $\begin{array}{c}x \\
3,9 \\
\end{array}$ & & 3 & & 3 & & & 3,9 & & & & & & & & & & & $\begin{array}{r}9 \\
-3\end{array}$ \\
\hline $\begin{array}{l}3.99 \mathrm{msc} \text {. Fabricated Metal Products } \\
39 \mathrm{msc} \text {. HRNufacturingi industries }\end{array}$ & & $4,7,8$ & & & & 3,5 & 4,8 & & & & & & & & & & & & & 4.8 & & & & \\
\hline $\begin{array}{l}391 \text { Jewelry, silverware, Pla ted wared } \\
393 \text { : ius ical Instruments }\end{array}$ & & & & & & & & & & & & & & & & & & & & & & & & \\
\hline $\begin{array}{l}\text { PWCHHISERY, EXCEPT ELECTRICAL } \\
\text { (SIC Major Group 35) }\end{array}$ & & $\sqrt{4}$ & 2,3 & $\overline{21}$ & 27 & 3 & & 2 & 23 & 2 & ${ }_{2}^{2}$ & & 1 & 1 & & & & & & 2 & & & & \\
\hline 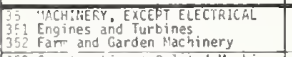 & & $\begin{array}{l}1 \\
x \\
x\end{array}$ & $x$ & $\bar{x}$ & & $\frac{1}{3}$ & 1 & ' & 3 & & 1.9 & & 1 & & & & & & & $x$ & & & & \\
\hline 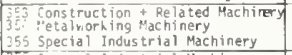 & & $\begin{array}{r}7,3,7 \\
x \\
2,3,5\end{array}$ & 1 & & & $\frac{3}{1.6}$ & & $\begin{array}{c}1.4 \\
1,2 \\
2 \\
2\end{array}$ & 1 & & 1,9 & & & & & 1 & & & & & & & & \\
\hline 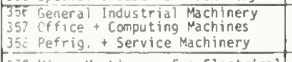 & & $\begin{array}{c}x \\
x, 4,9 \\
5 \\
9\end{array}$ & 1.4 & & $\begin{array}{l}6 \\
6\end{array}$ & $\begin{array}{l}7.8 .9 \\
3,6 \\
1\end{array}$ & $\begin{array}{l}3.4 .6 \\
2,5,6\end{array}$ & \begin{tabular}{|l}
$5.6,8$ \\
$2-4,9$ \\
5
\end{tabular} & \begin{tabular}{|l}
2 \\
3 \\
3 \\
5
\end{tabular} & 5 & 3.9 & $\begin{array}{r}, 8 \\
3 \\
5,6 \\
\end{array}$ & $\begin{array}{l}8 \\
3\end{array}$ & ${ }_{1}^{3}$ & & 3 & & & & $T$ & & & 3 & \\
\hline 559 Visc, lachinery, Exc. Electrical & & 9 & & & & & & & & 2 & & & & & & & & & & & & & & \\
\hline 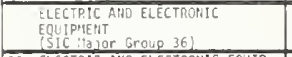 & 1 & $\begin{array}{ll}3 \\
3\end{array}$ & $\sqrt{2} 1^{3}$ & $\frac{3}{3}$ & & 2 & & 3 & 23 & $1^{2}$ & & & $2^{3}$ & $3^{3} 3^{2}$ & & 2 & $2^{3}$ & 2 & & & $4^{2}$ & $2^{3}$ & $2^{3}$ & $\frac{2}{32}$ \\
\hline 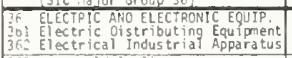 & & $\stackrel{x}{x}$ & 1 & ${ }_{1}^{2}$ & & 1 & & $\begin{array}{l}x \\
1 \\
1\end{array}$ & 2 & $\begin{array}{c}x \\
1,2,4\end{array}$ & 2 & $\begin{array}{c}x \\
1,3\end{array}$ & $\frac{2}{2}$ & & & 1 & & & & & & & & \\
\hline 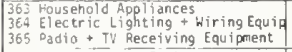 & 9 & $\begin{array}{c}1.2 .6 \\
1\end{array}$ & & & & ${ }_{3}^{4}$ & 4,5 & $1,2,4$ & & $\begin{array}{c}2,3,4 \\
i \\
i\end{array}$ & & & & & & $\begin{array}{c}2,4 \\
\times\end{array}$ & $1,6,8$ & $\begin{array}{l}x \\
x\end{array}$ & 1,6 & & & 1 & $i$ & \\
\hline 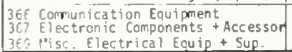 & $\frac{2}{4}$ & $\frac{2}{2,3,9}$ & & 9 & & $\begin{array}{l}1 \\
9\end{array}$ & & $\begin{array}{l}1,2 \\
1,4,9 \\
3\end{array}$ & $x$ & $\begin{array}{l}x \\
x\end{array}$ & & 4 & $\begin{array}{c}1,4-9 \\
1,2\end{array}$ & $\begin{array}{l}x \\
1,3=9 \\
1\end{array}$ & & & 2 & & & 3 & 2 & 3 & $\begin{array}{l}x \\
3,4 \\
9\end{array}$ & $\begin{array}{r}2 \\
4-9 \\
-3\end{array}$ \\
\hline 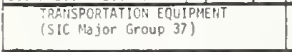 & 1 & $\frac{3}{3}$ & $3^{3}$ & 27 & & 2 & 2 & 4 & $\overline{3}$ & 2 & ${ }^{2} 1$ & 23 & $2^{3}$ & $3^{3} 3^{2}$ & & $2^{2}$ & & 2 & & 4 & $3_{3}^{2}$ & & $2^{3}$ & $3^{2}$ \\
\hline 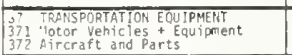 & $x$ & $\stackrel{x}{x}$ & ${ }_{x}^{x}$ & & & $x_{x}^{x}$ & $x$ & & $\underset{x}{x}$ & $x$ & & & $x$ & & & $x$ & $x_{x}^{x}$ & $x$ & & $\stackrel{x}{x}$ & & & $\begin{array}{l}x \\
x\end{array}$ & \\
\hline 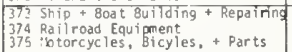 & 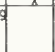 & $\begin{array}{l}1 \\
x \\
x \\
x\end{array}$ & $\begin{array}{l}x \\
x \\
x\end{array}$ & & & $\begin{array}{l}x \\
x \\
x\end{array}$ & $\frac{1}{x}$ & $\frac{x}{x}$ & & & 1 & $\begin{array}{l}x \\
x\end{array}$ & & & & & & $x$ & & & & & & \\
\hline 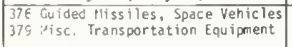 & $\bar{x}$ & $x$ & $\begin{array}{l}x \\
5\end{array}$ & & 5 & $\begin{array}{l}x \\
5 \\
5\end{array}$ & $x$ & $x$ & $x$ & $x$ & 7 & $\begin{array}{l}x \\
2\end{array}$ & $x$ & & & & $x$ & & & $x$ & & & & \\
\hline $\begin{array}{l}\text { INSTRUABNTS + RELATEO PROOUCTS } \\
\text { (STC Hajor Group 38) }\end{array}$ & 3 & $\sqrt[3]{3}$ & $2^{2}$ & $22^{2}$ & $1^{2}$ & $3_{3}$ & 3 & $\sqrt{3} 4$ & $2^{3}$ & 3 & $\sqrt[3]{3}$ & $\sqrt[3]{3}$ & $3^{4}$ & $1^{3} 4^{2}$ & $\begin{array}{ll}2 \\
3\end{array}$ & 3 & $3^{3}$ & 2 & $2^{2}$ & 3 & $\sqrt[4]{4}$ & $2_{2}^{2}$ & $2^{3} 2$ & $\int_{3}^{3}=1$ \\
\hline 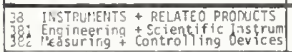 & 5 & $\begin{array}{c}x \\
3,4,9 \\
3\end{array}$ & $x$ & & ${ }_{4}^{x}$ & $\begin{array}{c}x \\
3,9\end{array}$ & $\begin{array}{c}x \\
x, 4 \\
3,9\end{array}$ & ${ }_{3}^{x}$ & $\begin{array}{c}x \\
2,3,9\end{array}$ & $2,3,9$ & $\frac{1}{3}$ & $\begin{array}{c}x \\
4,5\end{array}$ & $\begin{array}{c}x \\
3,5\end{array}$ & $\begin{array}{l}x \\
5,9\end{array}$ & & $x$ & $\begin{array}{c}x \\
2,3 \\
\end{array}$ & $\frac{1}{3}$ & $x$ & $x$ & $x$ & $\begin{array}{c}x \\
2,5,9\end{array}$ & $\begin{array}{l}x \\
3 \\
\end{array}$ & 2,3 \\
\hline 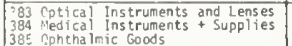 & & $\begin{array}{l}x \\
1\end{array}$ & $x$ & & & 2 & 1 & & & & & 1 & & & 1,3 & & 1,3 & $\begin{array}{l}x \\
1\end{array}$ & $x_{3}^{x}$ & $x$ & $\begin{array}{l}x \\
1\end{array}$ & & & 2 \\
\hline $\begin{array}{l}396 \text { Photographic Equi pment, + Sup, } \\
387 \text { hatches. Clocks and watthcas ses }\end{array}$ & $x$ & ${ }_{x}^{x}$ & & $\frac{x}{x}$ & & & & & $\begin{array}{l}x \\
x\end{array}$ & & & & & & & & $x$ & & & $x$ & & & 8 & $T$ \\
\hline 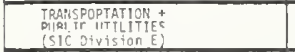 & $\sqrt{34}$ & 1 & $\overline{2}^{2}$ & & & ? & $\overline{3}$ & $\sqrt{4} 4$ & 2 & & $\frac{22^{2}}{2^{2}}$ & $\begin{array}{ll}2 & 1 \\
2 & 3\end{array}$ & $\sqrt[3]{4}$ & $4_{3}^{4} 3^{3}$ & & & & ${ }_{2}^{2} 1^{3}$ & $2_{4}^{2} 1^{32}$ & $\frac{21}{33}$ & 3 & & & $44^{3}$ \\
\hline 40 P.PILROAD TRANSPRRTATION & 10 & & 10 & & & 10 & & & & & & & & & & 10 & & & & & & & & \\
\hline $\begin{array}{l}\text { 4I LOCAL ANO IWTERURBAN } \\
\text { PASSENGER TPAISIT }\end{array}$ & & & & & & 70 & & 70 & & & & $\begin{array}{c}11,21 \\
40\end{array}$ & & & & & & & & & & & & \\
\hline 42 TPUCKIMG ARE WAPEHOUSING & & & 10 & & & & & & & & & $\begin{array}{c}10,21 \\
22\end{array}$ & & & & 10,31 & & & & & & & & \\
\hline 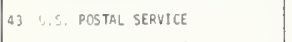 & & & & & & & & & & & & & $x$ & $x$ & & $x$ & $x$ & & & x & & & & \\
\hline 44 :LTEP TPANSPOFTATIOH & 11.20 & & & & & 63 & & & & & 11 & $\begin{array}{l}11,20 \\
41,54\end{array}$ & & & & & & & & & & & & \\
\hline 45. TPAisprirtatton BY AIP. & $\begin{array}{l}111 \\
21 \\
82\end{array}$ & & & & & $x$ & 82 & $x$ & 11 & & 83 & 82,83 & $\begin{array}{c}11,82 \\
83\end{array}$ & & & $\begin{array}{l}11,21 \\
822 \\
\end{array}$ & 82 & & & 11,21 & & & & 11 \\
\hline$\because 6$ FIPE LIIEES, EXCEPT IIRTURAL GAS & & & & & & & $x$ & & $x$ & & $x$ & & & & & $x$ & & & & $x$ & & & & $x$ \\
\hline AT TSPSTPOPTATIOH SERVICES & & & & & & 82 & & & & & & & & & & & & & & & & & & \\
\hline Ammarartist & $\begin{array}{l}11,21 \\
32,33\end{array}$ & & 11 & & & 11.21 & & 32,33 & & & & & 11,21 & $x$ & & 11 & & & & & $x$ & $x$ & & \\
\hline 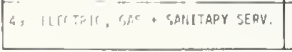 & 11 & 20 & 11 & & & & $x$ & 20 & 11,20 & 20 & $\begin{array}{c}22,23 \\
32\end{array}$ & $\begin{array}{l}11,20 \\
30,52\end{array}$ & 11 & 20 & & 20 & & & & 20 & & & & 20 \\
\hline
\end{tabular}


Table J-4. Direct users of NBS Outputs--SIC Major Groups 50-89.

\begin{tabular}{|c|c|c|c|c|c|c|c|c|c|c|c|c|c|c|c|c|c|c|c|c|c|c|c|}
\hline 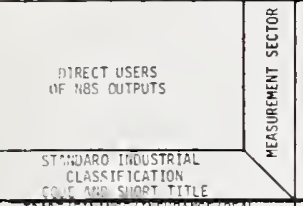 & 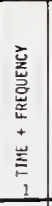 & 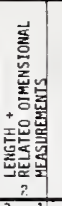 & 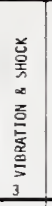 & 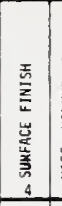 & 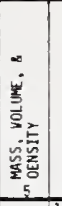 & 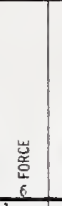 & 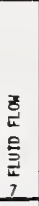 & 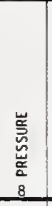 & 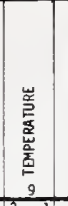 & 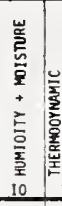 & 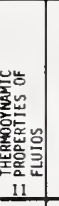 & 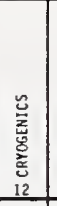 & $\begin{array}{l}\text { 䓌 } \\
\text { 悹 } \\
\text { 总 } \\
\text { 13 } \\
13\end{array}$ & 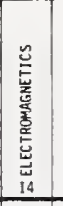 & 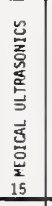 & 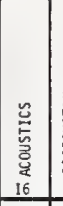 & 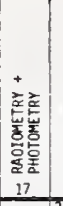 & 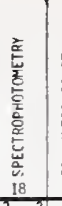 & 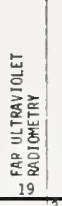 & $\begin{array}{l}\tilde{0} \\
0 \\
0 \\
20 \\
20\end{array}$ & $\begin{array}{l}\tilde{u} \\
\text { 岁 } \\
21 \\
\end{array}$ & 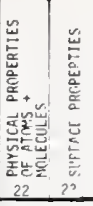 & 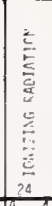 \\
\hline 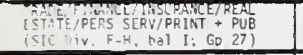 & 3 & $\begin{array}{l}3 \\
41 \\
\end{array}$ & & & & 2 & & 1 & $\begin{array}{ll}2 & 1 \\
2 & 1 \\
\end{array}$ & & & 1 & & & & & & $2^{2}$ & & $\frac{2}{1}$ & 3 & & $3^{4}$ \\
\hline$=$ WNLESALE TRADE- OURRBLE GODOS & & $\begin{array}{c}10,30 \\
84\end{array}$ & & & & & & & 10.86 & 43 & & 63,78 & & & & & & & & & 65,86 & & \\
\hline a lisale trale- nonourable gocos & & & & & $\begin{array}{c}22,70 \\
80\end{array}$ & & & & & & & $\begin{array}{c}40,50 \\
61\end{array}$ & & & & & & & & & & & \\
\hline $\begin{array}{l}\text { GULPWC MATERINLS * } \\
\text { GARUEE. SLPPLIES }\end{array}$ & & & & & & & & & & & & & & & & & & & & & & & \\
\hline EEATPL I'EPCHANOISE STORES & & & & & & & & & & & & & & & & & & 11 & & x & & & \\
\hline$\therefore$ roner stomes & & & & & 11.51 & & & & $x$ & & & & & & & & & & & & & & \\
\hline $\begin{array}{l}\text { UTOMOTIWE OERLERS + } \\
\text { SEISICE STRTIOKS }\end{array}$ & & & $\begin{array}{r}11,21 \\
91 \\
\end{array}$ & & 41 & & & & & & & & & & & & & & & & & & \\
\hline A APPA:RL + ECCESSORY STORES & & & & & & & & & & & & & & & & & & & & & & & \\
\hline $\begin{array}{l}\text { FURRITUPE - HOTE FURNISHINGS } \\
\text { SCCRES }\end{array}$ & & & & & & & & & & & & & & & & & & & & & & & \\
\hline SO ERT:LG ALO DRTIKING PLACES & & & & & & & & & & & & 12 & & & & & & & & & & & \\
\hline 三o "ISCELLANEOUS PETAIL & 44 & & & & & & & & & & & & & & & & & & & & & & \\
\hline$\because 8 \operatorname{sen} n i t i s$ & & & & & & & & & & & & & & & & & & & & $x$ & & & \\
\hline E! CPEOIT AGENCIES OTHER THAN BANKS & & & & & & & & & & & & & & & & & & & & $x$ & & & \\
\hline 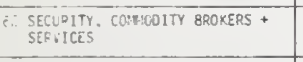 & & & & & & & & & & & & & & & & & & & & & & & \\
\hline C3 1:SUFAAICE CARRIERS & & & & & & & & & & & & 31 & & & & & & & & $x$ & & & 20,31 \\
\hline $\begin{array}{l}\text { fi I, SSURARCE AGESTS, 8ROKERS - } \\
\text { SEPVICE }\end{array}$ & & & & & & & & & & & & & & & & & & & & & & & \\
\hline FS PEAL ESTATE & & & & & & & & & & & & & & & & & & & & & & & \\
\hline $\begin{array}{l}\text { FF CGFBIMEO PERL ESTATE, IHSURAMCE, } \\
\text { ETC. }\end{array}$ & & & & & & & & & & & & & & & & & & & & & & & \\
\hline E. HCONG + it:ESTREMT OFFICES & & & & & & & & & & & & & & & & & & & & & & & \\
\hline 73 HCTELS + OTHER LODGING PLACES & & & & & & & & & & & & & & & & & & & & & & & \\
\hline 7 PEF OLIFL SEPVICES & & 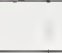 & & & & & & & & & & & & & & & & & & & & & \\
\hline 73 BUSIR:ESS SEPVICES & 91,92 & $\begin{array}{l}91,92 \\
97 \\
\end{array}$ & & & 91.979 & $\begin{array}{l}91,92 \\
97.99\end{array}$ & & 91.97 & 91.979 & 91.97 & & 91,97 & 91 & 91,97 & 91 & & 91 & & & $x$ & & 91,97 & \\
\hline 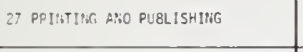 & & 53.93 & & $\begin{array}{r}53,54 \\
93,95 \\
\end{array}$ & & & & & $\begin{array}{l}21,31 \\
4 i\end{array}$ & & & & & & & & & & $41,533^{5}$ & $\begin{array}{l}51,52 \\
93\end{array}$ & & 21,31 & \\
\hline 7 AUTO PEPAIP, SERVICES + GAPAGES & & & 49 & & & & & & & & & & & & & & & & & & & 1 & \\
\hline $7 E$ IISC. PEPATR SERVICES & 31,99 & & 94 & & & & & & & & & & 29 & 22 & & & & & & & & & \\
\hline 78 NOTIOHS PICTUPES & & & & & & & & & & & & & & & & & & & & & & & \\
\hline 79 hWSEAUENTT + PECREATION SERVICES & & & & & & & & & & & & & & & & & & & & & & & \\
\hline i LeEcal sepUICEs & & & & & & & & & & & & & & & & & & & & & & & \\
\hline 23 SACIAL SEPVICES & & & & & & & & & & & & & & & & & & & & & & & \\
\hline 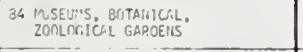 & & & & & & & & & & 11 & & & & & & & & & 11,21 & & & & \\
\hline 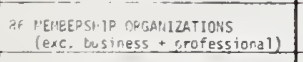 & & & & & & & & & & & & & 99 & & & 31 & & & & & & & \\
\hline ZE PPTHATE HCCSEHALOS & & & & & $x$ & & & & & & & & & & & & & & & & & & \\
\hline S "VISCELLATEENS SEPVICES & & 11 & & & 221 & 11,22 & & 11,22 & $=11,22$ & 22 & & & 11 & & & 11 & & & & 22 & & 22 & 11.22 \\
\hline 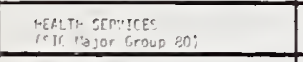 & & & & $22^{2}$ & $4^{2}$ & & & 1 & 3 & 1 & & & $\begin{array}{ll}22 \\
2^{2} \\
\end{array}$ & 1 & $2^{3}{ }^{3}$ & $2^{2} r^{3}$ & & $2^{2} 2^{2}$ & $2^{2} ?^{2}$ & 1 & & & $2^{4} 4^{3}$ \\
\hline HEALTH SEPVICES & & & & $\mid 71,726$ & & & & & 60,711 & & & $\begin{array}{ll}11,60 \\
71\end{array}$ & & 71 & $x$ & $\begin{array}{c}11,60 \\
81\end{array}$ & & $60.71 \begin{array}{ll}58 \\
71\end{array}$ & $\begin{array}{l}7.21 \\
50,60 \\
71,72 \\
\end{array}$ & 71 & 60 & & 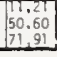 \\
\hline
\end{tabular}



This section of this report is a combination of three sections originally prepared for separate purposes, namely, the References section for the report proper, a Bibliography section which listed in chronological order all of the significant background materials accumulated or noted during the course of the 1972-75 NBS Study of the National Measurement System, and a Sumary of Background Documents section which summarized the essential content and impact of some of the more important items contained in the Bibliography. The Bibliography is the author's personal compilation of the source materials that he wishes to list as part of the permanent archival record of this project. As such, it includes many items that are of only limited availability, especially some of the NBS internal working documents that are now available only in fragmentary forms.

Items are listed in chronological order. A cross-referenced, alphabetized author index follows the bibliographic entries. The sources for abbreviations of journal citations are the Chemical Abstracts Service Source Index (American Chemical Society, Chemical Abstracts Service, The Ohio State University, Columbus, Ohio, 1975) and the NBS Manual for Scientific and Technical Communications (U.S. Dept. Commerce--Nat. Bur. Stand, June 1969, rev. June 1971).

[1] Jefferson, Thomas, Secretary of State, PIan for establishing uniformity in the coinage, weights, and measures of the United States, Report of the First Congress, second session, No. 15, pp. 13-30 (July 4, 1790), published in American State Papers, Class X, Miscellaneous, v. I, p. 13 (Gales and Seaton, Washington, D.C., 1834).

Purpose: Response to request of 15 January 1790 by House of Representatives "to prepare and report a proper plan or plans for establishing uniformity in the currency, weights, and measures of the United States."

Approach: (1) Technology assessment of means of achieving uniform weights and measures.

(2) Survey of weights and measures system in current use in the United States.

(3) Correspondence with England and France.

(4) Construction of two alternative scenarios for future U.S. measurement system.

Findings: (1) Decision by the U.S. should be postponed pending resolution of similar concerns in England and France.

(2) The second (pendulum) rod is the preferred invariable natural standard of length: "a uniform cylindrical body of iron, of such length, as, in latitude $45^{\circ}$, in the level of the ocean, and in a cellar, or other place, the temperature of which does not vary throughout the year, shall perform its vibrations, in small and equal arcs, in a period of one second of mean time."

(3) "To render uniform and stable the system that we already possess [basically that of England] [requires] ... 1st, That the present measures of length be retained, and fixed by an invariable standard. 2d, That the measures of surface remain as they are... 3d, That the unit of capacity, now so equivocal, be settled at a medium and convenient term, and defined by the same invariable measures of length. 4th, That the more known terms in the two kinds of weight be retained, and reduced to one series.... And $5 \mathrm{th}$, That the quantity of pure silver in the money unit be expressed in parts of the weights so defined." A minute change in the weight of silver in the recently established decimal coinage system is recommended, so "that this, as the unit of coin, will link in system with the units of length, surface, capacity, and weight, whenever it shall be thought proper to extend the decimal ratio through all these branches."

(4) As an alternative, a completely decimal system of weights and measures is proposed, which is based on the second rod being set equal to exactly five (new) feet, the new foot being experimentally equal to 11.744736 present inches.

Effects: The report was used as a basis for deliberation by a series of Congressional committees. The first, in 1791, opted for delay. The second, in 1792, opted for adoption of Jefferson's decimal system. The third recommended adoption of revision of the English system; a bi11 passed the House in May 1796 but died in the Senate. Difficulties in seeing a way through the technical perplexities inherent in the problem are probably the primary reason for the lack of Congressional action, despite repeated urgings by President Washington and urgent requests from the States for action to relieve the existing confusion in commercial transactions. 
[2] Adams, John Quincy, Secretary of State, Report of the Secretary of State upon weights and measures, 245 pages (J. D. Moore, Feb. 22, 1821), published in American State Papers, Class X, Miscellaneous, v. II, p. 656 (Gales and Seaton, Washington, D.C., 1834).

Purpose: Response to Senate resolution of March 3, 1817, to prepare and report to the Senate "a statement relative to the regulations and standards for weights and measures in the several states, and relative to proceedings in foreign countries, for establishing uniformity in weights and measures, together with such propositions relative thereto, as may be proper to be adopted in the United States."

Approach: (1) "Natural philosophy" of weights and measures.

(2) Development of the history of weights and measures from the earliest times, especially in England.

(3) Systematic consideration of the three major points defined in the Senate resolution.

Findings: (1) "While decimal arithmetic for the purposes of computation shoots spontaneously from the nature of man and of things, it is not equally adapted to the numeration, the multiplication, or the division, of material substances," so that it is not inherently obvious that a decimal measurement system is fully desirable.

(2) The power of the legislator is limited by the extent of his territories and the numbers of his people, and is limited over time. He has neither power over the facts of nature nor the will of his subjects. He is liable to enact laws in this field inadequate to their purpose and inconsistent with one another.

(3) "Such was originally the system of English weights and measures and such is it now in its ruins."

(4) "If that universal uniformity, so desirable to human contemplation, be an obtainable perfection, it is now obtainable only by the adoption of the new French system of metrology, in all its important parts.... This system... whether destined to succeed, or doomed to fail, will shed unfading glory upon the age in which it was conceived, and upon the nation by which its adoption was attempted, and has in part been achieved." "... the establishment of such a system so obviously tends to that great result, the improvement of the physical, moral, and intellectual condition of man upon earth; that there can be neither doubt nor hesitation in the opinion, that the ultimate adoption, and universal though modified application of that system, is a consummation devoutly to be wished."

(5) "But where is the steam engine of moral power to stem the stubborn tide of prejudice, and the headlong current of inveterate usage?"

(6) "A single and universal system can be finally established only by a general convention, to which the principal nations of the world shall be parties, and to which they shall all give their assent."

(7) "Of all nations of European origin, ours is that which least requires any change in the system of their weights and measures. With the exception of Louisiana, the established system is, and always has been, throughout the Union, the same."

(8) "A particular statement of the regulations of the several states relative to weights and measures, is subjoined to this report, in the appendix."

(9) Substantial inconsistencies exist among the several states in the measurement standards that are in use, and in the measurement capabilities that they possess.

(10) "In the exercise of the authority of Congress, with a view to the general uniformity of weights and measures, there are four different courses of proceeding which appear to be practicable: 1. To adopt, in all its essential parts, the new French system of weights and measures.... 2. To restore and perfect the old English system of weights, measures, moneys, and silver coins.... 3. To devise and establish a system by adaptation of parts of each system to the principles of the other. 4. To adhere, without any innovation whatever, to our existing weights and measures, merely fixing the standard."

(11) "The substitution of an entire new system of weights and measures, instead of one long established and in general use, is one of the most arduous exercises of legislative authority. There is indeed no difficulty in enacting and promulgating the law; but the difficulties of carrying it into execution are always great, and have often proved insuperable. Weights and measures may be ranked among the necessaries of life, to every individual in human society. They enter into the economical arrangements and the daily concerns of every family. They 
are necessary to every occupation of human industry; to the distribution and security of every species of property; to every transaction of trade and commerce; to the labors of the husbandman; to the ingenuity of the artificer; to the studies of the philosopher; to the researches of the antiquarian; to the navigation of the mariner, and the marches of the soldier: to all the exchanges of peace, and all the operations of war. The knowledge of them, as in established use, is among the first elements of education, and is often learnt by those who learn nothing else, not even to read and write. This knowledge is rivetted in the memory by the habitual application of it to the employments of men throughout life. Every individual, or at least every family, has the weights and measures used in the vicinity, and recognized by the custom of the place. To change all this at once, is to affect the well being of every man, woman, and child in the community.... Were the authority of Congress unquestionable to set aside the whole existing system of metrology, and introduce a new one, it is believed that the French system has not yet attained that perfection which would justify so extraordinary an effort of legislative power at this time."

(12) "The restoration of the old English... system... would require an exercise of authority no less transcendant than the introduction of the French system."

(13) Pursuing the third alternative seems to have little practical value.

(14) While our current system of weights and measures can certainly be improved, it would not be wise to do this unilaterally, independently of Great Britain, France, and Spain. To most effectively pursue the ultimate objectives implicit in the charge from Congress, "it is supposed to be most congenial to the end, to attempt no present change whatever in our existing weights and measures; to let the standards remain precisely as they are; and to confine the proceedings of Congress at this time to authorizing the Executive to open those communications with the European nations...., and to such declaratory enactments and regulations as may secure a more perfect uniformity in the weights and measures now in use throughout the Union. The motives are four:" a. We cannot afford to lose the present uniformity with Great Britain. b. The present system possesses virtues that we should not lightly sacrifice. c. French experience proves "that binary, ternary, duodecimal, and sexagesimal divisions are as necessary in the practical use of weights and measures, as the decimal divisions are convenient for calculations resulting from them; and that no plan for introducing the latter can dispense with the continued use of the former." d. "The only material improvement, of which the present system is believed to be susceptible, would be restoration of the identity between weights and silver coins," and it would not be worthwhile to give up our new coinage system to get this advantage.

(15) "In the mean time, should Congress deem it expedient to take immediate steps... the act of Congress should embrace the following objects: 1. To declare what are the weights and measures to which the laws of the United States refer as the legal weights and measures of the Union. 2. To procure positive standards... of the yard, bushel, wine and beer gallons, troy and avoirdupois weights; to be deposited in such public office at the seat of government as may be thought most suitable. 3. To furnish the executive authorities of every state and territory with exact duplicates of the national standards.... 4. To require, under suitable penal sanctions, that the weights and measures used at a11 the custom-houses, and land surveys, and post offices, and, generally, all the offices under the authority of the United States, in the execution of their laws, should be conformable to the national standards. 5. To declare it penal to make or to use, with intent to defraud, any other weights and measures than such as shall be conformable to the standards." "In fixing... a definition of the foot, its exact proportion to the standard metre of France should be declared." "The proportion of the troy and avoirdupois pounds to the kilogramme might be... declared in like manner."

(16) That the French system is worthy of the acceptance of the nations of the world, "is believed to be beyond question. But opinion is the Queen of the world; and the final prevalence of this system beyond the boundaries of France's power must await the time when the example of its benefits, long and practically enjoyed, shall acquire that ascendancy over the opinions of other nations which gives motion to the springs and direction to the wheels of power.

Respectfully submitted, John Quincy Adams." 
Effects: There was no immediate reaction on the part of Congress to the Adams report. On May 29, 1830, the Senate adopted the following resolution:

"he'sorved, That the Secretary of the Treasury be directed to cause a comparison to be made of the standards of weights and measures now used at the principal custom-houses of the United States, and report to the Senate at the next session of Congress."

This resolution marked the beginning of Federal action in this field.

[3] Hallock, W., and Wade, H. T., The Evolution of Weights and Measures and the Metric System (Macmillan Co., New York, N.Y., 1906).

[4] Measurements for the Household, Nat. Bur. Stand. (U.S.), Circ. 55, 149 pages (Aug. 1915).

[5] Functions, standards, purpose (one page statement), Nat. Bur. Stand. (U.S.) (1917).

[6] Whitney, A. W. , The place of standardization in modern iife (Central Executive Council, Inter American High Commission, Washington, D.C., 1924).

[7] Jones, S. A., Weights and measures in Congress. Historical summary covering the period of the Continental Congress to and including the adoption of the joint resolutions of 1836 and 1838, Nat. Bur. Stand. (U.S.), Misc. Publ. M122 (Mar. 1936).

[8] Briggs, L. J., The national standards of measurement, Ind. Stand., 227 (Sept. 1939).

[9] Moreau, H., The genesis of the metric system and the work of the International Bureau of Weights and Measures, J . Chem. Educ. 30, 3-20 (Jan. 1953).

Purpose: Definitive discussion of subject, published in scholarly journal.

Approach: Historical description of field, institutions, and technical efforts.

Findings: A definitive and concise history of the origins and activities of one of the oldest international institutions.

Appraisal: A key reference document for those needing such a concise summation.

[10] Perry, J., The Story of Standards (Funk and Wagnalls, New York, N.Y., 1955).

[11] McNish, A. G., Dimensions, units, and standards, Phys. Today, 19-25 (Apr. 1957).

[12] Huntoon, R. D., and McNish, A. G., Present status of research on physical constants, Nuovo Cimento, Suppl. 6, Ser. X., 146-84 (Jan. 1957).

[13] Smith, R. W. The Federai Basis for weights and measures, Nat. Bur. Stand. (U.S.), Circ. 593, 23 pages (June 1958).

Purpose: A historical review of Federal legislative efforts, statutes, and administrative action in the field of weights and measures in the United States.

Approach: Updating, expansion, and systemization of material contained in earlier NBS publications on this subject, especially NBS Misc. Publ. 64 and 122 by Louis A. Fischer and Sarah Ann Jones, respectively.

Findings: A connected and reasonably comprehensive story of the Federal contribution to the legislative basis for weights and measures admioistration in the United States.

Effects: A ready response to the continuing demand on NBS for information on various phases of weights and measures administration.

[14] MCNish, A. G., Classification and nomenclature for standards of measurement, IRE Trans. Instrum. I-7, 371-8 (Dec. 1958).

[15] McNish, A. G., The basis of our measuring system, Proc. IRE 47, 636-43 (May 1959).

Purpose: Description of current status and opportunities for improvement of physical standards which form the basis of our system for making physical measurements.

Approach: Historical survey; discussion of use of physical constants as standards.

Findings: (1) "We see a transition taking place now from a system based on man-made standards to a system based mainly on physical constants...."

(2) "The prototype standards seem to need little improvement. The advances that we must make in our metrology are in extension of the range over which accurate measurements can be accomplished. Particularly, we need techniques to measure accurately new quantities and new aspects of old quantities to meet the requirements of our expanding technology."

Appraisal: This is the first major pubiication in the train of thinking at NBS that has led directly to this present study of the National Measurement System.

[16] Bendick, J., How Much and Mow Many, The Story of Weights and Measures (McGraw-Hill, New York, N.Y., 1960). 
[17] Irwin, K. G., Romance of Weights and Measures, 144 pages (Viking Press, New York, N.Y., 1960).

Purpose: Description of the basic evolutionary history connecting our current weights and measures with their root sources, stripped of as much of the transient effects of accidental and regional eccentricities as possible. Correlation of the history of weights and measures with the general history and social conditions of different eras and nations.

Approach: Intense research into original sources and a very humanistic way of presenting the results.

Findings: The measurement systems of the ancient Middie East--Egypt, Phoenicia, and Babylon--were oriented to the purposes of peace and commerce, and formed a substantially uniform and rationalized decimal system, in its fullest development conceptually quite similar to today's metric system. Greece introduced the pace and the foot into this system, for military purposes, and in the process of doing so destroyed the decimal simplicity of the earlier system. Rome followed Greece. The Goths acquired the old Phoenician system. When the Goths conquered the Roman empire, the measurement system fragmented as different paths were followed in reconciliation of the Gothic and Roman systems. The Angles, Saxons, and Danes imported the simple Gothic system into England. The Normans brought in the French-Roman system. Our current customary system evolved from the marriage of the two. Meanwhile, the French started all over again with the metric system, which is coming to dominate the world.

Appraisal: A very fascinating story, not told elsewhere to my knowledge. I would like to see an independent verification of Irwin's interpretations.

[18] The 1960 Conference on Standards and Electronic Measurements, IRE Trans. Instrum. I-9, No. 2 (Sept. 1960).

[19] Lance, H.W., The Nation's electronic standards program: Where do we now stand?, IRE Trans. Instrum. I-9, 94-100 (Sept. 1960).

[20] McNish, A. G., and Cameron, J. M., Propagation of error in a chain of standards, IRE Trans. Instrum. I-9, 101-4 (Sept. 1960).

[21] A special report on measurement standards, ISA J 8, No. 2, 38-75 (Feb. 1961).

[22] Hachey, L. E., Better measurements through user feedback, ISA J 8, No. 2, 60-63 (Mar. 1961).

[23] The 01d Market, site of "first standard system of weights and measures," picture postcard from St. Augustine, Fla. (mailed 1961).

[24] Huntoon, R. D., Standards for the future, preprint, Annual Spring Conference, American Standards Association and Standards Engineers Society, Boston, Mass., 18 pages (May 24:25, 1962).

Purpose: Technological forecasting in the measurement standards field, for the guidance of attendees at 1962 standardization conference.

Approach: Trend extrapolation.

Findings: (1) Precision of measurement will continue to be of overriding importance and there will be a continuing demand to push it ahead on all fronts.

(2) The goal that the unit of measurement for physical quantities of the same kind should be the same, will be approached but not reached until the pace of progress diminishes greatly.

(3) The shrinking world will bring into being in the not too distant future the goal that all who are to be engaged in the cooperative process of making measurements and exchanging data should agree to the same unit and all should use it.

(4) The five basic quantity system with its units will continue for some time, with units for all other quantities defined in an independently reproducible way from them.

(5) In the next decade we may see the number of units established on our independent basis decreased to 3 or possibly 2 , but we will continue to consider five physical quantities with their units as basic.

(6) We must hope for progress toward uniformity of approach to the problem of using standards which are more precisely intercomparable than they can be related to the unit definitions. 
(7) We will see more and more of our standards tied to nuclear, atomic, or molecular properties.

(8) Advances in instrumentation and measurement brought about by discoveries such as the Mossbauer effect and lasers will permit the definition of all units in terms of arbitrary assignment of values to fundamental constants.

(9) The whole system will tend toward its inherent goals of simplicity, uniformity, and consistency.

(10) National standards laboratories will become free of the job of calibration and concentrate almost entirely upon development and dissemination of instrumentation and procedures which will put every major laboratory on a sound independent basis. The extensive problem of traceability will essentially disappear.

Appraisal: This paper almost but did not quite coin the phrase National Measurement System. The last conclusion today seems overstated.

[25] Selby, M. C., et al., A program to provide information on the accuracy of electrical measurements, Proc. IEEE 51, 569-74 (Apri1 1963).

[26] Eisenhart, C., Realistic evaluation of the precision and accuracy of instrument calibration systems, J. Res. Nat. Bur. Stand. (U.S.), 67C (Eng. and Instr.), No. 2, 161-87 (April-June, 1963).

[27] McNish, A. G., Fundamentals of measurement, Electro-Technology (Beverly Shores, Indiana), $113-28$ (May 1963).

Purpose: A basic tutorial paper.

Approach: Examination of historical concepts of measurement and the evolution of various measurement systems and techniques. The discussion covers both primary and derived quantities, precision and accuracy, physical constants, and the keystone position of centralized standards laboratories.

Findings: Implicit in the statements above.

Appraisal: A basic tutorial paper.

[28] Judson, L. V., Weights and measures of the United States, a brief history, Nat. Bur. Stand. (U.S.), Misc. Pub1. 247, 30 pages (Oct. 1963).

Purpose: Partial satisfaction of the continuing demand for information about the origins of the metrological standards of the United States on the part of students, educators, authors, government officials, and the general public.

Approach: Revision and updating of an earlier paper by Louis A. Fischer, NBS Misc. Publ.64. Findings: An historical account of the subject matter, plus a description of current and historical standards of mass and length now in the possession of NBS.

Appraisal: A strictly hardware and "museum" oriented paper.

[29] White, L. T., Jr., The medieval roots of modern science and technology, from Book, Perspectives in Medieval History, Ed. K. F. Drew and F. S. Lear (Univ. Chicago Press, Chicago, I11., 1963); reprinted in Book, The Economic Development of Western Europe, v. I, The Middle Ages and the Renaissance, Ed. W. Scoville and C. LaForce, pp. 60-75 (D. C. Heath and Co., Lexington, Mass., 1969).

[30] Lescure, W. J., Preliminary inventory of the records of the National Bureau of Standards (record group 167), General Services Administration, National Archives and Records Services, The National Archives (Oct. 1964).

[31] Man and his measures--the weights and measures mural, brochure, Nat. Bur. Stand. (U.S.), (undated--1965?).

[32] Egyptian Royal Cubit of Amenhotep I, single page, unattributed (undated--1965?).

[33] Huntoon, R. D., and Wildhack, W. A., Planning for better measurement accuracy, ISA J 12 , No. 1, 57-60 (Jan. 1965).

[34] Huntoon, R. D., Our measurement system and its future, Res. Dev. 16, No. 1, 16-21 (Jan. 1965).

[35] Huntoon, R. D., Role of laboratory measurement in physics teaching at the high school and college level, talk presented to Chesapeake section of the American Association of Physics Teachers (Apri1 10, 1965).

[36] Wildhack, W. A., Powel1, R. C., and Mason, H. L., Accuracy in measurements and calibrations, 1965, Nat. Bur. Stand. (U.S.), Tech. Note 262, 151 pages (June 1965).

[37] Powel1, R. C., Accuracy in electrical and radio measurements and calibrations, 1965, Nat. Bur. Stand. (U.S.), Tech. Note 262-A, 93 pages (June 1965). 
[38] Huntoon, R. D., Role of NBS in the National Measurement System, internal NBS memorandum, to list (Aug. 24, 1965).

[39] Astin, A. V., Away from arbitrary man-made standards toward a system based on physical constants, Res. Dev. 16, No. 10, 68-69 (0ct. 1965).

[40] Scientists discusS NBS role in the national measurement system, Nat. Bur. Stand. (U.S.), press release, TRG-6441, 5 pages (0ct. 5, 1965).

[41] Huntoon, R. D., Status of the national standards for physical measurement, Science 150, 169-78 (8 0ct. 1965).

[42] McNish, A. G., Measurement standards, Int. Sci. Technol., 58-66 (Nov. 1965).

[43] Huntoon, R. D., The basis of our measurement system, Physics Teacher $4,113-20$ (Mar. 1966).

[44] Eskite, W. H., Jr., Studies of the national measurement system, final report on Department of Commerce Science and Technologu Fellowship Program assignment, NBS internal working document (July 1, 1966).

Purpose: Assisting the Director of the Institute for Basic Standards in developing further the concept of the National Measurement System.

Findings: (1) Definition of the functional relationships between the organizations that make up the National Measurement System from the system's point of view, and the intellectual activities that govern their functioning.

(2) Identification, description, and definition of the users of the system as a group.

(3) Identification, description, and definition of specific users of the output of the system and of their problems in a quantitative fashion.

(4) Recommendations for future studies of the system.

(5) Provision of more meaningful data to management for decision making where programs interact with the National Measurement System.

Appraisal: This was a key intermediate study, which has by now been largely superseded by the effects of the passage of time, and the results of more recent studies. It contained the first attempt at a macroeconomic analysis of the National Measurement System.

[45] Huntoon, R. D., letter to Dr. D. Fishlock, describing calculation of numbers of measurements made per day in U.S. (Nov. 30, 1966).

[46] Cochrane, R. C., Measures for Progress--A History of the National Bureau of Standards, Nat. Bur. Stand. (U.S.), Misc. Publ. 275, 728 pages (1966).

Purpose: This book is designed to provide a better understanding of a highly specialized Federal agency among the community of scientists and engineers that the agency serves directly, among the general public whose taxes support it but who are usually only inderectly aware of its existence, and among Government officials who depend upon it for services or whose policy actions control its destiny.

Approach: That of a professional historian, relating the history of his primary subject to that of the larger society around it.

Findings: (1) In creating a National Bureau of Standards in the Federal structure at the turn of the century, Congress sought to redress a long-standing need, to provide standards of measurement for commerce and industry, the public, and the Government. Inevitably, the focus was on industry.

(2) In its first two decades the Bureau won an international reputation for its outstanding achievements in physical measurements, development of standards, and test methods. Through its new standards of measurement, instrumentation, and performance, it sought to raise the scientific level of industry.

(3) During World War I, NBS became a scientific laboratory for the military services.

(4) Determined to foster the new industries born of the war, the Bureau sought to become the national research laboratory for all industry.

(5) When the Great Depression came, the Bureau shared the obloquy heaped on commerce and industry. With greatly reduced appropriations and staff, the Bureau turned increasingly to fundamental research.

(6) By December 1941, fully 90 percent of the Bureau staff was already engaged in war research.

(7) Following World War II, the Bureau found itself in the forefront of the scientific revolution that had overtaken the Nation. 
(8) As the Bureau prepared to move to its new laboratories in Gaithers burg, its organization and functions underwent a new realinement of focus and purpose, as a principal focal point in the Federal Government for assuring maximum application of the physical and engineering sciences to the advancement of technology in industry and commerce.

(9) The Bureau's history over nearly three-quarters of a century discloses a highly viable form, responsive to national needs as they arise. As crusader and arbiter, creator and counselor of standards, it works for the future, as it has in the past, for the good society, and by its learning and good will makes itself felt throughout the Nation and the world. Appraisal: A very readable and fascinating document.

[47] Measurement, Pacemaker of American Economic Growth, booklet, U.S. Dept. of Commerce (U.S. Govt. Print. Off., Washington, D.C., 1966).

Purpose: A simplified explanation of the role measurement plays in our economy.

Approach: Popularized and basic discussion of measurements, and of the purpose and functioning of the national measurement system.

Findings: As Pacemaker, measurement can serve to limit the introduction of new technology if the system is inadequate, or it can open the door to new products, processes, and markets, if the system is proficient in all areas of science and technology. Measurement gives us knowledge and understanding. Actions and decisions based on knowledge and understanding cannot help but be superior to those based on an "educated guess", on estimates, or on ignorance.

Appraisal: A good popularized booklet, that should be reissued by NBS or the Department.

[48 ] Huntoon, R. D., Measurement system of the United States, Part 1, Automot. Ind., 75-78 (Jan. 15, 1967).

[49] Van de Houten, J., The standards laboratory as an element in the national measurement system, Preliminary report at 22nd Annual Meeting of the Standards and Metrology Division, American Ordnance Association (April 12-13, 1967).

[50 ] Brady, E. L., and Wallenstein, M. B., The National Standard Reference Data System, Science 156, 754-62 (12 May 1967).

Purpose: Definitive public description to the scientific community of the purpose, nature, and functioning of the National Standard Reference Data System.

Approach: Historical review and summary of current status and trends.

Findings: (1) The National Standard Reference Data System is a government-wide effort to give to the technical community of the United States optimum access to the quantitative data of physical science, critically evaluated and compiled for convenience.

(2) The System is a decentralized operation of national scope, with central coordination by NBS.

Effects: The desired information was put clearly on the record in a journal widely read by the members of the scientific community.

[51] Wildhack, W. A., Mason, H. L., and Powers, R. S., Jr., Accuracy charts for RF measurements, Proc. IEEE 55, 1056-63 (June 1967).

[52] Astin, A. V., Program memorandum and program and financial plan for Commerce Program Category V, The Physical Measurement System, NBS memorandum to Dr. J. Herbert Hollomon, Acting Undersecretary for Commerce (June 12, 1967).

Purpose: Program and budget justification.

Approach: Extensive discussion of the interaction of the National Bureau of Standards with major national programs and of the policy issues it faces in the operation of established programs; presentation of descriptive material describing ongoing programs in only a greatly condensed fashion. The term "Physical Measurement System" is used to describe total, nationwide measurement activities.

Findings: (1) The complex, extensive system of physical measurement which has developed with our industrialized society and which has, in fact, made its growth possible, represents a fixed investment and annual growth rate of many billions of dollars, distributed to all segments of the national economy.

(2) An underlying fact is that the Government has provided and will continue to provide the central facility and the tie-points upon which the system rests. 
(3) Although governmental, as well as private, industrial and scientific activities have grown rapidly in magnitude and sophistication, with consequent needs for more and better measurement and data capabilities, the basic NBS program which supports these needs has, by administrative decision, been held nearly constant for the past several years. This plan proposes to correct this situation.

(4) A comprehensive study to develop a better understanding of the physical measurement system has been going on at NBS for two years and will continue for several more.

(5) It has been estimated, roughly, that more than twenty billion measurements are made in this country each day in science, industry, commerce, and everyday life. All of us make measurements and a 11 of us make use of measurements.

(6) The physical measurement system meets three basic needs of society: for basic measurements and standards, for matter-materials data and standards, and for technological measurements and standards.

(7) Improvement of coupling to industry can best be achieved by expanding the Industrial Research Associate program to provide greater participation in NBS research programs by industry's staff and more cooperative links with the industrial sectors.

(8) The Bureau should initiate its own preliminary study to gather information to plan for the major study, when authorized by the Congress, of the issues connected with what the United States can do to adjust to the trend toward worldwide use of the metric system and the role that the Department of Commerce should play in this adjustment.

(9) Too large an allocation of NBS resources to planning studies would seriously impede research operations and could reduce outputs to the Nation to the point where NBS would not be fulfilling its mission and maintaining broad areas of existing competences. On the other hand, it is obvious that a certain amount of planning must be done more systematically than in the past.

(10) NBS should proceed as rapidly as possible in the direction of extending "self-calibration" capabilities in the national measurement system, when it is clear that to do so makes the system more effective. Pilot studies are in order.

(11) The proper NBS role with respect to independently reproducible standards is not clear. In most cases, the economics of duplication are so strongly prohibitive that the problem does not arise. National tie points at NBS are still essential.

Appraisal: This is the first major, thorough, conscious use by NBS of the National Measurement system concept for program planning and justification purposes.

[53] Galvin, H. B., Dollar investment in instruments, NBS internal memorandum to W. A. Wildhack (JuTy 13, 1967).

[54] Huntoon, R. D., The measurement system of the United States, Proc. 1966 Standards Laboratory Conference, Nat. Bur. Stand. (U.S.), Misc. Pub1. 291, 89-98 (July 13, 1967).

[55] Huntoon, R. D., Program memorandum for Departmental Program Category V: The Physical Measurement and Standards Program, NBS memorandum to Dr. John F. Kincaid, Acting Assistant Secretary for Science and Technology (Oct. 4, 1967).

[56] Huntoon, R. D., Concept of a national measurement system, Science 158, 67-71 (6 0ct. 1967).

Purpose: Public presentation of NBS use of the systems approach to improve understanding of the nation's measurement activities.

Approach: Narrative discussion of current state of NBS approach and of the understanding so far achieved.

Findings: (1) The systems approach in this subject is profitable.

(2) The value to the nation of the National Measurement System is in excess of $\$ 15$ billion a year.

(3) Like other social systems, the National Measurement System consists of two basically different interacting structures, the "conceptual system" and the "operational system." The former is universally applicable, the latter varies from nation to nation.

(4) Three general, ever-present needs of society have brought the System into being: needs for (a) basic measurements and standards, (b) data and standards on materials, and (c) technological measurements and standards.

(5) The System has three major technological networks: for instrumentation, for data, and for techniques. 
(6) The role of NBS as a key functional element of the National Measurement System is to provide (a) the central basis in the United States for a complete and consistent system for physical measurement, and (b) federal leadership to insure effective and efficient performance of the System.

(7) Trends in the System: (a) The inherent advantages of simplicity and coherence of the International System of Units (SI) will lead eventually to widespread use of this modern version of the metric system within the United States as in other countries. (b) An ability of any qualified laboratory to independently reproduce the SI units. (c) Self-calibration by the secondary laboratories of the System. (d) "The principle of stringency" will continue to guide NBS: It must focus its efforts on meeting the most stringent requirements of the system wherever there is enough need to justify the necessary investment in research. (e) Other elements of the System are giving serious, productive consideration to their respective roles and are generating recommendations for improvement in its operation.

Effects: Brought to the general scientific public attention a systematic new approach to understanding the role of measurements and of NBS in our society.

[57] Howlett, L. E., International basis for uniform measurement, Science 158, 72-74 (5 0ct. 1967).

[58] Schafer, G. E., Economic dimensions of the national measurement system, NBS internal memorandum to W. A. Wildhack (Dec. 12, 1967).

[59] Yates, J. T., Jr., Morgan, H. E., and Huntoon, R. D., Exploratory NBS studies of benefit-cost measurement in research and development, NBS internal working document, 33 pages (1967)

[60] Decrease in uncertainty of NBS measurements, unsigned, unattributed, undated document (about 1967).

[61] Dantzig, T., Number, The Language of Science, 4th edition (Macmillan Co., New York, N.Y., 1967).

[62] Atomic second adopted as international unit of time, Nat. Bur. Stand. (U.S.), Tech New Bul1., No. 1, 10-12 (Jan. 1968).

[63] Worth her weight in gold, brochure, 8 pages (Gordons Transports, Inc., Memphis, Tenn., Mar, 1968)

[64] Astin, A. V., Statement on the utilization of Federal laboratories, before the subcommittee on Science, Research and Development of the House Committee on Science and Astronautics (Mar. 27, 1968).

[65] Gentilini, A. V., Summary of national measurement system, NBS internal memorandum to members of motion picture committee, 35 pages (May 3, 1968).

Purpose: A source file from which an NBS film script on the subject may be developed, a reference for miscellaneous purposes, and a basis for articles, speeches, and feature stories.

Approach: Synthesis from pre-existing sources.

Findings: These are largely a recapitulation of points made in sources discussed above. The significance of this memorandum is that it is perhaps the earliest document on the NBS record that is aimed at substantially the same purpose as this report.

Effects: All available insight regarding the national measurement system is summarized in one document, as of 1968. Tentative discussions regarding a motion picture did take place, but no film was developed.

[66] Astin, A. V., Standards of measurement, Sci. Am. 218, No. 6, 50-62 (June 1968).

Purpose: Communication of state of art in physical measurement standards, to the general scientific community.

Approach: Historical review and summary of current status and trends.

Findings: The task of finding more accurate ways to measure length, mass, time and temperature never ends. The base units should be defined in terms of basic constants of nature, and this has been done for all except mass.

Effects: Definitive communication to the general scientific public.

[67] Eisenhart, C. Expression of the uncertainties of final results, Science 160, 1201-4 (14 June 1968).

[68] Wildhack, W. A., NBS outputs and impacts, NBS internal working document, 5 pages (Sept. 1968). 
[69] GOST 1 "The state standardization system," Izmer. Tekh., No. 9, 21-22 (Sept, 1968) (UDC 389.69093.2).

[70] Resko, S. I., ed., Metrological Service of the USSR, booklet, 84 pages (Publ. House of Standards, Moscow, USSR, 1968). Translated by M. C. Selby as Nat. Bur. Stand. (U.S.), Report 9756, 98 pages (May 27, 1970).

[71] Brief history and use of the English and metric systems of measurement, Nat. Bur. Stand. (U.S.), Spec. Pub1. 304A, 4 pages (1968).

[72] Precision Measurements and Calibration, Nat. Bur. Stand. (U.S.), Spec. Publ. 300, 12 volumes (1968).

[73] Zupko, R. E., A Dictionary of English Weights and Measures from Anglo-Saxon Times to the Nineteenth Century (Univ. Wisconsin Press, Madison, Wisc., 1968).

[74] The exotic pursuit of precision, photo essay. Fortune, 80-87 (May 1969).

[75] Mason, H. L., ed., Making Valuable Measurements (Proc. 1968 Standards Laboratory Conference, NBS, Boulder, Colo., Aug. 26-29, 1968), Nat. Bur. Stand. (U.S.), Spec.

Publ. 313, 177 pages (May 1969).

Purpose: Proceedings of the 1968 Standards Laboratory Conference.

Approach: Answering the Who? Where? How? and Why? of making valuable measurements.

Findings: Best summarized by the session titles:

(1) DOD Activities

(2) NCSL Liaison Delegate Reports

(3) NBS Activities

(4) International Measurements

(5) NCSL Committee Reports

(6) The Value of Measurement Agreement Comparison

(7) The Management of Equipment and Data

(8) The Management of Valuable Measurements

Appraisal: An early attempt by a major component group in the System to focus on improvement of the effectiveness of the entire National Measurement System.

[76] Morgan, H. E., The economic value of making measurements, Proc. 1968 Standards Laboratory Conference, NBS, Boulder, Colo., Aug. 26-29, 1968, Ed. H. L. Mason, Nat. Bur. Stand. (U.S.), Spec. Publ. 313, pp. 27-36 (May 1969).

Purpose: Definition of the word valuable in the context of a conference which has as its theme "Making Valuable Measurements," and indication of how one might measure the value of "valuable measurements."

Approach: Application of concepts and analytical approaches of the science of economics to the subject of measurements and the measurement system.

Findings: (1) Measurements are made primarily to provide information which leads to decisions which (a) al ter the method of attaining a given objective or (b) result in pursuing new objectives.

(2) The economic value of measurement data in case (a) will be the cost of resources saved by substitution of these data in reaching the stated goal.

(3) Economic value in case (b) relates to the effectiveness with which the new resources can be used in achieving the new goals.

(4) The economic value of a unit of measurement data to an individual producer of goods or services is the change, in total revenue from the sale of goods and services, induced by that additional unit of measurement service.

(5) The economic value of measurement data used directly by consumers of goods and services is given by the extent to which these data enable consumers to save other resources in attaining a given level of satisfaction, or to use other resources in reaching a higher level. Measurement of secondary effects is complex.

(6) Two methods of approximating the aggregate economic value of measurements are based on (a) the concept of consumer's surplus, and (b) input-output analysis. Both require detailed information about the way measurement data are used and information about the demand for final goods. Consumer's surplus measures value which users obtain and which they would be willing to pay more for than they actually pay, rather than go without the product. Where market prices of measurement related goods are known, input-output analysis may permit tracing through the consequences of interactions in the economic system, to indicate net economic value. 
(7) The value of publicly produced or used measurement data, which of ten involve a formal zero price to the public, is most basically determined by the trade-off value of substitutes.

(8) The value of measurement reliability can be handled in the fashions outlined above. Trade-offs between the cost of higher precision or reliability in general and the costs of other inputs must be made until minimum cost has been attained, in achieving any given goal.

(9) Empirical measurement of economic value requires (a) case studies of specific applications of measurement services, or (b) statistical data which indicate how measurements may have affected firms or industries. The latter are seldom sufficiently detailed to permit meaningful generalizations.

Appraisal: This is the only formal study (until now) on the public record of the use of economic techniques in evaluating the National Measurement System.

[77] Wolzien, E. C., New directions for NBS outputs, Proc. 1968 Standards Laboratory Conference, NBS, Boulder, Colo., Ed. H. L. Mason, Nat. Bur. Stand. (U.S.), Spec. Publ. 313, pp. 38-42 (May 1969).

[73] Modus operandi for production of NBS film dealing with the national measurement system, internal-NBS working document (13 May 1969).

[79] Stiehler, R. D., History of measurement and the SI units, Mater. Res. Stand. 9, No. 6, 14-18 (June 1969).

Purpose: A brief summarization for the general technical public of the subject. Approach: Historical narrative; analysis of strengths and weaknesses of SI; trend extrapolation.

Findings: (1) The so-called English units did not originate in England; they descended from antiquity.

(2) The confusion caused by the multiplicity of ancient units that were in use in Europe during the Renaissance was the stimulus that lead to the development of the metric units.

(3) Similarly, the multiplicity of metric units for the same quantity that have arisen since 1800 led to the SI.

Appraisal: An excellent and unique article.

[80] Huntoon, R. D., Lichtenstein, S., and Finger, G. A., The National Bureau of Standards prepares for the 1970's, Science 165, 867-74 (29 Aug. 1969).

[81] Kushner, L. M., The NBS contributions to technological measurements and standards, Mater. Res. Stand. 9, No. 10, 8-10 (Oct. 1969).

[82] Silverman, S., The national measurement system--a concept to assist the private sector, Mater. Res. Stand. 9, No. 10, 11-14 (Oct. 1969).

[83] Meinke, W. W., The NBS Standard Reference Materials program: past, present, and future, Mater. Res. Stand. 9, No. 10, 15-18 (0ct. 1969).

[84] Brady, E. L., The National Standard Reference Data System, Mater. Res. Stand. 9, No. 10, 19-21 (0ct. 1969).

Purpose: The preceding four items were published as a group under the general title "Measurement in the Public Sector," to provide a description to the technical public of the breadth of NBS programs supporting the national measurement system.

Approach: Historical review, philosophical discussion, narrative description.

Fundings: (1) Technological measurements and standards are use-related and are at the interface between science and its application in industry and government. The NBS program extends the principles of good measurement to the engineering fields and to the complex needs of today's society. Specific aspects include measurements for performance-based standards, of subjective human factors, and of the functioning of complete systems.

(2) The concept of a National Measurement System involves the entire complex of measurement activities within the United States. The central element of this system is NBS.

(3) Standard Reference Materials provide a basis for comparison of measurements on materials and aid in control of production processes in industry. About 600 different items are available from NBS.

(4) The National Standard Reference Data System aims to give the technical community optimum access to the quantitative data of physical science. NBS provides central coordination.

Effects: Concise public statement of several key NBS programs in support of the national measurement system. 
[85] Koeser, R. L., ed., Report of the 54th National Conference on Weights and Measures 1969, Nat. Bur. Stand. (U.S.), Spec. Publ. 318, 270 pages (Nov. 1969).

[86] Simson, B. G., and Radlinski, R. W., The accuracy of air tower pressure gages in suburban Washington, D.C., Nat Bur. Stand. (U.S.), Tech. Note 512, 10 pages (Dec. 1969).

[87] Gorozhanina, R. S., Freedman, A. Y., and Shaievitch, A. B., Standard Reference Materials: Standard Samples Issued in the USSR, booklet, 81 pages (Publishing House of Standards, Moscow, USSR, 1969). Translated by M. C. Selby as Nat. Bur. Stand. (U.S.), Spec. Pub1. 26030, 86 pages (June 1971).

[88] Burton, W. K., Measuring systems and standards organizations, 45 pages (American National Standards Institute, New York, N.Y., undated, estimated 1969).

[89] National measurements requirements committee report, 1970 Standards Laboratory Conference, 12 pages (5 May 1970).

[90] Clark, R. F., The impact of advanced electronic technology on measurements, preprint, 1970 Standards Laboratory Conference, 6 pages (June 1970).

[91] Root, L. W., New U.S. Air Force audit program, preprint, 1970 Standards Laboratory Conference, 19 pages (June 1970).

[92] Ritchie-Calder, Lord, Conversion to the metric system, Sci. Am. 223, No. 1, 17-25 (July, 1970).

[93] Taylor, B. N., Langenberg, D. N., and Parker, W. H., The fundamental physical constants, Sci. Am. 223, No. 4, 62-78 (Oct. 1970).

Purpose: Communication of importance of experiments designed to redetermine the numerical values of the fundamental physical constants to ever greater levels of accuracy.

Approach: Description of role of these quantities, of the importance of accuracy, of lessons from the past, of examples of the consequences that have stemmed from improvements in knowledge of these quantities, and of current technical approaches to this field; plus trend extrapolation.

Findings: (1) These efforts can yield information concerning the overall correctness of the basic theories of physics, in addition to improving the precision of the quantitative predictions of these theories.

(2) Experimenters tend to "debug" their work until they get agreement with generally accepted values, and may fail to keep going long enough to recognize the total range of errors involved. Consequently, good agreement among successive independent measurements may be illusory and only shown up by a later, truly definitive experiment.

(3) Precision determination of fundamental constants depends intimately upon the adequacy of the national physical measurement reference standards.

(4) This work is not finished.

Appraisai: A definitive publication on the physical importance of precise knowledge of the fundamental constants, that stopped short of description of the metrological importance of these quantities.

[94] Calibration and test services of the National Bureau of Standards, Nat. Bur. Stand. (U.S.), Spec. Pub1. 250--1970 edition (Dec. 1970).

[95] Siattery, W. J., ed., An Index of U.S. Voluntary Engineering Standards, Nat. Bur. Stand. (U.S.) Spec. Pubi. 329, 1000 pages (March 1971).

Purpose: Provision of a basic reference compilation of voluntary engineering standards titles.

Approach: Key-word-in-context indexing by permutation of titles.

Findings: (1) 19,000 voluntary engineering and related standards, specifications, test methods, and recommended practices, in effect as of December 31, 1969, published by some 360 U.S. technical societies, professional organizations, and trade associations.

(2) 6,300 more are contained in Supplement 1, with a cut-off date of December 31,1971 [139].

(3) An additional 5,700 are indexed in Supplement 2, with a cut-off date of Juty 1, $1974[251]$.

Appraisal: A definitive reference publication.

[96] Bell, F. C., and Wollin, H. F., ed, Report of the 55th National Conference on Weights and Measures 1970, Nat, Bur. Stand. (U.S.), Spec. Pub1. 342, 315 pages (Apri1 1971). 
[97] Noble, D. E., The challenge of intelligent decision making, Proc. Rome Air Development Center 20th Anniversary Celebration: The Next Twenty Years--the Promise and the Challenge, pp. 65-74 (Rome Air Development Center, June 9-11, 1971).

[98] Desimone, D V., A Metric America: A Decision Whose Time Has Come, Nat. Bur. Stand. (U.S.), Spec. Publ. 345, 188 pages (July 1971).

Purpose: Report to Congress in response to Public Law 90-472, An Act To authorize the Secretary of Commerce to make a study to determine advantages and disadvantages of increased use of the metric system in the United States.

Approach: Summarization of results reported in twelve supplementary volumes. Polling of thousands of individuals, firms, and organized groups, representative of our society, by public hearings, questionnaires, and many other techniques. Historical analysis and trend extrapolation.

Findings: (1) Eventually the United States will join the rest of the world in the use of the metric system as the predominant common language of measurement.

(2) America is already metric in some respects, and is becoming more so.

(3) The great majority of businessmen, educators, and other informed participants in the Study reported that increased use of the metric system is in the best interests of America. They also believe that it is better for the nation to move to metric by plan rather than by no plan at all.

(4) The key question is not whether but how and when America will choose to make the change. The key comparison regarding costs and benefits is between changing by plan versus changing with no plan--with no framework to guide the nation.

(5) It would be best for the nation to change to metric under a coordinated program that provides for flexibility and encourages the various sectors of society to deal with their particular problems voluntarily.

(6) Educational efforts should begin immediately, in the schools and for the public.

(7) International standardization should be participated in vigorousiy, to protect American national interests.

(8) Congress should assign the responsibility for guiding the change to a central coordinating body responsive to alt sectors of our society.

(9) In order to encourage efficiency and minimize the overall costs to society, the general rule should be that any changeover costs shall "lie where they fall."

(10) The Congress, after deciding on a plan for the nation, should establish a target date ten years ahead, by which time the U.S. will have become predominantly, though not exclusively, metric.

(17) There should be a firm government committment to this goal.

Effects: Administration commitment to metric changeover by pian, in accordance with the findings above.

Essentially continuously pending bills in Congress to implement these findings.

Concern by organized labor and small business about the "costs lie where they fall" principle. A combination of these concerns, parliamentary tactics, and national preoccupation with other matters prevented final action until the passage of the Metric Conversion Act of 1975, in December 1975.

[99] Huntoon, R. D., et a 1., U.S. Metric Study Report: International Standards, Nat. Bur. Stand. (U.S.), Spec. Pub1. 345-1, 157 pages (Dec. 1970).

[100] Clark, R. E., and Tascher, J.M., U.S. Metric Study Interim Report: Federal Government: Civilian Agencies, Nat. Bur. Stand. (U.S.), Spec. Pub1. 345-2, 328 pages (July 1971).

[101] Hatos, S. L., U.S. Metric Study Interim Report: Commercial Weights and Measures, Nat. Bur. Stand. (U.S.), Spec. PubT. 345-3, 116 pages (July 1971).

[102] Barbrow, L. E., coord., U.S. Metric Study Interim Report: The Manufacturing Industry, Nat. Bur. Stand. (U.S.), Spec. Publ. 345-4, 172 pages (July 1971).

[103] Cornog, J.R., and Bunten, E. D., U.S. Metric Study Interim Report: Nonmanufacturing Businesses, Nat. Bur. Stand. (U.S.), Spec. Publ. 345-5, 200 pages (July 1971).

[104] Robinson, B. D., U.S. Metric Study Interim Report: Education, Nat. Bur. Stand. (U.S.), Spec. Publ. 345-6, 216 pages (July 1971).

[105] Rothrock, B. D., ed., U.S. Metric Study Interim Report: The Consumer, Nat. Bur. Stand. (U.S.), Spec. Pub7. 345-7, 152 pages (July 1971). 
[106] Gordon, G. F., U.S. Metric Study Interim Report: International Trade, Nat. Bur. Stand. (U.S.), Spec. Pub1. 345-8, 188 pages (July 1971).

[107] Lomas, L., et a]., U.S. Metric Study Interim Report: Department of Defense, Nat. Bur. Stand. (U.S.), Spec. Pub1. 345-9, 132 pages (June 1971).

[108] Treat, Co F., U.S. Metric Study Interim Report: A History of the Metric System Controversy in the United States, Nat. Bur. Stand. (U.S.), Spec. Pub1. 345-10, 312 pages (Aug. 1971).

[109] Stiehler, R. D., U.S. Metric Study Interim Report: Engineering Standards, Nat. Bur. Stand. (U.S.), Spec. Pubi. 345-11, 264 pages (July 1971).

[110] Odom, J. V., ed., U.S. Metric Study Interim Report: Testimony of Nationally Representative Groups, Nat. Bur. Stand. (U.S.), Spec. Pub1. 345-12, 180 pages (July 1971).

[111] Huntoon, R. D., Extending the measurement infrastructure to meet the needs of developing establishments, NBS internal working document, 55 pages (JuTy 1971).

Purpose: Response to the question, What can or should NBS do, to aid developing establishments, domestic or foreign, to acquire a sufficient measurement capability?

Approach: Extension of reasoning and understanding developed for the U. S. National

Measurement System to proiect solutions of problems of developing establishments.
Findings: (1) Newly developing countries of the world and developing establishments domestically face similar problems in acquiring an appropriate measurement capability.

(2) The traditional patterns upon which our growth was based are not optimum for new countries in today's world, nor even always for our own.

(3) Nominally identical measurement actions do not give identical results. There is always a dispersion. Of all of the terms that can be used in dealing with this dispersion, compatibility is the one of the broadest significance. If accuracy is injected in a compatible system, it propagates to al1 units in that system. Compatibility is best achieved by an active approach, rather than the traditional passive calibration approach.

(4) The standard sample approach, which uses a sample of acceptable product, thing, or substance, as a basis for transfer of compatible measurements, independent of the system of weights and measures in local use, is especially stressed as needing careful study.

(5) Tie points to the international measurement infrastructure exist wherever the printed word can reach, transportation can provide hardware, and people with the necessary skill exist. A tie-point represents the meeting of a need for some specific measurement or complex of measurements, with an established capability in the measurement infrastructure, national or international.

(6) The essence of the improvement that is needed in the international measurment infrastructure lies in the dissemination of compatible measurement capability through the tie-points of the system.

(7) Passive harmonization, e.g., through classical calibration procedures, is fraught with peril and associated with much nonsense, in which paper evidence of instrument compatibility rules, rather than phvsical demonstration of it.

(8) Active harmonization is more complex, but it forces demonstration of the end object--compatible measurements--rather than of the intermediate, compatible instmamentation. Independently reproducible standards are an ideal, ultimate approach to active harmonization; of the basic units, only mass cannot so far be realized this way.

(9) Published data from any trusted source can be used as the basis for an active transfer process. Standard Reference Data can be an ultimate for such purposes.

(10) Standard Reference Materials are essential when it is possible to find stable substances with properties useful in the measurement system, that can be precisely and reproducibly measured, but which cannot be described so that the materials themselves can be easily, precisely reproduced.

(11) Careful cataloging of the level of compatibility available at different potential tie-points in the international measurement infrastructure should be undertaken by NBS, and the specifications established for needed tie-points that do not exist.

(12) "How-to"documents are needed for each kind of measurement compatibility transfer available at each tie-point, showing how to establish compatible measurements with that transfer mechanism.

Appraisal: A very penetrating study. 
[112] Langenberg, D. N., and Taylor, B. N., ed., Precision Measurements and Fundamenta] Constants, Nat. Bur. Stand. (U.S.), Spec. Pub7. 343, 543 pages (Aug. 1971).

Purpose: Proceedings of an International Conference held at the National Bureau of Standards, Gaithersburg, Maryland, August 3-7, 1970.

Aporoach: Collection and editing of papers by the Conference speakers.

Findings: (1) The essential connection between the fundamental physical constants and our choice and definition of the base units for physical measurements has been apparent for many years.

(2) Precision measurement plays an essential and crucial role in the development of all science and technology.

(3) In a 17 of our fundamental theories there appear a certain few parameters which characterize the fundamental particles and interactions we find in nature.

(4) The progress of our understanding of the physical world is very much intertwined with the advance of the art of precision measurement and its application to the determination of the fundamental physical constants.

(5) In recent years there have been notable advances in both theory and experiment relevant to the fundamental constants.

Appraisal: A definitive publication from a conference that was the first of its kind, and of fundamental importance in the measurement system infrastructure.

[113] A Metric America, Nat. Bur. Stand. (U.S.), Tech. News Bu11., 222-30 (Sept. 1971). [114] National Bureau of Standards at a Glance, Nat. Bur. Stand. (U.S.), book7et, 40 pages
(Sept. 1, 1971).

[115] Science Policy Research Division, Library of Congress; National Bureau of Standards, A Review of its Organization and Operations: A study prepared for the Subcommittee on Science, Research, and Development of the Committee on Science and Astronautics, U.S. House of Representatives, 236 pages (U.S. Govt. Print. Off., Washington, D.C., Sept. 8, 1971).

Purpose: A study prepared for the Subcommittee on Science, Research, and Development of the Committee on Science and Astronautics, U. S. House of Representatives, Ninety-second Congress, First Session, at its request, to provide background information as it begins a comprehensive series of oversight hearings on the Bureau.

Approach: Compilation from materials in the public record, with special attention to developments concerning the National Bureau of Standards since the last general Committee review in 1967 .

Findings: (1) Little information about the Bureau is available from independent sources.

(2) Diversity and technical nature of the Bureau's work make its comprehension difficult for the average citizen.

(3) There are significant uncertainties in the scope of NBS legal authority.

(4) Much NBS work is funded by other government agencies or private organizations with the result that the NBS budget is not reviewed as a whole in any public proceedings.

(5) NBS budget requests almost every year have been consistently reduced by the Department of Commerce, the Office of Management and Budget, and the Congress.

(6) Often the Bureau has been assigned urgent new tasks with no funds appropriated to carry them out, usually with no guidance as to what should be reduced to make room for the new work.

(7) The less visible and perhaps prosaic nature of its work has lacked the glamor needed to compete for recognition and support with the conquest of space, promoting nuclear power, and expanding national defense capabilities, despite the long-run pervasive impact of its work on American science, technology, and industry.

(8) Research and services for other organizations, currently at 40 percent of the total Bureau budget, have in the past been as high as 85 percent, and are a continuing source of potential imbalance in the Bureau's program.

(9) The proper role and extent of support by the Bureau of civilian technology per se is an unresolved question.

(10) Environmental problems affecting the Bureau's operations have grown up around it at its new site. 
(11) Despite continuing changes in NBS programs and organization, there is - evidence of undesirable delay in adapting the Bureau's output to the demands of $U$. S. industry, in response to continuing technological change and the commercial deployment of new products and services.

(12) Only a few major criticisms were found of NBS operations in the open literature during the 1960's.

(13) Suggested topics for further committee inquiry include (a) planning for the 1970's and beyond, (b) standard setting for the future, (c) U.S. conversion to the metric system (d) funding for the 1970's and beyond, (e) optimizing the utilization of the Bureau's facilities, ( $f$ ) optimizing its location with in the Executive Branch, (g) optimizing the administration within and of the Bureau.

(14) A basic question: To what goal should the NBS be oriented? The current statement used by the Director of the Bureau ("to strengthen and advance the Nation's science and technology and to facilitate their effective application for public benefit") is significantly broader than that of the Secretary of Commerce in the U.S. Govemment Organization Manual--1970/71 ("assuring the maximum application of the physical and engineering sciences to the advancement of technology in industry or commerce"). The answer to this question must inevitably affect NBS planning for the future and the intellectual, physical, and financial resources it will require to attain the desired objectives.

Appraisa 1: A very even-handed and perceptive document.

[116] National Bureau of Standards Oversight Hearings, Hearings before the Subcommittee on Science, Research, and Development of the Committee on Science and Astronautics, U.S. House of Representatives, Sept. 16, 21-23, 28, 1971, 387 pages (U.S. Govt. Print. Off., Washington, D.C., 1971).

Purpose: Hearings for complete overview and review of the activities of the NBS. Approach: Presentation of prepared statements by representatives of the Administration and other interested parties, and questioning by members of the Subcommittee.

Findings: A thorough review of the operations of NBS and the issues surrounding them.

Effects: The first time that NBS had been able to present, for about ten years, its complete story in a Congressional hearing. It was sympathetically received by the committee. Substantial statements of support were offered by the private sector.

[117] Branscomb, L. M., U.S. metric study, Science Teacher 38, No. 8, 58-62 (Nov. 1971).

[118] Ambler, E., Measurement standards, physical constants, and science teaching, Science Teacher 38, No. 8, 63-71 (Nov. 1971).

Purpose: Presentation during 1971 Convention of National Science Teachers Association. Approach: Historical and philosophical review of field of metrology, discussion of current scientific status and trends in field, trend extrapolation.

Findings: (1) Human intuitive knowledge is basic to metrology, and is based on biological sensors of truly exquisite sensitivity.

(2) A most essential part in the process of developing primitive learning and intuitive conceptualization into a more sophisticated understanding of the concept and its relation to the physical world, is how we define our concept more exactly and measure it more precisely so that we all mean the same thing.

(3) The touchstone we adopt in changing the measurement system is one of practical utility: We look for accuracy, reproducibility, directness, and convenience. The system must be acceptable in science, engineering, and everyday life on an international basis.

(4) A major current challenge to metrology is development of an objective science for measurement of subjective human phenomena, perception of noise, for instance.

(5) Perhaps one of the most important things science teaching can do today is to try to reverse the present alienation the general public feels toward science, by reestablishing its original aura of humanistic natural phizosophy. Appraisa : : A very thoughtful and penetrating discussion.

[119] Specifications, Tolerances, and Other Technical Requirements for Commercial Weighing and Measuring Devices, Nat. Bur. Stand. (U.S.), Handb. 44, 4th edition (Nov. 1971). 
[120] Draft report of the Instrumentation Panel of NAS-NRC Physics Survey Committee (Nov. 12, 1971).

[121] Mason, H. L., and Peiser, H. S., ed., Metrology and Standardization in Less-Developed Countries: The Role of a National Capability for Industrializing Economies, Nat. Bur.

Stand. (U.S.), Spec. Publ. 359, 390 pages (Dec. 1971).

Purpose: Proceedings of a Seminar of February 1-4, 1971. Definition of how NBS experience in metrology and standardization can be employed in collaboration with the U.S. Agency for International Development for assisting less-developed countries to build up their own technological infrastructures.

Approach: Presentations by expert participants from abroad and from NBS, with discussion.

Findings: (1) Caution is the best advice NBS has to offer.

(2) Developing nations should not be over-awed by the achievements of industrialized nations and those of metrological laboratories like NBS.

(3) We can all work together more effectively by comparing techniques, attitudes, and interests, as during this Seminar.

Appraisal: Established a sound basis for continuing NBS efforts in this field.

[122] Crane, B. M., Economic effects of an improved measurement, Ph.D. Dissertation, George Washington University (1971).

[123] Ambler, E., Entity Program Document for NBS Program A-1, Development, Maintenance and Improvement of the Standards of Physical Neasurement, internal NBS working document (Jan. 7, 1972).

[124] Ambler, E., Entity Program Document for NBS Program A-3, Evaluation of the National Measurement System, internal NBS working document (Jan. 7, 1972).

[125] Ambler, E., Entity Program Document for NBS Program A-7, Research to Improve Physical Measurements, internal NBS working document (Jan. 7, 1972).

[126] Bel1, F. C., and Wollin, H. F., ed., Report of the 56th National Conference on Weights and Measures 1971, Nat. Bur. Stand. (U.S.), Spec. Publ. 358, 252 pages (Mar. 1972).

[127] Branscomb, L. M., to help advance our Nation's science \& technological capabilities for the greatest public benefit, Mater. Res. Stand. 12, No. 5, 8-12 (May 1972).

[128] Kushner, L. M., We have decided to become more active at the policy level in voluntary standardization activities, Mater. Res. Stand. 12, No. 5, 13-14 (May 1972).

[129] Andrus, W. E., A focus for the Bureau and a11 voluntary standardization organizations, Mater. Res. Stand. 12, No. 5, 15-17 (May 1972).

[130] Ambler, E., A major innovation is our Measurement Assurance Program, Mater. Res. Stand. 12, No. 5, 18-23 (May 1972).

[131] Hoffman, J. D., IMR emphsizes accurate measurements and standards for materials, Mater. Res. Stand. 12, No. 5, 24-33, 71 (May 1972).

[132] Willenbrock, F. K., We can never afford to be technically wrong, Mater. Res. Stand. 12, No. $5,34-36,71-72$ (May 1972).

Purpose: The preceding six items are interviews or statements presented by NBS managers to communicate with the membership of the American Society for Testing and Materials

(ASTM) about current programs and policies of NBS.

Approach: Editorial commentary, interviews with NBS managers, publication of prepared papers. Findings: Implicit in the titles quoted above.

Effects: Concise and broad-ranging communication to ASTM membership.

[133] Ambler, E., Program to insure that IBS capability is used in the field to the maximum degree of effectiveness and to develop new capability where necessary, NBS internal memorandum, directed to IBS Division Chiefs and Dr. Leiss, 6 pages (May 5, 1972).

[134] Corruccini, R. J., The Role of Basic Standards in the Economy, NBS internal working document, generated in response to the request of Apri1 12, 1972, by the Assistant Secretary of Commerce for Administration, 41 pages (July 3, 1972).

Purpose: Study of the NBS standards of measurement to determine if their accuracy is sufficient for the needs of U. S. industry:

(a) Do NBS standards meet the needs of U. S. industry?

(b) What is the NBS plan for improving the accuracy of standards?

(c) In cases where standards should be improved, how much should they be improved, what would be the benefits and the cost? 
(d) What role do NBS standards play in increasing U. S. industry's ability to compete in foreign markets? Are there standards, presently unavailable or capable of improvement, that would give U. S. industry a competitive edge in foreign markets?

(e) Are there predictable technological developments that would create a need for NBS standards not now available?

Findings: (1) NBS maintains standards and calibration services for 49 measurement quantities and provides auxiliary services which ensure that the standards are applied to best effect in the economy, e.g., in manufacturing, exchange of goods, and the utilization of science and technology for economic growth.

(2) NBS standards do appear to meet most needs of U. S. industry. However, technology continually advances by means of new discoveries, and at any given time there will be new needs in certain areas that require attention. Since 1946, new needs have tended to appear first in the programs of government agencies using advanced technologies (e.g., defense, aerospace, and atomic energy), from whence they have diffused into client industries and then to civilian industry. More recently, a different pattern has emerged in which measurement needs are being generated by public concern for well-being and safety. Some measurement needs do arise directly from civilian industry.

(3) The dissemination of the standards is being increasingly monitored by NBS Measurement Assurance Programs which evaluate the adequacy of the user's procedures and assure that those measurement techniques are applied which are most appropriate for meeting user's real needs.

(4) The nature of these standards and services is subject to constant review to ensure that the most critical needs are met in a timely fashion and that on-going activities are phased out when appropriate.

(5) Needs are ascertained by contacts with the technological community, by questionnaires and publications, by special conferences and symposia, by advisory groups, and by special issue studies (technology assessments).

(6) NBS plans for improving the standards relate not only to accuracy but also to extension of the ranges in which standards need to be maintained, provision of needed standards of kinds which do not now exist, and continuing surveillance to assure their effective application in the field. Short-term plans are well described in current budget documents.

(7) The Institute for Basic Standards of NBS has begun a three-year study of the entire measurement system which will define the need for standards more comprehensively than before and lead to comprehensive plans for meeting these needs.

(8) Cost/benefit analyses are part of the objective of the long-range study. General answers cannot now be given.

(9) Availability of measurement standards--though necessary--cannot by itself assure success in foreign trade. However, we can see areas where improved standards are needed to support U. S. international trade.

(10) There are a number of foreseeable developments in measurement technology of such importance to the improvement of measurements that NBS could not responsibly neglect them.

(11). There are beneficial future technologies that cannot be brought to full fruition unless appropriate new kinds of standards are provided by NBS.

Effects: This was a preliminary report with respect to the current study of the National Measurement System. It served to set the tone and a pattern for the study. It provided reasonable answers to the immediate questions, and put the existence, motives, and nature of this study clearly on the record within the Department.

[135] Kushner, L. M., The role and value of measurement, Nat. Bur. Stand. (U.S.), Tech. News Bu11., 56, No. 9, 216-19 (Sept. 1972).

[136] Brief History of Measurement Systems, Nat. Bur. Stand. (U.S.), Spec. Pub1. 304A, rev. Oct. 1972. 4 pages (Oct. 1972).

[137] Rossmassler, S. A., ed., Critical evaluation of data in the physical sciences--a status report on the National Standard Reference Data System June 1972, Nat. Bur. Stand. (U.S.), Tech. Note 747,79 pages (Nov. 1972).

[138] Jewkes, J., Government and high technology, Occasional Paper 37 (Institute of Economic Affairs, The Wincraft Foundation, Dec. 1972). 
[139] Slattery, W. J., ed., An Index of U.S. Voluntary Engineering Standards, Supplement 1, Nat. Bur. Stand. (U.S.), Spec. Pub1. 329, Supp1. 1, 459 pages (Dec. 1972).

[140] Proceedings of the 1972 Joint Measurement. Conference, June 21-23 (Instrum. Soc. Am., Pittsburgh, Pa., 1972).

Purpose: Development of an interdisciplinary exchange of technical and managerial measurement concepts.

Approach: (1) The explanation to technical and management personnel of those aspects of measurement technology that form the common basis for, or are applicable to, various measurement fields and several measurement-dependent industrial functions.

(2) The interdisciplinary flow of measurement information (available in one field for application in another) on a technical level involving the electrical, thermal, dimensional, etc., fields.

(3) The generation of ideas and actions intended to increase in the universities the extent and quality of education in measurement science, and to identify ways of increasing the professionalism of those engaged in metrology.

Findings: These are most succinctly described by the session titles:

(1) The Role and Value of Measurement.

(2) The Measurement Effort as a Resource for Management.

(3) The Measurement Effort as a Technical Resource.

(A) When are Measurements Relevant?

(B) When are Measurements Adequate?

(4) Interdisciplinary Processes in Sensors/Transducers/Detectors.

(5) Interdisciplinary Solutions to Measurement Problems.

(6) Systems Metrology: The "Compleat" Problem Solver.

(7) Measurement Education--What It Is; How to Get It; How to Improve It.

Appraisal: The beginning of a continuing series of conferences, serving to tie the field of metrology together in the U.S., at the professional level, both managerial and technical.

[147] Executive Office of the President--Office of Management and Budget, Standard Industrial Classification Manual 1972 (U.S. Govt. Print. Off., Washington, D.C., 1972).

[142] U.S. Bureau of Census, Census of Manufactures: 1972, Alphabetic List of Manufactured Products (1967 SIC basis), series MC72-2 (Bureau of Census).

[143] Steiner, B., Optical radiation measurements: the impact of radiometry and photometry and the role of NBS, Nat. Bur. Stand. (U.S.), Tech. Note 594-4, 56 pages (Mar. 1973).

[144] Ambler, E., Progress of Study of the National Measurement System, NBS internal memorandum directed to IBS Division Chiefs, 6 pages (March 23, 1973).

[145] Bell, F. C., and Wollin, H. F., Report of the 57 th National Conference on Weights and Measures 1972, Nat. Bur. Stand. (U.S.), Spec. Pub1. 379, 216 pages (May 1973).

[146] U.S. Bureau of Census, Census of Manufactures: 1972, Numerical List of Manufactured Products (New (1972) SIC basis), series MC72-1.2 (U.S. Govt. Print. Off., Washington, D.C., May 1973).

[147] NBS policy for usage of SI units, Nat. Bur. Stand. (U.S.), Tech. News Bu11. 57, No. 6, 138-41 (June 1973).

[148] Risley, A. S., Time and Frequency Division progress report on the study of the national measurement system, NBS internal memorandum to J. R. Seed, 34 pages (June 5, 1973).

[149] Preliminary report. Assessment of the national measurement system for length, from Dimensional Technology Section of NBS Optical Physics Division, 40 pages (June 1973).

[150] Schweitzer, W. G., National measurement system study--wavelength, NBS internal preliminary report, 8 pages (June 1973).

[151] Ramboz, J. D., Progress Report on the national measurement system in the area of mechanical shock and vibration, from Vibration Section. NBS Mechanics Division, 21 pages, (June 29, 1973).

[152] Young, R. D., Technology assessment of the surface finish measurement system, preliminary report from Optics and Micrometrology Section, NBS Optical Physics Division, $17 \mathrm{~mm}$ (June 1973).

[153] Preliminary report, Assessment of the national measurement system for mass, from Dimensional Technology Section, NBS Optical Physics Division, $26 \mathrm{~mm}$ (June 1973).

[154] Preliminary report, Assessment of the national measurement system for volume and density, from Dimensional Technology Section, NBS Opt. Phys. Div., $17 \mathrm{~mm}$ (June 1973).

[155] Tate, D. R., Progress report, National measurement system for force, NBS internai preiminary report, 14 pages (June 29, 1973). 
[156] Compton, P. R., Study of the national fluid flow measurement system, a progress report from the Fluid Mechanics Laboratory, NBS Mechanics Division, 34 pages (June 29, 1973).

[157] The analysis of the national measurement system: pressure and vacuum, NBS interna prel iminary report, $10 \mathrm{~mm}$ (Jine 1973).

[158] Schooley, J. F., National measurement system for non-radiative thermometry, NBS internal preliminary report, $13 \mathrm{~mm}$ (June 1973).

[159] Wexler, A., Analysis of the national measurement system: microstudy: humidity, prel iminary report from the Humidity Section, NBS Mech. Div., $7 \mathrm{~mm}$ (June 29, 1973).

[160] Flynn, T. M., Cryogenics study of the national measurement system, preliminary report from the NBS Cryogenics Division, 104 pages (June 29, 1973).

[161] Belecki, N., et al., Analys is of the national measurement system, Electricity Division substudy, progress report, $7 \mathrm{~mm}$ (June 29, 1973).

[162] Anson, W. J., National measurement system progress report of the Electromagnetics Division, NBS internal memorandum to Dr. James Seed, $4 \mathrm{~mm}$ (June 30, 1973).

[163] Laser technology and the national measurement system (Quantum Électronics Micro Study Interim Report), $8 \mathrm{~mm}$ (July 6, 1973).

[164] Cook, R. K., ed., Progress report on microstudy of acoustical measurements as part of part of the national measurement system, NBS internal interim report, 10 pages (June 29, 1973).

[165] Kostkowski, H. J., Progress report, national measurement system study, radiometry and photometry, NBS internal preliminary report, 30 pages (June 29, 1973).

[166] Venable, W. H., Jr., Progress report, national measurement system study, spectrophotometry, NBS internal preliminary report, 10 pages (June 1973).

[167] Ott, W. R., Ultraviolet radiometry--Part I, a survey of the national measurement system, preliminary report from the Plasma Spectroscopy Section, NBS Optical Physics Division, $12 \mathrm{~mm}$ (May 16, 1973).

[168] Kuyatt, C. E., and Swyt, D., Preliminary report, infrastructure of the national measIIrement system, optics, $46 \mathrm{~mm}$ (June 1973).

[169] Progress report, national radiation measurement system study, preliminary report from the NBS Center for Radiation Research, $9 \mathrm{~mm}$ (June 30, 1973).

[170] Arthur, M. G. , Test Procedures Handbook for Surveillance Receivers below $100 \mathrm{MHz}$, Nat. Bur. Stand. (U.S.), Internal Report 73-333, prepared for U.S. Army Security Test and Evaluation Center, Ft. Huachuca, Ariz., 439 pages (Oct. 1973).

[171] National Bureau of Standards at a Glance, Nat. Bur. Stand. (U.S.), booklet, 46 pages (Nov. 1973).

[172] Roberts, R. W., A close look at the national measurement system, booklet, talk given at NBS, Gaithersburg, Md. (Nov. 14, 1973).

[173] Seed, J. R., and Pawlik, P. U., National measurement system - NCSL, the value of making measurements, preprint of paper prepared for NCSL Newsletter (Dec. 12, 1973).

[174] Marlowe, D. E., National measurement system, force - a microstudy, preprint of paper prepared for NCSL Newsletter (Dec. 12, 1973).

[175] Schooley, J. F., National measurement system, temperature - a microstudy, preprint of paper prepared for NCSL Newsletter (Dec. 12, 1973).

[176] Wexler, A., National measurement system, humidity measurement system - a microstudy, preprint of paper prepared for NCSL Newsletter (Dec. 12, 1973).

[177] Risley, A. S., and Howe, S. L., Study of the time and frequency portion of the national measurement system, NBS internal working document, $15 \mathrm{~mm}$ (Dec. 28, 1973).

[178] Lazar, J. W., and Norden, B. N., Length and related dimensional measurement study of the national measurement system, NBS internal working document, $46 \mathrm{~mm}$ (Dec. 15, 1973).

[179] Ramboz, J. D., Mechanical vibration and shock study of the national measurement system, NBS internal working document, 42 pages (Dec. 31, 1973).

[180] Young, R. D., Preliminary study of the national measurement system for surface finish, NBS internal working document, $30 \mathrm{~mm}$ (Dec. 1973).

[181] Simpson, J. A., and Norden, B. N., Mass study of the national measurement system, NBS internal working document, $25 \mathrm{~mm}$ (Dec. 31, 1973).

[182] Norden, B. N., Volume and density study of the national measurement system, NBS internal working document, $30 \mathrm{~mm}$ (Dec. 31, 1973).

[183] Marlowe, D. E., A study of force within the national measurement system, NBS internal working document, 30 pages (Dec. 1973).

[184] Compton, P. R., et al., Study of the national fluid flow measurement system, NBS internal working document, 42 pages (Dec. 27, 1973).

[185j Heydemann, P. L. M., Pressure and vacuum measurements study of the national measurement system, NBS internal working document, $16 \mathrm{~mm}$ (Dec. 1, 1973). 
[186] Schooley, J.F., The national temperature measurement system, NBS internal working document, $16 \mathrm{~mm}$ (Dec. 1973).

[187] Wexler, A., Humidity study of the national measurement system, NBS internal working document, $8 \mathrm{~mm}$ (Dec. 31, 1973).

[188] Flynn, T. M., Cryogenics division study of the national measurement system, NBS internal working document, 102 pages (Dec. 15, 1973).

[189? Belecki, N. B., Dunfee, B. L., and Petersons, 0., Electricity division study of the national measurement system, 91 pages (Dec. 1973).

[790] Sangster, R. C., Ries, F. X., Altschuler, H. M., and Anson, W. J., Study of the national measurement system in electromagnetics, NBS internal working document, 430 pages (Dec. 1973 ).

[191] Pallett, D. S., et al., Acoustics study within the national measurement system, NBS internal working document, 210 pages (Dec. 1973).

[192] Steiner, B, and Kostkowski, H. J., Radiometry and photometry study of the national measurement system, NBS internal working document, $18 \mathrm{~mm}$ (Dec. 1973).

[193] Venable, W. H., Jr., The role of IBS in spectrophotometry, NBS internal working document, $15 \mathrm{~mm}$ (Dec. 1972).

[194] 0tt, W. R., Vaccum ultraviolet radiometry survey of the national measurement system, NBS internal working document, $18 \mathrm{~mm}$ (Jan. 3, 1974).

[195] Swyt, D. A., Preliminary study of the national measurement system for optics, NBS internal working document, 165 pages (Dec. 1973).

[196] Mahler, R. J., The laser measurement system, NBS internal working document, 48 pages (Dec. 1973).

[197] Caswel1, R. S., Center for Radiation Research study of the national measurement system, NBS internal working document, 153 pages (Dec. 30, 1973).

[198] Executive summaries, micro analytical studies of the national measurement system, $7 \mathrm{~mm}$ (Dec. 1973).

[199] International Standard ISO 1000, SI units and recommendations for the use of their multiples and of certain other units, first edition -- 1973-02-01 (International Organization for Standardization, 1973).

Purpose: Establishment of an international documentary standard formally recognizing and defining the SI (International System of Units), for use in international standardization activities.

Approach: Committee and consensus; consistency with the International Bureau of Weights and Measures (BIPM).

Findings: Details of the use of SI.

Effects: Thorough entrenchment of SI as the measurement language for all international purposes. A basic reference document.

[200] Pawlik, P. U., Economic dimensions of the national measurement system, NBS internal working document, 350 pages (1973).

[201] The gallery, finer things from Amsterdam Co. (a catalog containing among other items many novel consumer measurement instruments) (1973).

[20'c] The National Conference on Weights and Measures, its organization and procedure, booklet, 10 pages (U.S. Dept. Commerce, about 1973).

[203] Mission, Office of Weights and Measures, U.S. Department of Commerce, Nationa? Bureau of Standards, booklet, 6 pages (about 1973).

[204] The weights and measures men, a pamphlet for consumers (National Conference on Weights and Measures, about 1973).

[205] Cohen, E. R., and Taylor, B. N., Specifications of the physical world: new values for the fundamental constants, Nat. Bur. Stand. (U.S.), Dimensions/NBS, 5 pages (Jan. 1974).

Purpose: Putting current best values for fundamental constants on the record. Approach: International committee effort.

Findings: (1) A set of values that agree as closely as possible with the experimental results while conforming as closely as possible to the accepted theoretical relations connecting the constants with one another.

(2) The accuracy and consistency of this adjustment are significantly improved with respect to either the 1963 or 1969 analyses.

(3) There are critical areas where additional measurements and theoretical calculations are indicated.

(4) For the great bulk of physical and chemical data, these values should serve as a standard reference set for the next several years.

Appraisal: A basic reference compilation. 
[206] Pontius, P. E., Mass and mass values, Nat. Bur. Stand. (U.S.), Monogr. 133, 39 pages (Jan. 1974).

[207] Seed, J. R., Progress report on the evaluation of the national measurement system, 72 pages (Jan. 1974).

[208] Eads, G., U. S: Government support for civilian technology: economic theory versus political practice, Research Policy 3, 2-16 (1974).

[209] Halford, D., Noise in complex signals -- an issue study in support of the Electromagnetics Division's national measurement system study, NBS internal working document, 137 pages (Apri1 15, 1974).

[210] Wilson, A. C., Automatic test equipment applied to electromagnetic measurements -- an issue study in support of the Electromagnetics Division's national measurement system study, NBS internal working document, 48 pages (April 15, 1974).

[211] Wilson, S. J., and Smith, R. N., ed., Report on the 58th National Conference on Weights and Measures 1973, Nat. Bur. Stand. (U.S.), Spec. Pub1. 291, 208 pages (May 1974).

[212] National Directory of Weights and Measures Personnel (Dept. Commerce, NBS, May 1974).

[213] 1974 Membership Roster, Precision Measurements Association (Precision Measuremenis Association, Burbank, Calif., June 1974).

[214] Jones, R. M., The Measurement of Lumped Parameter Impedance: a Metrology Guide, Ed. W. J. Anson, Nat. Bur. Stand. (U.S.), Monogr. 141, 211 pages (June 1974).

[215] Arthur, M. G., The Measurement of Noise Performance Factors: a Metrologu Guide, Ed. W. J. Anson, Nat. Bur. Stand. (U.S.), Monogr. 141, 211 pages (June 1974).

[216] Minnick, D. J., National census of weights and measures personnel, preliminary report, Nat. Bur. Stand. (U.S.) (June 1974).

[217] National Bureau of Standards, Nat. Bur. Stand. (U.S.), Spec. Publ. 397, 64 pages (June 1974).

[218] Morgan, H. E., The economic cost of physical measurements, NBS internal working document (June 30, 1974).

[219] Page, C. H., and Vigoureux, P., ed., The International System of Units (SI), Nat. Bur. Stand. (U.S.), Spec. Pub7. 330, 49 pages (July 1974).

Purpose: Promotion of knowledge and understanding of the International System of Units, encouragement of its use in all realms of science, industry, and commerce, and securing uniformity of nomeclature throughout the English-speaking world.

Approach: Joint translation (and publications) by the USA and UK from the original French text published by the International Bureau of Weights and Measures (BIPM), with review for accuracy by BIPM.

Findings: The definitive statement in the English language of the SI.

Appraisal: A basic reference document.

[220] Johnson, K. L., Fluid power measurement accuracy survey report, preprint of paper presented at the first Fluid Power Testing Symposium, Milwaukee, Wisconsin, 42 pages (Aug. 12, 1974).

[221] Roberts, R.W., The national/international measurement system, ASTM Standardization News 2, 9-13 (Nov. 1974).

[222] McCoubrey, A. 0., Expanding the nation's measurement system, ASTM Standardization News 2, 14-17, 59 (Nov. 1974).

[223] The National Conference of Standards Laboratories, ASTM Standardization News 2, 18-22 (Nov. 1974).

[224] International quality assessment, ASTM Standardization News 2, 23-28 (Nov. 1974).

[225] Porat, M. U., Defining an information sector in the U.S. economy, second year project report (Institute for Communication Research, Stanford University, Stanford, Calif., Nov. 1974).

[226] Dalke, J. L., Why metric and when?, TAPPI 57, No. 12, 72-75 (Dec. 1974).

[227] NBS Metric Kit, Nat. Bur. Stand. (U.S.), Spec. Publ. 410 (1974); contains the following items:

[228] Metric conversion card, Nat. Bur. Stand. (U.S.), Spec. Publ. 365 (Nov. 1972).

[229] For good measure, Nat. Bur. Stand. (U.S.), Spec. Publ. 376 (Dec. 1972) (a metric ruler).

[230] What about metric?, liat. Bur. Stand. (U.S.), brochure, 16 pages (1973).

[231] Roberts, R. W., The metric changeover, Nat. Bur. Stand. (U.S.), brochure, 3 pages (Sept. 1974).

[232] Brief history of measurement systems, Nat. Bur. Stand. (U.S.), Spec. Pub1. 304A, 4 pages (Sept. 1974). 
[233] NBS guidelines for use of the metric system, Nat. Bur. Stand. (U.S.), Letter Circ. 1056, 4 pages (Nov. 1974).

[234] Some references on metric iriformation, Nat. Bur. Stand. (U.S.), Spec. Publ. 389, 10 pages (revised 1974).

[235] Bennett, J., The economic impact of standard reference materials, NBS internal working document (about 1974).

L236] Klein, H. A., The World of Measurements (Simon and Schuster, New York, N.Y., 1974).

[237] Chapter 27, Photographic equipment and supplies, Chapter 36, Metalworking machinery and tools, Chapter 37, Instruments for measurement, analysis and control, and Chapter 38 , Medical and dental instruments and supplies, U.S. Industrial Outlook 1975 with Projections to 1980, pp. 261-65, 347-56, 357-71, and 372-79 (U.S. Dept. Commerce, U.S. Govt. Print. Off., Washinqton. D.C., 1974).

[238] Four papers on metric conversion: Clark, R. E., U.S. metrication - why?

Barbrow, L. E., Metrication in business and industry. Odom, J. V., Metric change and the role of education. Odom, J. V., The effect of metrication on the consumer.

Nat. Bur. Stand. (U.S.), information document prepared by Metric Information Office, 21 pages (undated, estimated 1974).

[239] Capabilities of the primary standards laboratory, January 1975, booklet, 34 pages (Measurement Standards Department, Sandia Laboratories, Albuquerque, N.M., Jan. 1975).

[240] Cali, J. P. et al., The role of Standard Reference Materials in measurement systems, Nat. Bur. Stand. (U.S.), Monogr. 148, 54 pages (Jan. 1975).

[241] Roberts, R. W., The other face of the measurement base, remarks at the Pittsburgh Conference on Analytical Chemistry and Applied Spectroscopy, Cleveland, Ohio, March 3, 1975, Nat. Bur. Stand. (U.S.), booklet, 24 pages (Mar. 1975).

[242] National Bureau of Stnadards annual report: Fiscal Year 1974, Nat. Bur. Stand. (U.S.), Spec. Publ. 418, 32 pages (Mar. 1975).

[243] Reis, R. X., and Anson, W. J., The national electromagnetic measurement system, NBS internal working document, 72 pages (March 31, 1975).

[244] Principles and practical approaches for evaluating international standards, final report JACKFAU-75-136, 75 pages (Jack Faucett Associates, Inc., Chevy Chase, Md., Apr. 3, 1975).

[245] Roberts, R. W., America's alternatives: the metric conversion, statement before the Subcommittee on Science, Research and Technology, House Committee on Science and Technology, on conversion of the U.S. system of weights and measures to the metric system, April 29 , 1975, Nat. Bur. Stand. (U.S.), booklet, 32 pages (Apri1 1975).

[247] Mahler, R. J., The national measurement system for lasers, NBS internal working document, 48 pages (May 1975).

[248] Program, Successful experiences in teaching metric, a conference in celebration of the one hundredth anniversary of the Metric Convention, 1875-1975, NBS, Gaithersburg, Md. (May 20-21, 1975).

[249] Richman, P., ed., Critical electrical measurement needs and standards for modern electronic instrumentation, report of a workshop sponsored by the National Bureau of Standards, Gaithersburg, Md., Sept. 23-24, 1974, Nat. Bur. Stand. (U.S.), Tech. Note 865, 74 pages (May 1975).

[250] Page, C. H., and Vigoureaux, P., ed., The International Bureau of Weights and Measures, translation of the BIPM centennial volume, Nat. Bur. Stand. (U.S.), Spec. Pub1. 420, 256 pages (May 1975).

Purpose: BIPM's official centennial volume.

Approach: Historical introduction followed by reviews of technical activities, written by technical staff of BIPM.

Findings: That which characterizes the BIPM at the time of its centennial is the blending of permanence, which comes from its mission, and of rapid renovation, as in the techniques used to accomplish this mission. BIPM furnishes standards to countries needing them, compares the standards of countries which are sufficiently advanced to establish their own standards, and contributes to research looking forward to the still higher precision of the future; it serves as a neutral and impartial scientific arbiter when national sensitivities impede an international agreement. It is also a center for discussion, for coordination, and for preparation of international decisions. The importance of the mission of the BIPM is well illustrated by the progressive adoption, in all countries, of the International System of Units.

Appraisal: A valuable, benchmark reference document. 
[251] Slattery, W. J., ed., An Index of U.S. Voluntary Engineering Standards, Supplement 2, Nat. Bur. Stand. (U.S.), Spec. Publ. 329, Suppl. 2, 472 pages (May 1975).

[252] Catalog of NBS Standard Reference Materials, 1975-76 edition, Nat. Bur. Stand. (U.S.), Spec. Publ. 260-1975-76 catalog, 90 pages (June 1975).

[253] Edger1y, S. J., ed., Report of the 59 th National Conference on Weights and Measures 1974, Nat. Bur. Stand. (U.S.), Spec. Pub1. 407, 284 pages (June 1975).

[254] Marlowe, D. E., A study of the national force measurement system, NBSIR 75-929, 40 pages (June 1975).

[255] Summary of calibration data for FY-75, NBS internal working document (July 1975).

[256] State and local weights and measures activity summary, July 1974 - July 1975, report of the Committee on Education, Administration, and Consumer Affairs, 60th National Conference on Weights and Measures (July 1975).

[257] Turan, K., They've got their standards, news item, The Washington Post/Potomac, pp. 10-11, 34-35 (Ju1y 20, 1975).

[258] Wargo, J., Should the Government control standards setting?, New Engineer 4 , No. 7, $21-23$ (July/Aug., 1975).

[259] DeMarco, J., Making a safer matchbook--a case study in standards setting, New Engineer 4, 24-27 (July/Aug., 1975).

[260] NBS guidelines for use of the metric system, Nat. Bur. Stand. (U.S.), Letter Circ. 1056, 4 pages (rev. Aug. 1975).

[261] National Bureau of Standards at a Glance, Nat. Bur. Stand. (U.S.), booklet, 46 pages (P.ug. 1975).

[262] U. S. Metric Association Newsletter 10, No. 3, 6 pages (Aug. 1975).

[263] Wexler, A., A study of the national humidity and moisture measurement system, NBSIR 75-933, 51 pages (Aug. 1975).

[264] McCoubrey, A. 0., The national measurement system and specific industrial needs, preprint of paper presented at the 1975 Fluid Power Testing Symposium, 8 pp. (Aug. 1i-14, 1975).

[265] de Bruyn, P. R., Industry and governmental interaction with NBS, preprint of paper presented at the 1975 Fluid Power Testing Symposium, 6 pages (Aug. 11-14, 1975).

[266] Recommended references of SI metric usage, one page (U.S. Metric Association, Inc., about Sept. 1975).

[267] Rossmassler, S. A., ed., Critical evaluation of data in the physical sciences--a status report on the National Standard Reference Data System, Apri1 1975, Nat. Bur. Stand. (U.S.), Tech. Note 881, 53 pages (Sept. 1975).

[268] Pallett, D. S., Noise and the national measurement system, preprint of paper presented at Noise-Con 75, National Bureau of Standards, Gaithersburg, Md., 25 pages (Sept. 15-17, 1975).

[269] Flynn, T. M., The national measurement system for cryogenics, NBSIR 75-825, 75 pages (Oct. 1975).

[270] Saga of the Troy pound, Nat. Bur. Stand. (U.S.), NBS Stand. 20, No. 21, 3 (Oct. 8, 1975).

[271] Calibration and test services of the National Bureau of Standards, Fees for services, Nat. Bur. Stand. (U.S.), Spec. Pub1. 250--Oct. 1975 Appendix (Oct. 1975).

[272] Guide to scientific instruments, Science 190, No. 4216A (25 Nov. 1975).

[273] National Bureau of Standards annual report FY 1975, Nat. Bur. Stand. (U.S.), Spec. Pub1. 437, 32 pages (nac. 1975).

[274] 1976 Buyer's guide issue, Instruments \& Control Systems, 256 pages (1975).

[275] Standard Reference Materials, 1975 price list, Nat. Bur. Stand. (U.S.), Spec. PubT. 260, supplement, 17 pages (1975).

[276] A walk through time, Nat. Bur. Stand. (U.S.), booklet, 22 pages (undated, 1975).

[277] National Conference of Standards Laboratories, booklet, 8 pages (undated, app. 1975).

[278] Physikalisch Technische Bundesanstalt - An Outline - PTB 175, brochure, 29 pages (1975).

[279] NBS standards information service, Nat. Bur. Stand. (U.S.), fiyer (1976).

[280] General Services Administration, Index of Federal Specifications and Standards

(U.S. Govt. Print. Off., Washington, D.C., Jan. 1976).

[281] America joins a metric world, Nat. Bur. Stand. (U.S.), DIMENSIONS/NBS 60, No. 2, 6-9 (Feb, 1976).

[282] Hudson, P. A., The national measurement system for medical ultrasonics, NBSIR 75-937, 19 pages (Feb. 1976).

[283] Procedures for a National Voluntary Laboratory Accreditation Program, Fed. Regist. 41, No. 38, 816.3-8 (Wed., Feb. 25, 1976).

[284] Weights and measures directory, iist of state, commonwealth, district, and major local weights and measures offices of the United States, Nat. Bur. Stand.(U.S.), directory (Mar. 1976).

[285] Nicodemus, F. E., ed., Self-study manual on optical radiation measurements: Part 1-concepts, Chapters 1-3, Nat. Bur. Stand. (U.S.), Tech. Note 910-1, 93 pages (Mar. 1976). 
[286] Mason, H. L., and Lloyd, I. M., Special technical facilities at the National Bureau of Standards, Nat. Bur. Stand. (U.S.), Spec. Pub1. 413, 1976 edition, 50 pages (Mar. 1976).

[287] Program, Measurements for the safe use of radiation, an NBS 75 th Anniversary symposium, Gaithersburg, Md. (March 1-4, 1976).

[288] The NBS Standard 75th Anniversary special issue, Nat. Bur. Stand. (U.S.), NBS Standard, 12 pages (Mar. 3, 1976).

[289] Ambler, E., Looking back: a 75 year preview of things to come, an address on the occasion of the 75 th Anniversary of the National Bureau of Standards, Nat. Bur. Stand. (U.S.), booklet, 28 pages (March 4, 1976).

[290] The President's message on Metric Bi11, Am. Metric J. 4, 101-5 (Unit 2, 1976) (includes a complete copy of P.L. 94-168, Metric Conversion Act of 1975).

[291] U.S. private organizations represented in the reference collection of standards maintained by the Standards Information and Analysis Section of the Standards Application and Analys is Division, National Bureau of Standards, NBS internal working document (May 1976).

[292] Edgerly, S. J., ed., Report of the 60 th National Conference on Weights and Measures 1975, Nat. Bur. Stand. (U.S.), Spec Pub1. 442, 272 pages (May 1976).

[293] Announcing the 1976 symposium of the National Conference of Standards Laboratories, the national measurement system--today and tomorrow, an anniversary review of our national industrial measurement system, preliminary program for meeting at NBS, Gaithersburg, Md., 0ct. 6-8, 1976 (May 1976).

[294] Risley, A. S., The national measurement system for time and frequency, Nat. Bur. Stand. (U.S.), Spec. Pub1. 445-1, 76 pages (May 1976).

[295] Young, R. D., The national measurement system for surface finish, NBSIR 75-927, 48 pages (July 1976).

[296] E 548-76, Standard recommended practice for Generic Criteria for Use in the Evaluation of Testing and/or Inspection Agencies, Annual Book of ASTM Standards, parts 10 and 41 (Am. Soc. for Testing and Materials, Philadelphia, Pa., July 1976).

[297] What six firms found going metric: A lot easier and cheaper than expected, U.S. News and World Report, p. 114 (July 5, 1976).

[298] Lazar, J. W., and Bach, R. L., The national measurement system for length and related dimensional measurements, Part I., NBSIR 75-926, part I, 113 pages (Aug. 1976).

[299] Haight, W. C. Klebanoff, P. S., Ruegg, F. W., and Kulin, G., The national fluid flow measurement system for fluid flow, NBSIR 75-930, 65 pages (Aug. 1975).

[300] Schooley, J.F., The national measurement system for temperature, NBSIR 75-132, 58 pages (Aug. 1976).

[301] Swyt, D. A., The national measurement system for optics, NBSIR 75-142, 60 pages (Aug. 1976).

[302] Sangster, R. C., Transactions Matrix description of the national system of physical measurements, NBSIR 75-943, 88 pages (Aug. 1976).

[303] Sangster, R. C., ed., Collected executive summaries, studies of the national measurement system 1972-75, NBSIR 75-947, 53 pages (Aug. 1976 \& Jan. 1977).

[304] Heydemann, P. L. M., The national measurement system for pressure, NBSIR 75-931, 40 pages (Sept. 1976).

[305] Cooper, J. S., P.helps, A. V., and Smith, S. J., The national measurement system for the physical properties of atoms and molecules, NBSIR 75-944, 38 pages (Sept. 1976).

[306] Ambler, E., Proceedings, National Conference of Standards Laboratories Symposium (Oct. 6, 1976).

[307] Sangster, R. C., Final summary report, study of the national measurement system 1972-75, NBSIR 75-925, 45 pages (Dec. 1976).

[308] Forman, H. I., The Department of Commerce looks at the voluntary standards system: reaction at the Office of Product Standards, talk presented at forum on An Evaluation Update on America's Voluntery Standards System, New York Sheraton Hotel, Dec. 7, 1976.

[309] A Directory of Standards Laboratories (National Conference of Standards Laboratories, 1976).

Purpose: Catalog of membersinip and capabilities.

Approach: Polling of members and other eligible organizations.

Findings: (1) List of laboratories and capabilities

(2) Directory of standards laboratories

(3) NCSL member delegates

(4) List of standards laboratories in zip code order

(5) NCSL Board of Directors and Regional Representatives

(6) National Liaison Delegates to NCSL from other organizations

Appraisal: A comprehensive directory to one segment of the national measurement system. 
[310] Proceedings of the Briefing Sessions on the U.S. Department of Commerce National Voluntary Laboratory Accreditation Program (June 15, 1976 at Washington, D.C., and June 22, 1976, at Los Angeles, Calif.) (American Council of Independent Laboratories, Washington, D.C., 1976).

[311] Rowland, G. A., National Voluntary Laboratory Accreditation Program, Proc. 1976 Symposium of the National Conference of Standards Laboratories, 12-13 (Nat'1 Conf. Stds. Labs, c/o NBS, Boulder, Colo., 1976).

[312] Pallett, D. S., The national measurement system for acoustics, NBSIR 75-937, 94 pages (Feb. 1977).

[313] Powel1, C. J., The national measurement system for surface properties, NBSIR 75-945 (March 1977).

[314] Fowler, H. A., Interaction diagrams - NBS impact charts of the national measurement system, internal NBS working document (April 1977).

[315] Kamas, G., ed., Time and frequency users' manual, Nat. Bur. Stand. (U.S.), Tech. Note 695,217 pages (May 1977).

[316] Porot, Marc U., The Information Economy, Office of Telecommunications Spec. Pubr. (nine volumes) (in press).

[317] Kamper, R. A., et al., The national electromagnetic measurement system, NBSIR 75936, 40 pages (June 1977).

[318] 0tt, W. R., The national measurement system for far ultraviolet radiometry, NBSIR 75-941, 73 pages (June 1977).

[319] Sangster, R.C., Structure and functions of the national measurement system NBSIR 75-949 (this report).

[320] Ramboz, J. D., The national measurement system for length and related dimensional measurements, Part II: Vibration and shock, NBS internal working document (in preparation).

[321] Pontius, P. E., Simpson, J. A., and whetstone, J. R., The national mass, volume, and density measurement system NBSIR 75-928 (in preparation).

[322] Klein, M., The national measurement system for the thermodynamic properties of fluids, NBSIR 75-934 (in preparation).

[323] Belecki, N. B., Dunfee, B. L., and Petersons, 0., The national electrical measurement system, NBSIR 75-935 (in preparation).

[324] Kostkowski, H. J., The national measurement system for radiometry and photometry, NBSIR 75-939 (in preparation).

[325] Venable, W. H., Jr., The national measurement system for spectrophotometry, NBSIR 75-940 (in preparation).

[326] Caswell, R. S., The national measurement system for ionizing radiation, NBSIR 75946 (in preparation).

[327] Poulson, B.W., Economic analysis of the national measurement system, NBSIR 75-948

(in preparation).

[328] Sangster, R. C., The measurement instrumentation industry, NBS internal working document (in preparation).

[329] 1976-77 Test and Measurement Equipment Guide, Quality 15 (Juiy 1976). 
Adams, J. Q. [2]

Altschuler, H. M. [190]

Ambler, E. $[118,123,124,125$, $130,133,144,289,306]$

Andrus, W. E. [129]

Anson, W. J. [162,190,243]

Arthur, M. G. $[170,214]$

Astin, A. V. $[39,52,64,66]$

Bach, R. L. [298]

Barbrow, L. E. [102,238]

Belecki, N. $[161,189,323]$

Bel1,F.C. $[96,126,145]$

Bendick, J. [16]

Bennett, J. [235]

Boyne, H. S. [297]

Brady, E. L. $[50,84]$

Branscomb, L. M. $[117,127]$

Briggs, L. J. [8]

Bunten, E. C. [103]

Burton, W. K. [88]

Cali, J.P. [240]

Cameron, J. M. [20]

Caswe11, R. S. $[197,326]$

Clark, R. E. [100,238]

Clark, R. F. [90]

Cochrane, R. C. [46]

Cohen, E. R. [205]

Compton, P. R. $[156,184]$

Cook, R. K. [164]

Cooper, J.W. [305]

Cornog, J. R. [103]

Corruccini, R. J. [134]

Crane, B. M. [122]

Dalke, J.L. [226]

Dantzig, T. [61]

de Bruyn, P. R. [265]

DeMarco, J. [259]

De Simone, D. V. [98]

Dunfee, B. L. [189,323]

Eads, G. [208]

Edger1y, S. J. $[253,292]$

Eisenhart, C. $[25,67]$

Eskite, W. H., Jr. [44]

Finger, G. A. [80]

Flynn, T. M. $[160,188,269]$

Forman, H. I. [308]

Fowler, H. A. [314]

Freedman, A. Y. [87]

Galvin, H. B. [53]

Gentilini, A. V. [65]

Gordon, G. F: [106]

Gorozhanina, R. S. [87]

Hachey, L. E. [22]

Hagerbaumer, J. [246]

Haight, W. C. [299]

$\mathrm{Hal}$ ford, D. [209]

Hallock, W. [3]

Hatos, S. L. [101]

Heydemann, P. L. M. $[185,304]$

Hoffman, J. D. [131]
Howe, S. L. [177]

Howlett, L. E. [57]

Hudson, P. A. [282]

Huntoon, R. D. $[12,24,33,34$, $35,38,41,43,45,48,54,55,56$, $59,80,99,111]$

Irwin, K. G. [17]

Jefferson, T. [1]

Jewkes, J. [138]

Johnson, K. L. [220]

Jones, R. M. [215]

Jones, S. A. [7]

Judson, L. V. [28]

Kamas, G. [315]

Kamper, R. A. [317]

Klebanoff, P. S. [299]

Klein, H. A. [236]

Klein, M. [322]

Koeser, R. L. [85]

Kostkowski, H. J. $[165,192,324]$

Kul in, G. [299]

Kushner, L. M. [81, 128, 135]

Kuyatt, C. E. [168]

Lance, H.W. [19]

Langenberg, D. N. $[93,112]$

Lazar, J.W. $[178,298]$

Lescure, Q. J. [30]

Lichtenstein, S. [80]

Lloyd, I. M. [286]

Lomas, L. [107]

Mahler, R. J. [196,247]

Marlowe, D. E. $[174,183,254]$

Mason, H. L. $[36,51,75,121,286]$

McCoubrey, A. 0. [222, 264]

McNish, A. G. $[11,12,14,15,20$, 27,42]

Meinke, W. W. [83]

Minnick, D.J. [216]

Moreau, H. [9]

Morgan, H. E. $[59,76,218]$

Nicodemus, F. E. [285]

Noble, D. E. [97]

Norden, B. N. $[178,181,182]$

Odom, J. V. $[110,238]$

Ott, W. R. $[167,194,318]$

Page, C. H. [219,250]

Pallett, D. S. $[191,268,312]$

Parker, W. H. [93]

Pawl ik, P.U. [173,200]

Peiser, H. S. [121]

Perry, J. [10]

Petersons, 0. [189,323]

Phelps, A. V. [305]

Pontius, P. E. $[206,321]$

Porat, M. U. $[225,316]$

Poulson, B.W. $[246,327]$

Powel 1, C. J. [313]

Powe 11, R. C. $[36,27]$

Powers, R. S. [51]
Radl inski, R. W. [86]

Ramboz, J. D. $[151,179,320]$

Resko, S. I. [70]

Richman, P. [249]

Ries, F.X. $[190,243]$

Risley, A. S. $[148,177,294]$

Ritchie-Calder, Lord [92]

Roberts, R. W. $[172,221,231$, $241,245]$

Robinson, B. D. [104]

Root, L.W. [91]

Rossmassler, S. A. $[137,267]$

Rothrock, B. D. [104]

Rowland, G. A. [311]

Ruegg, F. W. [299]

Sangster, R. C. $[190,302,303$, $307,319,328]$

Schafer, G. E. [58]

Schooley, J.F. $[158,175,186$, 300]

Schweitzer, W. G. [150]

Seed, J. R. $[173,207]$

Selby, M. C. $[26,70,87]$

Sha ievitch, A. B. [87]

Silverman, S. [82]

Simpson, J.A. [181,321]

Simson, B. G. [86]

Slattery, W. J. $[95,139,251]$

Smith, R. N. [211]

Smith, R. W. [13]

Smith. S. J. [305]

Steiner, B . $[143,192]$

Stiehler, R. D. $[79,109]$

Swyt, D. $[168,195,301]$

Tascher, J. M. [100]

Tate, D. R. [155]

Taylor, B. N. $[93,112,205]$

Treat, C. F. [108]

Turan, K. [257]

Van de Houten, J. [49]

Venable, W. H., Jr. $[166,193$, 325]

Vigoureux, P. [219,250]

Wade, H. T. [3]

Wallenstein, M. B. [50]

Wargo, J. [258]

Wexler, A. $[159,176,187,263]$

Whetstone, J.R. [321]

White, L. T. [29]

Whitney, A. W. [6]

Wildhack, W. A. $[33,36,51,68]$

willenbrock, F. K. [132]

Wilson, A. C. [210]

Wi1son, S. J. [211]

Woll in, H. F. $[96,126,145]$

Wolzien, E. C. [77]

Yates, J. T., Jr. [59]

Young, R. D. $[152,180,295]$

Zupko, R. E. [73] 
NBS-114A (REV. 7.73) 15. SUPP LEMENTARY NOTES

16. ABSTRACT (A 200-word or less factual summary of most significant information. If document includes a significant bibliography or literature survey, mention it here.)

The National Measurement System consists of the activities and mechanisms--intellectual and operational, technical and institutional--that provide physical measurement data to allow creation of the objective, quantitative knowledge required by our society. This report describes the structural and functional aspects of the system, with emphasis on the technical and institutional infrastructures, the international context, and basic impacts and trends. 16 appendices and an extended bibliography provide back-up detail. Measurement is necessary in conduct of the life of the individual, pursuit of science, operations of society, and employment of technology, for describing, predicting, communit cating, deciding, controlling, and reacting in dealing with the physical universe. Our model of the system employs five structural levels: 1. Conceptual foundation--the International System of units (SI). 2. Basic technical infrastructure--documentary standards and specifications, instrumentation, reference data, reference materials, predictive methods, science and trained people. 3. Realized measurement capabilities. 4. Dissemination and enforcement network--documentary standardization institutions, instrumentation industry, state and local offices of weights and measures, standards and testing laboratories and services, regulatory agencies, and NBS. 5. End-use measurement\$ market-place. BIPM, the International Bureau of Weights and Measures, is the central agency internationally. Major trends of the system include increased complexity and integration, improved quality control and information resources, automation, metrication, and an increasingly fundamental scientific base.

17. KEY WORDS (six to twelve entries; alphabetical order; capitalize only the first letter of the first key word unless a proper name; separated by semicolons) Instrumentation; measurement standards; National Bureau of Standards; national measurement system; standard reference data; standardization organizations; weights and measures.

18. AVAILABILITY X Unlimited

For Official Distribution. Do Not Release to NTIS

Order From Sup. of Doc., U.S. Government Printing Office Washington, D.C. 20402, SD Cat. No. C13

X Order From National Technical Information Service (NTIS) Springfield, Virginia 22151

\begin{tabular}{|l|c|}
\hline $\begin{array}{l}\text { 19. SECURITY CLASS } \\
\text { (THIS REPURT) }\end{array}$ & 21. NO. OF PAGES \\
$\begin{array}{l}\text { UNCL ASSIFIED } \\
\text { (THIS PAGE) }\end{array}$ & 142 \\
\hline $\begin{array}{l}\text { 20. SECURITY CLASS } \\
\text { UNCLASSIFIED }\end{array}$ & 22. Price \\
\hline
\end{tabular}



REQUEST CARD FOR REPORTS OF NATIONAL MEASUREMENT SYSTEM (NMS) STUDY (Circle No's wanted)

925 FINAL SUMMARY REPORT 929 FORCE

943 TRANSACTIONS IN NMS

947 COLL. EXEC. SUMMARIES

948 ECONOMIC ANALYSIS NMS

949 STRUCTURE/FUNCTIONS NMS

345-1 TIME \& FREQUENCY

926 LENGTH \& DIMEN. MEAS.; VIBRATION \& SHOCK

927 SURFACE FINISH

928 MASS, VOLUME, DENSITY
930 FLUID FLOW

931 PRESSURE

932 TEMPERATURE

933 HUMIDITY \& MOISTURE

934 THERMODYNAMICS OF FLUIDS

825 CRYOGENICS

935 ELECTRICITY

936 ELECTROMAGNETICS
937 MEDICAL ULTRASONICS

938 ACOUSTICS

939 RADIOMETRY/PHOTOMETRY

940 SPECTROPHOTOMETRY

941 FAR UV RADIOMETRY

942 OPTICS

944 PHYS. PROP. ATOMS/MOL.

945 SURFACE PROPERTIES

946 IONIZING RADIATION

REQUEST CARD FOR REPORTS OF NATIONAL MEASUREMENT SYSTEM (NMS) STUDY (CirCle No's wanted)

925 FINAL SUMMARY REPORT

943 TRANSACTIONS IN NMS

947 COLL. EXEC. SUMMARIES

948 ECONOMIC ANALYSIS NMS

949 STRUCTURE/FUNCTIONS NMS

345-1 TIME \& FREQUENCY

926 LENGTH \& DIMEN. MEAS.; VIBRATION \& SHOCK

927 SURFACE FINISH

928 MASS, VOLUME, DENSITY
929 FORCE

930 FLUID FLOW

931 PRESSURE

932 TEMPERATURE

933 HUMIDITY \& MOISTURE

934 THERMODYNAMICS OF FLUIDS

825 CRYOGENICS

935 ELECTRICITY

936 ELECTROMAGNETICS
937 MEDICAL ULTRASONICS

938 ACOUSTICS

939 RADIOMETRY/PHOTOMETRY

940 SPECTROPHOTOMETRY

941 FAR UV RADIOMETRY

942 OPTICS

944 PHYS. PROP. ATOMS/MOL.

945 SURFACE PROPERTIES

946 IONIZING RADIATION

REQUEST CARD FOR REPORTS OF NATIONAL MEASUREMENT SYSTEM (NMS) STUDY (CirCle NO'S wanted)

925 FINAL SUMMARY REPORT

943 TRANSACTIONS IN NMS

947 COLL. EXEC. SUMMARIES

948 ECONOMIC ANALYSIS NMS

949 STRUCTURE/FUNCTIONS NMS

345-1 TIME \& FREQUENCY

926 LENGTH \& DIMEN. MEAS.; VIBRATION \& SHOCK

927 SURFACE FINISH

928 MASS, VOLUME, DENSITY
929 FORCE

930 FLUID FLOW

931 PRESSURE

932 TEMPERATURE

933 HUMIDITY \& MOISTURE

934 THERMODYNAMICS OF FLUIDS

825 CRYOGENICS

935 ELECTRICITY

936 ELECTROMAGNETICS
937 MEDICAL ULTRASONICS

938 ACOUSTICS

939 R.ADIOMETRY/PHOTOMETRY

940 SPECTROPHOTOMETRY

941 FAR UV RADIOMETRY

942 OPTICS

944 PHYS. PROP. ATOMS/MOL.

945 SURFACE PROPERTIES

946 IONIZING RADIATION 
FROM: NAME:

Place

Stamp

TITLE :

Here

ORGANIZATION:

ADDRESS:

CITY/STATE:

COUNTRY/ZIP:

T0: PROGRAM INFORMATION OFFICE NAT IONAL BUREAU OF STANDARDS BOULDER, COLORADO, USA 80302

FROM: NAME :
TITLE:
ORGANIZATION:
ADDRESS:
CITY/STATE:
COUNTRY/ZIP:

Place

Stamp

Here

TO: PROGRAM INFORMATION OFFICE NATIONAL BUREAU OF STANDARDS

BOULDER, COLORADO, USA 80302

FROM: NAME :

Place

Stamp

TITLE :

Here

ORGAN IZATION:

ADDRESS:

CITY/STATE :

COUNTRY/ZIP:

TO: PROGRAM INFORMATION OFFICE NATIONAL BUREAU OF STANDARDS

BOULDER, COLORADO, USA 80302 